
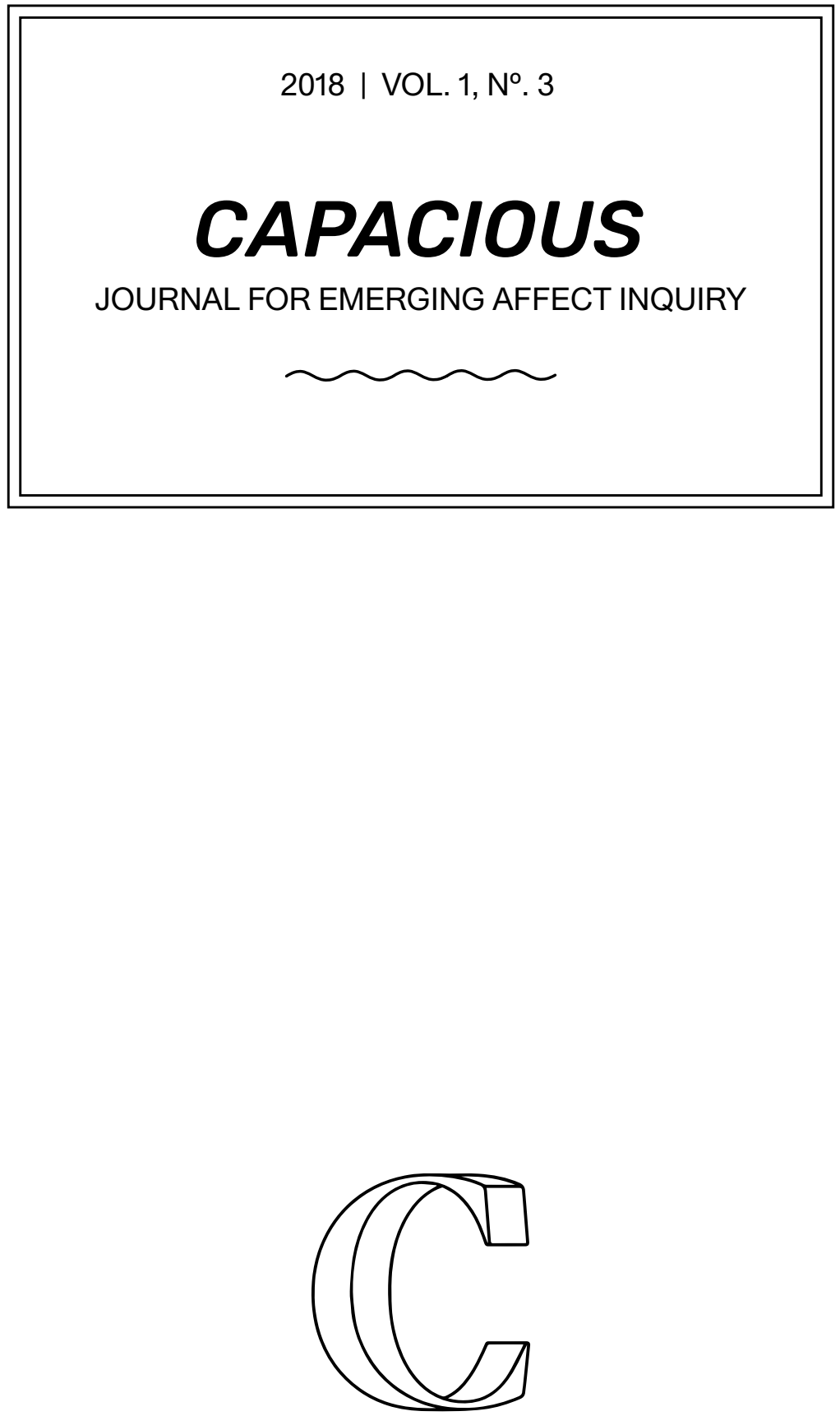


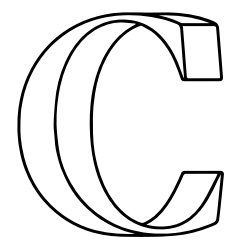

Capacious: Journal for Emerging Affect Inquiry Vol. 1 No. 3

Capacious is an open access journal and all content is licensed under a Creative Commons Attribution 4.0 International License (CC BY 4.0).

ISBN-13: 978-1727709063

ISBN-10: 1727709063

capaciousjournal.com

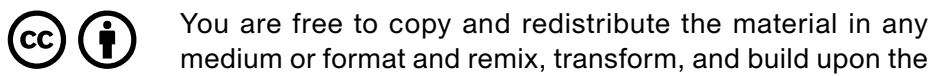
material for any purpose, even commercially. You must give appropriate credit, provide a link to the license, and indicate if changes were made. You may do so in any reasonable manner, but not in any way that suggests the licensor endorses you or your use. 


\section{Editorial team}

$\sim \sim$

\section{CO-EDITORS-IN-CHIEF}

\section{Gregory J. Seigworth}

Millersville University

Managing Editor

editor@capaciousjournal.com

\section{Mathew Arthur}

Vancouver School of Theology editor@capaciousjournal.com

\section{ASSOCIATE EDITORS}

\author{
Wendy J. Truran \\ University of Illinois, \\ Urbana-Champaign \\ production@capaciousjournal.com
}

\section{Bryan G. Behrenshausen}

Red Hat

production@capaciousjournal.com

\section{ca·pa-cious kə'pāSHəs/ \)}

adjective

having a lot of space inside; roomy.
Capacious: Journal for Emerging Affect Inquiry is an open access, peer-reviewed, international journal that is, first and foremost, dedicated to the publication of writings and similar creative works on affect by degree-seeking students (Masters, PhD, brilliant undergraduates) across any and all academic disciplines. Secondarily, the journal also welcomes contributions from early-career researchers, recent post-graduates, those approaching their study of affect independent of academia (by choice or not), and, on occasion, an established scholar with an 'emerging' idea that opens up new avenues for affect inquiry. The principal aim of Capacious is to 'make room' for a wide diversity of approaches and emerging voices to engage with ongoing conversations in and around affect studies.

This journal will champion work that resists:

- the critical ossification of affect inquiry into rigid theoretical postures

- the same dreary citational genealogies

- any too assured reiteration of disciplinary orthodoxies

The journal will always encourage the energies and enthusiasms, the fresh perspectives and provocations that younger scholars so often bring to bear on affect within and across unique and sometimes divergent fields of intellectual endeavor. Capacious seeks to avoid issuing formal 'calls for papers' and 'special theme issues.' Submissions to this journal are accepted at anytime and are welcome to pursue any and all topic areas or approaches relating to affect.

Our not-so-secret wish is that essays and issues will forever remain capacious and rangy: emerging from various disciplines and conceptual [t]angles. Indeed, our aim for every journal issue would be that its collected essays not really coalesce all that much, but rather rub up against one another unexpectedly or shoot past each other without ever touching on quite the same disciplinary procedures, theoretical presuppositions or subject matter.

Capacious shall always endeavor to promote diverse bloom-spaces for affect's study over the dulling hum of any specific orthodoxy. From our own editorial practices down through the interstices of this journal's contents, the Capacious ethos is most thoroughly engaged by those critical-affective undertakings that find ways of 'making room.'

Gregory J. Seigworth

Mathew Arthur 


\section{Editorial board}

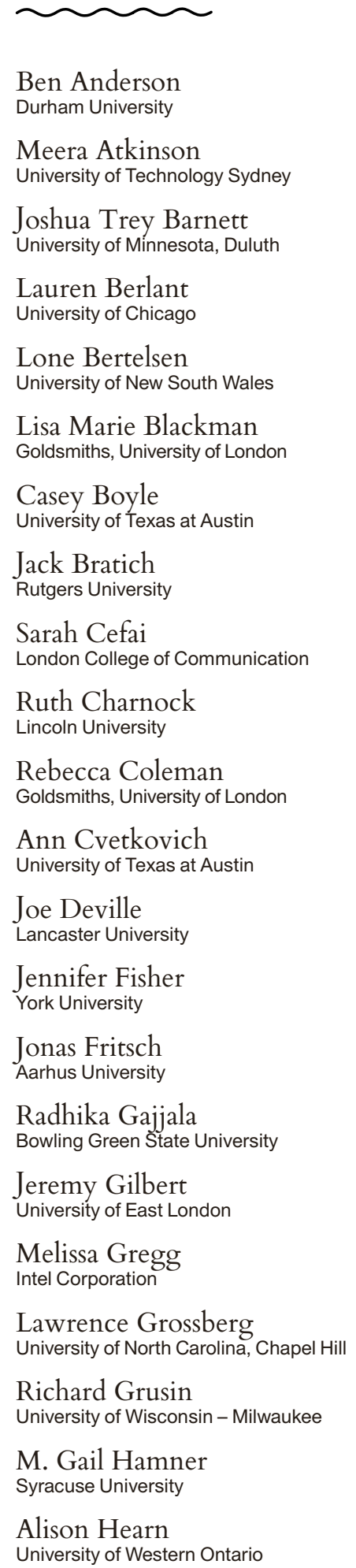

Anna Hickey-Moody
RMIT University

Ben Highmore

University of Sussex

Deborah Kapchan

New York University

Tero Karppi

University of Toronto

Anu Koivunen

Stockholm University

Ali Lara

The City University of New York

Jennifer LeMesurier

Colgate University

Mona Mannevuo
University of Turku

Erin Manning

Concordia University

Belén Martin-Lucas

University of Vigo

Brian Massumi

University of Montreal

Shaka McGlotten

State University of New York, Purchase

Andrew Murphie

University of New South Wales

Jussi Parikka

Winchester School of Art

Susanna Paasonen

University of Turku

Carolyn Pedwell

University of Kent

John Protevi

Louisiana State University

Jasbir Puar

Rutgers University

Andrej Radman

University of Delft

Jason Read

University of Southern Maine

Jenny Rice

University of Kentucky

Michael Richardson

University of New South Wales
Tony Sampson

University of East London

Donovan Schaefer University of Pennsylvania

Natasha Schüll

New York University

Kyla Schuller

Rutgers University

Janae Sholtz Scroggs

Alvernia University

Hasana Sharp

McGill University

Steven Shaviro

Wayne State University

Chad Shomura

University of Colorado, Denver

Nathan Snaza

University of Richmond

Eliza Steinbock

Leiden University

Elizabeth Stephens

University of Queensland

Kathleen Stewart

University of Texas at Austin

Kristin Swenson

Butler University

Fredrika Thelandersson Rutgers University

Marie Thompson

Lincoln University

Milla Tiainen

University of Helsinki

Virginia Villamediana

FLASCO

Isabel Waidner

Roehampton University

Elizabeth Wilson

Emory University

Julie Wilson

Allegheny College

Emily Chivers Yochim

Allegheny College 


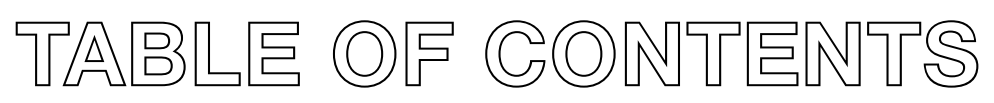

INTRODUCTION

i Fielding Affect: Some Propositions Andrew Murphie

ARTICLE

2 The Grace of my Perfect Skeleton: An Autoethnographic Analysis of the Anorexic Body

Lea Muldtofte

INTERSTICE

16 Boundary Affects: Stills from the Songwork Catalogue

Ben Spatz with D. Soyini Madison

26 ARTICLE

Regurgitative Reading

Marnie Ritchie

INTERSTICE

50 Du Bois and Blur

M. Gail Hamner

ARTICLE

58 Queer Sonic Cultures: An Affective Walking-Composing Project

Sarah E. Truman and David Ben Shannon

INTERSTICE

80 Good Morning 1877, Sit Down:

On Civility, Reconstruction, and

Our Revanchist Moment

Kyla Wazana Tompkins and Tavia Nyong'o
INTERSTICE

104 The Humiliation of 'Sex with Optimism':

Fieldnotes from Tinder

Sarah Cefai

ARTICLE

124 The Leaky Dimensions of Film and War, or Some Connective Tissue

Smiljana Glisovic

INTERSTICE

142 Introduction to Jerkism:

Excerpts from Aqua Rara

Jock Cousteaux

ARTICLE

152 Composting Settler Nationalisms

Mathew Arthur and Reuben Jentink

AFTERWORD

183 Sonnets

Maya Pindyck 


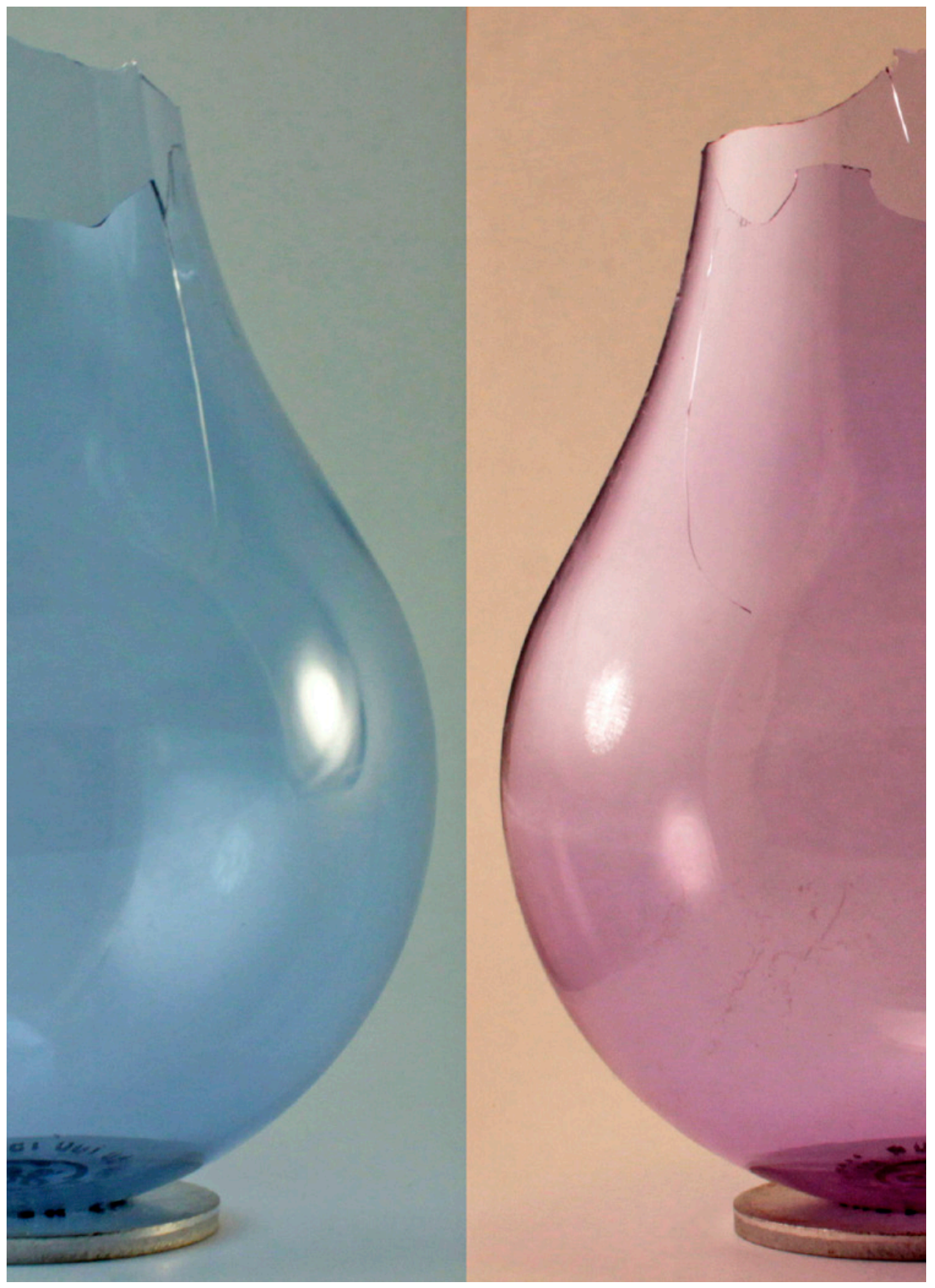

Neodymium bulb under two different types of light, Scientific29, 2011 Creative Commons Attribution 4.0 (CC BY 4.0) 


\section{FU[ELDING AFFEGT: \\ Andrew Murphie \\ UNIVERSITY OF NEW SOUTH WALES, SYDNEY} SOME PROPOSIIONS

... O Horizon alludes to the Tagorean horizon of soil and sky. It aims to situate people in times and scales in which soils and trees are not only grounds for education but figures of education.

\section{—The Otolith group on their film, O Horizon (Butler 2018)}

Capacious has wisely positioned itself as a journal for "emerging affect inquiry ... across any and all academic disciplines". Yet elsewhere we find something like an attempt to coalesce-occasionally even to delimit and police-a field of study. There is now-tentatively, at times argumentatively-something we call affect studies, or perhaps as often affect theory. How can the tensions involved, between disciplinary requirements and "emerging affect inquiry," be thought? Is a field of study, however it might be formed, a good fit for work with affect? On the other hand, would such a field of study have any future, when "categories traditionally assigned to the arts, the humanities, and the sciences are now colliding, collapsing, and converging in manners that are confusing, complex, and incoherent" (Butler 2018)? Further, what relation does all of this have to a world in which "soils and trees are not only grounds for education but figures of education” (Butler 2018, n.p.). 


\section{Some short propositions:}

Any possible affect studies would not suffer from "gaps in the field." Affect itself is everywhere and long has been (other fields are all arguably a certain packaging/ delimiting/ policing of affect). It is no surprise that there has been and is a profusion of rich thinking and work with affect ${ }^{2}$ (the history of Chinese philosophy, the I Ching or Book of Changes; Indian aesthetics; diverse ecological thinking; First Nations' complex affiliations and relations to country and earth; psychoanalysis, physics, sociology, a geography of emotions, cybernetics, behaviourism; art, music of all kinds; magic, ritual; politics of all kinds . . . the list is infinite). Affect itself is in everything, although it takes things to be processes or events. Viewed from a certain (processual) perspective, everything is, beginning, middle and end, a matter of affecting and being affected. Affect is therefore only impossibly an "object of study."

\section{2}

Every methodology necessarily involves affecting and being affected. Yet this suggests that there is no particular methodological suite that would define a field of study for affect, unless this consisted of something like experiment with process, relation and event. When it comes to affect, technics in general-human, nonhuman, inorganic and multiple combinations of these-is an open question.

\section{3}

Yet somehow, we do have something like affect studies or theory. (If for no other reason, we know this from all those who so eagerly contest or reject it, in a return to....). Affect studies as it has arisen until now could be understood as a moving feast of somewhat paradoxically limited constitutions of the field, and of methodologies regarding affect (sometimes playfully engaged with work with affect as experiment with process, relation and event, and sometimes not). These paradoxical constitutions respond both to institutional demands and to the need to pull apart, often from within, longstanding and many would say Eurocentric 
attempts to purify thought, will, and knowledge of affect. So, on the one hand, some recent narrower constitutions of affect studies have the world on their side even as they deny a great deal of it at times. On the other hand, any affect study is defying terrifying odds in terms of the politics of institutions, and indeed of 'Western thought'. William James (2008 [1912]) perhaps summed up the basis for what actually happens in affect studies long ago:

... 'is,' 'isn't,' 'then,' 'before, 'in,' 'on,' 'beside,' 'between, 'next,' 'like, ' 'unlike,' 'as, 'but,' flower out of the stream of pure experience, the stream of concretes or the sensational stream, ... and they melt into it again as fluidly when we apply them to a new portion of the stream. (44)

\section{4}

Affect theory is in a different situation to affect studies. It does at times have its own narrower formulations, as part of affect studies. Yet, like affect, affect theory is everywhere, the abstract accompaniment of whatever it is that's going on. Which is to say that affect theory per se involves some kind of conceptual or abstract feeling about how affect works, with perhaps added premonition about what affect is going to do next. It is a constituting part of living affectively, which is to say, simply living. As such, affect theory itself is affective. It assembles a series of powers to affect and be affected, from within/as a part of affective events. All theory is therefore affect theory, though some, primarily some European and American rationalist theories, do considerable work to pretend that they are more or less than this. Affect theories would then include: "animism" (Arthur 2018); most Chinese philosophy from Confucianism and Taoism to dialectical materialism; the feel in music; all human and nonhuman embedded assumptions, conditionings and habits; etc. Even the like of gravity or sunshine could be said to carry affect theory as what was ground becomes also figure. Gravity-which is affecting and being affected par excellence-is a force that literally attracts or draws away, affecting and being affected between celestial bodies, animal bodies, other bodies, and all these together. We might thus say that gravity determines 
both a practice and a theory-a speculative pragmatism that becomes the groundless ground zero of desire. Or, think of sunshine, another simultaneously simple and complex affective force. Sunshine, coming so clearly as it does from elsewhere, gives the basis not only for life (and for fossil fuels, industrial revolutions, or for that matter climate change and renewables) but, conceptually, for data, in Whitehead's sense of data as "the potential for feeling" (1978 [1929], 88).

\section{5}

The general nature of both affect and affect theory suggests that affect studies is perhaps not best pursued as the territorial quest for a delimited field (with a constitution of names and appropriate concepts, or appropriate delimiting tensions between a small set of competing concepts and objects of study). Affect studies might be better pursued, and indeed often is, in the more experimental mode I have suggested above; developing propositions and techniques for "fielding," in order to participate in the "crystallisation of fields of potential movement" (Massumi 2015, 119). Indeed, fielding and feeling-whether in a blush or the movement of a wind through a forest, or the viral contagion of an idea-are very close. This fielding/feeling makes the world. As Whitehead (1978 [1929]) put it, the world is a "medium" for the "transmission of influences" or feeling (286). Affect studies understand that, within this, one does not know the world so much as attune to it. Fielding is as participatory, as affected as it is affecting. Erin Manning (2016) writes that "fieldings . . . before all else are a tuning of affective tonality" (217). This is a participation in the ongoing constellation of an affective cosmos. It is not based only on the question of the object-what is affect, or on our (completely necessary) development of a field of study of such an object. Affective politics is also more than a politics concerning what should happen according to these objects. What is true for those working with affect is:

[that] which most successfully dip[s] back into the finite stream of feeling and grow $[s]$ most easily confluent with some particular wave or wavelet. Such confluence not only proves the intellectual operation to have been true ... Only in so far as they lead us, successfully or unsuccessfully, back into sensible experience again, are our abstracts and universals true or false at all (James 2008 [1912], 46) 
6

The tensions of affect studies are not then about, for example, feeling and emotion versus a broader affecting and being affected, and everything that falls out from this. The deeper tensions of affect studies are caught between two very different, if intertwined, formations of ecologies of practice and their formations of time. On the one hand, there is the need to accommodate standard academic practicereading, writing, publishing, teaching, being cited, aligning oneself within the taxonomies and value-adding exchanges and orderings of certain names (or for that matter concepts, or valorisations of certain fields of study). On the other hand, there is affect studies' real work (though work that changes its nature within and between each moment): working to attune to what I will call the immanence of the communicative event.

\section{7}

I once stubbed my toe and could neither fall nor recover my upright position. I tumbled forward, windmilling my arms for perhaps seven or eight metres, and then fell through a plate glass window, as if in some cartoon. As I fell, my head positioned itself close to the ground, under the now falling glass. I thought it could be my last moments (it wasn't-aside from some stitches I was fine). Time really did slow down remarkably. There was a beautiful sound like hundreds of tinkling bells as little shards of glass, mixed with blood from my head, fell all around me like beautiful tiny, red and silver lights. The moment was, and has remained until this day, profound (lucky that I was). I think it was time slowing down that drew my attention to this as an immanently communicative event-and an event of the world as the transmission of influences or feeling in which affecting and being affected involved an immanent refolding of powers. One could of course discuss any event as communicative and affective in this immanent unfolding and refolding of powers, though it happens that it is a little odd-and perhaps more than a little disturbing-to pay attention to this when you might not want to. This would include those events we usually consider communicative in an everyday sense-conversations, giving papers at conferences, lecturing, teaching, discussing things over coffee, negotiating a handshake or a hug, or who goes through a door first ... simply speaking and/or listening (who does either, and how?). Yet we seldom discuss the immanence of the communicative 
event, perhaps precisely because this might mean acknowledging that this is where the work of affect, communication and (im)mediation (Manning, Munster, and Stavning Thomsen 2018) is done, in and as the making of the moment. It is also where, more importantly, powers really do form, unform, and play themselves out.

Paying closer attention to the immanence of the communicative event would change the world. Yet we tend to prefer our politics elsewhere. We are great on communication strategies and performances issues, and general theories about what's going on (this is something of an example of course). All this work is usually directed towards other places, other times, larger structures and infrastructures of feeling and power. In many ways, it is directed towards the constitution of fields of study, or activity, elsewhere. This can of course be important. It can at the same time involve self or group interests, as an investment in the future formations of powers.

\section{8}

Yet at the same time there is a way in which we always fully inhabit the immanence of the communicative event and its direct transmission of influences, and folding of powers. This is in what we could call simply, the real, immediate feeling of power as a constitutional part of each event. We always tend to know how much power we have (or more correctly, how much power-and the feeling of power-has us). Or rather we always feel this, even if we do not immediately 'know' it. (And no doubt part of the distribution of powers in the communicative event involves who feels what kinds of distribution of powers and how immediately.)

Asking questions of this has always been the real strength of work within affect studies, and a large part of its ethics. Experimenting with how this feeling of power might be differently gathered, speculative pragmatically, within the immanence of communicative events, might be just as important a part of the ethics of affect studies.

\section{9}

Affect Studies needs such an ethics. Yet it can perhaps (and indeed often does) juxtapose such inhabiting of the strange multiplicities of feelings of power in events with a careful noting and a reworking of the way the "history of the present" comes 
into such events (Berlant 2016: Massumi 2015, 207ff; Foucault 1979, 31). In doing so it questions many core assumptions about how things work, and what's going on-assumptions about the distribution of powers to affect and be affected, and of feelings of power in any immanent event in constructions of race, gender, capital, etc.

\section{0}

Questioning the history of the present of the neurotypical distribution of powers within the immanence of the communicative event is important for many reasons. It is important not least because the neurotypical is so fundamental to the formations of the university, and research and education more generally. It is important more specifically because there are many traces of neurotypical concepts and formations of feeling within thinking, and working with feeling itself. All work with affect-formal or informal-involves an ongoing distribution of powers as to who gets to feel, or to be conceived to feel, in what ways, and how and in which situations. This is crucial to neurotypical (and in league with this, other) erasures of diversity. It is also crucial to the way that institutions such as universities (and many others) support fundamental underpinnings of power that are reduplicated, if differentially, within the communicative and affective in situ. This includes some troubling, if often assumed complex distributions of powers, and feelings of power, as to what will even count as communicative and/or affective, within the very conception, technical design, techniques and strategies of communication (including of course those aspects of communication so key to academic apportionings of the feeling of power). If there is a gap in the field at the moment, this might be it. As Manning writes, "It is still far too rare that we discuss neurotypicality as that which frames our ways of knowing, of presenting ourselves, of being bodies in the world" (Evans and Manning 2018, n.p.). ${ }^{3}$

Generally, it is perhaps no accident that so many find in affect studies a way of working towards new pathways through the constitution of powers in the immanence of the communicative event. This often involves a speculative empiricism. As autist Tito Rajarshi Mukhopadhyay (2015) writes in What I Learned in Special-Ed:

I created my own learning goals, which in turn created some very interesting situations. I analyzed the responses of people to these situations-what I call my social experiments. I became an empiricist. Why shouldn't the autist study the neurotypical? Why shouldn't he make productive use of his time? By becoming a scientist and philosopher, I was able to master my boredom (9). 


\section{1}

One of the obstacles to these new pathways is a peculiar conflation of so-called "theory of mind" (the idea that one can develop a working conception of the thoughts and feelings of others, in other words, of their 'mind') with something like a computational theory of mind (so that, we might say, due to our commonality, computers can have a working knowledge of our 'minds' and we of theirs). Or so that we can say, for example, that we can see ourselves, or others, in our or their data. Such conflations have been incredibly important to so much of postcold war, cognitivist, and informational culture (and in turn to the educational, managerial, and other cultures they have infused). Melanie Yergeau (2013) has pointed to a certain constitution of powers, and feelings of power, around feeling itself as part of theory of mind. This produces, of course, an active and savage exclusion of the neurodiverse.

\section{2}

Perhaps for a theory of mind-general, computational, cognitivist, or otherwisewe could substitute the large variety of affect thinking that doubles attention to the multiplicity that is affective capacity immanent to a situation. Here there is much to learn from outside neurotypicality (even if such a thing as neurotypicality does not in fact exist beyond its formation as a key distribution of powers and feelings of power). In fact, there is much to learn about the immanence of the communicative event itself.

Anne Corwin speaks of neurotypicals as those who "chunk" experience: neurotypicals perceive by categorizing. Autistic perception, on the other hand,troubles categories, feeling-seeing the world coming into itself. Autistic perception is the direct perception of the forming of experience (Evans and Manning 2018, n.p.).

In other words, the non-neurotypical experience is often that of fielding rather than chunked fields. 
Another task for affect studies has been to rethink the basics of representation, and of signs in terms of what we might call an affective semiotics (inspired by the work of Ana Ramos, forthcoming). This would make affect a semiotic of the moving, of the affecting and affected, of, as even Claude Shannon remarked, the ongoing "transformation of information" (in Horgan 2017), rather than the clear communication of information. It would not take signs or symbols as quasi-objects but rather as signaletic matter (Stavning Thomsen 2018). Subject and object would emerge from signal-semiotic fields rather than communicate through them. Affect would not become a contesting of the representational by the non-representational but rather a reconceiving of what representation, and mimesis, involve (Gibbs 2010). An affective semiotics would be close to what Whitehead (1978 [1929]) called "symbolic reference," which concerns the immanent formation of perception as the world's basis for what is only the one special case of what we call signs and symbols among other instances of symbolic reference (121). Symbolic reference combines our immediate perception of a fielding with the very movement of fielding itself. In other words, it is a very affective and whole world notion of both the symbolic and reference.

\section{4}

Perhaps then, we can rethink what has become the very core of the materialist version of the cognitive and the rationalist-symbolic processing in the brain as thinking. To begin, we might think it as, first, processing which may or may not involve symbols as we usually think them. Second, we might think of it as signal processing (as part of the world as the transmission of influences). Thirdly, however, we might think of thinking itself not directly as the kind of binary logic that is the basis for many cognitive models, but instead as a kind of proprioception within the brain. Thinking itself involves an immanence of communicative/affective events. The brain literally has a kind of proprioceptive feeling of its own shifting state, as sense (that neuroscientists refer to as connection and different "weights" of connection and so on). Finally, we might then undo the figure of the brain in order to realise the full powers of working ecologies of mind into which an unfigured brain might participate. As Deleuze and Guattari (1994) write, "[N] ot every organism has a brain, and not all life is organic, but everywhere there are forces that constitute microbrains, or an inorganic life of things" (213). 


\section{5}

Perhaps then we can begin to breakdown the longstanding division of matter (as that which is static) and process that still inhabits even affect studies. This breakdown would not work to favour either matter or process, but rather favour an emphasis on what affects and is affected.

\section{6}

And perhaps, then, affect studies would be even more prepared for what is no longer just a rhetorical 'changing world.' What new affects, powers of affecting, and being affected are arriving with climate change? What would be a way to think affective powers within the event encounters of the different speeds and formations of A.I.?

\section{7}

How are we to feel, to work within events, when we have to deal with so many changes, with both climate change and automation at once, for example?

\section{8}

None of this is to say that affect, per se, is in itself a wonderful thing and should in some impossible or contradictory way be "pursued." Rather, better means of attending to affect, and being able to experiment within affect's formation powers, may be the crucial contribution of affect studies, even after the dissolution of other disciplines and institutions. 


\section{Endnotes}

1. Thanks, as always, to all at the Senselab in Montréal from where much of this thinking has emerged (although they are not to blame for glitches). Thanks especially to Mayra Morales for a workshop we ran on differential communication/ differential movement.

2. See Nikitah Okembe-RA Imani's critique of Eurocentric notions of time (2018, 47), during which he in turn draws on Marimba Ani's critique of the Platonic bifurcation of reason and rationality, and desire and pleasure, in order to create a free will/predestination opposition within a linear and overarching concept of time (1994). See also Denise Ferreira Da Silva on Descartes' division of the interior and the exterior, the latter involving an 'affectability' to be avoided by "man, the subject of knowledge" $(2007,44)$. Affect Studies as a field perhaps only becomes possible, if at the same time the more necessary, in the shadow of such formations.

3. Manning also writes: "To engage with neurodiversity is to speak up about the extraordinary silence around neurotypicality and to acknowledge that we do not question ourselves enough as regards what kinds of bodies are welcomed and supported in education, and in social life more broadly" (Evans and Manning 2018, n.p.).

\section{References}

Ani, M. (1994). Yurugu: Africa-Centred Critique of European Cultural Thought and Behaviour. Trenton, NJ: Africa World Press.

Arthur, M. (forthcoming). Writing Affect and Theology Indigenous Futures. In Bray, K. and Moore, S. eds., Affectivity and Divinity: Affect Theories and Theologies. New York: Fordham University Press.

Berlant, L. (2016). Interview with Lauren Berlant. IPAK Centar. Available at: https://youtu.be/Ih4rkMSjmjs [Accessed 29th July, 2018]. 
Butler, L. (2018). The Otolith Group talks about O Horizon, 2018. Artforum, July 24. Available at https://www.artforum.com/interviews/the-otolith-grouptalks-about-o-horizon-2018-76090[Accessed 29th July, 2018].

Deleuze, G and Guattari, F. (1994) What Is Philosophy? New York: Columbia University Press.

Evans, B. and Manning. E. (2018). Histories of Violence: Neurodiversity and the Policing of the Norm: Brad Evans interviews Erin Manning. Los Angeles Review of Books, January 2. Available at https://lareviewofbooks. org/article/histories-of-violence-neurodiversity-and-the-policing-of-thenorm/\#![Accessed 29th July, 2018]

Ferreira Da Silva, D. (2007). Toward a Global Theory of Race. Minneapolis: University of Minnesota Press.

Foucault, M. (1979). Discipline and Punish. New York: Vintage.

Gibbs, A. (2010). After Affect: Sympathy, Synchrony, and Mimetic Communication. In Gregg, M. and Seigworth, G. eds., The Affect Theory Reader. Durham: Duke University Press, pp.186-205.

Horgan, J. (2017). Profile of Claude Shannon, Inventor of Information Theory. Scientific American Blogs, July 26. Available at https://blogs. scientificamerican.com/cross-check/profile-of-claude-shannon-inventorof-information-theory/ [Accessed 29th July, 2018].

James. W. (1912). Essays in Radical Empiricism. New York: Cosimo. (2008).

Manning, E. (2016). The Minor Gesture. Durham: Duke University Press.

Manning, E., Munster, A. and Stavning Thomsen, B. M. (forthcoming, 2018). Immediations. London: Open Humanities Press.

Massumi, B. (2015). Ontopower: Wars, Powers, and the State of Perception. Durham: Duke University Press.

Mukhopadhyay, T. R. (2015). Plankton Dreams: What I Learned in Special Ed. London: Open Humanities Press. 
Okembe-RA Imani, N. (2018). The Implications of Africa-Centred Conceptions of Time \& Space for Quantitative Theorizing: Limitations of Paradigmatically-Bound Philosophical Meta-Assumptions. In Phillips, R. ed., Black Quantum Futurism. Philadelphia: Afrofuturist Affair Books, pp. 31-48.

Phillips, R. ed. (2018). Black Quantum Futurism. Philadelphia: Afrofuturist Affair Books.

Ramos, A. (forthcoming). Affective (Im)Mediations and the Communication Process.

Stavning Thomsen, B. M. (2018). Lars von Trier's Renewal of Film 1984-2014. Aarhus: Aarhus University Press.

Yergeau, M. (2013). Clinically Significant Disturbance: On Theorists Who Theorize Theory of Mind. Disability Studies Quarterly. 33 (4). Available at http://www.dsq-sds.org/article/view/3876/3405 [Accessed 29th July, 2018].

Whitehead, A. N. (1929). Process and Reality. New York: The Free Press. (1978). 


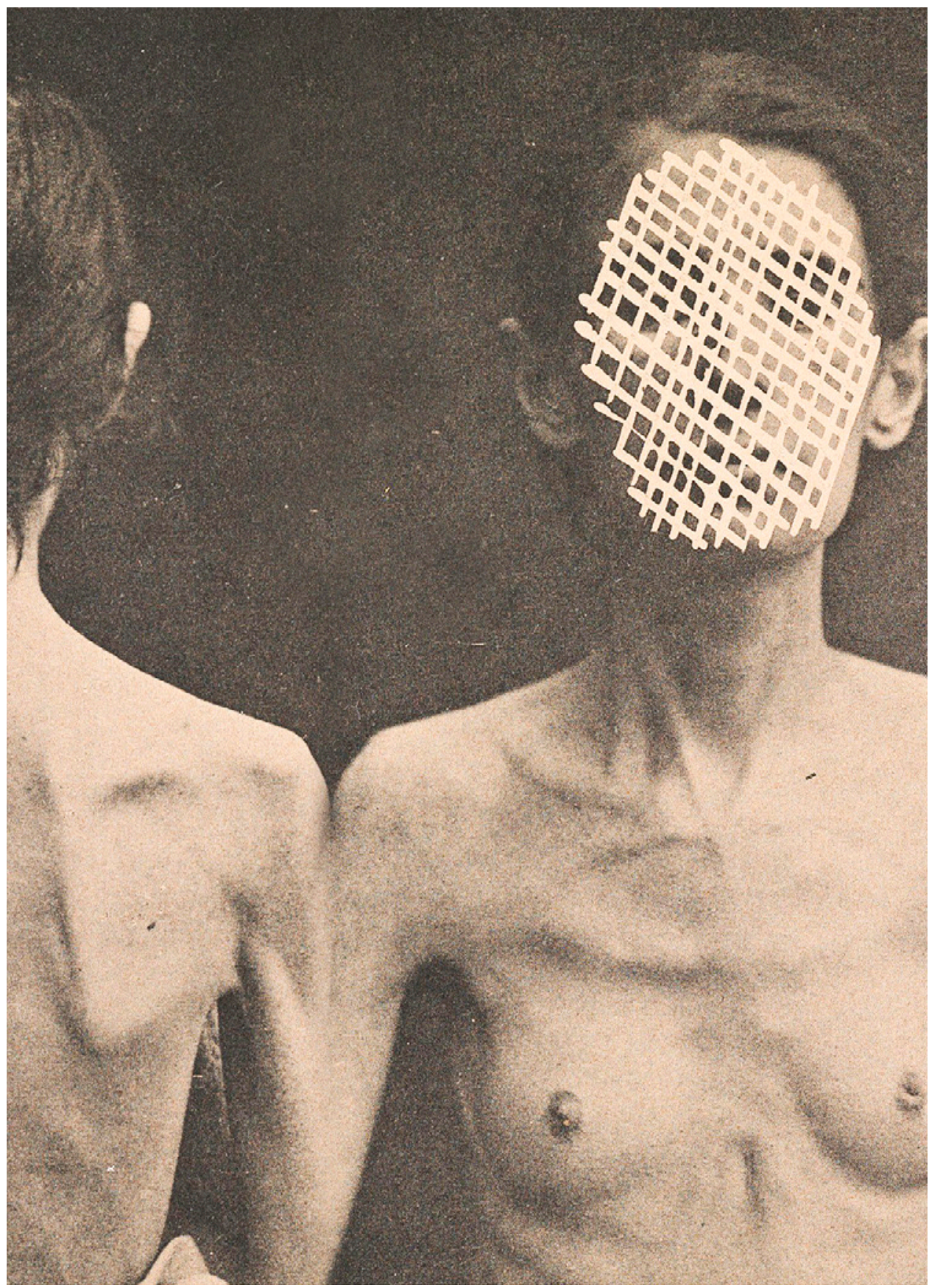

Emaciation Dans L'Anorexie Hysterique, Nouvelle Iconographie de la Salpetriere, 1888 Creative Commons Attribution 4.0 (CC BY 4.0) 
TI局 GRAG居 OF MY PEREECT SRELETON: ANA AUTOEIINOGRAPRIC ANALYSIS OF TIE ANOREXIC BODY

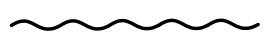

\section{Lea Muldtofte}

AARHUS UNIVERSITY

The psychiatric realm as well as social scientists are trying to understand and give insights to what is going on in the mind of a person, who is suffering from the diagnosis anorexia nervosa. However, for various reasons, the voices of the anorexic subject are usually discarded or misunderstood, which seems paradoxical, since drowning their voices have usually lead them to speak through their bodies in the first place. This essay provides a nuanced account of the suffering from anorexia from the perspective of an embodied experience with the disorder and reveal a paradoxical construction, a bloc of becoming that produces a very specific becoming. Through the thoughts of Deleuze, this article presents a first-person encounter of anorexia as a protest at three planes; on the level of the body, on the level of the closest intersubjective assemblage and on the level of culture and context.

\section{KEYWORDS}

anorexia, body politic, Deleuze, organism, agency 
Wearing a white dress, I was sent to the hospital directly from my final exam of high school, shivering with cold in late June. People were complimenting my tan, not realising that it was the colour of my inside shining through my transparent skin. I went smiling through the doors that were immediately locked behind me, triumphantly hungry, wearing my anorexic diagnosis like a crown on top of bones, innocent and virgin-like, so close to nothing that I was finally heard, that I finally had a voice. My bones spoke. More effectively than my voice ever could administer. I was not let out for almost a year.

It had taken me 8 months to delete my monthly periods, accentuate bones instead of flesh and make every vein flow visibly over my skin like small purple channels. Even one right on my forehead. I created a translucent corporal landscape; I thought it beautiful and I was so proud of my project. Eventually, I could not sit or lay down anymore without it hurting, so I used my computer sleeve to sit on wherever I went. Never had I done anything in silence so perfectly, so visibly, so obvious for the world to see. I offered everybody with eyes to share my terror and my beauty, my power in the fragility that could never have been attained in any other way. And with my continuous smile, and "I'm fine" responses, I held people away. I spent hours looking in the mirror, feeling myself and my bones, and pain became a measurement for success. If I had eaten more than what my standards could tolerate, I would strip naked, lie down, roll back and forth to the rhythm of wooden floor against vertebra, vertebra, vertebra, until it hurt so much that I was certain that the bones were still there.

What seems striking, looking back, is that my shrinking was applauded all the way, until I was finally just bones with diaphanous skin-not by the ones closest to me, the family, who saw nothing until it was too late, trusted the reasonable, good little girl to have everything under control as always. My surroundings implicitly or explicitly admired my body, my dedication, my discipline, and their assumption of my power. Three weeks before I was admitted to the hospital, I was approached by a modelling agency, and in the gym women would ask me for diet and exercising advice in order to lose weight-since I had the looks of an obvious expert. At some point, I almost ran a little geschäft, where I would make diet plans and training schedules for people, and if I sometimes responded to a compliment with "some say that I look anorexic," they would comfort me with the fact that "people are just jealous." 
By the time I entered the hospital, however, with the diagnosis anorexia nervosa, jealousy was replaced with a rare combination of disgust and admiration. People would either tell me that I resembled someone out of a concentration camp, a cancer patient, or a fashion model (exaggeration, of course). They would accuse me of being vain, immature, or insane as well. I will not dismiss that I was, or definitely became, all three of these things in some ways. Self-constitution through restriction, deprivation, and inhuman rules is unquestionably self-centred, and would undoubtedly make most people mad. However, only to make defects or the extremity of the suffering person's mind responsible for the disorder-as it is done within treatment at least in Denmark-would be to completely ignore the complexity of the phenomenon of anorexia. Maybe that is why the treatment is so ineffective.

This essay will try to explore three directions with regards to the anorexic body. Three directions that might appear contradictory, and they might very well be, but then again, the overall point here is that the enigma of the anorexic body does not have one answer, but multiple inexhaustible explanations. I am positive that this essay will leave behind more questions than answers regarding anorexia; but these questions need a voice within the field of cultural and affect studies. Anorexia, and eating disorders in general, should not be left to the psychiatric realm (exclusively) to be explained and treated behind the locked doors of impenetrable institutions. Because behind those doors anorexia, as I just mentioned, becomes a problem on the level of the individual: a product of an insane, irrational mind, an unfortunate, weak, passive victim of media influences. What a load to put on one person's shoulders and mind! Especially since the anorexic body is more or less the opposite: it has extreme force and agency. It is, of course, produced through assemblages, family, and cultural structures as a protest against obedience, via extreme obedience.

The three directions are inspired by Gilles Deleuze and his description of anorexia in Dialogues, a conversation with Claire Parnet. Here he tries to define anorexia as a "history of politics" $(1987,111)$. A protest on three planes: on the level of hunger/food, on the level of the family, and on the level of consumer society. I have reformulated them into three themes, which will be the focal points for this essay: the body, the family or the closest intersubjective assemblage, and the culture and context. They cannot strictly be separated since, of course, the body, the family and their cultural surroundings are constituted through a connection with each other, but for the sake of analysis, as we know, separation can be helpful. I will progress through these three directions and discuss Deleuze's argument, which I follow most of the time. Eventually, I part from it in certain ways. 
As for material, I will use myself and my embodied experience with anorexia. Why have I never before thought to engage in academic discussions concerning anorexia, much less engage my own experience with it? Because to have your every-minute negotiating hell exist in one's work is not particularly attractive. But, even though intelligent and respectable literature on anorexia in cultural studies is emerging and includes literature that incorporates voices of anorexic subjects, the discussion would benefit from having more non-interpreted voices with an embodied experience of anorexia talking back. Examples of scholars who engage their bodies and experience with anorexia in their work in order to explain, explode, and nuance opinions and discussion around eating disorders include Elspeth Probyn (Probyn 1993; 2005) and Paula Saukko (Saukko 2008). My voice and body can be a contribution making this voice stronger. Further, the anorexic voice is usually contested or dismissed as being unworthy, because the discursive opinion of a person with such a diagnosis is characterised by notorious manipulative behaviour. As Rebecca J. Lester states in her ethnographical analysis of anorexia patients: "[P] atients are frequently perceived as not only incapable of accurate reality testing but as being deliberately manipulative, or playing on others' emotional investments in order to obtain desired ends (cf. Ramjan 2003)" (Lester 2016, 9). Speaking as an anorexic, admitting to your illness, immediately cancels the sincerity and rationality of the voice. Anorexics are silenced. ${ }^{1}$ But I have a privileged position, ways to channel my voice, so that I hopefully may reach readers and escape the locked-in position of being diagnosed a liar. As a way of highlighting certain aspects from a poetic perspective besides my own body, I will also use an excerpt from the novel Morte ai Vecchi by Franco Bifo Berardi. Eventually, I hope to reach a non-concluding conclusion about anorexia as a paradoxical construction, a bloc of becoming that produces a very specific becoming and, thus, proposes anorexia as a space for introducing the ends of constructivism.

\section{The body praxis}

Throughout three pages of Dialogues, where Deleuze ruminates over anorexia, he sees the phenomenon as self-evidently a refusal (1987). Anorexics do refuse, they do eat less than other people, that is true. But, in fact, contrary to what many might think and contrary to the general opinion of people that I have met (especially in treatment), it is not a refusal of the body image as such. It is not, 
in all cases at least, only or primarily a dedicated punishment towards a look which the anorexic subject is not content with and therefore tries to alter. How could it be that simple? On the contrary, as I read my own thoughts through the thinking of Deleuze, I did not hate my body or my look at all, not prior to when my shrinking started, and especially not during it. I used my body. I did this in a constant and meticulous negotiation and calculation between body, flesh, and intake: like weighing myself (at least) three times a day, reducing food to its value in calories, measuring myself, sitting on the bus making sure that my thumb and index finger could meet around my upper arm etc.

Instead of a refusal of the body, Deleuze calls anorexia a refusal of the organism, ${ }^{2}$ which is slightly different: "There is a whole plane of construction of the anorexic, making oneself an anorganic body" $(1987,110)$. While it seems paradoxical, it should be highlighted that refusal and negation, then, apply to a construction of a specific doing, which I find important. More than a frozen diagnosis attributed to a certain status of a body, anorexia should be regarded as first and foremost a praxis, preceding the diagnosis. And this praxis, however extreme, corresponds to a generally acknowledged praxis of dieting, a correct way of eating. The praxis of anorexia then is what Bray and Colebrook, with reference to Deleuze and Guattari, calls "a series of interconnected practices," connections and disconnections to and from body, praxis, and surroundings. In this light, anorexia should be considered not only for what it destroys, but for what it "creates and invents" (Bray and Colebrook 1998, 58).

This praxis of a refusal of the organism in interconnected practices I truly recognise because this is about mastery, about refusing, and about mastering the disturbance of needs and signals from the body, which seemed to me so claustrophobic. The need for food, or responding to the need for food, reminded me of dependence. Dependence upon a system which was forcing me into social settings and temporal restrictions (oh the horror of mealtimes, and the fact that clocks, and daily pauses surround eating-this I will return to). The constant disconnections and connections between the exterior restrictions, my own restrictions, the numbers representing my restriction in weight, my representation in the mirror, food and how this was represented in calories, all affected my constructed praxis, and determined how I felt. It numbed my loneliness and made me continue. I would say that instead of responding to hunger as a signal and need from the organism, the representation of my body and of food in numbers was violently intervening. They interfered and affected me, and caused me to be, literally, moved. 
In a reading of Marcel Proust's In Search of Lost Time Deleuze demonstrates exactly how representations or signs in the world are not primarily referring or representing, they are not mediators or conveyors of information. Instead, a sign induces a violence in its encounter with a body, and this meeting doessomething to this body, forces it to react or to transform in some way (Deleuze 2003). Frederik Tygstrup observes that the sign concept, which Deleuze introduces here, is inspired by Spinoza and his understanding of affect. Spinoza distinguishes between affectio-a sort of incoming affect, and affectus is to be understood as an outgoing affect: the reaction of the body, the being affected (Tygstrup 2015). Affectivity, in this sense, is a dynamism of affecting and being affected, but as Tygstrup points out, it does not stop there: "when somebody is affected, this somebody is likely to change agency as well, affecting the environment in turn" (Tygstrup and Devika $2015,15)$. Seen in this way, the refusing and measuring practices of the anorexic in regards to body, organism, and intake are "practices of connection" and these practices, as they affect representations-which, in turn, affect the anorexic body-"form the event of the anorexic as such" (Bray and Colebrook 1998, 62).

Accordingly, the praxis of refusing the organism: measuring, calculating, and regulating body and food; deprivation, restriction, and adjusting is then that which partakes in constituting the construction of the anorexic. Discovering that my body worked, my brain worked, and I could force it into functioning, even though I was refusing the organism's greedy demands-all while occupied with the thought of minimizing my numbers every minute of the day-was a triumph. And then it paid off in shrinking. I watched with pride the organismic transformation, the sculpture, I was creating through refusing this organism.

Getting at the same point but through a phenomenological analysis, Dorothée Legrand insightfully suggests that obeying the organism reduces one to exactly that-an anonymous organism, an object:

while eating, one is not only assuming survival; one is also negating one's subjecthood by incorporating food, thereby incorporating oneself into the realm of anonymous organic processes and of corpses, assuming one's dependence to one's objecthood, thereby negating the sovereignty of one's subjecthood $(2011,506)$.

The anorexic, then, will regard the very act of eating as a feeling of losing subjectivity, according to Legrand. In another study, Anna Lavis, discusses the absence of food, the practice of starvation as a way of understanding the anorexic subject, understood as maintenance through absence (2013). 
Importantly, however, as is also noted by Legrand, my anorexic praxis was not a refusal of food full stop. It was not absence. On the contrary, I was obsessed with food, and not only in the way that it is clinically proven that starvation causes a manic fantasizing of nutrition, although such fantasies were also present of course. For me it was this neurotic game; these negotiations, calculations, compensations, tricks, in order to make me master of the organism for the purpose of approaching my bones. I would not not eat. I would eat very specific things. And, in fact, most of the threads on pro-ana websites, which are created and used by people with eating disorders, are dedicated to eating and not not eating. In this way, I differ from Deleuze and how he describes the anorexics relationship with food: "The anorexic thinks that food is fundamentally bad, hence the need to select and extract particles, or to spit it back out" $(1987,111)$.

I understand why people, including Deleuze, would think that anorexics in general are disgusted with food. Especially because it is a common lie that the anorexic tells people around her in order to deliver a logical explanation for saying no. And spitting things out is a clear manifestation of disgust, a gesture of "I don't want that in me." But I have met only a few anorexics who fight food because they truly think it is poison or unclean. In these cases, the person has been so maddened by the disease that delusion has taken over. The "taste and spit" that Deleuze talks about here is a common starvation praxis, but has more to do with refusing the organism than with disgust, I would say. It concerns, what Deleuze beautifully calls, the anorexic's double betrayal in all three planes. First is hunger, the betrayal of the organism's needing signal: "anorexics are enthusiasts: they live treason or the double turning away in several ways. They betray hunger, because hunger tricks them by making them subject to the organism" $(1987,110)$.

This double turning away is described in Dialogues in relation to a regime of treason with a centre of subjectivation, instead of a centre of significance (1987, 107). Like God becoming the point of subjectivation, he turns away from his subjects, who then turn away from him. With regard to the anorexic, the "taste and spit" is definitely a betrayal performed by the betrayed, a trick played upon the organism. Being extremely hungry, putting food in your mouth, letting it rest there, tasting it only to spit it back out is a refusal of the organism within the organism itself; it is treason to the point of mockery. I would do it with bread, because that would be what I would feel like the most. Along similar lines, I was in the hospital with a girl, who would consume extreme amounts of sugar-free sweets. They disappear into your mouth without you having to swallow, bordering and guarding the organismic entrance, without giving in to it. 


\section{Germinating organism}

In an excerpt from Berardi's novel, a chapter called "Anorexia Sister," we also see this behaviour. The chapter is a stream of consciousness from Anita, an anorexic girl, and it includes a description of her anorexic friend Marcella. At some point during the stream, Marcella has a grain of rice in her mouth for 42 days, which she refuses to swallow, just keeping it in her mouth, just inside the gates of the organism:

I saw Marcella sucking a grain of rice for 42 days. She also kept it tight in her mouth in class. It seemed that a green string, a talking plant, would sprout from her throat. Her mother begged her day and night through hiccups that resembled rattles "do it for mum, do it for me!" but Marcella simply sputtered (Berardi 2016, 175).

Marcella in this way performs the ultimate betrayal. She not only tricks hunger with constant taste without giving in to it, she also blocks the entrance of the organism, refusing any other possible nutrition to enter, clinging to-almost protecting-her grain of rice.

In this description, a tension and a fear towards not being able to master the organism is present in Anita, poetically written into the fact that a grain can germinate. Germination, something that an organism can perform on its own, is something she cannot control, and this is anxiety-provoking for her. As when Marcella finally swallows her grain of rice, and Anita imagines the reaction of the organism, which has now been given life within Marcella, through that rice grain. She imagines, thus, her own sprouting as well. Her organismic development as a result of eating (gains weight is what she means here):

Marcella swallowed her grain of rice, and in vengeance, it started to geminate. A rice paddy was born in her stomach. Today I feel like that grain of rice which remained stuck in Marcella's mouth for 42 days $(2016,176)$.

The anorexic betrays the organism, because she feels the organism has betrayed her. The double betrayal. The anorexic tricks the organism, tries to master it, and she does it in an almost cruel way. ${ }^{3}$ She masters a transformation of her body by denying the organism. She constructs and, paradoxically, becomes through negation, becomes through subtraction and shrinking. However, this absurd but dedicated mockery of the organism ends up mocking nothing and no one more than the anorexic herself. I will come back to this at the end. 


\section{The family}

Moving next to anorexia as a protest against the family, or what I have called closest intersubjective assemblage. I do this in order to avoid limiting the occurrence of anorexia to one set of particular relationships. Following Deleuze's anorexic double betrayal, he continues: "they betray the family, because the family betrays them by subjecting them to the family meal and a whole family politics of consumption" $(1987,110)$. As I described before, the need of food, or responding to the need of food, was a praxis associated with dependency and constraints; dependency upon a system, locking me into social settings and institutions dictating my time. Sitting and eating together at a certain hour is a standard for well-functioning families in proper-functioning Scandinavian upper-middleclass suburbs. It is inherent in cultural norms; it is something we do and should do with our children or partner. Quality-family-time. Sitting and not eating, however, does shake up the fluxes and structures within any given family; hacking at and exposing this somnambulistic "quality-family-time." This small protest changes the affects and rhythms of numbness, disrupts the routines, which are part of a family-time-checklists and usually questioned by nobody. Even as this protest eventually causes intersubjective tension and intensities, exuding pain, frustration, and other kinds of imprisonment for everyone involved.

Eating is the clock of institutions as well, it is breaks (in fact the word for meal in Danish is mailtid; mealtime). Breaks are unpredictable social assemblages, assemblages one has rarely chosen oneself. You are enslaved to social situations, to a social organism, when a clock strikes 12 , or 6.30 pm because the cosmos has decided that bodies have needs at that time. To me this was claustrophobic, and anorexia was definitely a way to disrupt it. I disconnected from these outside restrictions in order to connect to my own new rules, creating a "being otherwise" (Bray and Colebrook 1998, 58). It was treason. A way of silently saying, "I don't need your mealtime or your breaks." However, anorexia for me became the most powerful tool with regards to voice. I unfortunately discovered that extreme shrinking is a very visible process. It works because the anorexic body invites other people to be spectators of its slow destruction. Others are sort of chained participants, involved without the influence to intervene. In this way, the anorexic practice of starvation and slow disappearance changes intersubjective assemblages, such as the family and the relationships, in which the anorexic participates. It is extremely inclusive and exclusive at the same time. Twice in my life I have been deprived of a voice, interrupted, mocked, not worthy of being listened to within my own home. In both cases, anorexia saved me, even as it almost cost me my life. Since I started talking through the visibility of bones, creating a space where no one could interrupt me, this was eventually and, sadly, very effectively heard. 
Returning to Berardi's novel, Marcella also has a fallout with her mother, who begs her to eat. I am not a mother myself, but I can imagine, and have experienced through my own mother the fundamental contradiction of not being able to feed one's child, since that is the very purpose of a mother's body. Interestingly enough, Marcella's refusal is also mute, also bound to the fact that she uses her mouth to do something other than talk. She is using her mouth to not eat, which becomes her very explicit activity, and this activity is also her answer to her begging mother: not eating her grain of rice.

\section{Culture and context}

This is a huge discussion that I can only superficially touch upon. I have tried to show in other settings how the praxis of anorexia speaks just as much about the disorder of the culture surrounding body-ideals and food-trends as it does of the disorder within the anorexic mind.

Turning to this third protest, for Deleuze, anorexia becomes a political act against consumption as such. A protest against eating as consumption, obviously, and against being consumed by structures. But he highlights the political act against consumer society in particular. He says: "anorexia is a political system, a micro-politics: to escape from the norms of consumption in order not to be an object of consumption oneself [...] She will turn consumption against itself" $(1987,110)$. Consumption, yes. Earlier I have found it amusing that people would think that anorexia had anything to do with the fact that Iwanted to look like a fashion model. Now it makes me angry that it seems to still be the dominating discourse regarding the cause of the disorder.

In a recent Danish newspaper article, the head of the Danish organisation against eating disorders comments on a new study showing that native Danes are more likely to develop an eating disorder than first and second-generation immigrants. His explanation is that Danish girls-note girls-have a tendency to become more affected by fashion magazines than girls from a different ethnic origin than Danish, because their relation to Danish body and ideals are different. Immigrant body ideals are more curvy. He was quoted:

It is often more accepted to have curves as woman within the immigrant community. We witness a tendency, where native Danish girls are more affected by fashion magazines than girls with an immigrant background, because there is a difference in body ideals (Folkman 2017, my translation). 
Besides the racial and stereotyping problems in this statement, and the automatic segregation in placing non-native Danes in a pool of non-western Danes (assuming the west against the rest as usual), male anorexics are also shut out of the discussion here, as they also usually are. Furthermore, this quote confirms a simplified version of the anorexic subject as a vulnerable reader of mass media images, thus completely reducing the complexity of the disorder. Such statements serve to do nothing but confirm a discursive misunderstanding of anorexia, and instead of focusing on anorexia as a set of interconnected practices of protest with a high level of agency, it is reduced to what Bray and Colebrook call "the pathologization of women's reading practices” (Bray and Colebrook 1997, 51).

To say that torturing your body and mind has the purpose of becoming something out of a magazine, inherent in this purpose must also lie an assumed desire to be consumed, to be attractive, to "look good." To be the object of consumption, in other words. The anorexic body definitely wants to be consumed, but only in the double betrayal. Anorexics are grotesquely aesthetic, yes, but they betray the cultural standards of beauty and stereotypes-by becoming the exaggeration, by exactly refusing to become an object of consumption. I was not interested in beauty. I was interested in looking dangerous, in looking fragile, because therein was my power. It was not myself as overweight I was trying to escape. It was the healthy, good-looking, completely normal version of me that terrified me. I was relieved when my partner lost sexual interest in me.

I am not saying that my anorexia had nothing to do with body ideals. In fact, I have to admit that if my surroundings were not obsessed with being fit, sticking to a diet, correctly exercising, correctly eating, I am sure I would have chosen another self-destructive solution, and the disorder wouldn't have stuck with me for so long. For some, me included, anorexia cannot be detached from western body ideals; but I was not so much reacting to my own desire to be ideal as I was reacting to other's desire to be ideal. Understand that anorexia is a solution to a problem: a solution to an emptiness, a voicelessness. You are willing to let your body become an object for principles, a "micro-politics" in Deleuzean terms, to be at least something. I performed the norms and ideals of culture to a grotesque perfection. One of the girls I was admitted to the hospital with spoke a beautiful sentence in relation to this:

If I can be more than they want to be, if I can do more than what they want to do, I might be good enough. Not good. Just good enough (Britta). ${ }^{4}$

In this way, anorexia is the ultimate performance of the norm that dictates the ideal-the correct way to eat, train, and exercise. It is a becoming-structure, a becoming-discourse, an act of perfection, of correctness, which in its treason 
becomes a caricature. Eventually, for some (most of the users on pro-ana websites for instance), anorexia is a paradoxical becoming-diagnosis, where the goal of becoming is nothing but destruction.

Deleuze uses the term: "involuted body," which means a body that becomes a body of the in-between. The anorexic is the in-between; it is betraying organisms on several planes. She is treason, mockery, irony.

\section{Ends}

Anorexia illuminates multiple layers of constraining organisations within life as such, or more accurately, within western life. Read the anorexic body and practice as a visual text, and it reveals the order, or the disorder, of society-and this is important and valuable. However, I want to make a concluding note. In Deleuze's description of anorexia and in other mass-media understandings of anorexia, if the anorexic body is not insane or a victim of capitalism or patriarchist stereotypes, then the anorexic becomes an aesthetic figure, almost a feminine hero, defying these categories. I am afraid that I am painting that picture myself-have painted it-which is regrettable, because it undermines the pain and torture that comes with anorexia. And this does not need aestheticizing, and it is definitely not heroic.

"It is a feminine protest of a woman, who wants to have a functioning of the body and not simply organic and social functions which make her dependent" Deleuze says $(1987,110)$. And that is the paradox of everything regarding this disorder. Trying to escape dependency and fighting claustrophobia, traps one in the cruellest of addictions; a maddening obsession. I became addicted to shrinking, to watch my bones' visibility under my skin. An anxious, compulsive act that stripped me from anything social to the point where I-literally, as one of my friends pointed out-had nothing left to lose, nothing but the anorexia of course. In this void the disorder will thrive. The betrayal becomes tripartite, the betrayed betrays what betrayed her, and in that process, she betrays life. I betrayed the hunger, which I despised, yes, but I was never able to extinguish it. I let passions go instead. In Deleuzian terms, I did micro-politics by performing the double betrayal of systems that were threatening to constrain me. However, in my understanding, politics belongs to conversation and solidarity, and there 
is nothing like solidarity about anorexia; it is self-centred and lonely. The final treason, and the most obvious, is when the construction comes to a final end: she dies. Anorexia for all its building, constructing, and becoming has one linear trajectory, and that is towards death; which will end whatever micro-politics she was performing. I was admitted to the hospital with seven other people, three of us are alive today. If the anorexic does not die, many will be in and out of hospitals for years, very much constrained to the identity of the sorry un-Deleuzian binary of being either sick or normal depending on numbers on scales and body mass index 17.5. I was. Anorexia is a boundary figure, an involuted body that escapes definition (eventually), even its own definition as involuted.

I will end with Anita, and her prayer to mother ana, who art in heaven: "may it triumph, the grace of my perfect skeleton" (Berardi 2016, 173).

Hopefully not.

\section{Acknowledgement}

A special thanks to Christina Jerne for translating Franco Berardi's text from Italian to English and for providing me with the courage to write this piece.

\section{Endnotes}

1. People are outraged and baffled when anorexics, and people with other eating disorders, create online for a where their voices are not deprived. Pro-ana-fora are communities of understanding.

2. The body, family, culture, and contexts are of course organisms. Anorexia can thus be said to be a refusal of organisms in general.

3. Limited by language, I use 'she,' but I mean all kinds of anorexic bodies.

4. Britta's real name and identity are hidden. 


\section{References}

Berardi, F. B. (2016). Morte ai Vecchi. Milan: Baldini \& Castoldi.

Bray, A. and Colebrook, C. (1998). The Haunted Flesh: Corporeal Feminism and the Politics of (Dis)embodiment. Signs 24 (1), 25-67.

Deleuze, G. and Parnet, C. (1987 [1977]) Dialogues. New York: Columbia University Press.

Deleuze, G. (2003 [1964]) Proust et les Signes. Translated by Frank, Søren. København: Det lille Forlag.

Folkmann, A. (2017). Forskning: Danskere rammes oftere af Spiseforstyrrelser end Indvandrere. Jyllandsposten [online] https://jyllands-posten.dk/indland/ ECE9777029/forskning-danskere-rammes-oftere-af-spiseforstyrrelserend-indvandrere/ (Accessed 09 August, 2017)

Lavis, A. (2013). The Substance of Absence: Exploring Eating and Anorexia. In: Abbots, E.-J. and Lavis, A. eds, Why We Eat, How We Eat: Contemporary Encounters between Foods and Bodies. Surrey:Ashgate.

Legrand, D. (2011). Ex-Nihilo: Forming a Body out of Nothing. In: Mackay, R. and Negarestani, R. eds., Collapse, Vol VII: Culinary Materialism. Falmouth, UK: Urbanomic, pp. 499-558.

Lester, J. R. (2016). Ground Zero: Ontology, Recognition, and the Elusiveness of Care in American Eating Disorder Treatment. [published online ahead of print October 24, 2016]. Available at: https://doi. org/10.1177/1363461516674874. [Accessed 08 August, 2017]

Probyn, E. (2005). Chewing the Fat. Griffith Review (4). https://griffithreview. com/articles/chewing-the-fat/ (Accessed March 30, 2018)

Probyn, E. (1993). Sexing the Self: Gendered Positions in Cultural Studies. London: Routledge.

Paula S. (2008). The Anorexic Self: A Personal Political Analysis of a Diagnostic Discourse. New York: State University of New York Press.

Tygstrup, Frederik (2015) Proust og Det Frynsede Selv. Passage-Tidsskrift for litteratur og kritik. 30 (73).

Tygstrup, F. and Sharma, D. Eds. (2015). Structures of Feelings: Affectivity and The Study of Culture. Berlin / Munich / Boston: Walter de Gruyter. 


\title{
BOUNDARY AFFECTS:
}
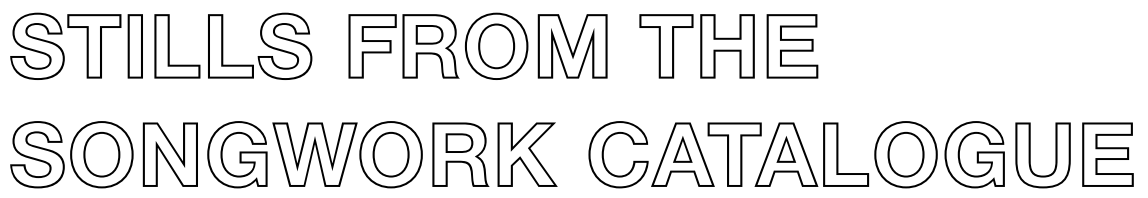

\author{
Ben Spatz \\ UNIVERSITY OF HUDDERSFIELD ENGLAND \\ D. Soyini Madison \\ NORTHWESTERN UNIVERSITY
}

Text by Ben Spatz with D. Soyini Madison

Performance by Ben Spatz

Videography by Nazlıhan Eda Erçin and Agnieszka Mendel

Video stills selected by Ben Spatz

\section{The Songwork Catalogue}

In May and June 2017, I ran a full-time 'embodied research laboratory' at the University of Huddersfield, England. Using a new methodology of working configurations and transversal video, the trio team-Nazlihan Eda Erçin, Agnieszka Mendel, and myself-produced about 40 hours of video during this period. The videos document experimental embodied practice in the field of songwork, including solo, duo, and trio explorations of a set of songs learned from the Smithsonian Folkways digital archive. More information on the project can be found at urbanresearchtheater.com.

One of the extraordinary features of video is that it is composed of photographs. An hour of video contains literally thousands of images. In selecting stills for this paper, I first decided to draw only from the videos documenting myself as solo practitioner (other publications from the project will be more 
fully co-authored). I then searched, often frame by frame, for images evoking the wildness and nuance of affect. I looked for hidden moments that were difficult to name, that skirted the boundaries of known or unknown affects. Not all of the images include my face. In some of them I do not look, to myself, like myself. And of course, the work being done here is not only embodied. The effect of the affect, if any, arrives to the page through the camera: doubly mediated.

The reduction to eight images invites schematization. It is tempting to name each one and thereby create yet another (even if deliberately heterodox) typology of affects: pensive, active, dog, harmed, sparks, yearning, giddy, vessel-could these be additional 'sisters' to our more familiar emotions?

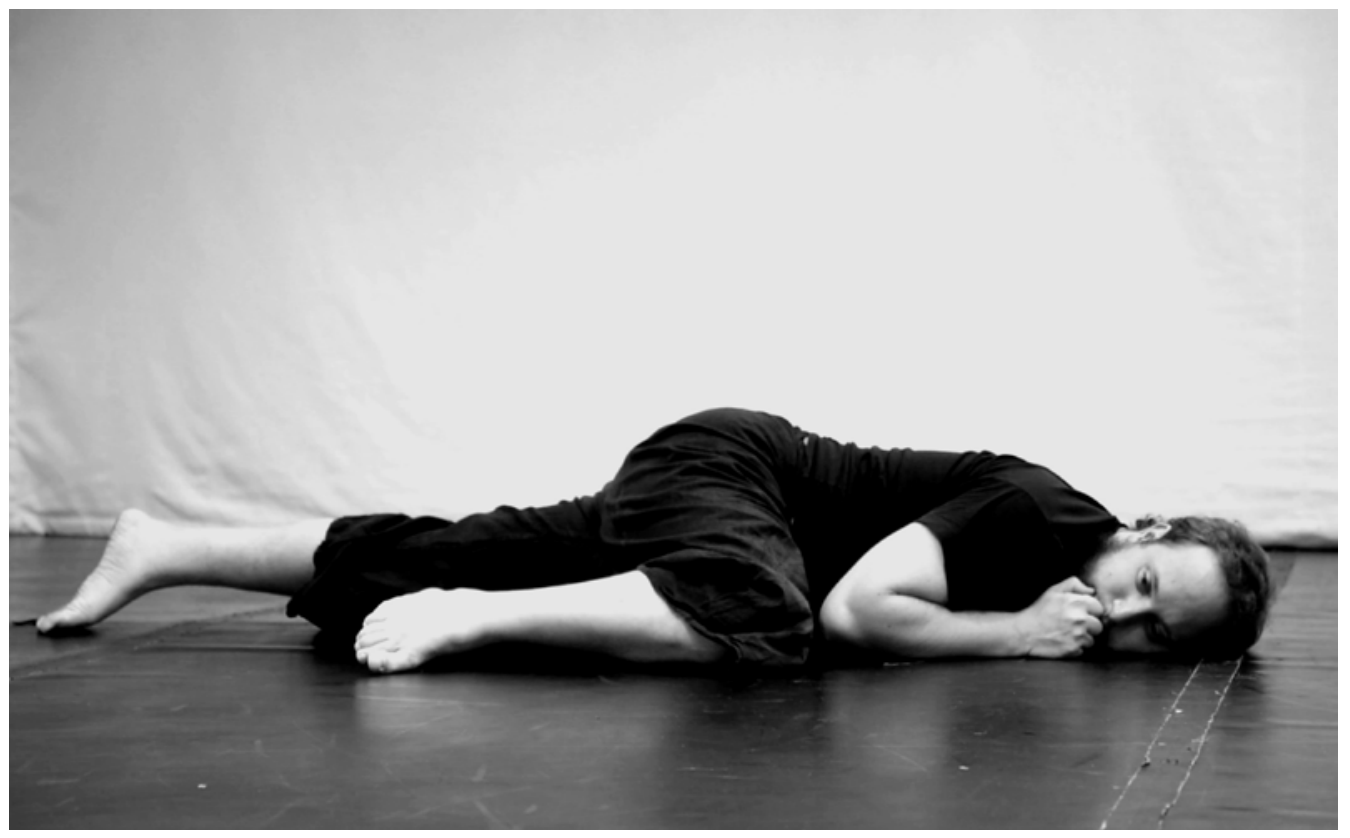

\section{Ben Spatz Interview with D. Soyini Madison ${ }^{1}$}

DSM: It seems embodied research is inseparable from history and relations as well as the time and labor required to make it generative or consequential. I'm thinking about politics and the material resonances of embodied research. How would you describe your method of embodied research and its unfolding? 
Is there a memorable example of rupture or realization that set your process in a different or added direction-a moment that emerged, something newly done or deeply felt?

BS: I am always thinking these days about the institutionality of the laboratory. Much has been written about the violence of the laboratory space, from Linda Tuhiwai Smith (1999) noting that research is a 'dirty word' in Australian indigenous communities, to Karen Barad (2007) choosing the strikingly violent metaphor of the 'cut' to describe how scientific measurement produces knowledge. Yes, the laboratory is 'inseparable from history and relations', it is a place of time and precisely of labor. I constantly return to Bruno Latour's (1983) statement about the power of the laboratory to transform the world: 'Give me a laboratory and I will raise the world!' This transformation does not have to be a violent, colonial one. It all depends what kinds of labor take place in the laboratory, what kinds of cuts are made. I imagine another kind of laboratory as a leverage point for another kind of world.

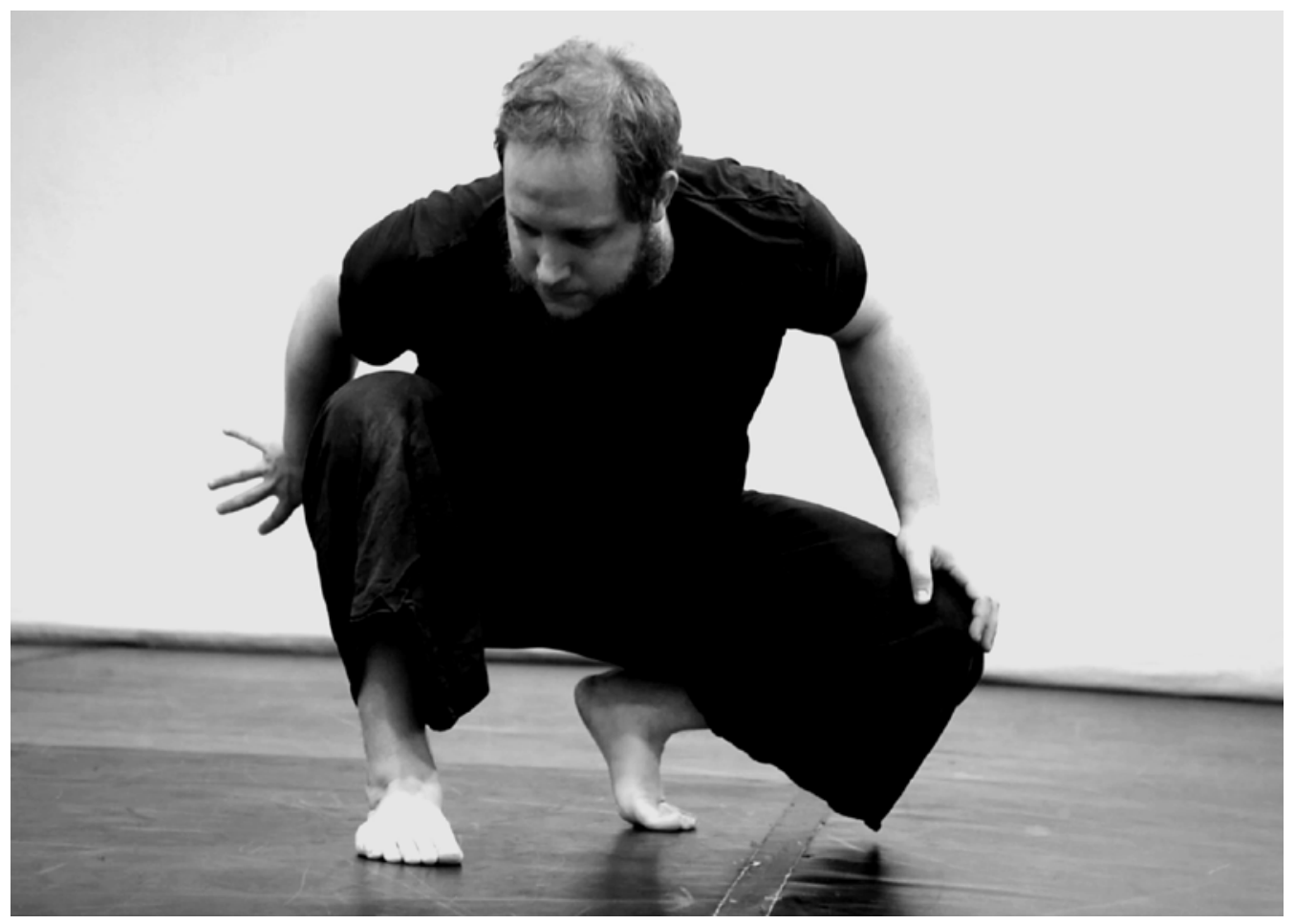

This past summer has taken me through moments of enormous discovery. After two months of narrowly focused embodied research in songwork, my team was visited by anthropologist Caroline Gatt, who suggested that we bring our books into the workspace. That proposal set off a chain reaction which has exploded my concept of embodied research and rendered our methodology more genuinely 
empirical than I could previously have imagined. With this shift it finally seems possible to imagine new forms of institutionality that are more adequate to the sonic and movement dimensions of embodiment, and perhaps less wholly inadequate to our present social and environmental crises.

Many people are writing about the new omnipresence of digital media and suggesting parallels with the early print era. I myself have long believed that performance studies as such would not be thinkable outside the history of cinema and audiovisual recording. But only in the past couple of months have I begun to think that the new availability of digital media could open other kinds of institutionalities having to do with embodiment itself. The development of cinema since the early twentieth century did not lead in this direction. The artistic power of the director and the economic power of the producer marginalized

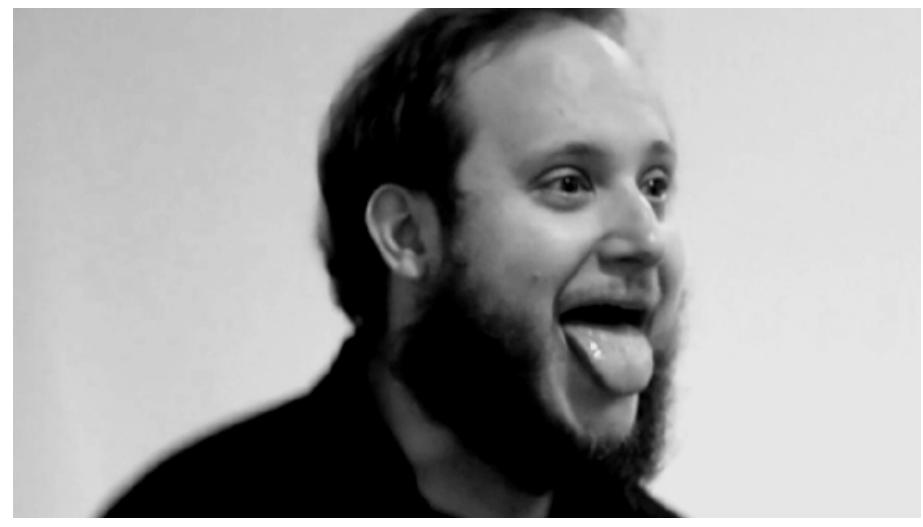
the power/knowledge of performers in film; and pushed those who care about the agency of the body into live performing arts, where at least the performer still retained a degree of freedom. But maybe this trajectory can now be altered.

DSM: Your distinction and analysis of 'technique' and 'practice' have been exceedingly helpful to me in my ethnographic work, and how I think about the profundity of the small gesture or the taken-for-granted things our bodies can do. Your work has been instrumental in how I now (re) think about enactments of fieldwork and oral history relative to justice. How would you describe justice and how the distinction/comparison of technique and practice might figure in to it?

BS: First, what you have asked means the world to me. My whole project of theorizing technique (as knowledge and in relation to practice) is inextricably bound to an underlying orientation towards justice and ecology. However, it has not always been clear to me how to articulate this impulse without reducing the 
emergent qualities of embodiment to existing quantities in social scientific or other critical language. I deeply admire historians and cultural critics, and have often regretted my own apparent inability to insert myself directly into public discourse as they do. At the same time, I am looking for a way to speak publicly that does not foreclose the grounding of my perspective in my own embodiment. This again is why the intersections of body, book, and video have been so astonishing to me in the past few months. We have public intellectuals who make discursive arguments and we have public performers who sing and dance, but at present we have virtually no place for public orators who combine these modes of enactment.

I have now started to look in both the critical Jewish tradition and the critical Black tradition at the idea of the prophetic, and I am starting to wonder whether the prophetic has to refer to a particular combination of discursive content and

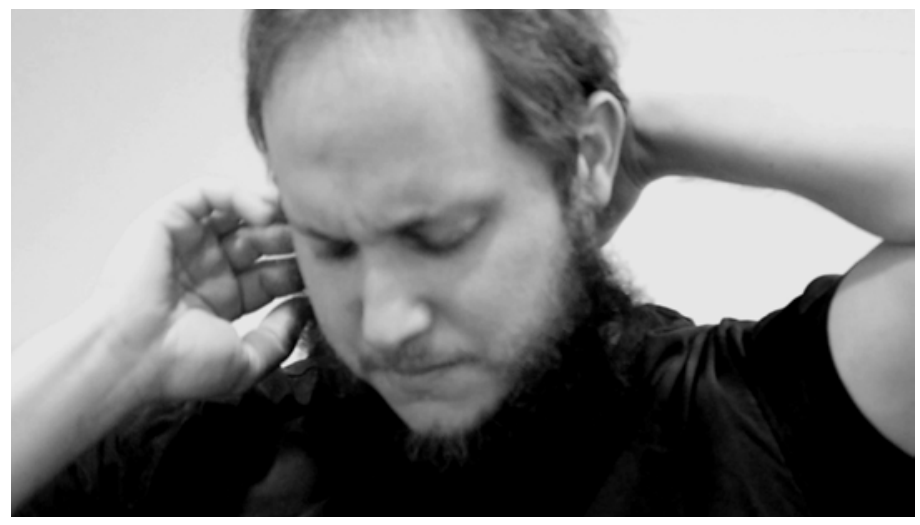
embodied technique. It seems to me that in critical fieldwork and oral history, there are tremendously profound potentials for prophetic enactments of justice but that these have been barred from the public sphere during the reign of the logos. If indeed the logos is now going to be demoted and begin to function alongside the audiovisual, then there is an opening for a realignment of knowledge communities in the name of justice. Of course, the audiovisual can be co-opted and controlled, and used in very violent ways, just like the linguistic. It is a question of who controls the media, or rather a question about the structure of the institutionalities of media, which is why all my energy (including the new Journal of Embodied Research) is currently focused on trying to develop new pathways and relationships between embodied practitioners and the audiovisual field.

Can there be techniques of justice, or only practices of justice? The ancient Greek philosophers looked for techniques of the good, but in poststructuralist contexts it seems impossible to pin down anything so reliable. I know that technique is much more than language; that language is only one kind of technique. 


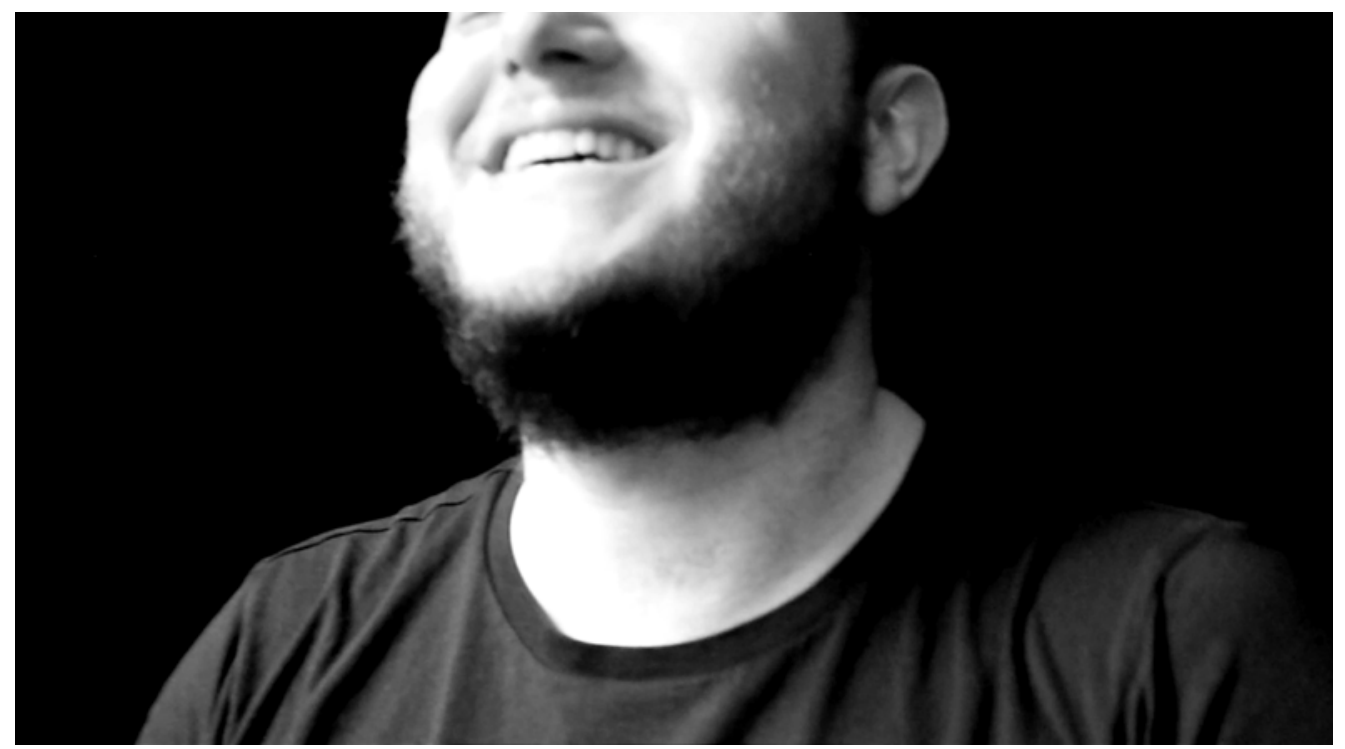

Perhaps rather than universal techniques of justice what we need are techniques that function at the level of the planetary in this particular moment. In that case, maybe these new media will make possible songs and images of justice that allow for its institutionalization in ways we cannot yet imagine. The book I am writing now is based on the question: 'What is a song?' When Caroline Gatt asked me why I was working with songs (and not books or computers), I said that in this moment it seems like humanity may have to give up many things in order to survive, but one thing I am certain we do not have to give up is songs. I want to be able to speak, or rather, to practice, about justice publicly, but I do not yet feel able. I hope that by answering a question like 'What is a song?', I will then be able to grasp 'What is justice?' in a more adequate way.

DSM: You seem driven. You are abundantly busy. Alice Walker says-and I am paraphrasing her-'We must do the work our soul must have'. It seems that you are doing 'soul work'. Why do you do this work? What moves you to do this work?

BS: This question is most difficult to answer because so many layers of myself overlap in my work: the personal, the ethno-cultural, the political, and the spiritual bordering on the mystical-which always risks the messianic. Even before all the recent critical work on whiteness in the US, I constantly interrogate my projects to examine whether they are not falling into the traps of some kind of savior mentality, wanting to prove myself 'good' or 'innocent,' or to earn my 


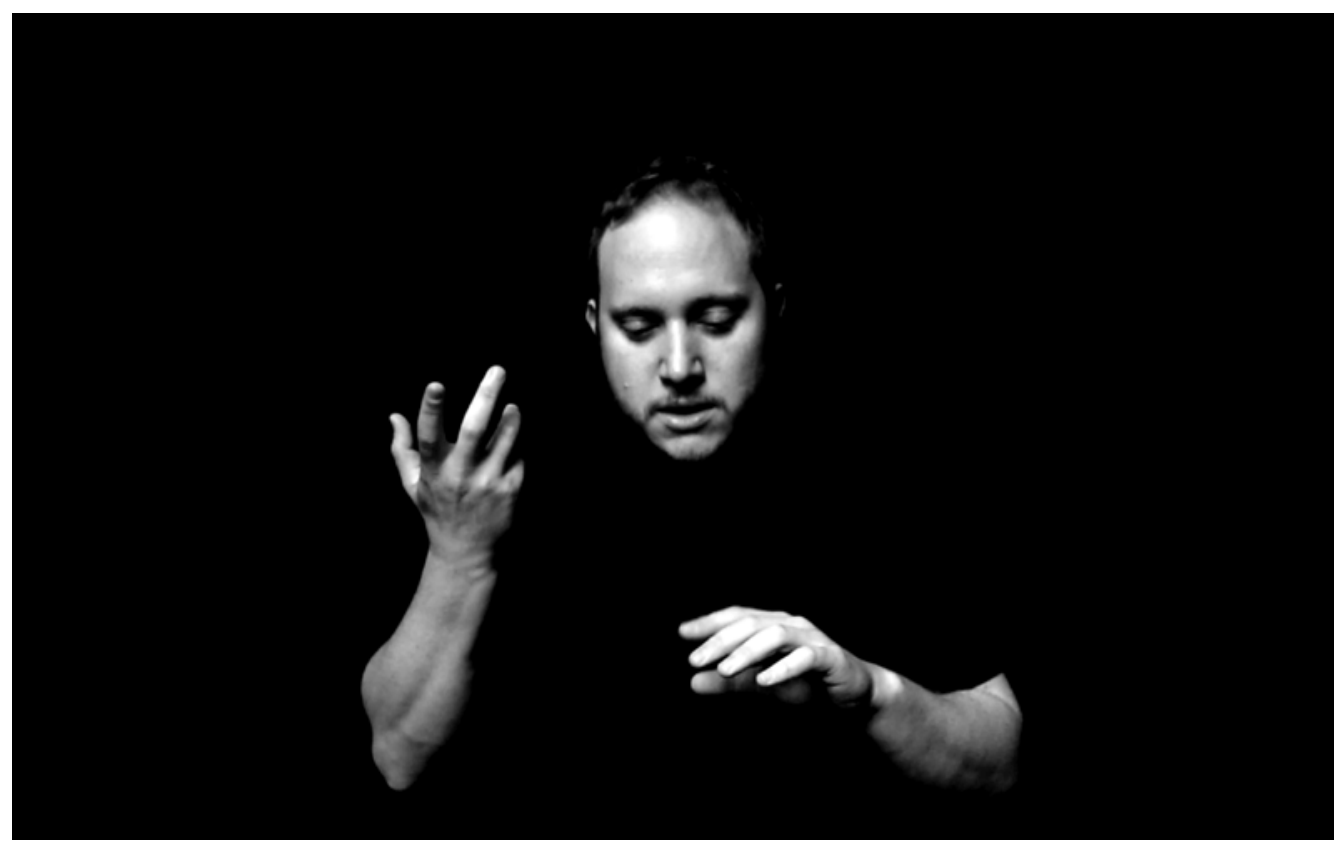

way out of guilt rather than purely serving. But I also realize that, as the Walker quote suggests, the only way to serve is to find ways of serving that are also healing to oneself.

I guess I would say that I am driven by two things: a constant fear about ongoing social and environmental violence, and a desire to integrate different aspects of my being. The fear is rational to a degree, in that it responds to actual facts about climate change, the prison industrial complex, the refugee crisis, etc. But it is also a kind of lived trauma which I would now link to the particular history of European Jews, and the extremely vexed position of critically oriented white Jews in the United States: the ingrained sense of worry and impending doom; the commitment to social justice; the struggle with complicity to racism; and even the particular relationship to reading and writing that comes from being the source but not the endpoint of Christian imperial logos.

I would connect this last point, about the Jewish relationship to logos, to my own youthful experience of feeling trapped within a fluency of reading and writing. From this sense of being trapped within a critical discursive space, I was driven to pursue a long journey away from language in order to find my own embodiment. Later I came back to writing and found that I could use my skill with language strategically, to make space for critically informed embodied practice. Today I am driven, on one level, by the idea that the digital audiovisual space of 
the internet might just be that urgently needed commons in which our species can find a way to pull itself back from the brink of self-destruction; and, on another level, by the ongoing personal need to bring together speech and song, book and video, so that I can finally undertake public (that is, serving) work in a way that does not sever my linguistic self from the physical, vocal, erotic, vulnerable, 'grain' of my body.

\section{Endnotes}

1. This interview was conducted by D. Soyini Madison as part of her research for her book Performed Ethnography and Communication: Improvisation and Embodied Experience (2018). This excerpt was reproduced with kind permission of Routledge, Taylor \& Francis Group (pp 6-11).

\section{References}

Barad, K. (2007). Meeting the Universe Halfway: Quantum Physics and the Entanglement of Matter and Meaning. Durham: Duke University Press.

Latour, B. (1983). Give Me a Laboratory and I Will Raise the World. In: Karin Knorr-Cetina and Michael Mulkay, eds. Science Observed: Perspectives on the Social Study of Science. London: Sage Publications, 141-170.

Smith, L. T. (1999). Decolonizing Methodologies: Research and Indigenous Peoples. New York: Zed Books. 


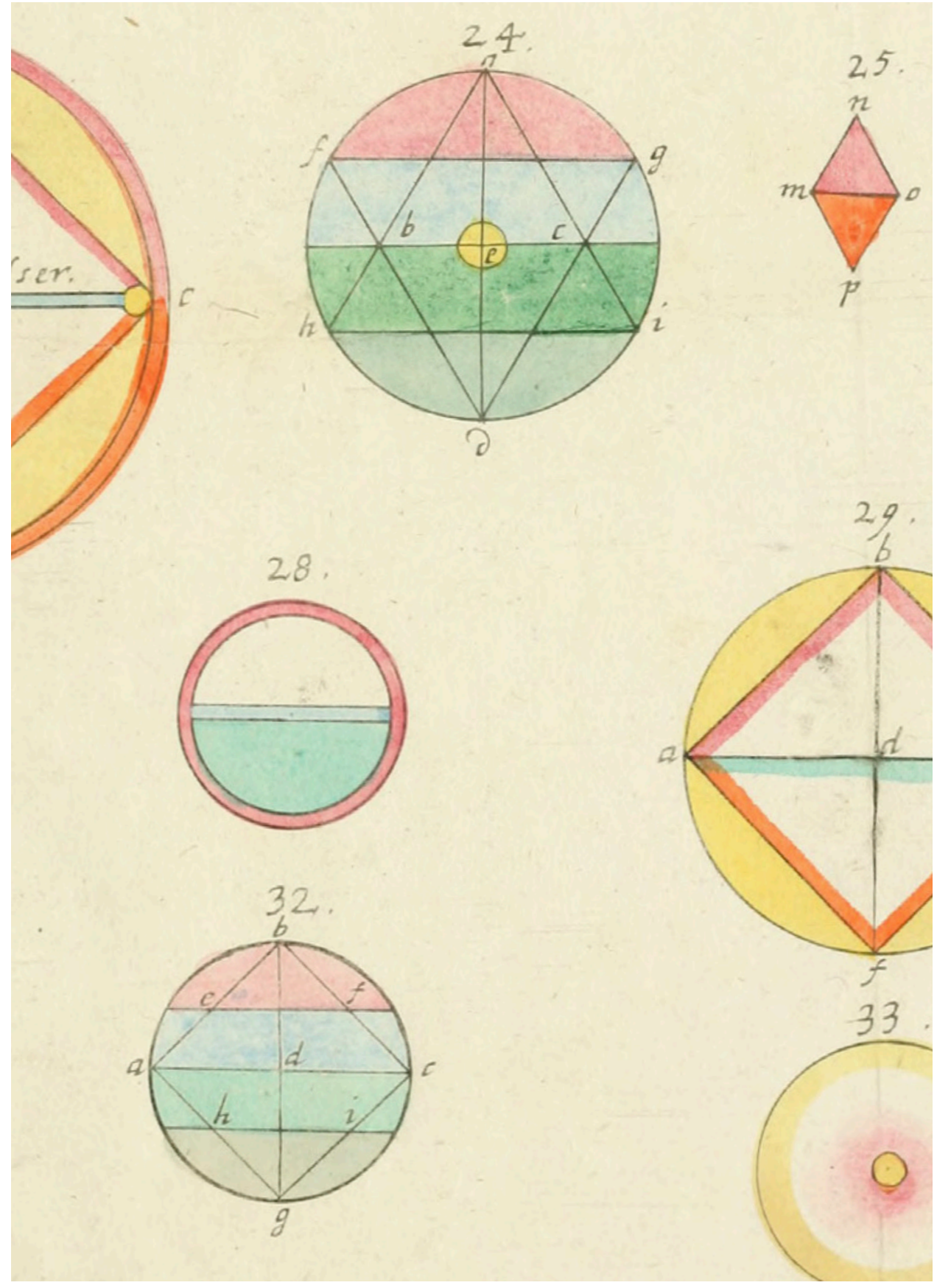

Opus mago-cabalisticum et theologicum (detail), Georg von Welling, 1719 


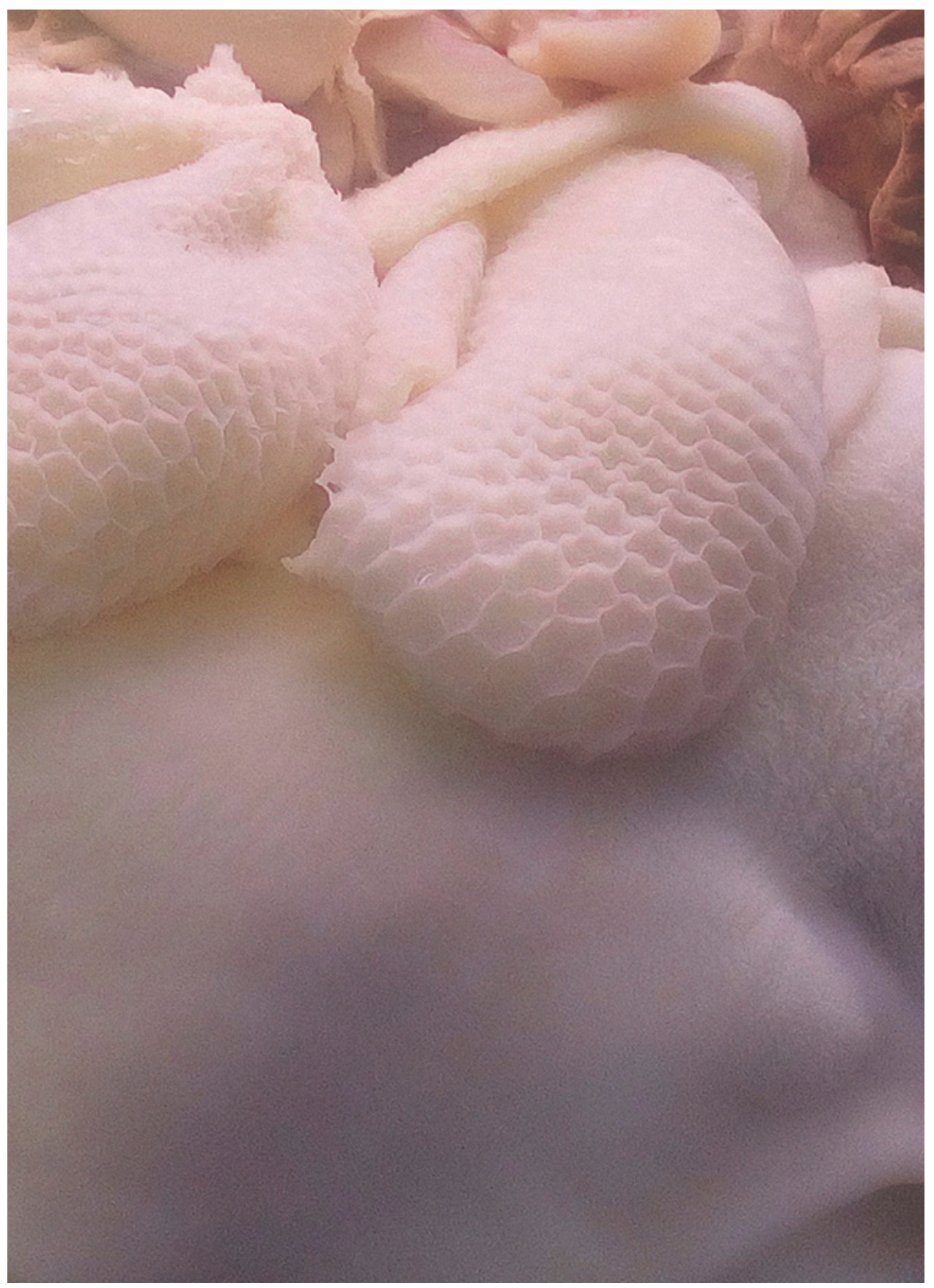

Beef tripe at Boqueria, Barcelona, Fructibus, 2017 Creative Commons Attribution 4.0 (CC BY 4.0) 


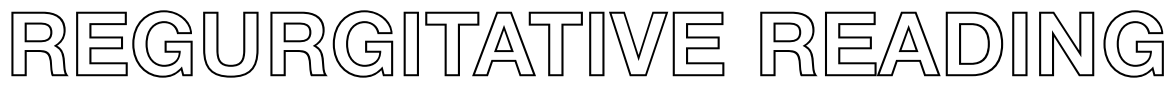

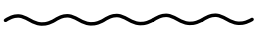

\author{
Marnie Ritchie \\ UNIVERSITY OF TEXAS AT AUSTIN
}

Reading repeats on readers, something that we cannot quite stomach-an excessive something that, while confusing and repelling, calls readers back to re-reading. In the spirit of operationalizing this excess, this essay traces a form of regurgitative reading (chewing cud) in Friedrich Nietzsche's corpus that follows the reflexes and refluxes of a text. Though linked with the ressentiment of the herd, cud-chewing is also an interpretive process of engaging the affective excesses of everyday life toward the play of language-what Diane Davis calls an "affirmative purgative"-where disgust can more loudly belch a "no" to conventional reading practices. This essay wagers that this regurgitative reading style is best performed with Eve Sedgwick's indigestible insights on paranoid and reparative reading styles. The Nietzschean metaphorical apparatus helps us glimpse the banality and unbearable proximity of disgust within oscillations between paranoia and reparation. At stake through these re-readings is, first, an ethic of reading that rejects full assimilation and understanding, and second, an unleashing of creative reading in affect theory.

\section{KEYWORDS}

affect, close reading, Friedrich Nietzsche, disgust, regurgitation 
"Rumination and eternal return: two stomachs are not too many for thinking." -Gilles Deleuze, Nietzsche and Philosophy

Affect theory foregrounds the fact that reading involves contact with an excess, something that impresses itself upon readers and escapes conscious thought. Reading is a process of assimilation-appropriation-incorporation (or, eating an-other); meaning a reader takes in parts of a reading in order to understand and identify with it. At the same time, reading repeats on readers, it is something we cannot quite stomach; we never quite "get it," and we cannot fully assimilate the authors and voices we encounter. Affect scholars interested in this spillover have argued for re-valuating change, surprise, and negativity in practices of reading (see Cvetkovich 2012). Most notably, Eve Sedgwick (2003, 2007) writes that reading's encounters with the "new" (inassimilable) object-remains that arrive involuntary from elsewhere, can break up the conventional, rote reading practices that value univocal, linear, so-called rational exegesis. This essay asks: What are the qualities of these encounters with outsides in/as reading? What are we to make of the un-stomachable in reading? And how might these encounters with the new mobilize reading anew? By ruminating on/with Friedrich Nietzsche's animal-adorned corpus, this essay offers a practice of regurgitative reading that takes the over-flow of reading as an opportunity to think again, to read again, to begin again. Following along with textual encounters with ruminants, animals who revolve moistened portions of food (cud) with their rumen muscles, this essay catches onto a form of reading in Nietzsche's corpus that is a constant processual over-turning of affects. Chewing-cud is a form of regurgitative reading that embraces the active role of disgust in signaling what cannot be fully digested in reading. Expounding this regurgitative reading offers two overall stakes for affect theory: an ethic of reading that tries to vomit up the mastery of assimilationist reading which presumes to metabolize everything; and the un-domesticating of affects to unleash creative force in reading.

In this essay I wager that Nietzsche's regurgitative reading practice is best performed by ruminating on Sedgwick's works about reading styles, especially as Nietzsche was important to her thinking throughout her career. While Nietzsche surfaces throughout her works, I focus on "Paranoid Reading and Reparative Reading, Or, You're So Paranoid, You Probably Think this Essay is About You" and "Melanie Klein and the Difference Affect Makes" for their direct rearticulations of ressentiment in terms of the paranoid style and their discussion of reading as a form of digestive incorporation. No approach to reading in affect theory 
might be as chewed over as Sedgwick's theories of paranoid reading, reading that aims toward monopolistic repetition, and reparative reading, reading that aims toward opening love. Sedgwick's parsing of paranoid reading and reparative reading is one part of her incredible legacy inspiring queer and feminist scholarship, and an integral part of articulating her ideal of "a mind receptive to thoughts, able to nurture and connect them" $(2003,1)$. Sedgwick's essay and her readers cannot vomit up, in full, a paranoid disposition, and it is not clear that arriving at an ideal affective disposition was ever Sedgwick's intent.

I would like to suggest that Nietzsche's cud-chewing helps squeak out a suggestion of a third way of reading that is not explicitly offered by Sedgwick but performed in the passages of Sedgwick's essays: reading as an ongoing regurgitation. The metaphorical apparatus of Nietzsche's cud-chewing shows how Sedgwick's writings perform the co-mingling of paranoia and reparation. The overflows, that intervenes in and constitutes the digestive remains of reading, are the surprises of the new that Sedgwick's reparative reading seeks to welcome. However, Nietzschean regurgitative reading underscores two important qualities of this "new" excess: first, the oscillation of paranoia and reparation aims toward the overcoming of paranoia through banal movements; and second, the new of reading may be an abject object. A reading that brings a reader back, again, not to a renewed intimacy with something like a whole self, like reparative reading, but to a constant exposure to an outside, or extimacy. Disgust is the affective motor force of regurgitation. It acts as an unavoidable, yet productive negativity with the capacity to change public taste. It offers up vomited remains for re-incorporation.

This essay outlines two forms of rumination in Nietzsche's writings in the first two sections of this essay: the rumination of ressentiment, or vengeful identity formation that rejects an-other as a constitutive gesture; and the rumination that spits up the first kind. Elaborating upon the rumination that spits up the small man of ressentiment, I detail the creative and ethical potential of regurgitative reading for affect theory. Given how the Nietzschean metaphor of cud maps onto Sedgwick's writings, especially in her Kleinean vocabulary of incorporation, I engage Sedgwick's theories of paranoia and reparative reading styles in the third section. In this section, I show how cud-chewing is implicit but performed in two of Sedgwick's essays, and I elaborate on how cud-chewing can lead readers to approach Sedgwick's theories anew. I end by inviting readers to ruminate-with me on affect studies' many exciting engagements with affective reading practices. 


\section{Rumination and ressentiment}

Animals are everywhere in Nietzsche's corpus (See Acampora and Acampora 2004), and cows are recurring figures who ruminate by chewing cud in Untimely Meditations, The Gay Science, Thus Spoke Zarathustra, and On the Genealogy of Morals, in particular. This essay chews through Nietzsche's many ruminations on ruminants to explicate another form of reading: chewing cud. Cud is a moistened portion of food that has already been swallowed and regurgitated by the rumen muscles of a ruminant (common examples of ruminants include cows, goats, sheep, giraffes). Cud is a portion of food that is available for re-chewing, to expedite digestion. Nietzsche's works refer to cud and cows as they pertain to practices of rumination: the process of revolving something in the mind and, in psychiatry, the obsessive repetition of that process ("Rumination, n." 2016). Along with associations with the reflex-through the gullet of an animal ("rumen" names the animal's first stomach and/or throat), rumination also refers to deep meditation that empties the mind of weighty everyday concerns ("Rumen, $n$." 2016; "Rumination, n." 2016).

Nietzsche was interested a great deal in the new bodily habits and values of modern biology and medicine. His own bodily ailments have been objects of intense speculation. His correspondences detail travails with "the coils of dysentery and diphtheria" and, later, paralysis, headaches, vomiting, and suicidal fantasies (Middleton 1969, 69, 294). Nietzsche expressed gratitude for "every good night spent, for every warm ray of sun, even for an orderly digestive system!" (Middleton 1979, 79). He dissociated his abdominal pains from his writings, joking, "I have never heard of flatulence inspiring a philosophical state" (79). While Nietzsche longed for good health, Silke-Marie Weineck (2006) argues that he threatened to turn philosophy "into a science of shit" (37). Nietzsche writes that he gives birth to "a saturnalia of spirit that has patiently withstood a terrible long pressure" [indigestion] (cited in Weineck 2006, 38). Nietzsche's works are, to borrow a phrase from Michael O'Rourke (2014), scatogrammatological (96). We get the image of a Nietzsche with subterranean sensibilities, this is a Nietzsche who pops up briefly in Deleuze's reading $(2006,116,134,178)$. Within the entrails of Nietzsche's books, digestion, health, and diet are bound to philosophy and philology. His works figure reading, interpreting, and evaluating as chewing cud. Re-turning to Nietzsche's many voices glimpses how reading becomes eating, and vice versa. 
An aphorism in Human, All Too Human shows irritation with "dyspeptic authors who write only when they cannot digest something" and who try to "transfer their own annoyance to the reader" (Nietzsche 1986, 248). These are thinkers of ressentiment, a disposition that produces goodness only out of reactive vengeance for a perceived injury (Nietzsche 1989a, 36). The identity produced by ressentiment refuses to relinquish the perceived offense, because this "I" depends upon self-victimization. Nietzsche maligns the domestication of the "herd," the becoming-predictable of mankind, through the internalization of ressentiment, which turns the vengeful eye inward (See Nietzsche 1989a, 97-16F3). Sentences in Nietzsche's works gag and reel when confronted with herd behaviors. Nietzsche's "counterideal" to ressentiment $(1989 \mathrm{~b}, 313)$ Zarathustra, undertakes a journey to find companions who might feel mutually sick with the state of "man" now. After ten years spent in a cave in solitude, Zarathustra emerges and experiences a wave of disgust: "Behold the superfluous! They are always sick; they vomit their gall and call it a newspaper. They devour each other and cannot even digest themselves" $(1978,50)$. In ressentiment, to regurgitate cud means to copy an economy of the same-to eat and assimilate everything that others feed you. Religions conscript unthinking domestication by offering poor bodies a "long mechanical labour of the lips" so they "never [have] any thoughts of their own" (Nietzsche 1974, 92; on this section's disdain, see Smith 2004). Nietzsche figured ressentiment as a great weariness or disgust with life, a state of ennui and bitterness.

Nietzsche describes Judeo-Christian morality, where cud chewing plays an important role, as the birth-place of ressentiment. According to passages in Deuteronomy and Leviticus, the only kosher animals are those who both chew cud and divide each hoof in two. Cud-chewing becomes tied up in eternal salvation from worldly suffering through cleansing rituals. Nietzsche makes clear that this rumination in the service of ressentiment promises but cannot guarantee human happiness, the eternal pursuit of greener pastures. Underwritten by Nietzsche's own encounter with cows during a bout of loneliness, recounted in Ecce Homo (1989b, 304), the scent of cows supplants Zarathustra's cold loneliness with warmth and cheerfulness. In the field of cows, Zarathustra encounters the "voluntary beggar," who tries to learn chewing the cud from the cows, ironically, by preaching at them $(1978,268)$. Like Nietzsche's own thought-"they [the cows] had warmth"-the beggar believes the cows have found the ticket to transcendent happiness $(1989 \mathrm{~b}, 304)$. The voluntary beggar insists that the kingdom of heaven is meaningless if one does not "learn this one thing: chewing the cud!" (Nietzsche 1978, 269). In the second of the Untimely Meditations, a herd grazing in a field stands in for the cow and beggar's naïve, unhistorical perspective (Nietzsche 1997b, 60-61). Rumination that empties out the past-and so any pain or pleasure-is too extreme for Nietzsche. So too is rumination that 
cultivates a fixation on the past. The rumination of ressentiment destroys life (any becoming, any future) because it cannot digest the past at all (Nietzsche 1989a, 58). Ressentiment's rumination devalues forgetting, a force that can disable cycles of reactive punishment. The cow is a figure in Nietzche's writings that accepts that force, that simply forgets (1989a, 38). Lest we forget, however, Nietzsche reiterates that there is another form of rumination, a regurgitative reading that spits up the small man of ressentiment.

\section{An "affirmative purgative"}

Chewing cud in Nietzsche's works is also a form of reading that regurgitates man: the rational, sovereign actor who calculates the future, wills a "painless, timeless subject of knowledge," disavows the dancity of language, relies on "either/or" thinking, and aims to know in absolution (1989a, 119). The preface to the On the Genealogy of Morals implores readers to approach Nietzsche's aphorisms with patient rumination: "one has almost to be a cow and in any case not a 'modern man'” (1989a, 23). Nietzsche's works are peppered with aphorisms about the best readers for him; each rejects the "modern man" who issues "a 'no' to language and its paths of sensuality, its gait and dance" (Menninghaus 2003, 174). By negating such a figure, Nietzsche engages in what Diane Davis (2000) refers to as "spitting up the Proper and its rationalism, a vomiting of vomiting itself," disgorging the reading practices that would purge non-wholly-rational considerations from a text (242). Avital Ronell echoes the Nietzschean vomit as an affirmation: "For Nietzsche, vomiting represented a reversal of assimilation by the digestive system ... [I]t was: 'No, I won't assimilate this; I'm going to reject this. I want to puke out all the poison I've been fed by philosophy, by history, by patriarchy" (cited in Davis 2000, 172). The task of reading pursues the reader, pumping cud forward and back into contemplation through revolt. The repetition of the churn lets one chew again, or say yes to, what has been pushed back. An "affirmative purgative" is a regurgitational reading that chews-over toward unleashing multiplicities, or the play of language (Davis 2000, 242). This essay retches such a practice of regurgitative reading (for what is writing if not wordvomit) as it pertains to affect theory.

What might an "affirmative purgative" look like in affect theory? In practice, chewing cud exegetically stumbles back toward the "reflex and reflux" movements as textual form: how a text lurches, vomits, or doubles back (Brinkema 2014, 
139). Chewing cud does not arrive on the scene, or in a disciplinary field, to find meaning. Chewing cud means saying yes to unexpected affective forms: uneven pace and punctuation, irony and humor, rants and asides, a polyphony of voices, and bouts of textual nausea. When approaching a text, certain questions become pertinent for this reading practice: What remains? What could not be swallowed? What was excreted? What was easier to digest with repetition? This reading is poignant for drawing out stomach-churning encounters rather than typical disciplinary conventions that might want to hide these reflexes and refluxes. Victor J. Vitanza (1997) offers an example, for he does not hide disgust for a centralized, objective position with which to view rhetorical histories: "(Therefore, I vomit up The History of Rhetoric. Vomit. Vomit. Vomit)" (331). The textual form of disgust here is a gustatory parergon. Three parenthetical lurches mark how the text cannot assimilate an objective position. In an affirmative purgative, the tickles of what does not sit well bubble up in/as text, offering a chance to re-think anew, with gusto.

Furthermore, the return of cud demands for Nietzsche "the art of exegesis," which is only possible by connecting thought, evaluation, and affect (1989a, 23). Recoiling from Immanuel Kant's thoughts on reason, Nietzsche argues that exegesis is a process of reflection and interpretation that arises from affects. Even while subjective experiences of affects change over time (see Foucault 1977), Nietzsche's regard for affect as a transitional bodily state resonates with contemporary renderings of affect. The German affekt (affect) in Kant's Anthropology from a Pragmatic Point of View (1996) is a state of feeling of either pleasure or displeasure, "which does not give rise to reflection (namely the process of reason whether one should submit to it or reject it)" (155). Despite some ambivalence in Kant's writings about productive affects, he demotes affect in relation to reason; he writes that affects startle the mind's "composure," like a "stroke of apoplexy" $(155,156)$. Although Nietzsche at times regards affects as states of feeling, his works position affects as bodily eruptions with varying degrees of intensity-which produce impressions and evaluations in repetition (see Wollenberg 2013). Nietzsche expresses that scanning a poem or aphorism may give a reader an impression, a fuzzy outline of an idea. Rumination, the lingering over an impression again, glimpses a second dimension of reading: evaluation (Deleuze 2006, 29). Nietzsche (1968) writes:

What is the meaning of the act of evaluation itself? Does it point back or down to another, metaphysical world? (As Kant still believed, who belongs before the great historical movement.) In short, where did it originate? Or did it not "originate"?Answer: moral evaluation is an exegesis, a way of interpreting. The exegesis itself is a symptom of certain physiological conditions, likewise of a particular spiritual level of prevalent judgments: Who interprets?-Our affects. (148) 
Evaluation does not arise in a metaphysical vacuum, and affective response is for Nietzsche a mode of interpretation. Against dissociation of thought and affect, Nietzsche asks, "to suspend each and every affect, supposing we were capable of this-what would that mean but to castrate the intellect?" (1989a, 119). Two stomachs are "not too many for thinking," because thinking involves the active re-turning to affect, intensities that voice valuations (Deleuze 2006, 31). To bracket affect would be to make thinking a useless stub with no feeling tendrils to sense.

Disgust is the affective motor force of regurgitation and is therefore essential to thinking, reading, and writing anew. Given disgust's role as the activating agent of regurgitation, regurgitative reading cultivates the reflex of disgust; meaning that it welcomes the inability not to say no to the return of cud, or the affective excesses that return through the banal overflow of reading itself. "Disgust" is an imperfect translation of the German Ekel, which refers to an overpowering estrangement registered on the body (see Faulkner 2013; Menninghaus 2003). Derrida points to the importance of Ekel in Nietzschean thought: "the work 'Ekel' (disgust, nausea, wanting to vomit) comes back again and again to set the stage for evaluation" $(1988,23)$. For Nietzsche, vomiting helps develop taste and distaste by insisting on recurring re-evaluations; disgust will therefore not stay in a consistent affective state but will change as tastes change. Disgust acts as a tastemaker. That is not to say that disgust is univocally good. There is an array of violent regurgitations to consider alongside cud-chewing: bulimia, food illness, overeating, seasickness, etc. Cud-chewing is indeed violent. Passing a lump back up into one's throat and down again is not altogether fun. While recognizing that these other frustrated incorporative practices perform important ethical and political effects and exist in multiple forms, cud-chewing is distinguished by the banal up-and-down of remains, in repetition. Cud-chewing attempts to activate the ethical and creative potential of disgust, its potential to reject something and embrace something new. Disgust's rejection is a semi-rejection; the food is kept in the rumen's mouth in order to be re-incorporated. Regurgitation is a way in which rumens can begin to eat again. If we figure disgust as an aversion felt on a body from something becoming too close, disgust demands subsequent distance from a contaminant. Importantly, disgust in Nietzsche's texts indicates when the "bad air" of ressentiment is in close proximity (1989a, 47). Despite the desire of Zarathustra and Nietzsche to have long legs and escape into the fresh mountain air (Nietzsche 1978, 40; Nietzsche 1989a, 96), vengeful impulses to purify life cannot be escaped. There is no promise of full inoculation from this venom. Disgust, however, continually issues a "no"; it refuses to swallow the poison and instead pumps it back up into contemplation. 
By rejecting assimilation, the cow affirms, or says "yes" to disgust. The cow's "yes" is not the all-encompassing "yes" of the donkey, swine, or undiscerning men. As Deleuze explains, the ass is not the figure of Dionysian affirmation par excellence, because the ass hears "only yes," a yes "which is not able to say no" (Deleuze 2006, 178). Zarathustra issues a "Yea-Yuh," a gung-ho cowboy-cry whose exuberance dismisses the "shrewd" eye or ear that is able to catch onto the habits of the modern man (178). The bray of "Yea-Yuh" is also the "yes" of swine and undiscerning men, who have endless metabolisms, who want to assimilate everything. Zarathustra proclaims:

\begin{abstract}
Verily, I also do not like those who consider everything good and this world the best. Such men I call the omni-satisfied. Omni-satisfaction, which knows how to taste everything, that is not the best taste. I honor the recalcitrant choosy tongues and stomachs, which have learned to say "I" and "yes" and "no." But to chew and digest everything-that is truly the swine's manner. Always to bray Yea-Yuh-that only the ass has learned, and whoever is of his spirit. (Nietzsche 1978, 194)
\end{abstract}

Bathed in hogwash, the "omni-satisfied" exhibit no disgust and therefore no taste. The "Yea-Yuh" limits affirmation to a resignation toward "being or what is" (Deleuze 2006, 183). Instead, the cow's "no" speaks back to the perfect digestion that boasts of its infallible operations. Vomiting and expelling intervene in the will to a closed economy of digestion, an economy that wipes its appendages clean of change, iterability, and remains with its infinite metabolism. Jacques Derrida (1991) positions Hegel's dialectic as the Great Mouth that takes in everything and Kant's aesthetic economy as the clean machine that cannot do with any vomit (see Birnbaum and Olsson 2009). Disgust issues a "no" toward being taken-back-in to the Dialectic's perfect aesthetic economy, symbolized by one stomach.

In other words, disgust reveals reading as an encounter with extimacy: an uncomfortable separation from oneself, where something unwanted impresses itself upon readers from elsewhere and cannot simply be taken in and understood (on extimacy as re-birth see Kristeva 1982). Disgust brings a reading body to the threshold of regurgitation, unbearably close to something unwanted. Cud-chewing does not just tolerate this unpleasant negativity but fashions passages and offshoots from where disgust can speak. While reading, something is trying to get through, so a reader must register this disgust, smacking one's lips. Therefore, even while disgust is involuntary, it is a trained no-saying that demands re-evaluation by initiating delay. 
In embracing contact with excesses, the Nietzschean affirmative purgative produces ethical potential and creative potential. First, chewing cud has exceptional ethical potential as a reading practice; because it is a drawn-out, open process that transmutes the repetitions of purging (so nothing remains) and/or eating everything (so nothing remains) into extensive regard for how reading each time eats another, with remainder, in some form. Chewing-cud engages remains in a way that does not wipe one's hands, claws, or hoofs of them in complete understanding or appropriation. Nietzsche's preface to Daybreak indicates that philology cultivates the practice of chewing something over: "this art does not so easily get anything done, it teaches to read well, that is to say, to read slowly, deploy, looking cautiously before and aft, with reservations, with doors left open, with delicate eyes and fingers" (1997a, 5). Doors, mouths, passages remain open in a process of slow and incomplete assimilation-appropriation-incorporation.

Perhaps the most instructive example of the ethical potential of regurgitative reading comes from Zarathustra's monologue about a philosopher-to-come in the third part of Thus Spoke Zarathustra. As Zarathustra crosses the ocean he recites a parable to searchers, researchers, and all those who seek open seas, about a large black snake who climbed into the throat of a shepherd. Zarathustra recounts that the shepherd bit off the head of the snake, which symbolizes the weight of historical convention and the small man of ressentiment. Once the shepherd spits the snake's head back out, the shepherd transforms into terrifying hysterics. The nausea of this encounter later returns to Zarathustra. Holed up in his cave, he stirs from a seven-day coma, sick from indigestion. Still tripping, Zarathustra cannot process disgust with the eternal presence of the asphyxiating circuitry of the snake: “Alas! Nausea! Nausea! Nausea!" $(1978,219)$. The animals nudge Zarathustra with a suggestion: get some air. They explain that the world wills everything, including his near-death experience, again. The lesson appears to be that remains return in an ever-open relationality, and mastery over them is folly.

Rumination offers a second important stake: unleashed creative force. Cud-chewing underscores that a slow diagnostic is not just a way of rendering docile or making-tame. Instead, rumination is also a loosing energy for creative and artistic pursuits. Though Nietzsche could barely stomach it, he left his appetite open to the vengeful nastiness of the purportedly rational man because such an encounter contains the potential for metamorphosis: " $[\mathrm{N}]$ ot in order to purge oneself of a dangerous affect by its vehement discharge ... but in order to be oneself the eternal 
joy of becoming" (1989b, 273, my emphasis). As Zarathustra recalls his hallucinatory encounter, he longs for the shepherd's transformation into uncontrollable laughter: "My longing for this laughter gnaws at me" (160). The churning back of affects opens up a reader to the influence of ferality: a wild transformation into laughter through a series of in-jest-ings.

Reading in the service of un-domesticating the senses would insist on opening smelling and tasting mechanisms to unknown sensations, which translates into a renewed appreciation for disgust. Loosing creativity from predictable reading practices is a "training without taming" (Acompora 2004, 8). Nietzsche's philosophies of animality-indebted to but also skeptical of Darwinism's naturalismaffirms the close relationship between "man" and predators. Nietzsche's disgust is directed at the reduction of the "beast of prey 'man' to a tame and civilized animal, a domestic animal," for domestication snuffs out the wild tendencies of man (1989a, 42). Rather, creativity results from reclaiming some bestial qualities of man, like a renewed, animalistic appetite. Disgust is not necessarily a natural human affect for Nietzsche-as in a transcendent constant that registers as the same sensation on every body-but variations of disgust act as trainers for the senses; disgust remakes taste and distaste, and Nietzsche proposes that "man" may have lost his taste for wildness itself. If disgust re-opens our palates anew, away from a common tastelessness of the herd, the transformed feral reader may still find inspiration in the cow in the sense of tapping into a banal over-flow, a too-muchness. Becoming like a feral cow, pregnant with milk might make a reader feel uneasy. Indeed, readings are unable to contain the involuntary intimacies, digressions, and multiple voices involved in chewing over. A creative reading would welcome the overflow as a chance for surprise and play.

Given the ethical and creative potential of cud-chewing, this essay attempts to chew over key works by both Nietzsche and Sedgwick that regards reading as a practice of incorporation. Again, the dice throw here is that Nietzschean language performs regurgitation and can help us glimpse another performance of regurgitation in Sedgwick's works. But also, that there is an ethical reason for trying to work through Sedgwick; all claims to rethink reading in affect theory are unavoidably indebted to Sedgwick's distinctions between paranoid reading and reparative reading (see Cvtkovich 2012; Flatley 2010; Love 2010b; Nyong'o 2010; Wiegman 2014). Reading Sedgwick, there is no choice but to partially assimilate her thoughts and ideas (see Hanson 2011). A contemporary rendering of regurgitative reading cannot help but flow from an appropriation-assimilation of Sedgwick's renderings of ressentiment. 
In what follows, I use the Niezschean language of vomiting to draw out a reading practice performed in Sedgwick's works: the ongoing regurgitation of reading, wherein paranoia and reparation infuse one another, as a banal process of incorporation.

\section{Paranoid/reparative/regurgitative}

What bubbles up for us in Sedgwick's corpus is how it seems to welcome the repulsive contact rehearsed each time through reading; like Nietzsche, Sedgwick re-evaluates negativity and surprise. The Nietzschean metaphor of cud-chewing underscores two important features of this contact with the "new," both of which can be lost in the more recuperative gestures within Sedgwick's works. First, the oscillation of paranoia and reparation aim toward the banal overcoming of prior disgust with life (which, for Nietzsche, is a passing through, an undergoing). Second, the contact with disgust brings a reader not to intimacy with something like a "whole" self but a self ever-given over to an unbearable exposure. The transmutations of paranoia and reparation and their various combinations pass through the unavoidable banality and unbearable proximity of disgust.

The history of reading affect passes through and cannot readily bypass Sedgwick's incredibly enabling works, especially in the particular case of Nietzsche's cud-chewing. Nietzsche was an important thinker for Sedgwick. Addressing concerns about why she goes to Nietzsche in Epistemology of the Closet ("but... Nietzsche?"), Sedgwick writes that no one can know in advance the limits of gay-centric literature (1990, 53). Nietzsche's ressentiment is an important theme throughout her oeuvre, beginning with the recursive dynamics of ressentiment at work in heteronormative panic in the late 19th century. She painstakingly reads the homosocial and homophobic relations between Nietzsche and Richard Wagner in Nietzsche's dual critique and embrace of decadence and sentimentality. The paranoid style of heterosexual panic, she notes, takes the form of an anti-sentimentality, that is a veiled sentimentality for heterosexual, moralizing circuits of knowledge: "the identifying interspecularity and fatal symmetry of paranoid knowledge" (100). Sedgwick calls the yoking sentimentality to the projective loathing of ressentiment "ressentimentality" (151). In "Melanie Klein and the Difference Affect Makes," Sedgwick likens Nietzschean ressentiment to the paranoid position for how it is "marked by insatiability, hatred, envy, and anxie- 
ty" and vomits projective venom at others (636). For Sedgwick, a hypervigilant, self-congratulatory position of ressentiment sends all ambiguity and surprise packing or registers them only as non-sense. There are therefore both deliberate and nondeliberate resonances between Sedgwick's paranoid and reparative reading (the schizoid and depressive position, respectively, when she uses the language of Melanie Klein) and Nietzsche's delineation of ressentiment and its overcoming. In what follows, I focus on "Melanie Klein and the Difference Affect Makes" and "Paranoid Reading and Reparative Reading" for their articulations of paranoid and reparative reading practices in terms of incorporation. In "Paranoid Reading and Reparative Reading," Sedgwick argues that one not need be paranoid to know, nor to make that knowledge relevant to combatting oppression. Paranoia, she says, is one form of arriving at and displacing knowledge. For her, "Paranoia knows some things well and other things poorly" (130). What, then, do paranoia and reparation offer as reading styles?

The Nietzschean metaphors help us tease out that the differences between reading styles revolve around practices of eating/reading, how they digest object-remains. Reading is a practice incorporating objects, or partial assimilation-appropriation of an-other. A reader tries to take in, understand, and become something other-than oneself through reading-a process that is always incomplete (see Derrida 1991). Sedgwick extrapolates from Melanie Klein that knowledge-production involves eating others, and so the language of Kleinean oral incorporation can map onto Nietzsche's cud-chewing, and vice versa.

Sedgwick's fascination with Klein involves how Klein's psychoanalysis is grounded in affect, because Klein focuses on the subjective, qualitative experiences of infants $(2007,628)$. Klein is interested in things or objects, by which she means that "people and hacked-off bits of people" that one ingests and rejects in the "internal dynamics of the emerging psyche" $(629,632)$. For Klein-and Sedgwick notes this is not so much a break with Sigmund Freud's theories of repression and Oedipal identity formation so much as a sidestep-the infant's primary defense mechanisms involve "splitting, omnipotence, and violent projection and introjection" (633). Infants are born into a schizoid/paranoid position, which has five features: hostility toward ambivalence, dualities of good and bad objects, a limited view of agency as either powerless or all-powerful, greediness that wants to hold onto good objects within/as oneself, and projection of the unacceptable parts of oneself onto others (633). This position's defense mechanisms guard against a fundamental dread that one's greedy object relations (the need to take in and hold onto "good" objects and spit out "bad" objects at others in order to be oneself) poses a threat to others and oneself (633). Projective identification, which Sedgwick says is "coextensive" with ressentiment in adults, is a process that spits the intolerable 
parts of oneself onto an-other (636). While this projection is an inevitable part of psyche formation, the depressive position is an anxiety-mitigating position of infants and adults that attempts to remediate the internal objects of a self. A depressive position reassembles the object-parts of others and oneself to care for them, because in this position, good and bad objects are coterminous; an infant or adult no longer must believe one's internal self is good only by rejecting the influence of others. The depressive position forfeits the "I know you are but what am I?" bitterness of paranoia and instead claims oneself as necessarily conditioned by others (636). Sedgwick writes that a depressive position, where ambivalence, more complicated agency, a relaxed grip on others, and less venomous bile at undeserved others can emerge, "requires discovering over and over" $(2003,632)$.

Key here is that-like ressentiment and its regurgitative overcoming-paranoia and reparation eat others, differently. Consider the contrast between paranoia and reparation, from Sedgwick (2003), in further detail:

[T] he paranoid position-understandably marked by hatred, envy, and anxiety-is a position of terrible alertness to the dangers posed by the hateful and envious part-objects that one defensively projects into, carves out of, and ingests from the world around one. By contrast, the depressive position is an anxiety-mitigating achievement that the infant or adult only sometimes, and often only briefly, succeeds in inhabiting: this is the position from which it is possible in turn to use one's own resources to assemble or "repair" the murderous part-objects into something like a whole (128).

Paranoia defensively projects, carves, and ingests others, toward protecting a self from potential danger. Paranoia is a reactive stance with the productive function of forestalling pain (137). Paranoia, Sedgwick writes, is "a position of terrible alertness"-terrible presumably because the alert is relentless and uncontrollable $(2003,128)$. Paranoia insists on forming an unquestionable consensus and monopolizing space to expand its imperative that one can never be paranoid enough. Sedgwick asks: "where then to find a position from which to interrupt its [ressentiment's] baleful circuit?" (635). One answer might be to introduce new circuits or patterns of eating. A reparative position, she writes, reproduces the eaten part-objects into "something like a whole" (my emphasis). So, while both readings use others to reconstitute a self, reparation nurtures this self with regard for others. The "more satisfying" whole-like object of the "self" can better seek pleasure, construct strategies of survival, and become receptive to love. 
Lauren Berlant (2011) asks what many might wonder about reparative reading: How do we know when repair happens? And is it about nourishing this one "self"? According to Sedgwick, reparative reading tends to a self whose environment is hostile to its nourishment, as Hanson says, "martyrdom is built in to it" (2011, 105); but this tending (to attachment, sexuality, history as an ongoing process) is collective. It is, as Berlant says, not just "about me" (2011, 125). Sedgwick describes how her queer friendships spanning three different generations do not get the pleasure of anticipating futures, given each friend's likelihood of early death (an even more haunted statement given Sedgwick's death). By flagging how principles of individuality sneak into Kleinean positions, though, Berlant cautions against any idealized program of better thought or reading. A program of better reading overestimates "the proper clarity and destiny of an idea's effects and appropriate affects" (124). Sedgwick similarly excoriates theories that "form an insoluble loop of positive feedback" $(2003,12)$. Reading with any program-a self-assured system that knows in advance what it will find-inspires a position that forecloses the emergent quality of reading.

Even while reparation can inspire collective healing, it is not that reparation is the ideal reading practice to imitate against paranoia for Sedgwick. Sedgwick (2003) mentions that "it is sometimes the most paranoid-tending people who are able to, and need to, develop and disseminate the richest reparative practices" (150). Sedgwick instead points to how paranoia and reparation "interdigitate" (145), or grasp hands, as part of a "mutual inscription": "I am also, in the present project, interested in doing justice to the powerful reparative practices that, I am convinced, infuse self-avowedly paranoid critical projects, as well as in the paranoid exigencies that are often necessary for nonparanoid knowing and utterance" (128-129; on recursion, inter-digitation, and Sedgwick see N'yongo 2010). The language of interdigitation is interesting for its implied intimacy between Klein's schizoid and depressive positions (144).

If the question is not just how paranoia and reparative reading differ, but how they mash up, some questions arise: do the two positions combine to form thirds, fourths, others? How do paranoid positions stamp out and generate depressive positions, and vice versa? How would we characterize the oscillation of the positions? Sedgwick states that to speak of nondualism (making two into three, i.e. rendering reparation and paranoia into something like paranation, reparanoia, etc.) can be a sweeping invitation for constructing a new duality or taking everything back to (square) one $(2003,2)$. How might we imagine an interdigitation whose thirdness "takes up duality and carries it far away from unity, opening it up and sustaining it"? (Deleuze, quoted in Seigworth 2000, 248). 
Here, the Nietzschean metaphorical apparatus of cud's re-incorporations can be helpful, because it highlights that the infusion of paranoia and reparation would not take the form of a dialectic, the clean digestive economy where positions clash and produce something new out of their opposition. The Nietzschean apparatus helps us see the banality and unbearable proximity of disgust within oscillations of paranoia and reparation.

Rather than feeling omni-satisfied with either paranoia or reparation, cud-chewing highlights the banal interplays of paranoid and reparative tendencies. In other words, emphasizing reading as a banal process undercuts the impulse to turn reading over to ressentiment's omni-satisfaction, the sovereign authority of a reader who is relentlessly self-assured in either a position of paranoia or reparation. Sedgwick's dislike for Elizabeth Bishop's "One Art" poem comes from a similar discomfort with the imperative to contain and/or purge everything. Bishop's poem contains the line, "The art of losing isn't hard to master." Sedgwick wryly writes, "I picture it on a refrigerator magnet, say, urging dieters not to open the door" $(2003,3)$. Losing is hard to master because it cannot be mastered. What disgust affirms is a purgative aesthetic that relinquishes, from the start, the mastery Sedgwick describes in Bishop's poem. Instead, mastery gives way to valuing everyday hustles. Such banal struggles between paranoia and reparation is expressed most by Sedgwick when she recounts how she moves from a paranoid position to a depressive position in relation to the HIV/AIDS epidemic and her breast cancer diagnosis, respectively. Whereas the former was constricted in queer dread from witnessing dispossession and death, Sedgwick's confrontation with her own "nonbeing" took the shape of depression (640). The oscillations of the positions flow through everyday shifts in pressure. The infinite metabolism that gives and takes with ease, that reads and confronts everything, underestimates the extent to which all processes, all verbs over-flow in/as everyday recursions.

Rumination offers no striking intervention, salvation, or rescue in its banality. Ruminants are given-over to an everyday field or plane. Digesting food speaks to the movements of pure process: grazing, biting, chewing, churning, digesting, re-chewing, defecating, re-chewing. Cud-chewing is the banal trajectory of process itself: "No mutual elevation, no descent as critical rope-repelling, no saintly chronicle of always unglimpsed, but later redemptive, everyday salvation: it is a trajectory that is only and ever extruded through the banal as immanent (over) 
flow" (Seigworth 2000, 230). The banality of reading underscores that reading as cud-chewing will not offer a clear point of redemption or salvation from suffering; instead, any healing will be more like the sigh of relief after spitting up something that did not sit quite well.

To fill in an image of cud-chewing's everyday, banal aesthetic, we might consider how the cow's regurgitation differs in force and speed from projectile vomiting. If we were to consider a sliding scale of regurgitative velocities, cud-chewing would be marked by slowness, procrastination, and delay rather than immediacy, confrontation, and haste. As an illustrative point of comparison, we can consider how Lauren Berlant and Michael Warner (1998) end their essay "Sex in Public" with a scene of erotic vomiting. Within a performance witnessed by Berlant and Warner, a twenty-something heterosexual boy (the bottom) is restrained in a chair while his partner (the top) feeds him just enough milk and food to keep him gagging without vomiting. The boy's stomach begins convulsing, the crowd's attention tightens, and the partner puts two, and then three fingers down the boy's throat and allows the boy to repeatedly vomit-climax on his stomach. While cud can rush back into one's mouth, repeatedly startling and gagging rumen muscles like the boy's throat, cud-chewing's movement is more often a slow churn. In other words, the pressing of all that remains from reading-the inassimilable lingering questions, asides, and unsettled affects-can rush back to a reader. Disgust returns.

Cud-chewing slows down disgust's emitted projectiles and reincorporates some of what comes back up into another re-reading. Cud-chewing's force may not reach the climaxes of erotic vomiting described by Berlant and Warner (then again ... Zarathustra did convulse in his cave quite a bit), but cud-chewing does display similar tenderness-a mixture of "trust and violation" (565). Sedgwick provides perhaps the best example of a tender reading churn when she assesses what it is like for her to read Klein: "Engaging closely with Klein often feels like getting stoned, in the sense that the unchecked proliferation of the reader's sense of recognition, endlessly recursive and relentlessly architectonic, quickly turns into a kind of fractal ineffability, resistant to the linear formulations of ordinary exposition" (2007, 629). As if stoned, a reader's endlessly recursive reading seems like a way of making a reader and her interpretations more placid, but its delay proliferates pleasure. To again borrow some language from Nietzsche, a reader has to almost be a (dopey) cow.

In addition to banality, the interplay of paranoia and reparation is marked by intermittent, unavoidable contact with disgust, which can register as negative. That reparative reading cultivates in readers and others to something like a whole, 
implies that reparation brings about renewed intimacy with objects. Nietzsche's disgust, or bodily alienation, would suggest that reading brings objects too close, to the point where there needs to be a subsequent distancing. Disgust says "no" to something that is unbearably close. Thus, the closeness of regurgitative reading is not exactly "close reading," which reclaims renewed, comfortable intimacy with a text. The intimacy of cud-chewing is an unbearable exposure to an inassimilable outside, in the sense that what comes up in the experience of exposure startles and gags a reader and her understanding. Rumination returns a reader to her "own" extimacy, the enfolding outside passages of affect that recur. The Nietzschean metaphor of cud-chewing can force all reading practices to confront what they might rather not: recursions of "extra-being," "impersonal/a-human 'excess'" (Seigworth 2000, 240). The intermittent spitting-up of the violent purging tendencies of prior reading habits can be nourishing, as cud-chewing can be for cows. However, disgust reminds us to halt our recuperative tendencies. Disgust forces us to begin reading again, abjected. Any reparation only happens, if it happens, on the ground of affective despondency. Sedgwick writes, Nietzsche put the "rancid back into rancor" $(1990,149)$. He sniffed out and gagged on whiffs of ressentiment (with all its paternal mastery) "re-sniffing ... re-tonguing, re-palating" (149). Reparation passes through disgust, which promises to return.

Regurgitating Sedgwick's essays through a Nietzschean third way unleashes the ethical and creative potential that comes from the unavoidable return of an excess that impresses on readers. This excess-return is both banal and unbearable. Excess, Greg Seigworth writes, "derives, neither from a body or a world in isolation, but from the banal movements of pure process," which Nietzsche figures as eternal return (240, my emphasis). The eternal return has been claimed as a philosophical thought-experiment and a theory of reincarnation, but it is also a banal, processual affirmation of disgust. Eating ressentiment does not offer a return to something like a whole, like reparative reading. The recovery of cud-chewing is more like a hard-won struggle of standing in manure, where the dream of understanding through reading will never quite arrive but will churn eternally. Again, as Nietzsche's parable about the researcher on the open, nauseating seas shows, the disgorging may at best resemble letting one's paranative and reparanoid eatings vomit up all the poison one's been fed by convention. 


\section{Conclusion}

This essay has tried to both retch out and perform an affective reading practice upon the works of Nietzsche and Sedgwick that takes as a starting point the fact that reading involves contact with the un-stomachable, or inassimilable. Reading, even while it is a practice of eating (assimilation-appropriation-incorporation), is not a clean digestive machine; reading produces excesses through incorporating, vomiting, and defecating (taking this in, expelling that, vomiting that back up). Each time one comes at a text that has been pre-chewed, that text also remains open to re-chewing. Disgust signals those moments when something cannot be chewed over fully. Cud-chewing affirms reading's re-turn to/of disgust from elsewhere as the subterranean passage of thought toward something new. Cud-chewing brings forth-through slow diagnostics and open nostrils-the re-turn of an external pressure that pumps cud both backwards and forwards as a way of multiplying potential paths for thought, reading, and writing. What I have tried to show is that an unbearable, repugnant nearness has striking ethical potential for how it fashions regard for remains and creative potential for how it welcomes unpredictable affects.

What this essay spits out, with Nietzsche and Sedgwick's many voices, is that cud-chewing-insofar as it is an act of partial incorporation-assimilation-appropriation-involves operationalizing the violent intimacies of disgust. Reading involves an unpleasant contact that is rehearsed over and over, which opens up the chance to spit up any squeaky-clean conventional pressures, re-visit something that did not make sense, and play with the remains left in reading's wake. When applied to Sedgwick's writings, the metaphor of cud shows that regurgitative reading involves banality and unbearable proximity. If reading is incorporation, it is surely a gross, everyday, impossible affair. Yet regurgitative reading's mucky aesthetic is precisely why it offers the potential for ethics and creativity; it declares, ever-joyful, "Churn on, readers!"

The above ruminations are invitations to ruminate-with in our affective readings. Vitanza (1997) offers that chewing cud's “excessive ruminations" buck the driveto-truth that insists that there exists the one true reading of which other readings are a mere copy (12). Despite a reader's desire to make reading practices into a tome, rumination does not offer redemptive salvation. The cows-even with their special talent for forgetting-do not promise freedom from this world's suffering or from the slow slog of reading over. Imitating the cows to the extent that one believes, like the beggar, he has mastered their way of being is a "no go." Not only is there is no way of swallowing Nietzsche nor Sedgwick whole, but reading will never gobble up cud-chewing itself. Instead, ruminating-with means entering 
into wild proximities with excesses of a shared banal process, including the recursive entanglements of paranoia and reparation. In cud terms, we might say that rumination will send mastery back to be re-chewed. An affirmative purgative is a risky renunciation. If something comes back for us to chew over, here, it is that making room for an affirmative purgative in the repertoire of affective reading takes guts. Yes, even two stomachs.

\section{Acknowledgments}

The author thanks Michael O'Brien, Diane Davis, Joshua Gunn, Jaishikha Nautiyal, and Daniel Krasnicki or their helpful comments, Gregory Seigworth, Mathew Arthur, Wendy Truran, Ben Highmore, and Zachary Samalin for their patience and insights, and an unnamed female Polish cow who ran away from a farm to join a herd of bison for her inspiration.

\section{References}

Acampora, R. R. (2004). Introduction. In: C. D. Acampora and R. R. Acampora, eds., A Nietzschean Bestiary: Becoming Animal Beyond Docile and Brutal. New York: Rowman \& Littlefield Publishers.

Acampora, C. D. and Acampora, R. R. eds. (2004). A Nietzschean Bestiary: Becoming Animal Beyond Docile and Brutal. New York: Rowman \& Littlefield Publishers.

Berlant, L. (2011). Cruel Optimism. Durham, NC: Duke University Press.

Berlant, L. and Warner, M. (1998). Sex in Public. Critical Inquiry, 24 (2), pp. 547-566.

Birnbaum, D. and Olsson, A. (2009). An Interview with Jacques Derrida on the Limits of Digestion. e-flux, [online] 2. Available at: http://www.e-flux. com/journal/02/68495/an-interview-with-jacques-derrida-on-the-limitsof-digestion/ [Accessed 5 Nov. 2016].

Brinkema, E. (2014). The Forms of the Affects. Durham, NC: Duke University Press.

Cvetkovich, A. (2012). Depression: A Public Feeling. Durham, NC: Duke University Press. 
Davis, D. D. (2000). Breaking up [at] Totality: A Rhetoric of Laughter. Carbondale, IL: Southern Illinois University Press.

Deleuze, G. (2006). Nietzsche and Philosophy. Translated by H.Tomlinson. New York: Columbia University Press.

Derrida, J. (1988). The Ear of the Other: Otobiography, Transference, Translation. Edited by McDonald, C. Translated by P. Kamuf and A. Ronell. Lincoln: University of Nebraska Press.

Derrida, J. (1991). “Eating Well,” or the Calculation of the Subject. In: E. Cadava, P. Connor, and J. Nancy, eds., Who Comes After the Subject?, 1st ed. Trans. Connor, P. and Ronell, A. New York: Routledge, pp. 96-119.

Faulkner, J. (2013). Disgust, Purity, and a Longing for Companionship: Dialectics of Affect in Nietzsche's Imagined Community. The Journal of Nietzsche Studies, 44 (1), pp. 49-68.

Flatley, J. (2010). Unlike Eve Sedgwick. Criticism, 51 (2), pp. 225-234.

Foucault, M. (1977). Nietzsche, Genealogy, History. In Editors. D. F. Bouchard. Language, Counter-Memory, Practice: Selected Essays and Interviews. Translated by D. F. Bouchard and S. Simon. Ithaca, N.Y.: Cornell University Press, pp. 139-164.

Hanson, E. (2011). The Future's Eve: Reparative Reading after Sedgwick. South Atlantic Quarterly, 110 (1), pp. 101-119.

Kant, I. (1996). Anthropology from a Pragmatic Point of View. Edited by H.H. Rudnik. Translated by V. Lyle. Carbondale, IL: Southern Illinois University Press.

Kristeva, J. (1982). Powers of Horror: An Essay on Abjection. New York: Columbia University Press.

Love, H. (2010a). Close but Not Deep: Literary Ethics and the Descriptive Turn. New Literary History, 41 (2), pp. 371-391.

Love, H. (2010b). Truth and Consequences: On Paranoid Reading and Reparative Reading. Criticism, 51(2), pp. 235-241.

Menninghaus, W. (2003). Disgust: The Theory and History of a Strong Sensation. Translated by H. Iland and J. Golb. Albany: State University of New York Press.

Middleton, C. ed. (1969). Selected Letters of Friedrich Nietzsche. Translated by C. Middleton. Chicago, IL: University of Chicago Press.

Nietzsche, F. (1968). The Will to Power. Edited and translated by W. Kaufman and R. J Hollingdale. New York: Vintage Books. 
Nietzsche, F. (1974). The Gay Science: With a Prelude in Rhymes and an Appendix of Songs. Translated by W. Kaufman. New York: Vintage Books.

Nietzsche, F. (1978). Thus Spoke Zarathustra: A Book for None and All. Translated by W. Kaufman. New York: Penguin Books.

Nietzsche, F. (1986). Human all too Human: A Book for Free Spirits. Translated by R.J. Hollingdale. New York: Cambridge University Press.

Nietzsche, F. (1989a). On the Genealogy of Morals. Edited and translated by W. Kaufman and R. J Hollingdale. New York: Vintage Books.

Nietzsche, F. (1989b). Ecce Homo. Edited and translated by W. Kaufman. New York: Vintage Books.

Nietzsche, F. (1997a). Daybreak: Thoughts on the Prejudices of Morality. Edited by M. Clark, and B. Leiter. Translated by R.J. Hollingdale. New York: Cambridge University Press.

Nietzsche, F. (1997b). Untimely Meditations. Edited by D. Breazeale. Translated by R.J. Hollingdale. New York: Cambridge University Press.

Nyong'o, T. (2010). Trapped in the Closet with Eve. Criticism, 51 (2), pp. 243-251.

O'Rourke, M. (2014). Bleurgh! Interalia: A Journal of Queer Studies, [online] 9, pp. 94-126. Available at: http://interalia.org.pl/media/09_2014/O-Rourke. pdf [Accessed 5 Dec. 2016].

Rumination, $n$. (2016). Oxford English Dictionary [online]. Available at: http:// oed.com [Accessed 4 Nov. 2016].

Rumen, $n$. (2016). Oxford English Dictionary [online]. Available at: http://oed. com [Accessed 4 Nov. 2016].

Sedgwick, E. K. (1990). Epistemology of the Closet. Berkeley: University of California Press.

Sedgwick, E. K. (2003). Touching Feeling: Affect, Pedagogy, Performativity. Durham, NC: Duke University Press.

Sedgwick, E. K. (2007). Melanie Klein and the Difference Affect Makes. South Atlantic Quarterly, 106 (3), pp. 625-642.

Seigworth, G. (2000). Banality for Cultural Studies. Cultural Studies, 14 (2), pp. 227-268.

Smith, D. (2004). Nietzsche's Hinduism, Nietzsche's India: Another look. The Journal of Nietzsche Studies, 28 (1), pp. 37-56. 
Stark, T. (2004). Even Better than a Cow, O Zarathustra! In: C. D. Acampora and R. R. Acampora eds., A Nietzschean Bestiary: Becoming Animal Beyond Docile and Brutal. New York: Rowman \& Littlefield Publishers.

Vitanza, V. J. (1997). Negation, Subjectivity, and the History of Rhetoric. Albany: State University of New York Press.

Weineck, S. (2006). Digesting the Nineteenth Century: Nietzsche and the Stomach of Modernity. Romanticism, 12 (1), pp. 35-43.

Wiegman, R. (2014). The Times We're In: Queer Feminist Criticism and the Reparative “Turn." Feminist Theory, 15 (1), pp. 4-25.

Wollenberg, D. (2013). Nietzsche, Spinoza, and the Moral Affects. Journal of the History of Philosophy, 51 (4), pp. 617-649. 


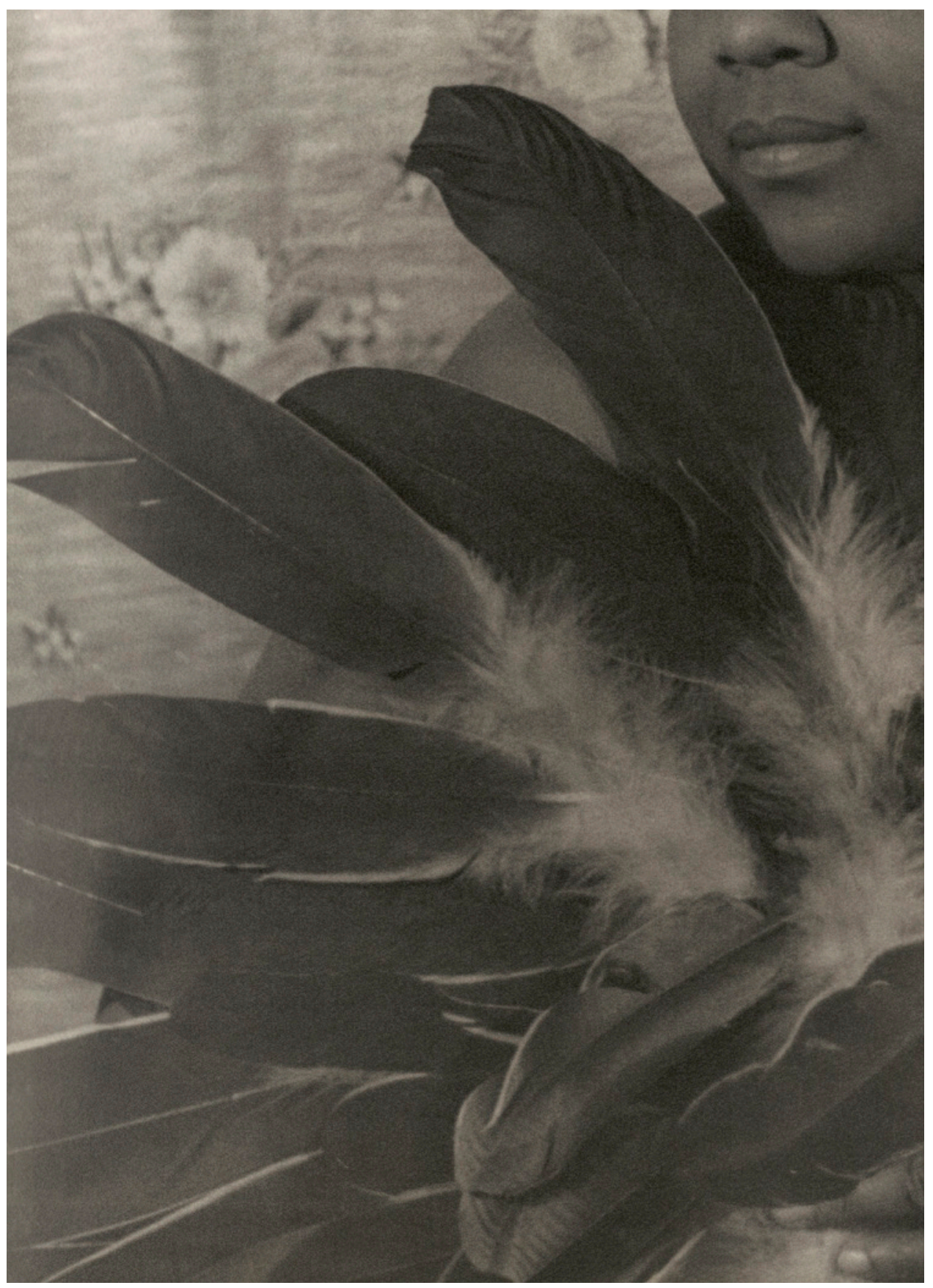

Bessie Smith (detail), Carl Van Vechten, 1936 Library of Congress, Prints \& Photographs Division (LC-DIG-ppmsca-09571) 


\title{
DU BOIS AND BLUR
}

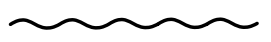

\author{
M. Gail Hamner
}

SYRACUSE UNIVERSITY
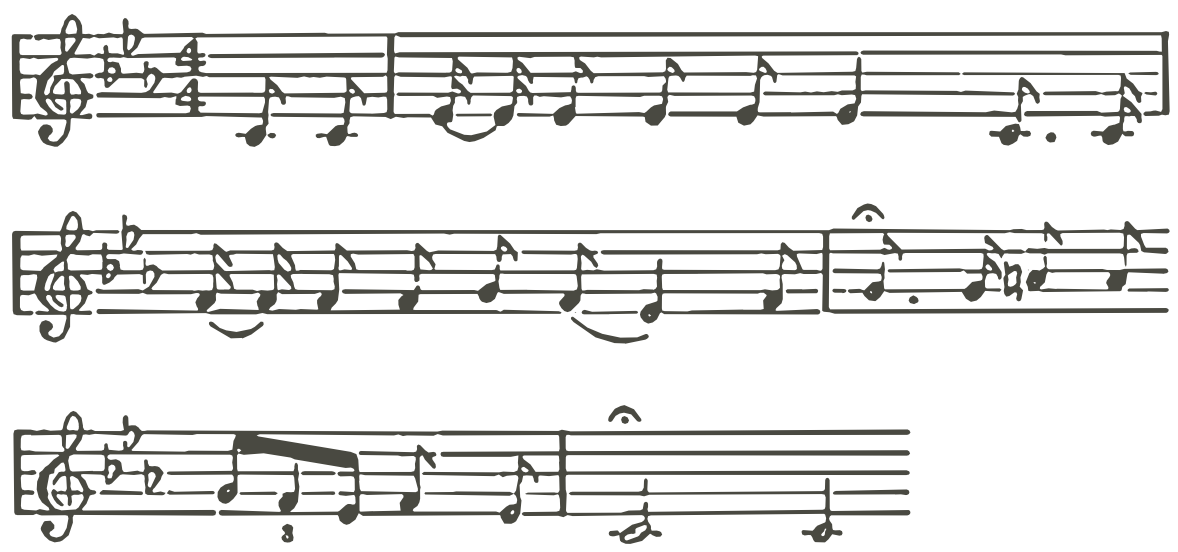

(Chapter 13, "Of the Coming of John", this music paired with a stanza from "Mrs. Browning")

At the head of each chapter of The Souls of Black Folks, W.E.B. Du Bois inscribes a pairing of poetry and music. He lays out attributed words of (White, European or American) poetry and subtends them with scored but untitled and unattributed notes of (Black, slave) music. The author comments briefly on the bottom half of this arrangement in his Forethought: "Before each chapter, as now printed, stands a bar of the Sorrow Songs,--some echo of haunting melody from the only American music that welled up from black souls in the dark past" (3). He doesn't explain what Sorrow Songs are, why their melodies constitute a paradigmatic national music, or why he pairs them with the words 
of established poets. Though his final chapter discusses Sorrow Songs at length, I am less interested in what Du Bois says about the "weird old songs" (167) than in the slippery affects he evokes by their formal arrangement with the poetry. These affects dodge and bang up against states of exclusion and access, and-eventually, I think-teasingly poke at readers' complacencies about voice, pleasure, and belonging.

Imagine opening this book in 1903, the year of its publication. To 'get' these epigraphic pairings a reader would have to know poets and poetry and be able to sight-sing printed music. Such a reader is educated. Her aesthetic formation has trained her to notice, and make sense of, tidbits like these as guideposts for the intellectual content forthcoming in the chapter. As such, the epigraphs grant a kind of access. They function as aesthetic signals, indeed as signals with increasing momentum and insistence since the head of every chapter repeats the same formal pairing. The educated and aesthetically sensitive reader is put on alert that something important is going on.

Even this imputed, educated reader will orient herself differently to the poetry than to the music, a difference crassly captured as that between the same and the other, or more generally, of the culturally dominant and the culturally sub-dominant or exotic. As such, the epigraphs perform a kind of exclusion. Because not all readers are educated, because even educated readers will not align with the cultural history of the bars of music, and because Du Bois provides no lyrics, titles, or songwriter attributions, the epigraphs posit an aesthetic experience and immediately mute and muzzle it.

This slippery doubledness of access and exclusion enacts something akin to pressing two magnets with the same polarity up against each other. The shared space on the page of these poetry-music pairs asserts a commonality-a like charge, if you will-and yet it is just this equal charge that pushes the poetry and music apart. Even an ideal, educated reader might miss the effects-the affects-of these pairings, precisely because such a reader might yield to her intellect's ardent attempt to settle on meaning, and settle, therefore, on the meaning of the poet$r y$, thinking the bars of music must be something like the poem's background accompaniment.

Anna Gibbs's theorization of "mimetic communication" offers a better way into the affective economy at play in these epigraphs $(2010,186)$. These epigraphs thus include "corporeally based forms of imitation," that "[a]t their most primi- 
tive, ... involve the visceral level of affect contagion, the 'synchrony of facial expressions, vocalizations, postures and movements with those of another person,' producing a tendency for those involved 'to converge emotionally" (186). Gibbs correlates mimesis with Tomkins's affect theory, which depicts the patterning of pre-personal impulses with concepts and memory (what I've called the affecognitive), and argues that attending to the visceral stratum of social patterning helps us grasp the centrality of affect to "the making-and breaking-of social bonds... [that] form the basis for a sense of 'belonging,' and, ultimately, of the polis, as what forms the affective bases of political orders" (191). Drawing from Benjamin's work on mimesis, Gibbs notes that mimetic communication does not require an "I" or even a cogent semiotics. "Mimicry is not a representation of the other," she writes, "but a rendering—a relation between things" (193).

If the visceral bonds of mimetic communication form a polis and sustain feelings of belonging, they also can form a counter-polis and the feelings of belonging together in non-belonging. The wordless and unattributed bars of music-black marks that a reader may or may not sight-sing into melodytranscribe the patterned counter-polis of slavery. In a peculiarly elusive and aggressive manner, Du Bois uses them to evoke the visceral mimetic communication so instrumental to the social bonds of slave survival. Repetitively presented but still elusive, these bars of slave songs sample the affective bonds forged within bondage; that is, within the isolating but no less shared experiences of grief, pain, and terror, and those ineffable affects that escape bodies as they twinge, stab, gasp, and moan in response to the miasma of existing as un/ human, as object-subject: that is, as owned property. Du Bois's unmarked and un-lyricized bars of music do not represent slavery, we might say, but render the state of slavery-that state of utter constraint through which bodies are forced into utter subjugation.

In the very moment of his rendering slavery in this manner, it slips away from semiotic capture. It is as if Du Bois wants to slip slaves and slavery onto the page, right under the nose of the reader. Right there under the famous poets crooning the fullness and burdens of the human heart, and yet do so in a way that shows, in the very moment of his rendering slavery..., it slips away from semiotic capture. It is as if Du Bois wants to slip slaves and slavery onto the page, right under the nose of the reader, right there under the famous poets crooning the fullness and burdens of the human heart. And yet do so in a way that shows, in the contemporary words of Fred Moten, "There's no remembering, no healing. There is, rather, a perpetual cutting, a constancy of expansive and enfolding rupture and wound" (2017, ix). 
Perhaps these poetry-music pairings function as hit-and-run performances of Saidiya Hartman's supposition in Scenes of Subjection: "What if the presumed endowments of man-consciousness, sentiment, and reason-rather than ensuring liberty or negating slavery acted to yoke slavery and freedom?” (5). Hartman attends closely to White attributions of slave "pleasure," especially the putative Black love for song and dance. Analyzing what she terms "the difficulty and slipperiness of empathy" (18) by means of "the thin line between witness and spectator" (19), Hartman sits with White claims that slaves, on the one hand, do not feel pain, and on the other hand, are always happy, joyful creatures ready to dance and sing. In response to the baffling fact that the traumas of the slave coffle, slave market, and slave field are so regularly and categorically denied, she points out the double bind of Black flesh: both valued as owned object of labor and sex, and Black flesh devalued as nothing but owned object of labor and sex.

Hartman quotes at length from Abraham Lincoln's depiction of encountering a slave coffle on a steamship. Imagining the sad partings and certain hard labor and whippings that lay in the captives' future, Lincoln marveled that "amid all these distressing circumstances, as we would think of them, they were the most cheerful and apparently happy creatures on board" (34). To Hartman, Lincoln's words "suggest that song, dance, and game discredit any and all claims of pain" and she concludes that "these scenes of enjoyment provide an opportunity for white self-reflection, or, more broadly speaking, the elasticity of blackness enables its deployment as a vehicle for exploring the human [i.e., white] condition" (34, italics added). Because of "the assimilative character of empathy" (35), Whites simply missed what was going on in the songs, which enacted what Paul Gilroy calls "the politics of a lower frequency" (35).

Hartman counterbalances Lincoln's assimilative empathy with Frederick Douglass' memory of slave songs from his youth:

They would sing as a chorus to words which to many would seem unmeaning jargon, but which nevertheless, were full of meaning to themselves. I have sometimes thought that the mere hearing of these songs would do more to impress some minds with the horrible character of slavery, than the reading of whole volumes of philosophy on the subject could do. (DuBois 2017, 34) 
Douglass is careful not to extend too quickly his reception of these songs toward a universal conclusion. The songs might impress "some minds" with the affective counter-polis of slave survival. Other minds-like Lincoln's-slide past the pain and pivot quickly to a reflection on "the" human (White) condition. (Here it might be productive to read Hartman alongside Kyla Schuller's The Biopolitics of Feeling.)

Du Bois knows that both some minds and other minds will read his book. The affective labor of his epigraphic pairings lies not in a dialectic of poetry and music nor the space in-between poetry and music, but in what Moten might call their blur; because while the stanzas of poetry express something of substantialized humanity, the bars of music evoke (i.e., bang up against and dodge) "the resistant, relentless impossible object [that] is subjectless predication, subjectless escape, escape from subjection" (2017, vii) - in other words, the un/humanity of the slave. This impossible subject/ion is rendered through the visceral affective mimesis of song, and yoked in Du Bois's epigraphs to the freedom of (White) substantialized humanity as its subtended, murmuring-muted ground.

\section{Acknowledgements}

The author gratefully acknowledges friends who commented on earlier versions of this piece: Kyle Bass (who saved me from an error and pointed me to scholarship on early 1900s domestic piano playing), Zachary Braiterman, Randall Johnson, Coran Klaver, Stephen Meyers, Greg Siegworth, and Joseph Winters.

\section{References}

Abbott, L. and Seroff, D. (1996). 'They Cert'ly Sound Good to Me': Sheet Music, Southern Vaudeville, and the Commercial Ascendancy of the Blues. American Music, 14 (4), 402-454.

Dubois, W.E.B. (2007). The Souls of Black Folks. Edited by B.H. Edwards. New York: Oxford University Press.

Edwards, B. H. (2007). Introduction. In: Du Bois, W.E.B., The Souls of Black Folks. New York: Oxford University Press.

Gibbs, A. (2010). After Affect: Sympathy, Synchrony, and Mimetic Communication. In: M. Gregg and G. Seigworth, eds., The Affect Theory Reader. Durham: Duke University Press. 
Hartman, S.V. (1997). Scenes of Subjection: Terror, Slavery, and Self-Making in Nineteenth-Century America. New York: Oxford University Press.

Hobson, V. (2013). Plantation Song: Delius, Barbershop, and the Blues. American Music, 31 (3), 314-339.

Karpf, J. "The Early Years of African American Music Periodicals, 1886-1922: History, Ideology, Context." International Review of the Aesthetics and Sociology of Music 28: 2 (1997), 143-168.

Miller, B. H. (1995). Household Periodicals: An Unstudied Source of American Music. Fontes Artis Musicae, 42 (4), 311-319.

Moten, F. (2017). Black and Blur (Consent not to be a single being). Durham, NC: Duke University Press.

Moten, F. (2003). In the Break: The Aesthetics of The Black Radical Tradition. Minneapolis: University of Minnesota Press.

Radano, R. M. (1995). Soul Texts and the Blackness of Folk. Modernism/Modernity, 2 (1), 71-95.

Sundquist, E. (1993). To Wake the Nations: Race in the Making of American Literature. Cambridge, MA: Belknap Press of Harvard University.

Winters, J. (2016). Hope Draped in Black: Race, Melancholy, and the Agony of Progress. Durham, NC: Duke University Press. 
WUAT BRING TIEY

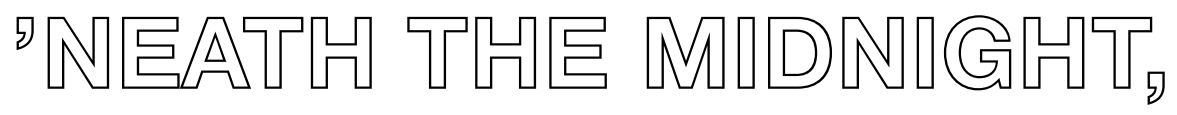

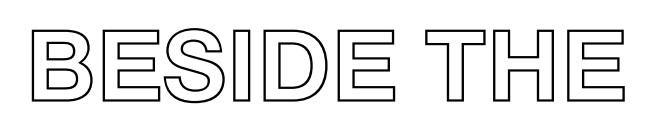

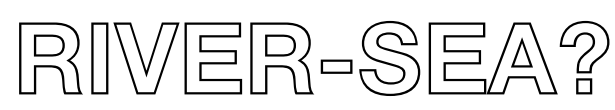

\section{TIEY BRING}

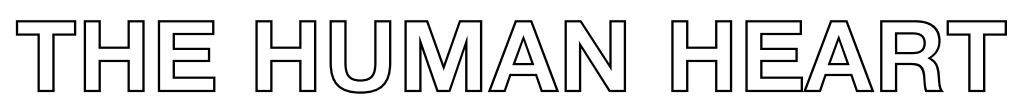

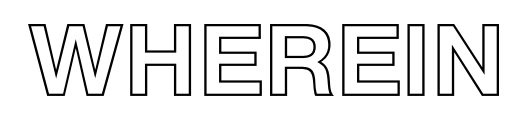

\section{NO NIGMTLY}

GALM CAN BE⿱口口:

$$
\text { TIRAT DROPPERI }
$$

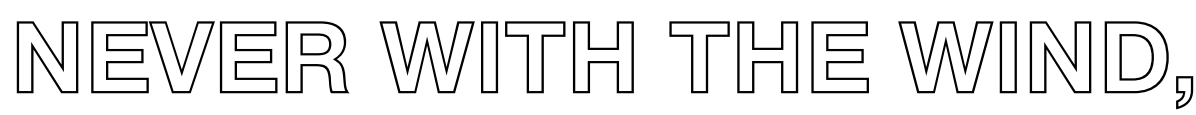

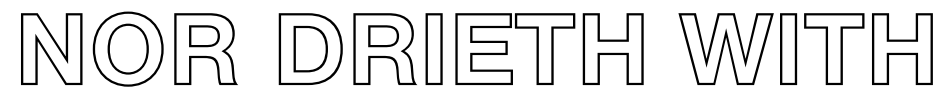

『几區 D馬:

(C) CALM UT: GOD:

TUY GALM IS BROAD

$$
\text { 『(C) COVER }
$$

spuRlus T(O).

$$
\text { 吹居 RIV居R }
$$

F凸○WE[几 ON. 


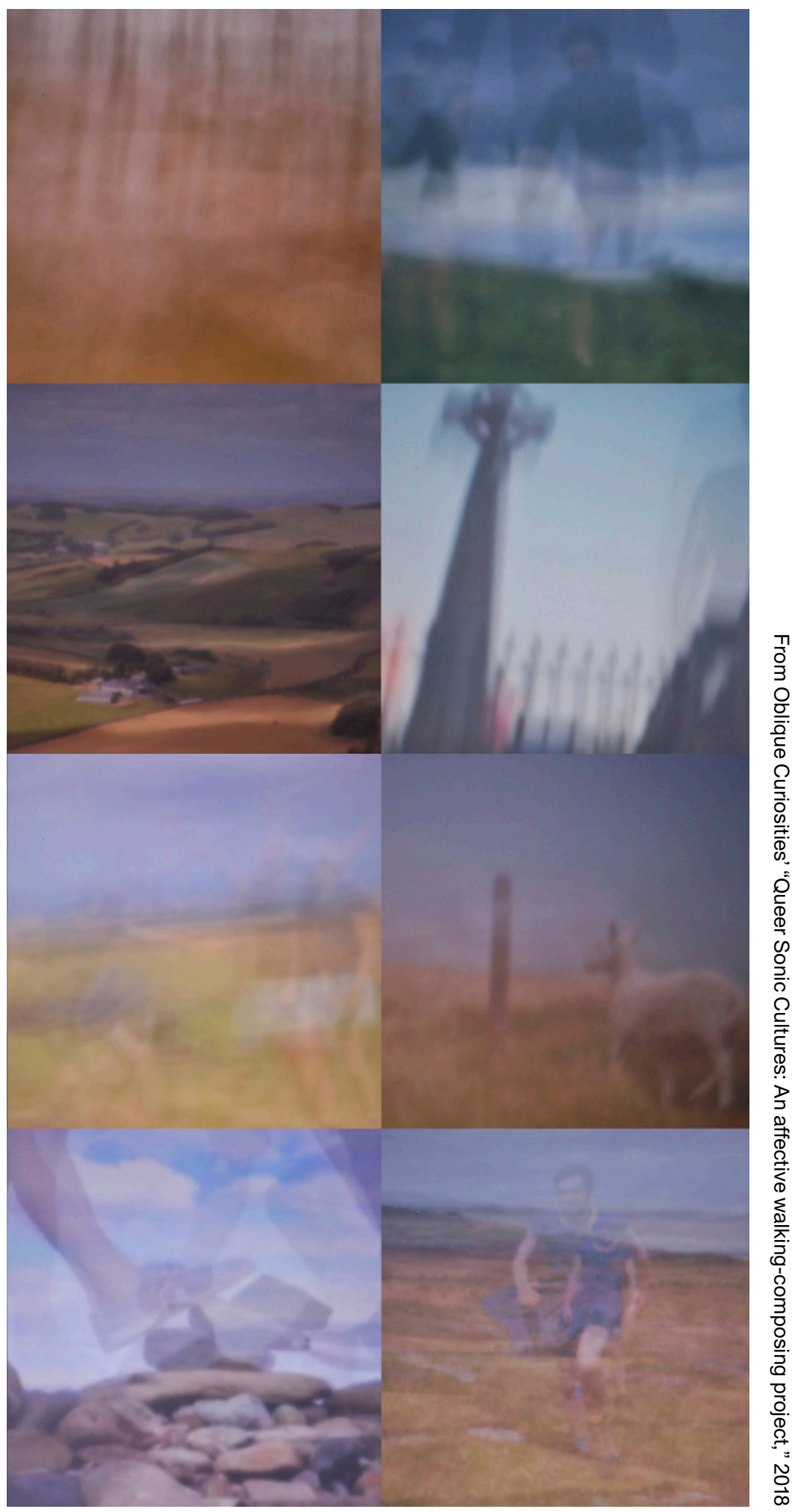




\section{QULEER SONG GULURRES: AN AFFEGTIVE WALRUNG. GOMPOSING PROJEGJ}

\section{Sarah E. Truman and David Ben Shannon MANCHESTER METROPOLITAN UNIVERSITY}

Walking in nature has long been associated with creativity. Yet walking's associated research and artistic practices remain dogged by representationalism. Concomitantly, intersectional concerns of race, gender, and dis/ability determine what kinds of bodies are allowed to walk where (and in this case, the where is Brexit-era Britain). This article attempts to navigate the complexity of these tensions, contextualizing a fiveday walking research-creation project along St. Cuthbert's Way that we called Queer Sonic Cultures. As academics and artists interested in the relationship between walking and composition, our initial propositions are to become affectedas we walked and to create sonic cultures (songs) using whatever affected us along the way. In using research-creation as a research methodology, we understand our artistic compositional practice of co-creating lyrics-melody-harmony-production-arrangement as the research. Unlike some forms of arts-based research that use an artistic form to disseminate research findings, in research-creation the artistic practice is the research and the theory. In the interests of continuing to make this apparent, we shall prefer to describe this contextualizing article as Academic Liner Notes. The Academic Liner Notes begin with a brief description of the location of the walk, contextualized within the tradition of walking and composing in the British landscape, and the use of sound-based methods and literature to represent such landscapes. Following this, we will introduce research-creation as a methodology contextualized within affect studies. We argue that the resultant sonic cultures (nine in total) rather than representing the walk, in fact, more-than-representationally intensify the affective dimensions of the relations we were part of along the way.

\section{KEYWORDS}

research-creation, affect, sound, walking and composition, creative writing 


\section{Queer Sonic Cultures}

Before continuing to read the Academic Liner Notes, you should first listen to our Queer Sonic Cultures (capaciousjournal.com/article/queer-sonic-cultures). They are the research-creation!

\section{'Academic Liner Notes': description of project, or 'in a curious life, take an oblique stream'}

St. Cuthbert's Way tracks the path of 7th century monk St. Cuthbert. It is a $100 \mathrm{~km}$ public footpath that runs from Melrose, Scotland to Lindisfarne, England. The path along the border of Scotland and England, winds across rolling mountains, through villages, and over the top end of the windswept Pennines. The final $5 \mathrm{~km}$ can only be completed at low tide over the ocean floor causeway to Holy Island. Hundreds of seals live near the island and bark a magnificent haunting wail that carries over the landscape. St. Cuthbert's Way is a recently designated footpath (1997), although it was created along a route that has been used, in part, as a Christian pilgrimage site for over 1000 years. It took us five days to complete the walk. As colleagues and friends, we have composed "sonic cultures" (Truman and Shannon 2015) together since 2011 and conducted walking-sound research with WalkingLab. Off the back of these cultures, we have founded a glitch-folk band, Oblique Curiosities, where we continue to grow and use our cultures as prompts for further research-creation.

We frequently improvise songs when we walk together. For this project, we wanted to investigate the relationship between long distance walking and composition practices. Given our academic research interests in affect theory, we completed the walk with a commitment to "becoming affected" (McCormack 2008, 9), registering those affects compositionally and productive-of our queer sonic cultures. We understand culture both in the socio-cultural sense and (after the microbial method) as the site of proliferation for something-new. These sonic cultures are "more-than-representational" (Truman 2016, 138) documentations of our walk, in that they both represent affective intensities we experienced on the walk and are productive-of something more.

As queer artists and academics, we draw queerly on the body of scholarship known as queer theory to queer walking, nature, and composition. After Eli Clare (2001), we use the term queer in its "general sense, as odd, quirky, not belonging; and in 
its specific sense, as referring to lesbian, gay, bisexual, and transgender identity" (361), to which we would append other non-normative sexual or gender identities. Queer research can be "any form of research positioned within conceptual frameworks that highlight the instability of taken-for-granted meanings and resulting power relations" (Browne and Nash 2010,4). We activate queer as both a noun and a verb in our scholarship.

\section{Walking, nature, creativity, research, and their inheritances}

Walking in nature is a big deal in Britain. Britain's walking heritage includes many ancient trackways, green lanes, and footpaths (e.g. the Pilgrim's Way from Winchester and Canterbury) that walkers and pilgrims continue to use. There is a preponderance of scholastic writing and guidebooks about walking in the UK, and centuries of literature from Chaucer to Austen to Woolf feature characters strolling in the landscape or through cities. Numerous authors use walking as a narrative device, literary theme, or as a method for generating content, such as Wordsworth's romantic strolls in the Lake District. There are also books about walking as a lost art and books on where to walk as part of the pervasive stereotyping of Britain's 'green and pleasant land.' Music demonstrates a similar link between nature and nation. Euro-Western (and particularly British) 'classical' composers often attribute their music-or are attributed (whether they like it or not!) - to Nature, for example, Beethoven's 6th (posthumously Pastoral) symphony with its Nature-themed movement descriptions; or the attribution of Elgar's music to his wandering in the Malvern Hills; and Williams' The Lark Ascending and pastoral-themed Fantasias.

And yet, after Alison Kafer (2013), we are led to wonder what 'passes' in/as Nature? The sound of footfalls or majority enunciations of English would perhaps seem more 'natural,' than alternative movement habits (such as automatic wheelchairs), or diverse speech patterns in the countryside. As queer subjects walking in the landscape we might be marked as 'unnatural.' However, during our walk our cis-genders and whiteness insisted we be read as a 'straight' couple, and pass in ways that others never could ("Your ... husband? Oh, I'm sorry! Boyfriend."). Carolyn Knowles (2008) discusses how whiteness is produced and flourishes in rural Britain and is bolstered by histories (and the ongoing presence) of colonialism and slavery. For Knowles, the British countryside "stands for more than it is: it produces, embodies and sustains whiteness on behalf of the nation" (170), and maintains a position as the core of British identity. 
Springgay and Truman (2018a) critique how walking, when framed through romantic poets and naturalists-and, we argue, music composers-operates as a privileged (ableist) practice, and a white cis-heteronormative time-space. The literary tradition is steeped in tales of lone (white) male walkers setting out into the wild in search of inspiration, in ways that racialized, gendered, and dis/abled bodies historically could not (and still cannot). According to John Wylie (2005), a walk in the English countryside "involves at least some attunement with the various sensibilities still distilling from sublime and romantic figurations of the self, travel, landscape and nature" (235). These romantic geographies are re-affirmed in much contemporary walking literature, and through stories and songs of the UK's artistic tradition to such an extent that an 'inherent' relationship between the creative canon and landscape begins to appear as pre-given. Without an understanding of how imperial power relations pervade the English creative canon and language, its assumed social, cultural, sexual (cis-hetero), and racial attunement (whiteness) can also appear co-extensive with the landscape. The classical and literary creative canon invigorates and builds the capacity for white-cis-hetero conceptualizations of humanity, and re-centers whiteness as co-constitutive of the British landscape. Much like the wider expansion of Britain's economic and imperial virility, such a capacitation depends upon the debilitation and disparagement of women, dis/abled, working class people, and Queer, Trans, Black, Indigenous and People of Colour (QT/BIPOC), and is maintained through white supremacy, and ongoing settler colonialism.

The link between nature, walking, and creativity has been discussed in many fields, and frequently scholars have conducted research that attends specifically to sound and sonic walks in varied landscapes (Lorimer \& Wylie 2010; Gallagher 2016). What are commonly referred to as soundwalks are often used to explore the "sonic ecologies of place" (Springgay and Truman 2017, 35). Phonographic field recordings in nature typically aspire to a sonic representation of place, wherein sounds are selected either for their socio-sonic veracity or else their spectomorphological properties (Rennie 2014). In these productions, the sounds of the recordist are minimized or erased, and they often go to great lengths to avoid registering any anthropogenic sounds in order to enact a romanticized notion of the 'natural' (Gallagher 2015; Michael 2011). Increasingly, fields such as geomorphology are attempting an artistic representation of landscape, where Nature provides "aesthetic inspiration" to the extent that past geomorphological transformations can be discerned from historical images, literary accounts and 
songs (Tooth et al. 2016, 1793; Griffiths et al. 2018). Our Queer Sonic Cultures project did not set out to sonically represent the places we walked but rather we proposed that we become affected by our walk, and repurpose those affects for our sonic compositions as part of an "ethical commitment to learning to become affected" (McCormack 2008, 9).

Scholars have recently begun to incorporate walking as a research subject, a method, and a methodology. Stephanie Springgay \& Sarah Truman (2018a) critique how-across these threads-walking is variously instrumentalized, seen as inherently innovative, and uniquely productive-of innovation. After Springgay and Truman, rather than focus on what a method produces, we, as artist-researchers, focus instead on the affective (in)tensions we bring to a method (Springgay \& Truman 2018b). This is our theoretical approach to research-creation.

\section{Research-creation}

Research-creation is the interrelated practice of art, theory, and research (Truman \& Springgay 2015). It is a "thinking-with and across techniques of creative practice" (Manning \& Massumi 2014, 88-89) that moves away from approaches to qualitative research that assume data can be collected, extracted, and then represented, and towards an affective, emergent, relational and more-than-representational approach to doing-research (Thrift 2007; McCormack 2008; Truman 2016). We also suggest that a research-creation event invokes a queer temporality in its disruption of regular space-time delineations.

Affect has been theorized from within a variety of academic lineages (Seigworth and Gregg 2010). We understand affect within our research-creation practice as "the becoming sensation, a force or intensity manifested at the surface of the body" (Springgay and Zaliwska 2017, 276-277), "found in those intensities that pass body to body ... in those resonances that circulate about, between" (Seigworth and Gregg 2010, 1), felt-or-not, capacitating and debilitating further affectivity (Massumi 2015; Puar 2017).

Similar to our critiques of the whiteness of walking and creative inspiration in the landscape, we critique affect studies for sometimes erasing patterns of marginalization, and reinscribing compulsory white, hetero, Europhallic (Moten 2003) ablebodiedness (see Ahmed 2004, 2010; Weheliye 2014; McRuer 2016; Palmer 2017; Puar, 2017). When affect is depoliticized and assumes a neutral circulation, as well as (state-sanctioned) capacity for affectation, it masks its conflation of neutral as white. This re-centers whiteness and 'Man' as a universal category 
(Wynter 2003). Universal Man affects but is never affected. He circulates, builds capacity, and sticks to everything, but nothing sticks to him. And, as evidenced in the recent and short-lived furore surrounding use of the term 'gammon' in the UK as an epithet for enraged red-faced white men (Lang 2018), anything that does stick is quickly silenced.

An ethics and politics of becoming affected must attend to how affects stick to or smear-past QT/BIPOC and dis/abled bodies, onto whom cis-heteronormative, racialized and dis/capacity and debility is always-already inscribed (Ahmed 2004; Lara et al 2017; Weheliye 2014). Drawing from these "frictional" (Puar 2012) understandings of affect, we position our walking-composing as registering the affective dimensions of ordinary encounters (Stewart 2007), where "things hanging in the air are worth describing" (Stewart 2011, 447). However, our 'descriptions' are not linguistic representations, but rather, in keeping with our adoption of research-creation, reach for a more-than-representational engagement of affective intensities.

Both affect studies and research-creation prioritize material and corporeal practices that converge around a "shared concern for nonconscious, non-cognitive, transcorporeal, and non-representational processes" (Springgay and Truman 2017, 11). According to Vannini (2015), the "non-representational answer to the crisis of representation lies in a variety of research styles and techniques that do not concern themselves so much with representing life-worlds as with issuing forth novel reverberations" (12). In this regard we understand our songwriting and queer sonic cultures as re-circulating the mined affective intensities of our journey; walking-composing-sounding intervenes into the material intensities of the present-future through "improvising with the already-felts" (Manning 2009, 30).

We composed with affective intensities, already-felts and phonographic artefacts mined from the environment to create our affectively-productive melody-lyrics-harmony-tempo-key-arrangement-production-synthesis-phonography-performance-vibration-codec-mp3-speakers. Each affect does not "just prompt thought, but also generate[s] sensations resonating in the body as well as the brain-frissons of excitement, energy, laughter, silliness" (MacLure 2010: 282). Every feature of each song is co-compositional in its rendering of and reaching for a more-than-representational account of the evocative ordinariness and piercing bizarrity of everything. 
Following Lone Bertelsen and Andrew Murphie (2010), the affective unfolding of our sonic cultures is:

cross-temporal, implying a participation of 'temporal contours' in each other, singly or in the looping of refrains. This cross-temporality constitutes the movement of experience into the future (and into the past, as memory) (italics original, 146).

More-than-representational practices perform a queer temporality. Each sonic culture is a pressing together of ever-multiplying spatial, temporal, and affective emplacements that could never have touched, but are here relived and re-represented in a queering of chronological time (this is similar to our critiques of affect and walking studies above, as queer studies has been critiqued for re-centering whiteness and class privilege: Puar 2007; Muñoz 2010).

\section{Conditions of possibility}

We were both prepared and unprepared for the walk. We had sneakers, hats for the sun, cameras, a tablet (equipped with a microphone, and digital audio workstation and MIDI sequencing software), notebooks, postcards, and a bowtie and a dress in case we wanted to dress-up. We had a van transporting our bags from guesthouse to guesthouse, so we could walk lightly. But we had no map, no compass, no rain gear, and no warm clothes. We hoped the weather was clement, and that there were lots of towns to stop in and good signage. The first day of the walk we met a group of well-prepared British walkers replete with walking poles, boots, and all manner of hiking gear. They were markedly unimpressed by our unpreparedness (and reminded us of this several times throughout the walk when they invariably passed us after we got distracted by heather, or had to loop through a wood/thicket/ bull's pen after getting lost).

In preparing for the research-creation event of walking-composing, we used Barad's (2007) "conditions of possibility" as an umbrella term for the discursive-material arrangements that initiate particular material (re)configurations. These are theorized across the sometimes-overlapping yet un-conflatable concepts of enabling constraints, propositions and activation devices. Enabling constraints (Davis, Sumara, \& Luce-Kapler 2008) articulate how constraining features of a project can be both limiting and productive. Erin Manning (2013) discusses how propositions are immanent to events and co-constitutive. Following Whitehead (1978), propositions can also be seen as both actual and speculative - they draw from actuality as well as propose what could be (Truman \& Springgay 2016). An activation device (Springgay \& Truman 2018) "forces something new to occur" not to "extract or 
collect information, but to insert itself within the walking-writing-practice as a thinking-making-doing” (135). As part of the material-discursive arrangement of our research-creation process, we will offer some exemplifications of these intersecting concepts as they relate to the tablet we brought with us every day of our walk.

- Trumey (Sarah) was against pushing a Steinway up Wide-Open Hill, because she knew she'd end up doing all the pushing when Shanny (David) was in a grumble-funk. As such, we were constrained as to what instruments and digital music equipment we could bring. The lack of a Steinway might be an enabling constraint, but the addition of a tablet is also an enabling constraint. We were forced (enablingly constrained) to compose using a touch screen (rather than a piano keyboard or mouse). This found us drawing sliding melodies with our waggle fingers as our sole means of notation, which in turn may have influenced our reliance on theremin-esque virtual instruments in our songs (that and our mutual obsession with Doctor Who).

- Our initial proposition was to become affected as we walked and to create our sonic cultures using whatever affected us along the way. Propositions probe what could be. Openness to phono-affects and their graphemic registering renders them (en)durable (Weheliye 2005). In this way, the tablet as a phono-graphic device was also propositional. Not only could we play music on it, it wrote sounds (as audio) and melodic intention (as MIDI data) digitally, which Steinways just can't do. Ironically, with digital media and archival procedures changing at alarmingly fast rates, the digital files might seem like they'll out last us, but they may become unreadable within our lifetimes.

- The tablet was also an activation device. It inserted the beginnings of the music production process into the lyric-writing, and melody-humming, and frog-marching, and nettle-stinging, and... and... and... Being able to accompany our marching with 8-bit snare sounds, or our melody-humming with chords probed the process in particular directions.

Some of our conditions of possibility were determined before the walk:

Walk St. Cuthbert's way in five days; $24 \mathrm{~km}$ on the first, $28 \mathrm{~km}$ on the second, $19 \mathrm{~km}$ on the third, $19 \mathrm{~km}$ on the fourth, and $10 \mathrm{~km}$ on the fifth. Remember Brian Eno and his Oblique Strategies. Time signature. Queer the landscape. Write songs as we walk (lyrics, rhythm, melody, affect, space, repeat). 
Some of our conditions of possibility prompted us in different ways on different days during the walk:

Tablet. Note pad. Pinhole camera. Dress up in dresses and bowties.

Other conditions of possibility emerged in the middle of the walk and were not pre-planned:

Forget food. Realize we forgot food. Forget water. Realize we forgot water. Meet racist Brexiteer in quaint village. Bring baggage of Shanny's recent ex-boyfriend. Get into a big fight with each other (x3). Get lost (x5). Trample through stinging nettles $(x \infty)$. Chew-up and apply (not)dock leaf. Read Maggie MacLure (2013) next to an open sewer. Hornet's nest. Bull in field. Karen Barad. Quantum Physics. Human-Time Lord Meta-Crisis.

Doctor Who.

Pilapalapoptipings.

Run.

Longing.

Heather.

Wind.

Pain.

Delirium.

$\&$

Each of these conditions of possibility determined the material-discursive arrangement that formed our songs. Our phono-graphical practices registered sounds. Our 'song-o-graphical' writing practices registered affect.

As we marched, we chanted, scribbled, and played with our lyrics; sometimes, a running joke became a song, and others a running lyric became a joke. "Oh ... [insert noun] ... Wouldn't that be sexy?!" Many of the lyrics were written in response to specific encounters during the walk (e.g. "In the night silence lilting fragrance and neglect"), while others drifted in during conversations; hinted at lyrical inheritances that were circulating as a result of our being together, walking, talking (e.g. “不爱就是不爱; if there's no love there's no love”). Thematically, 
the lyrics defined the tone of each song. The meter and rhythm co-determined each other, but also necessitated re-writing of the lyrics. We used the tablet's microphone to record footfalls and splashes and seal-songs for later reworking as drum lines and goodness-knows what, and whistled snatches of melodies. We also drew harmonies and tapped out virtual drum lines into the tablet and noted the instruments we would use to develop the compositions (e.g. bagpipes). We exported these performances as MIDI and AIFF files into Digital Performer when we reached our guesthouse for the night and channeled them through software-synthesizers and sample libraries such as MOTU'S MX4 and Proton, East West's Symphonic Orchestra, Pianos and SD 2, YMCK's Magical 8-bit, Michael Bietenholz's Resonance, and Adam Monroe's Honky-tonk Piano. The next days, we would chant the lyrics and tap rhythms over and over as we walked.

After we finished the walk, we continued to work on the production and arrangements of the queer sonic cultures, but only when we were in the same geographic place (we lived on different continents until recently). We finalized the structures of each queer sonic culture in Hamilton and Muskoka in Ontario, Canada, and Reykjavik, Iceland; the final voice parts were recorded in Manchester and London, UK, and Santiago de Compostela, Spain; mixing was done in Liverpool, UK. Each of these components continued to be a negotiation between our different tastes and expectations.

\section{I could not then but now I can say (my queery, feary, deary)}

Affects swirled around us and through us during the walking and composition process. They were prickly and sticky and atmospheric and moody and spacious and luminous and resonant and tight and claustrophobic. Yet, three years after our walk, we are not the same. The cultures are still laced with the sadness of a recent break-up and the aching tension of each foot-fall, but we have moved on (hamstrings and all). However, as part of an ethical commitment to becoming affected (McCormack 2008), and assuming response-ability for the worlding in which we participate (Barad 2007), while writing this accompanying article and re-working the sonic cultures in Brexit-era Britain, the whiteness still sticks.

In order to make clearer the relationship between a stroll in the British countryside, walking and whiteness, we elucidate some of the features of one sonic 
culture: Three Black Military Helicopters documents our being left-out-of-joint by unexpected and affective disturbances on the walk.

- Three armed military helicopters buzzed us on Wide-Open-Hill; the insertion of the military into the seemingly serene landscape reminded us of Britain's heritage.

- The continuing theme of whiteness that never left us on the walk: from the increasing creepiness of English 'heritage' dining rooms, to the Bangladeshi restaurant owner's recounts of racism. One particular incident involved a white woman drawing Shanny into a discussion on who 'belongs' in the countryside (where his political leanings were assumed to be in-keeping with a particular identity as a white cis-male British walker). After the conversation, the smell of dog shite was overpowering as we left the village; it bled into the affective hangover of the discussion and lingered all about us for miles.

- A further disturbance occurred during an encounter with an overwrought walker while Shanny was dressed-up in a polka dot dress for a photo opportunity. The man repeatedly yelled at us across the hillside for the location of an "orienteering (something)." Our queerness, our incompetence as walkers, and our ill-preparedness were obvious; we failed to pass on so many levels. We got scared, yelling back "We don't understand that question; we're not walkers!" and fled down the hill-side. We fled the wrong way, completely off the track, got lost amongst the ferns and heather, stepped on a bee's nest, tried to escape through a bullpen, and then tried to escape from the bull by jumping over an electrified fence.

A post hoc listening of the song today seems to suggest multiple ways in which these multiple 'out-of-joints' appear to inspire the song (although we remain unclear as to how conscious we were of each inspiration at the time):

- The meter jarringly switches from four beats in each bar to three for the "chorus' section (from a regular $4 / 4$ to a waltz-time $3 / 4$ ); this section is also not diatonic (i.e. not in the harmonic key that has been established throughout the rest of the song), while the voices are auto-tuned to achieve a melody that would normally be impossibly out of their range.

- Instruments traditionally associated with the 'classical' canon (violins, cello and piano) perform an increasingly disharmonious, yet resolutely 'major' (i.e. 'cheerful'), accompaniment to lyrics such as "Racial slurs in Woolerville, dog shit smells and bees nests; Whiteness ascends, whiteness ascends, imperialism!" 
- A juddering, endless arpeggiator hovers throughout the song.

- The melodic phrase heard during the verse lasts eight bars; the chord sequence across the eight bars is: $\mathrm{C}, \mathrm{Ab}, \mathrm{Bb}, \mathrm{F \#}, \mathrm{C}, \mathrm{Ab}, \mathrm{Bb}, \mathrm{F \#}$. Each of these chords is 'major' (i.e. 'cheerful') because the middle note of each chord (its 3rd) is in its highest position. However, the vocal melody flattens that note in the fifth bar. This means that, throughout the verse's fifth bar, the accompaniment is 'cheerfully' playing in C major while the vocalist is singing 'unhappily' in C minor and creating quite a disorientation in the process! When heard with the lyrics, this creates a sinister accentuation; for instance, in the case of the first line of lyrics, it falls on the underlined words: "Three black military helicopters puncture the solitude."

\section{Coda: Ice-pick in my eye}

In reference to one of the original prompts of the project: in what ways would walking a long distance help our composition process; our practice of walking-composing appears to support claims that walking can lead to inspiration, under the right circumstances. We could have written queer sonic cultures elsewhere, but they wouldn't be these ones. These sonic cultures are very much inspired by our walk and entangled with our walk. Yet the already-felts ("Meeting the Universe Halfway"; "Shanny's Break-Up”; “Wouldn't that be Sexy?!”) that we brought with us on the walk were as generative as the magnificent vistas and sloppy mud-toes we encountered.

The sensibility of research-creation demands that art be taken as seriously as the research and theoretical components. We recognize that between us we have a substantial skill-set, decades of experience in our art-practices, and a close personal relationship, as well as overlapping research and theoretical interests; we acknowledge the privilege and scarcity inherent in the development of that skill-set. The walking was inspirational, but hundreds of hours of 'working' the inspiration was necessary to produce the sonic cultures we created. Our co-writing lead to many cuts that our sensibilities couldn't purpose. For example, there are three distinct versions of "All", two of which are erased, and many lyrics remained unused. We spent many hours on the various vocal lines, both during recording and in post-production, cutting across multiple takes, compressing and de-essing-not to mention auto-tuning! We decided that we could not between us manage the 
type of performances needed to make "Cruel Bliss (sweet pain)" work, so the final version features Luke Jennings on voice and guitar.

In listening-to and re-working the sonic cultures, we were inspired by Steve Goodman's use of Augoyard and Torgue's effects unit (2012), wherein an effects unit is described as modulating or distorting sound as it passes through (rather than just being a neutral component). Further to this, we note that the soundings of each component of an effects unit-diodes and oscillators in traditional hardware or digital algorithms in their contemporaries-are heard in the signal output. For instance, our overused Cyberman voice is achieved using a virtual ring modulator. The carrier wave of the ring modulator's (virtual) oscillator is joined with the input signal to create a new sound. In this way, both we as composer-listeners, and our sonic cultures modulate and distort affect, as well as making something new!

Rather than understanding our sonic cultures as a repository that documents and represents our walking-composing project, we understand them as a kind of "anarchive" (Murphie 2016, np). Andrew Murphie (2016) discusses how anarchives, unlike official archives, resist interpretation and allow us to instead focus on the affective and material process of production-in this case, sonic-affective. The sonic cultures don't capture the walk, but more-than-represent it in each anarchival listening.

Our final (bonus) culture, "Ice-pick in my eye" is an affective response to the process of completing this article. It is a playful critique of our own academic writing process and sometimes overwrought use of theoretical terms. We hope you will direct it towards your own scholarship to encourage the academy to laugh.

\section{(Liner) liner notes}

We refer to ourselves as Trumey and Shanny.

\subsection{Buttermoon}

$1.1120 \mathrm{bpm}, 4 / 4$, D minor

1.2 "The sonic culture includes Theremin, an electronic instrument developed during the 1920s that was popularized by its use in low-budget 1950s sci-fi and horror films." 
2.0 It's Okay to Say "No" (to What Isn't Working Out)

$2.1120 \mathrm{bpm}, 4 / 4, \mathrm{Ab}$

2.2 "The main lyric was advice passed on to Trumey about leaving a previous job, and was repurposed for Shanny on the occasion of him having a bad breakup and turning gloomy. The song includes time-stretched and reversed glass shattering samples."

\subsection{Wouldn't That (Be Sexy)?}

$3.1120 \mathrm{bpm}, 4 / 4, \mathrm{~F}$

3.2 "The lyrics, melody, and production remain mostly unchanged from the afternoon when we first constructed them. The singing was done in one take. Inspired by our mutual obsession with "Doctor Who," broad, late-70s/early-80s inspired software-synthesizers are used throughout. This culture concludes with a bassoon and bass clarinet playing quartal phrases, treated with iZotope's free vinyl plug-in to mimic the sound of an old record. The scream was heavily contested-Trumey felt it should only happen once, Shanny thought it should happen for four or five minutes; we settled on repeated iterations that grew steadily more distorted through a ring-modulator and, thus, less scream-like. The lyrics are a diffractive walking-with philosophers Donna Haraway and Karen Barad (who Trumey was reading) and Missy from Doctor Who (who Shanny kept quoting)."

4.0 Cruel Bliss (Sweet Pain)

$4.170 \mathrm{bpm}, 4 / 4, \mathrm{C}$

4.2 "This is the first culture that we wrote, and the last to be finished. We took an impression of the song with us on the walk, including a melody and chord sequence that we had earlier explored on guitar and piano. We later added a sizeable sampled string section, digital static, chinking glass sounds from our walk, and fourteen separate software-synthesizers. Our original vocal takes (sung into the tablet mic) are still incorporated into the song as backing lines, and after the first chorus; the lead vocals were re-performed by our old friend Luke Jennings, who also added electric guitars. As a proposition for further thinking, the guitars enabled the song to carry additional instrumentation, including taiko drums and field toms, a drum kit, and a bass guitar line. Finally, we added a Cyberman voice to the start of the song saying "I waited for you" through a ring-modulator in reference to the ill-fated Ms. Bill Potts. Some of the synthesizers operate on algorithms that continue to run regardless of whether or not the play-button is held. Derrida and other post-structuralists, as well as sonic methodologists, 
have attended to how meaning is always deferred in a text, and the purity of a sounding is always changed by the vibrational media (e.g. Gershon 2017). Even accounting for this, "Cruel Bliss (Sweet Pain)" is materially different every time it is played, with the performance bounced for distribution, only one of innumerable possibilities. Due to this, we haven't been able to recreate our favorite bounce of the song."

5.0 Hurry Up Lover, and Love, The Days Grow Short

5.1127 bpm, 4/4, NA

5.2 "Uses the original voice recording (hence its relative poor quality). We cut up a single recording of the voice and deployed it to accentuate the natural rhythms in the recording. The lyrics are a proposition."

6.0 Three Black Military Helicopters

6.1 138 bpm, 4/4 \& 3/4, C

6.2 "The name of the song comes from the unexpected presence of three black military helicopters on the widest vista of the walk, Wide-Open Hill. It uses an arpeggiator and disorienting lyrical and time signature changes."

7.0 All

$7.186 \mathrm{bpm}, 4 / 4, \mathrm{C}$

7.2 "The major pentatonic scale, from which we construct our melody, uses the first five tones heard when sounding consecutive intervals of a fifth (five tones apart) from the first note of a key (C, G, D, A, E). These tones are then rearranged within one octave; in our song this produces the tones C, D, E, G, A. George Russell (1953/2001) argues that the fifth is the second most open-sounding interval (after the octave) due to its placement in the overtone series-where the doubling of the frequency of a tone produces an ever-darkening series of intervals. We "riff" on this, by flattening the third during the English translation. This changes the sequentially fifth interval from a fifth (A, E) into a tritone (A, $\mathrm{Eb})$; an interval historically banned by the Church for its satanic qualities. We also include seal-songs sampled during the Pilgrim's Path mud walk during the culture's concluding A Capella section. The lyric hook is from a sad phrase Trumey overhead in Nanjing, China many years ago that has always haunted her."

\subsection{Friend}

8.1 $180 \mathrm{bpm}, 4 / 4, \mathrm{Bb}$ minor

8.2 "The culture begins only using 8-bit parts, recreated using the free YMCK Magical 8-bit digital synthesizer." 
9.0 Deary, Feary, Queery

$9.1120 \mathrm{bpm} .4 / 4, \mathrm{Bb}$

9.2 "Includes samples of footfalls recorded during the walk. The coda lyric is performed falsetto, digitally tuned down to create an impossible voice. The lyrics are inspired by marching along St. Cuthbert's Way and trying to sound like a fisherman's song."

Bonus: Ice-pick In My Eye

120 bpm. 4/4, F

"Written during the process of writing this article in Coimbra and Lisboa, Portugal in March 2018, the culture playfully teases some of our favorite theoretical concepts, including, inevitably, our own concept of the icepick. We hope you will take it with you."

\section{Acknowledgements}

We would like to thank our blind peer-reviewers (who chose to reveal themselves as part of the peer-review process) Lone Bertelsen and Isabel Waidner for their helpful feedback. We would like thank Stephanie Springgay at WalkingLab for her piercing insights throughout this project. Finally, we would like to thank St. Cuthbert for leading us past abandoned Abbeys and speckled spires, verdant mornings, and lilac hillcrests. And we would like to thank whoever invented the Theremin.

Because of the success of this research-creation project, we have continued making music together and plan to release an album under the band name Oblique Curiosities later in 2018. Some of these sonic cultures will be on the album.

\section{References}

Ahmed, S. (2004). The Cultural Politics of Emotion. New York, NY: Routledge. Ahmed, S. (2010). Happy Objects. In M. Gregg \& G.J. Seigworth, eds., The Affect Theory Reader. Durham, NC: Duke University Press, 29-51.

Barad, K. (2007). Meeting the Universe Halfway: Quantum Physics and the Entanglement of Matter and Meaning. Durham, NC: Duke University Press. 
Berlant, L (2010). Cruel Optimism. In: Gregg M. \& G. Seigworth, eds., The Affect Theory Reader. Durham, NC: Duke University Press, 93-117.

Bertelsen, L., \& Murphie, A. (2010). An Ethics of Everyday Infinities and Powers: Felix Guattari on Affect and the Refrain. In M. Gregg \& G. J. Seigworth (eds. The Affect Theory Reader. Durham, NC: Duke University Press, 138 - 157.

Clare, E. (2001). Stolen Bodies, Reclaimed Bodies: Disability and Queerness. Public Culture, 13 (3), 359-365.

Davis, B., Sumara, D., \& Luce-Kapler, R. (2008). Engaging Minds: Changing Teaching in Complex Times (2nd Ed.). New York: Routledge.

Gallagher, M. (2015). Field Recording and the Sounding of Spaces. Environment and Planning D: Society and Space, 33 (3), 560-576.

Gallagher, M. (2016) Sound as Affect: Difference, Power and Spatiality. Emotion, Space and Society, 20, 42-48.

Gershon, W. (2017). Sound Curriculum: Sonic Studies in Educational Theory, Method, and Practice. Abingdon:Routledge.

Goodman, S. (2012). Sonic Warfare: Sound, Affect and the Ecology of Fear. Cambridge, MA: MIT Press.

Griffiths, H. M., Salisbury, E. Tooth, S. (2018). "May God place a bridge over the River Tywi:" Interrogating Flood Perceptions and Memories in Welsh Medieval Poetry. In G. Endfield \& L. Veale, eds., Cultural Histories, Memories and Extreme Weather. London: Routledge.

Halberstam, J. (2005). In a Queer Time and Place: Transgender Bodies, Subcultural lives. New York: New York University Press.

Kafer, A. (2013). Feminist, Queer, Crip. Bloomington, IN: Indiana University Press.

Knowles, C. (2008). The Landscape of Post-Imperial Whiteness in Rural Britain. Ethnic and Racial Studies, 31(1), 167-184.

Lang, S. (2018). Gammon Race Row: Why British Twitter is Boiling Over About a Meaty Slur [Online]. The Independent. Available at https://www. independent.co.uk/news/uk/politics/gammon-race-row-twitter-brexit-ukpolitics-ukip-a8353836.html [Accessed 5th July 2018].

Lara, A. Liu, W., Ashley, C. P., Nishida, A., Leibert, R., \& Billies, M. (2017). Affect and Subjectivity. Subjectivity, 10 (1), 30-43. 
Lorimer, H. \& Wylie, J. (2010). Loop. Performance Research, 15 (4): 6-13.

Luciano, D. \& Chen, M. Y. (2015). Introduction: Has the Queer Ever Been Human? GLQ: A Journal of Lesbian and Gay Studies, 21(2).

MacLure, M. (2010). The Offence of Theory. Journal of Education Policy, 25 (2), 277-286.

Manning, E. (2009). Relationscapes: Movement, Art, Philosophy. Cambridge, MA: MIT Press.

Manning, E., \& Massumi, B. (2014). Thought in the Act: Passages in the Ecology of Experience. Minneapolis, MN: University of Minnesota Press.

Massumi, B. (2015). Politics of Affect. Cambridge, MA: Polity Press.

McCormack, D. P. (2008). Thinking-Spaces for Research Creation. Inflexions, 1 (1).

Muñoz, L. (2010). Brown, Queer, and Gendered. In K. Browne \& C. J. Nash, eds., Queer Methods and Methodologies: Intersecting Queer Theories and Social Science Research London, UK: Routledge, 55-68.

Murphie, A. (2016), ed., The Go-To How To Book of Anarchiving. [online]. Montreal, QC: SenseLab. Available at: http://senselab.ca/wp2/wp-content/ uploads/2016/12/Go-To-How-To-Book-of-Anarchiving-landscapeDigital-Distribution.pdf. [Accessed 1st April 2018].

Puar, J. (2007). Terrorist Assemblages: Homonationalism in Queer Times. Durham, NC: Duke University Press.

Puar, J. (2012). "I would Rather be a Cyborg than a Goddess:" BecomingIntersectional in Assemblage Theory. philoSOPHIA, 2 (1), 49-66.

Puar, J. (2017). The Right to Maim: Debility, Capacity, Disability. Durham, NC: Duke University Press.

Rennie, T. (2014). Socio-Sonic: An Ethnographic Methodology for Electroacoustic Composition. Organised Sound, 19 (2), 117-124.

Russell, G. (1953). The Lydian Chromatic Concept of Tonal Organization. Reprint. Brookline, MA: Concept Publishing Company, 2001.

Seigworth, G. J., \& Gregg, M. (2010). An Inventory of Shimmers. In M. Gregg \& G. J. Seigworth, eds., The Affect Theory Reader. Durham, NC: Duke University Press, 1-25. 
Springgay, S. and Truman, S. E. (2016). Stone Walks: Inhuman Animacies and Queer Archives of Feeling. Discourse: Studies in the Cultural Politics of Education, 36 (6), 851-863.

Springgay, S. and Truman, S. E. (2017). A Transmaterial Approach to Walking Methodologies: Embodiment, Affect, and a Sonic Art Performance. Body E Society, 23 (4), 27-58.

Springgay, S. \& Truman, S. E. (2018a). Walking Methodologies in a More-thanHuman World: WalkingLab. London: Routledge.

Springgay, S. and Truman, S. E. (2018b). On the Need for Methods Beyond Proceduralism: Speculative Middles, (In)Tensions, and Response-Ability in Research. Qualitative Inquiry, 24 (3), 203-214.

Springgay, S. \& Zaliwska, Z. (2017). Learning to be Affected: Matters of Pedagogy in the Artists' Soup Kitchen. Educational Philosophy and Theory, 49 (3), 273-283.

Stewart, K. (2007). Ordinary Affect. Durham, NC: Duke University Press.

Stewart, K. (2011). Atmospheric Attunements. Environment and Planning D: Society and Space, 29 (3), 445-453.

Thrift, N. (2007). Non-Representational Theory: Space, Politics, Affect. New York, NY: Routledge.

Tooth, S., Viles, H., Dickinson, A., Dixon, S., Falcini, A., Griffiths, H. M., Hawkins, H., Lloyd-Jones, J., Ruddock, J., Thorndycraft, V. R., Whalley, B. (2016). Visualizing Geomorphology: Improving Communication of Data and Concepts Through Engagement with the Arts. Earth Surface Processes and Landforms. 41, 1793-1796.

Truman, S. E. (2016). Becoming More than it Never (Actually) Was: Expressive Writing as Research-Creation. Journal of Curriculum and Pedagogy, 13 (2), 136-143.

Truman, S. E. \& Shannon, D. B. (2015). Queer Sonic Cultures [Online]. WalkingLab. Available at: https://walkinglab.org/portfolio/queer-soniccultures/ [Accessed: 29 March 2018].

Truman, S. E., \& Springgay, S. (2015). The Primacy of Movement in ResearchCreation: New Materialist Approaches to Art Research and Pedagogy. In M. Laverty, \& T. Lewis eds., Art's Teachings, Teaching's Art: Philosophical, Critical, and Educational Musings. New York, NY: Springer, 151-164. 
Vannini, P. (2015) ed., Non-Representational Methodologies: Re-Envisioning Research. New York: Routledge.

Weheliye, A. G. (2005). Phonographies: Grooves in Sonic Afro-Modernity. Durham, NC: Duke University Press.

Weheliye, A. G. (2014). Habeas Viscus: Racializing Assemblages, Biopolitics, and Black Feminist Theories of the Human. Durham, NC: Duke University Press.

Whitehead, A. (1978). Process and Reality (corrected ed.). New York, NY: Free Press.

Wylie, J. (2005). A Single Day's Walking: Narrating Self and Landscape on the South West Coast Path. Transactions of the Institute of British Geographers, 30 (2), 234-247. 


\section{ICE \\ POSTIUMANISM AFFECT TIIEORY \\ ONTOLOGY \\ NEW MATERIALISMS}

\section{ASSEMIRLAGE \\ AGENGEMRENT}

IGE口PICR!

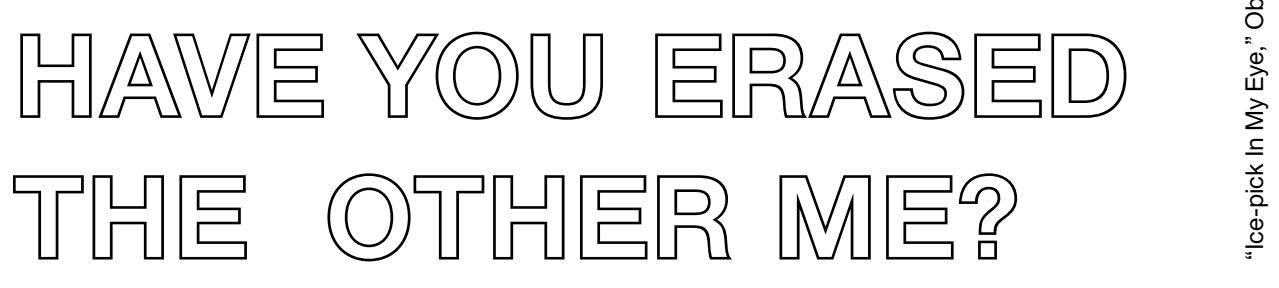




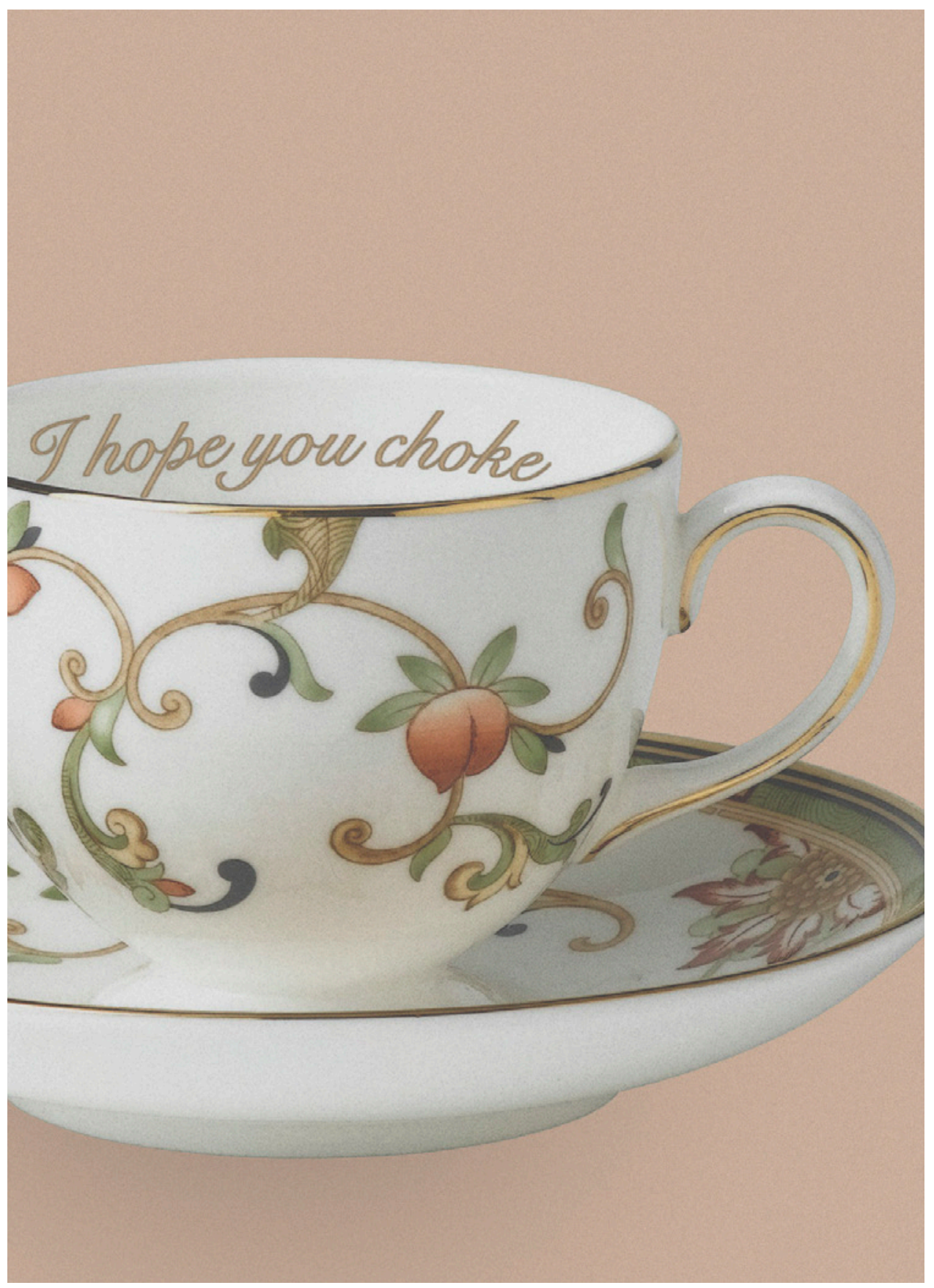

Wedgwood Oberon Leigh Flora teacup in the style of 'rude teacups' from Etsy Creative Commons Attribution 4.0 (CC BY 4.0) 


\section{GOOD MORNING I 877. SIT DOWN: ON CIVILIVY. REGONSIRUCION. AND OUR REVANCIIST MOMENT} Kyla Wazana Tompkins and Tavia Nyong'o POMONA COLLEGE AND YALE UNIVERSITY

Tavia Nyong'o and Kyla Wazana Tompkins' "Eleven Theses on Civility" blogpost to the journal Social Text (July 11, 2018) offers a bracing and pithy set of provocations around the political aesthetic of civility that is completely convincing in its capacities to distill and dismantle the race-/class-/sex- and other normative parameters ( "the affective shape of administrative violence") of this discourse. Their post has been widely circulated and deservedly so.

When Kyla messaged me to say thanks for signal-boosting their theses on the Capacious Facebook page, she added that she'd just read the dialogue between Kate Hayles and Tony Sampson published in the second issue of Capacious-and that she and Tavia had been engaged in a months-long email exchange since the day of Trump's inauguration, culminating in their Social Text posting. Needless to say, I immediately asked for a peek: all with an eye toward seeking permission to share their epistolary to-and-fro with our readers. Such a boundary-testing, room-making conversation between two established scholars working in or around affect studies fits precisely with what will continue to be a special feature (a 'dialogue') in every issue of Capacious. 
So in what follows you will encounter the fuller backstory that bled into those eleven theses on civility: unspooling with historically informed urgency, sounding out and perpetually refining each other's theoretically-nuanced readings of our contemporary and quite perilous conjuncture, exploring the stakes for all kinds of political/affective investments and disinvestments, threading the matter of race through the entirety of their conversation as the absolutely visceral register for any and every moment of coming cultural transformation in the body-politic as a whole. We could not be more excited and honored to publish this vital dialogue between Tavia Nyong'o and Kyla Wazana Tompkins in Capacious!

P.S. One more thing: keep an eye out for Tavia Nyong'o's Afro-Fabulations: The Queer Drama of Black Life coming out on NYU Press in November.

- Greg Seigworth, co-editor of this journal

\section{KYLA AND TAVIA}

We wrote this dialogue across 2017 as a political crisis unfolded. In it we explore a term-civility-that we felt was being reshaped under the new political imperatives (the new 'crisis normal') of our present moment. In the following dialogue we ask: Why does civility seem like a pressing term to consider? What tools can we, as scholars of race, sexuality, and performance, in the United States bring to this current moment? And then too, what new pressures are being brought to bear on this term as the political sphere undergoes a traumatic explosion of uncivil affect? Is civility useful? Is incivility? What are their paradoxes or alternatives?

We are both trained as scholars of performance, race, and sexuality in the nineteenth-century United States. What we come to decide in this dialogue-particularly at this key moment of the twentieth anniversary of Saidiya Hartman's Scenes of Subjection (1997), is that the parallels between our moment and in the period following the failure of reconstruction in 1877 feel both real and illuminating as a way to parse the election of 2016, and to think about what is ahead of us as we try to survive, resist, and think beyond the Trump-Pence years.

Taking up civility and incivility as an aestheticized affect that recurs across histories of race, class, and governance in the United States, we ask: given civility's contemporary resurgence as a term punitively applied to leftist speech and activ- 
ism while institutions support right-wing speech's stated desire to be 'academically freed' of left aesthetic imperialism under the guise of 'political correctness,' what do these terms offer us in the shape of future politics?

\section{Part one: civility in relation to the present political moment}

\section{KYLA}

Tavia, you had a throw-away line at your amazing 2017 MLA talk on a panel with Zakiyyah Iman Jackson and Kimberly Juanita-Brown revisiting "Saidiya Hartman's Scenes of Subjection at Twenty," in which you said you were interested in thinking about civility, and I caught the line and I wanted to take you up on it and see what you're thinking about.

I've been interested in civility for a while on a number of levels. I've become interested in civility as a mobile disciplinary discourse that is enacted against political dissidence and, of course, unevenly applied according to class and race and gender and so on.

Much of my interest, of course, comes from my research into the early Progressive era. In my current work I explore the notion that civility is a bureaucratic aesthetic that functions politically while simultaneously pretending to be neither political nor aesthetic but rational. In short, I'm trying to think about the birth, in the progressive era, of what Dean Spade (2015) later comes to call administrative violence. In that sense-basically a Rancierean understanding of civility as a covert political aesthetic, or even a rhetorical mode which guards the boundaries of access to politicity-civility is about naming the secret affective agreements of administrative biopolitical governance as they get instantiated in the name of civil rights, regulatory law, and the infusion of scientism and social scientism into the project of governance during the Progressive Era. And what is fascinating to me is that what I am calling civility goes hand in hand with federal-level solutions to the failure of the post-emancipation, Reconstruction project. This is not to condemn Progressivism as Bad; I'm not trying to be simple-minded here. Rather, I'm asking about the deeply encoded forms of classed and race violence found in the heart of progressivism that might in turn lead to its undoing. In short, how is the civility of progressivism also a form of violence?

I'll just say, by the way, that I also wonder, as I begin this conversation with you on the day of Donald Trump's unbearable inauguration, whether a critique of civility is hopelessly out of date. Like: 'wow! I have a critique of liberal goodwill?' How warm and comforting the moment in which I conceived of my project seems 
from this moment, in which the stakes of the political just blew through the roof. Like, I wish the imperfections of the New Deal were our biggest problem. But on the other hand, what I'm trying to get at in this project is the ongoing refusal of the respectability project that underlies small-p progressivism-almost every form of progressivism-to allow for actual substantive change within left politics: that is to say, that I experience or have witnessed the civility of progressivism as a kind of active political negation based in certain kinds of classed aesthetics. That negation, for me, often happens at the level of aesthetic judgement about the discordant wrongness of being, or refusing legitimacy to, what are perceived as bad subjects or subjects acting 'in bad form.'

In short, I'm frustrated with the inability of the left (and I direct this at myself as well) to really listen to people where and how they really are, in the bodies and voices and registers they arrive in; I'm pissed at the Clinton campaign and the Democratic Party for abandoning all working-class people, not just whites; and I really feel like that abandonment contributed to the insane results of the last election, in which the sheer performance of Trumpian incivility just smelled and tasted like change to people who really want change. But how to line up that critique with a moment in which, as you said in your talk, the revanchist-amazing word-politics of the moment are coming at us via an avatar of incivility?

In terms of your own interests, can you tell me about the sites at which an idea like "civility" connects with or demonstrates what we want to call "politics"? What is civility to you? Why does it feel like a pressing term to you at this political moment? Why do you think incivility has so much traction right now? And then can you elaborate on your engagement with the term vis-à-vis Scenes of Subjection?

\section{TAVIA}

I can see that we have been grappling with some of the same questions and problems. In the MLA talk you refer to, I was responding to what I have perceived to be the overemphasis on reading the first half of Scenes of Subjection, sometimes an overemphasis on just its famous opening lines, which as you know contain Hartman's injunction against the casual reproduction of scenes of torture and violence under slavery in scholarship. To this day, we are sometimes under an injunction that sees all depictions or descriptions of black suffering and/or death as uniformly problematic, as opposed to always needing an effort of contextualization. The emphasis on reading the problematic of the first section of Scenes-the problematic Hartman terms the "Formations of Terror and Enjoyment"-has par- 
tially obscured the fact that half of the book is not about slavery but rather about the afterlives of slavery, specifically the postwar reinvention of white supremacy through segregation, debt peonage, and racial terror.

With this second half of Scenes-titled with pointed irony "The Subject of Freedom"-in mind, my MLA remarks were especially focused on the final chapter: "Instinct and Injury." Hartman analyzes here the post-war deployment of the concepts of white "instinct" and "natural affinities" as part of how the preservation of white supremacy was justified in the wake of the "injury" of civil war. This section, I suggested, should be required reading in a post-Obama political landscape. On the 20th anniversary of Hartman's text I was calling reader's attention to her analysis of how the freedwomen and men were framed as indebted to the white race for their freedom; how whites experienced emancipation as an injury to their prior enjoyment of supremacy; and how quickly and imaginatively they sought to rebuild it upon new foundations.

As I've written elsewhere, "natural born" white citizens (contrasted in the white supremacist imaginary with blacks whose citizenship had been granted by the Fourteenth Amendment) had to rally around their innate and instinctual dignity so as to prevent the ruinous leveling of "practical amalgamation" and "social equality," terms which took on new meanings in the postwar period (which also invented "miscegenation" discourse as we came to know it, as Elise Lemire amongst others have written). Basically, freedom and citizenship were held to be contingent upon segregation and the legal prohibition of "miscegenation." This is where I pick up the story of civility. "Civility" was racialized from the start as a formula for preserving the freedom of the white race. But freedom as Chandan Reddy reminds us, never precludes violence. Ritualized and legitimate violence, often outside the law, could paradoxically be the first resort for defending this civility. The deep history of what Reddy calls "freedom with violence" (as opposed to the "freedom from violence" that liberal civility claims to extend) is key in this decisive period.

In my MLA talk I also called for resituating Scenes of Subjection within a cluster of books from that same period that include Robert Reid-Pharr's Conjugal Union and Amy Dru Stanley's From Bondage to Contract. What reading Hartman together with these other scholars reveals is, above all, the pertinence of change over time as something other than 'progress.' I want to push us to think categories like freedom, citizenship, civil rights, and civility not as ideological ruses, or not simply as ruses, but also as densely historical fictions that produced real effects that have to be grappled with. We don't just live in the afterlives of slavery, after all, we also live in the afterlives of freedom and citizenship. The paradox is that all 
these afterlives are so ambiguous in terms of what they bequeath to the present. And yes, what an awful conjuncture within which to try to think about these questions! But to push back a little on your closing implication that the topic you have proposed feels out of date in the age of Trump: I think to the contrary, that the newfound politicity of rudeness or rancor (or whatever the opposite of civility is) only underscores the ongoing relevance of the set of historical questions you have so ably outlined for us. If what Ranciere calls politicity can be thought in terms of the libidinizing of politics, a cathexis that is always interruptive of the placid and in fact dull norms we call 'civil,' then perhaps we can pose the problem you are presenting as one of politics without civility.

I'm a little fearful at the enthusiasm with which I see politics now embraced as a kind of sporting event and media spectacle, an embrace which I associate from my own experience growing up in postcolonial Africa, not with democracy but with authoritarianism (just as I experienced the upsurge of "show of force" armed police after 9/11 in New York not with greater security, but actually as a tacit admission of greater insecurity). Under authoritarianism, knowing the codes of civility was a life or death matter for everyone, and profanity, rancor, and rudeness held an explosive capacity they seem to lack in America's much more raucous and bawdy culture. So, I may not be as reluctant as you to take refuge in civility's affordances (even the affordance or privilege of being able to say, not everything is politics). I take this to mean that there will be now, and for the foreseeable future, a certain libidinal saturation of the political, akin to masculinist investments in sports and war. I guess this is the first sense in which I am not the only one to characterize our moment as "revanchist."

But what sort of libidinal politics are we faced with? I hear two possibilities in your opening propositions: the first being that the politics of 1877 (coincidentally Rutherford B. Hayes victory in the 1876 election was another time the loser of the popular vote nonetheless took the electoral college). That victory led to the end of Reconstruction and the triumph of white revanchism. The avatar for such a politics today is probably Steve Bannon or Stephen Miller. The other possibility, the politics of 1933, offers a sort of pre-emptive challenge to your own critique of mainline US progressivism and its accompanying politics of uplift and respectability. The avatar for such a politics today is undoubtedly Bernie Sanders. If the New Deal is our high-water mark for welfare state progressivism (despite all we know about the racial bias of the welfare state, as recounted by everyone from political scientists like Ira Katznelson, to journalists like Ta-Nehisi Coates), what is the purpose of a critique of civility? Does it matter if we are dealing with revanchist racists, color-blind liberals, or both at the same time? 
When you ask about the uses of civility and incivility today, I think about that dramatic moment of the campaign, when Black Lives Matter activists "rudely" interrupted a Sanders speech (I think the accompanying social media hashtag, hilariously, was \#BowDownBernie), temporarily infusing the preferred scenario of the New Deal bitter enders with some "black girl magic." Without taking ideological sides in that particular confrontation, reflecting back upon it now, it does seem to provide a kind of dialectical image for the present conjuncture: \#BowDownBernie was a clapback against resurgent social democracy seeking to politically represent and speak for black movements against state and vigilante violence, but also a calling in of Sanderistas to a renewed engagement with the ethical critique of the movement for black lives (different, at any rate, from the Clintonistas and their cynical deployment of "intersectionality" as a cipher for neoliberal multiculturalism). That Sanders' moment of potentiality and emerging strategy culminating in the upset victory of a rightwing candidate promising law and order and presaging a threatened clampdown on the rights of even nonviolent demonstrators, should not cause us to lose site of the promise of this robust disruption of civil politics by black feminist righteous discontent.

To return to the burdened subject of freedom-which you ask us to think of in terms of an aesthetic of governmentality-that is precisely what I am also seeking in a reading of the second half of Scenes. The other scene of black subjection, if you will. On the subject of this scene of civility, I read Hartman to be arguing that post-bellum white revanchist politics are driven by sentiments of racial injury, resentment, vengeance, anger, and humiliation. Racial democracy is actually experienced as a humiliation of white settler futurity. The deep, historical origins of what we now call "toxic white masculinity" may lie here!

And if we had to identify your aesthetic form of governmentality, one that concretized this double bind of civility and rudeness, we could do little better than consider the dominant popular culture of that period: blackface minstrelsy. In minstrelsy, after all, black incivility redounds to the political detriment of the race, while homeopathic elements of that same incivility in blackface can actually enhance the authenticity of white herrenvolk democracy. Read politically, at least, the rough music of blackface entailed borrowing a rude and vulgar vitality attributed to the black for purposes of libidinizing white cultural politics, in such a way as to render those resources absolutely toxic for the would-be black political actor. I struggled to articulate this in my chapter on "minstrel trouble," in part because I did not follow out the progression of the form, as I would now like to, into the post-bellum decades. But that work was already accomplished, I think, by Michael Rogin! 


\section{Part two: civility and questions of academic freedom relevant to the current political crisis}

\section{KYLA}

Let's talk about the pushback to so-called political correctness, which is terrifying on the one hand but also, I think, the return of U.S. anti-intellectualism but with the gloves off. I mean I'll just say that I live in an institution that has a civility clause in its faculty handbook, reserving the right to evaluate someone on "how they get along with others" and incivility is absolutely the term, locally, that I see applied to any kind of internal dissent. And as I talk to colleagues across the country I hear particularly women of color, but also others, saying: I'm told I'm too aggressive. So, the dislike is obviously political, but it is generally phrased as an aesthetic evaluation: too pushy, too outspoken, discordant etc. It's not what you say but how you say it! Couldn't you ask more nicely? What I see you pointing to in the confrontation between BLM and the Sanderistas is a strategic deployment of uncivil disobedience toward the reshaping of leftist civil politics: a calling out that is a calling in as you elegantly say.

But the paradox here is that the resurgence of white nationalism as a cultural formation, as you key into what you've already said about the relation of white supremacy to settler colonialism, is also organized around incivility, albeit one with a different genealogy. The freedom to be rude! The freedom to express oneself? So white incivility is freedom, but brown and black incivility is violence. It must be Tuesday.

Here again I want to return to the point that civility is an aesthetic mode, within which regulatory models coercively operate, that feels like unfreedom. And I think that we really need to think about the fact that whether on the left or on the right, many of us are agreed on that point even as we are diametrically opposed in our political desires. We want to be free to say the thing we want to say that seems true to us. We want to be less disciplined, less regulated. And yet: regulation is the mode in which small-p progressivism and large-P Progressivism meet to ascertain that change will happen; formalized comportment agreements are what have historically been put in place to structure protections against violence. 
Adjacently then, we are talking about infrastructure and process, both of them the gum and the gunk in the gears of the dream of friction-free capital as well as efficient and immediate Fascism. Which brings me to another sense of the word civil: that of the civil service. Because like many people I am counting on the work of longtime civil servants, Mueller, the EPA, the scientists, and others to slow the violence of this rank government down. The revenge of the mid-level bureaucrat! The mid-level bureaucrat who is paradoxically one of the symbols, as far as I can tell, of this other new figure of political critique, the microagression. Because if you've ever had to apply for welfare, as I had to when I was in graduate school in Canada, or engage the state and ask for help in any way, you know that that dude, or that lady, sitting between you and what you need is the person who can make the whole thing feel like an exercise in shame-an aesthetic of affective violence-or the moment of respite you are entitled to before you can gather your resources again. In short, we are relying on the very people whose limited sites of agency and evaluation are often the sites where survival is or is not determined, or alternately, where daily grinding indignity is meted out.

Imani Perry said something on social media the other day that really struck me: she said that this moment of the criticism of identity politics in the name of political correctness is actually sublimating the really good critiques of identity politics, which do exist. So, just to try out a thought: what if these conjoined sites of critique, from left and right, are simultaneously a call for a different aesthetic form of governance? Where does that leave us in thinking about how infrastructure, process and regulatory governance?

\section{TAVIA}

I think a parallel to Imani Perry's comment about identity politics could be made. Just as the right-wing attack on identity politics makes us all defend it in public, however nuanced our classroom or written critiques. Similarly, the right-wing pushback against campus sexual harassment politics has made it more difficult to surface the queer and feminist critique of the limits of Title IX. So, for instance, at least one critic of Laura Kipnis, Ann Stoler, has gone so far as to accuse Kipnis of collaborating with right-wing opponents of feminism. While there are many zestful instances of profane and inspiring feminist publicity pushing back against patriarchy-from the Slut marches to protest signs reading "Pussy Grabs Back"-it still remains to be seen if this call for a "difference aesthetic form of governance" as you call it won't settle for good old repression as a response to so many abuses of power. 


\section{Part three: multiple temporalities we are working in; the importance of thinking through the present in relation to the post-reconstruction period}

\section{KYLA}

Maybe this is a moment to clarify how we are thinking about the multiple temporalities within which we are writing and here I'm reminded of my text to you on the morning of the Trump inauguration: "good morning 1877, sit down." We are both thinking about the crisis of the Trump election and the rise of rightwing and white nationalist politics via our understanding of the post-1877 period; I hear us both saying that the critique that Hartman levels at reconstruction politics is the critique to be leveled at Obama/Democrat politics and is also a critique to be leveled at the basic terms of U.S. historiography, which seeks to laud those precious twelve years between 1865 and 1877 as the years in which we almost had it right. But actually, that moment already had, and fundamentally contained the seeds-the trace! — of its own undoing.

I'm going to take a moment to stake my own argument here, for the importance of a return to historical work in American Studies and in other interdisciplinary sites, which we obviously share and which you named above as the need to think "conjuncturally." There is so much great interdisciplinary historical work happening now, around re-reading the archives of slavery, around resurrecting moments of failure and political defeat in the name of excavating possibilities for future freedom. But much of it is happening from people living in disciplinary homes. And it drives me somewhat mad that-and excuse me if this seems like an overstatement-somehow work on any period prior to 1950 has to be relegated to particular disciplinary piles, like Literature or History, and rarely finds a foothold in the sites where we are doing our political thinking, like Ethnic Studies, Performance Studies, Gender Studies or American Studies. The presentism or even immediatism of those sites, by which I mean a tendency to prioritize the contemporary period, is, it seems to me, a missed opportunity to deepen critique by thinking across periods. And for me, the urgency with which it seems to me we have to return to the post-1877 moment, in order to excavate the festering traces of this moment, and the foreclosed possibilities of that moment, only testifies to that.

Following your lead in returning to Hartman's prescient critique in Scenes: what do you think of the moment in the opening sections of the chapter called "Instinct and Injury" when she is taking up the apparently liberal Louisianian author 
George Washington Cable-one of the vaunted "nice white guy" authors of nineteenth-century literary studies, alongside Mark Twain and Herman Melville-on the totally loopy terms of his opposition to segregation. In the essays she cites Cable as arguing against segregation as it was upheld by the Supreme Court's 1883 overturning of the Civil Rights Act of 1875. But Cable's argument is this:

Cable argued that the separation of the races presumably necessitated by the danger of the black presence in fact resulted in a far greater danger-the commingling of the upper ranks and the lower orders imposed by the color line.[...] Instead Cable advocated the "just assortment" of refined and uncouth elements indifferent to color, thereby displacing issues of race and class with those of decency and refinement....[He] advocated the policing and normalization of the abhorrent and degraded lower orders, primarily because of the danger they posed-"the fear that the stupid, the destitute, and the vicious [would] combine against them [the upper ranks] and rule by sheer weight of numbers (165-166).

Hartman then says:

what is interesting here is the displacement of race as the central question of the social qua social and the recommendation of a more encompassing and, dare we say, nefariously "egalitarian" mode of social incarceration targeted at the lower classes...Cable hoped that the abolition of invidious racial distinctions would lead to a social order structured by preferences and affinity and, of course class differentiations (166-167).

I'm skipping a lot here. But I think that what Hartman is saying in this chapterabout what she comes to call the "social"-is that the shell game of racial biopolitics under liberal capitalism is that it, in actual fact, polices and produces the space of the private, understood here as the "social" and therefore the apparently "personal," all the while claiming the social/private to be unregulatable and thereby leaving racism intact. So then, what is aversive-the uncouth, the unwashed, the unpropertied-is a personal thing, and indeed the Supreme Court used ideas of the private to protect new state laws and step away from regulating aversion. And this is what makes a decision like Plessy, enforcing segregation as long as it happens between putatively "natural" differences, possible.

Admittedly, Cable's logic is a bit eccentric to the period so maybe we don't want to work from there without reservation. But I think what's key here is that Hartman builds her analysis of this space she calls "the social" out of a critique of a socalled progressive agenda. In short, the point for me here is that even progressive politics have also been undergirded by a hygienic policing of bodies-what she calls bourgeois civility - that almost but not exactly mirrors the less polite racisms (you elegantly call it "a readiness to violate those norms") which is a formulation I want to think more about; on her blog and, in her Social Text piece, Lauren Berlant (2017) called it "the feeling of being free" of the "other side" of the political equation. 
So, if we are working towards a definition of civility, perhaps civility is about the extra-legal calcification of the lines of aversion which undergird the organization and local practice of the juridical and the biopolitical. I mean, there's an aesthetic logic resting behind the fact that "reasonableness" is a key legal concept; because any other approach is uncouth.

This brings me then to my second point, and that's where I'll stop. My question at this second moment is this: is Hartman's idea of the "social" analogous to, or correlated to, what you are calling "culture" above, when you cite Benjamin? And can you elaborate on what you mean when you say the left must respond by making culture political again? But also, am I saying that the left is the problem, and are you saying that the right is the problem, and aren't both of those things true? Obviously, both are true. Are we "genre-flailing", as Lauren so beautifully put it?

\section{TAVIA}

No doubt we are "genre-flailing," if by that term we understand Lauren to be calling attention to the necessary, and necessarily improvisatory, work of struggling for ways of getting out of the current deadlock and into a new conjuncture, by means of genre. I'm unafraid of genre-flailing, which is what I understand Benjamin's open-ended dialectical conclusion to have been about. No doubt "communism" was as uneasy a genre for him to rest in as it is for us here and now. The genre of the academic conversation we are presently engaged in, thinking together and across each other's critical terms and investments, is one sign of the productivity of this flailing (although that is for the reader to judge).

Another sign of our flair for the flail, I think, is the spectacle of two nineteenth-century scholars trying to "build a bridge to the nineteenth century" by discovering the origins of the present crisis in the unfinished work of reconstruction. But why not embrace that contradiction? A flail is, after all, just a self-deprecating word used to describe a certain velocity of critical thinking that, perhaps, can take on a sort of self-cancelling quality to it. When we flail it is often because we have tried to, and failed, to hit (the ground running). Instead of landing a telling blow, we have spun around and only further disoriented ourselves. I'm pretty convinced that we are not alone amongst left intellectuals in knowing intimately this kind of "epic flail."

At the same time/rhyme, what Lauren Berlant finds between "fail" and "flail" makes me also hear the word "flair." Can we fail with flair? After flailing around, can we recover a sense of poise? I'm reminded here that Sianne Ngai associates the flail with 
the zany, the aesthetic category she in turn connects to figurations of the mode of production in contemporary capital. While the zany flail is not exactly uncouth or uncivil, I hear you wanting to make a case for some sort of associative diagram of these terms as indexing a class-conscious opposition to demands for civility on liberal bourgeois terms. And I, in turn, am hesitant to believe any diametrical contrast to bourgeois civility will do the trick of negating neoliberal governmentality. Again, I want to think conjuncturally, which may be a punk-ass way of saying, I want to reserve the right to ape civility when it suits me.

And yet I couldn't be more sympathetic to your case, particularly when you bring up Cable's vision of "the social," which does sound for all the world like a nineteenth premonition of the neoliberal multiculturalism that Jodi Melamed so effectively critiques, and that has gone mainstream in the Obama-Clinton mainstream of the Democratic Party. I feel very much in solidarity with your radical discontent about that particular version of civility (for example, we see it in the "love trumps hate" messaging, that attempts to shift partisan rancor into a juxtapolitical realm of niceness and manners: I much prefer "pussy grabs back" and other "rude" replies).

\section{KYLA}

First, I think I might want to push back on the idea-maybe I'm misunderstanding you-that if "civility is a form of violence...we needn't fear it...insofar that civility and incivility are tactics adopted by a range of political actors..." I guess what I might say here is, I am completely in agreement with you in aligning civility with a history that biopolitically polices racial uplift and that thereby undermines the revolutionary potential of reformist movements. But I think the missing term for me here is capital? As in: what is the algebra of race and class [and gender of course, because as Glenda Gilmore tells us, it's black women who form the front line of racial, which is to say community, uplift labor, literally labor because black women are the people who can get actual work and find some political traction during the worst periods of Jim Crow] that makes it impossible for working-class people to organize together across racial lines and against capital. This is not a Pollyanna-ish plea to negate or ignore the material harm of whiteness as a prized possessive investment across Euro-American class lines; nor am I trying to claim a priority to class over race. To be clear, both of those would be bankrupt political positions for me.

But I do really want to say that civility for me is about the embrace of class mobility and therefore about the abandonment of the crucial and necessary work of articulating class and race together as intersecting-I'm citing Crenshaw here on purpose-and simultaneous. And at the same time, I want to say that discursively race and class strategically bifurcate the key demographics-working class whites 
and people of color-in whose united hands the only revolutionary possibilities for the United States actually lay, in the late nineteenth century and in the twentieth [and twenty-first] centuries as well. The concretization of whiteness as a privilege to which working-class whites were happily persuaded to adhere is the greatest political sleight of hand and the worst political disaster that ever happened to the potentialities of the post-civil war moment. Whiteness defeated anti-capitalist and anti-racist revolution, if that revolution was ever going to happen, which it probably wasn't, but let us live as if it were.

But jumping more than one century forward, for me I want to say that the abandonment of labor, the abandonment of the union base-and let's remember how important unions and unionized civil service jobs were to working-class African Americans in the mid-century-was the moment for me when the Democrats, most recently in the form of Hillary Clinton, lost the country. Not that the unions always did it right either. That's when the so-called liberal left lost their location on the left and made this disgusting white and nativist revanchism-the return of this revanchism-possible. Because it's only from radical socialist, which is to say, anti-racist and anti-capital organizing, at the base, that real left organizing can emerge. And what I want to think about is how returning to that base might be an uncivil, or, riffing off of Cathy Cohen's words, a "deviant" interracial and interclass political formation. So in the sense that civility as a discourse is always an anti-working class-understanding the working class to be not only white but also black, immigrant, illegal, queer and otherwise as well-and here I'm thinking about Janet Mock inciting the women's march on Washington to chant "sex work is women's work!" or Rod Ferguson's invocation of the black trans sex worker in Aberrations in Black as the key figure from which to imagine a new historical materialism-from this analysis I am loathe to agree that we should fear incivility in and of itself.

That said, you are so right when you say that you are "hesitant to believe any diametrical contrast to bourgeois civility will do the trick of negating neoliberal governmentality." I suppose I am methodologically experimenting in how far we might take an aesthetic critique, how large we can scale it up. I would like an aesthetically uncivil left based in a critique of racial capital and I think we should counter Trumpist incivility with a different but related incivility-like let's go lower-but also with a politics that builds critique from the theoretical and practical, political and cultural, production of a multi-racial coalition of working-class peoples. And I guess in some ways what I'm talking about here is style: a left with 
an affective style that speaks across class and race demographics. A left that takes up the evacuation of the rational public sphere, what some used to call "politics" (in distinction from what Ranciere would call "the political"), as a question of effective affective political aesthetics.

\section{TAVIA}

Let me take up your proposal to think towards a definition of civility as "the extra-legal calcification of the lines of aversion which undergird the organization and local practice of the juridical and the biopolitical." I think we are talking here about governance through norms and may have a different relation to what may lay outside "the rule of law." I probably need to say that I grew up around a very "call me Mr. Tibbs" version of postcolonial black civility. In that milieu, we employed manners, rectitude, and social ritual as a way of enforcing the equality that white colonizers and ex-colonizers never really wanted to give us. Robert Reid-Pharr's Conjugal Union, which came out at about the same time as Scenes of Subjection, and remains under read, is very good on this point. The postbellum black novel of domesticity imagines "clean houses" and "peculiar people" as a constricting aesthetic of governmentality that is better than the alternative (slavery, impoverishment, madness, "the black outdoors"). This is a proto-class, or class-aspirational ethic as much as it is a class-consolidating norm. We won't get very far, for instance, by miscrecognizing The Garies and Their Friends, as a hegemonic text! Reid-Pharr is perfectly lucid as to what kind of prison this domesticity is (and a version of queer black studies emerges in the sequel to this book, "Tearing the Goat's Flesh," which he later publishes separately in Studies in the Novel, and which is sort of "the part that had not part" in the original dissertation). And yet, in terms of the historical imagination, Reid-Pharr seems unwilling to surrender the possibility that in certain places and times in our history, these counter-civilities have been viable tactics of resistance, survival, or protective coloration.

When I evoked Benjamin's “Critique of Violence," I was riffing off your prior placement of civility within an aesthetic of governmentality. Also proximate to our current discussion, I now realize, might be Homi Bhabha's essay "Sly Civility," an essay where he suggests that one of the stratagems of the colonized is to ritualize the encounters of colonial rule in such a way as to maximize an apparent "symmetry" between their cultures. Wole Soyinka's Death and the King's Horsemen would be an excellent text to consider in this light. Part of the power of sly civility-or could it be counter-civility?-is that it reserves the right to respond to the policing of civility with a range of tactics and stratagems, rather than being baited into the hysteric's posture: why am I who you say I am? In it is one way of saying, to quote Maxine Waters: I am reclaiming my time! 
Let me turn here to what I see happening in your own work on the racial biopolitics of health and queer feeling in the Progressive Era, if I may. Reading your work, I see an afterlife of slavery on view in the white determination to retain the black body as a generator of value and well-being for white supremacy, while rendering incoherent black attempts to lay claim to those social goods of citizenship and the good life. Not to turn constantly to the present regime, but at one point I became curious as to who Donald Trump "follows" on Twitter: of the forty odd accounts when I checked, only one was Latino (conservative commentator Geraldo Rivera), and the black account was authored by a pair of modern day minstrels! That Trump should feel the need to respond to the trauma of a black presidency by turning to this deep restorative fount of racist well-being tells us at least two things: the flagrant quackery and snake-oil salesmanship of this post-truth moment in politics is really anything but new; and: the response of the Clinton-Obama Democratic Party to lump these profane elements into a "basket of deplorables" was elitist to the core.

This is all to say that many days I locate myself within what I understand to be one point of agreement between the afro-pessimism of a Frank J. Wilderson and the undercommons of Fred Moten and Stefano Harney. While these theoretical positions are increasingly presented as incommensurable-in the same way Moten and Hartman were for a long time imagined to be occupying radically alternate positions on questions of subjectivity and resistance-what they share, if one reads The Undercommons and Red, White, and Black in counterpoint, is an unrelenting critique of the manner in which the US sociopolitical order renders blackness pathological. Or to use your terms: renders it unhygienic and unhealthy. I'm not trying to ignore the very real differences and stakes in their positions when I say that, for me at least, this returns us to your opening evocation of Rancierean "politicity": a term that I am finding very helpful to think with if I understand it correctly.

Politicity makes me think of "politesse" and, through that association, to the covert traffic between "politeness" and "politics." I think that is part of the rub here. The undercommons and afro-pessimism both keep returning us to a traversing of the classical fantasy of democratic politics as that activity which is conducted by elites on behalf of the women, minors, slaves, and barbarians who are to be excluded (violently if necessary) from that sphere. The Ancient Greek agora, we might say, was the first site for what Trump now calls "locker room talk." Politics is the kind of words men can use amongst themselves when they do not have to 
fear being overheard, challenged, or clapped back by women and other social inferiors. This is indeed part of what the Marquis de Sade, at the birth of modern democracy, savagely satirizes in his pornographic manifesto "Frenchmen, one more effort if you would be citizens."

\section{Part four: civility as a key site for thinking into and planning beyond the impasse of the political present}

\section{TAVIA}

So, all this is to say: one tension I hear emerging in our conversation is that you keep saying: civility is a ruse, I want to smash civility. And I keep saying: civility is a ruse, and the least civilized are those who pretend and enforce "civility." I want to reserve the right to play along under certain circumstances for certain experimental purposes (no guarantees!) Civility, I think I am coming to believe, is a biopolitics that enforces a certain scandal of the impolitic upon dangerous bodies in advance of anything they say or do. We are always already uncivil because we are always already uncivilizable; white masculinity gets to be rude, savage, violent, wild, whatever, because at the end of the day these behaviors can be construed as renewing or regenerating, rather than serve as disqualifications from, white civilization and supremacy. For instance, we live in a political culture where a former Republican candidate can pick a fight with a hip hop star using excremental language, and the exchange works to demonize black masculinity while confirming white male rhetorical command of a streetfighting idiom.

\section{KYLA}

Oh, man. Back to our texts. At some point in the middle of March 2017 you texted me, "Why is Mike Huckabee helping resuscitate Bow Wow's career? The public sphere has become an episode of Rugrats." And after figuring out what you were talking about-some awful public back and forth between Bow Wow, Snoop Dog and the 44th Governor of Arkansas in which the latter called Snoop "Poop"-I said: "It's all bad reality tv. Like actually the tv has gone inside out and we are in it." And we both wondered: is this the end of politics? And: are they acting out, which you called repressive desublimination or are these nasty little battles serious?

I mean, can you really have a conversation about incivility and not end with poop and dog? Aren't excrement and animality and blackness the limit? And if I'm hearing you right that is what you are saying, about the place of blackness in Western aesthetico-politics and about the ultimate incommensurability of blackness and so-called civility, in your citation of Wilderson's afro-pessimism, 
wherein blackness is the case limit for where the human as both an avatar for rights and as a collapsed political project ends (a point, we need to say, that Sylvia Wynter and Hortense Spillers got to first). Huckabee's vulgarity only brings to the fore those connections, which if I understand you, you see as the mask of civility falling away temporarily in order to re-assert or re-energize itself.

I hear what you are saying about sly civility and I am convinced, not least because I hear you saying something about the strategic deployment of civility as drag that really seeks to weaponize, as it were, the slyness in "sly civility" as strategy but also non-consent. That said, I agree that civility is a ruse, but I don't believe that the structures and institutional actors who benefit from civility believe that it is so. In my experience, those institutional actors really believe that the class and race-based logic of civil performance actually adheres to their essential selves. Most of all I don't believe that the least civilized are those who pretend and enforce "civility" because in saying that I feel like we are still holding on to civility as a virtue. What I do think that statement gets at is the deep well of disdain that some of us have for ruling demographics, with their terrible shamelessness and uninhibited bad manners: that freedom to be so unerringly vile-to grab pussies-and to never doubt their own value. My favorite person on this is Koritha Mitchell who has this unerring way of skewering the hypocrisies of institutional racism. And my favorite meme about this is \#whitemediocrity. Or, from my childhood growing up with many West Indians in Toronto: "no home training"! Or basically, \#noshame

What Trump has, that we as intellectuals, as educated people with post-secondary educations, do not have, is a rebellious relation to civility that, while obviously narcissistic and increasingly the ravings of an isolated would-be sovereign (cf his insane Twitter account), did ring effective both emotively and affectively during the election precisely because it was a critique of the classed aesthetics (or facticity as Steven Shapin has documented) of rational civility and therefore of the left. Even and while in the academy and on the streets. some of us are variously read otherwise and made to pay for it, and even and while I want to make this point here without saying that this is a guy with an actual political critique. So like yes: I despise and fear Trumpian incivility not least because I also think it signals the kind of violent bawdy white terrorism that I talk about in my Social Text piece, in which I draw on Mbembe's ideas of the intimate terrorism of the colonial carnivalesque. But I also admire it, a tiny bit, because I hear in it an impropriety or an anti-propriety that I wish left politics could return to-on her blog Lauren referred 
to it as "the noise in his message" (and she too cites Hartman)—and I think the pull to sound here, to the sensory reordering of his interventions, is really important.

I suppose I might invoke my own upbringing right now as the child of very, very poor working class whites and very, very poor North African immigrants, the latter of whom emigrated to the Americas with a boatload of tenuous cultural capital inherited from living under French colonialism. I am solidly middle class now, but I desperately miss the sound of working-class or at least non-college-educated people, in English, French and Arabic, talking politics to each other, taking each other seriously as thinkers and theorists, being impolite, loud, brash, rude. I miss it the way I miss smoking sometimes, you know? As a sense memory or as background noise. I feel like I heard some of the sound of those politics in the noise emerging from the least crazy of the Trump voter's, when they talked. And although I excuse no racism and no violence and no classism, and I don't accede to the idea that working-class whites voted for Trump, nonetheless I mourn an entire culture, this United States, that has been trained to not know how to make the connection between their immediate grievance and structural change. Or even worse, to think of structural change as the defeat of individual freedom.

Again, I'm not attributing class consciousness to Trump! For god's sake, no. But I am saying that his incivility-exactly the crudeness of his attempts-sounds and smells like an 'outside' to the classed aesthetics of the left-which-is-not-a-left-anymore. And I wish we could find a way let that outsideness in without letting all of his other violences in.

To return quickly to Dean Spade here, but also to think about this question of noise: civility is a critical term for me because it allows me to work analytically across multiple scales of analysis, from the governmental to governmentality. If, for Dean Spade, the space and exercise of administrative infrastructure is a key site for activist intervention because it is precisely where violence takes place against trans folks trying to survive the system, my interest, as a nineteenth-centuryist must necessarily turn to the moment in which that infrastructure gets institutionalized, which is precisely the period Hartman is talking about. Hartman turns our attention to the deep political violence of the post-reconstruction period; it seems key then that the current civil service-and you see here how the "civil" might be a key analytic form to follow here-is founded in 1883 with the Pendleton Civil Service Reform Act. Can we draw a line from the politics of respectability and the history of civility as it is linked to different and divergent class formations to these seedling moments in the creation of the progressive state? And what interdisciplinary methodologies-perhaps an attention to the haptic, to the distribution of the sensible-might aid in that project? 


\section{TAVIA}

So, returning again to your call to conjugate the politics of 1876 and 2016 in some kind of historical sequence, leads me to suggest another antonym for civility. That is to say: in both the historical and personal registers of your account of the depoliticizing effect of the enforcement of norms of civility, I understand you to be suggesting that the antonym for civility is neither incivility nor rudeness, but militancy. It is the militancy of black Reconstruction that the Compromise of 1877 brings to an end. It is the militancy of Black Lives Matter that Trump's call for "law and order" reacts to. And, when one turns to student activism on campus-which liberals love to disparage and bemoan as illiberal in form and therefore somehow a greater threat to American democracy than the inequality, anti-black racism, xenophobia, and militarism they are standing up to-where here clearly the target of civility is quite transparently a new militancy that owes little, for better or worse, to the establishment. Is thinking of the contrary civility / militancy helpful for you?

As for your use of Dean Spade's work, I think you are onto something that trans theory and activism has been attuned to in particular: what I might want to think of in terms of micropolitics. I want to hear more about the Pendleton Civil Service Reform Act, and the construction of a system of administrative norms that, in turn, must be confronted through militancy (which is, in a way, civil rights 101: confronting segregating lunch counters, schools, pools, waiting rooms, public accommodations). Elsewhere I suggested we might think of the sequel to such "civil disobedience" a kind of "civility disobedience": a tactical and strategic disruption (as opposed to spontaneous and emotional) of the norms that reproduce in the present the same kinds of structures of administrative violence that civil disobedience was so effective in contesting.

\section{KYLA}

I think that I may want to go bigger than just militancy without disavowing militancy itself. I think what I may want is a reordering of the boundaries of what counts as political thought, political performance, and strategy in the context of this total political epistemic and need we say ecological crisis. One way of reordering politics against rationality might be to say that we stop looking for one political solution and instead understand that any effective political opposition is going to happen on many fronts, from the antifa to peaceful protest, including militancy and including the deployment, from within state bureaucracy of a kind of sly civility. And I think that change will have to lead with what speaks to feeling before we ever get to what rebuilds infrastructure and social nets, if we 
have time for that given the planetary apocalypse. But more than that, when I think about incivility, I think about a political openness to speaking or making affiliations across the aesthetic boundaries that order the sense of what a valid political actor is. What happens when we make the most unexpected affiliations?

\section{References}

Benjamin, W. (1996). Critique of Violence, Selected Writings; Volume 1 1913-1926. Cambridge, MA: Belknap Press.

Berlant, L. (2017). Big Man. Social TextOnline. January 19. Available at: https:// socialtextjournal.org/big-man/ [Accessed 22 August 2018].

Berlant, L. (2018). Genre Flailing. Capacious: Journal for Emerging Affect Inquiry. Vol 1 No. 2: 156-162. Available at: https://doi.org/10.22387/CAP2018.16 [Accessed 22 August 2018].

Bhabha, H. (1985). Sly Civility. October, 34 (Autumn), 71-80.

Cho, S., Crenshaw, K. and McCall, L. (2013). Toward A Field of Intersectionality Studies: Theory, Applications, and Praxis. Signs: Journal of Women in Culture and Society, 38 (4), 785-810.

Cohen, C. J. (2004). Deviance as Resistance: A New Research Agenda for the Study of Black Politics. Du Bois Review: Social Science Research on Race, 1 (1), 27-45.

Crenshaw, K. (2005). Mapping the Margins: Intersectionality, Identity Politics, and Violence against Women of Color (1994). In R. K. Bergen, J. L. Edleson, \& C. M. Renzetti, ed., Violence against Women: Classic Papers. Auckland, New Zealand: Pearson Education New Zealand, 282-313.

Dru Stanley, A. (2011). From Bondage to Contract: Wage Labor, Marriage, and the Market in the Age of Slave Emancipation. Cambridge; New York: Cambridge University Press.

Ferguson, R. A. (2004). Aberrations in Black: Toward A Queer Of Color Critique. Minnesota: University of Minnesota Press.

Gilmore, G. E. (2013). Gender and Jim Crow: Women and The Politics of White Supremacy in North Carolina, 1896-1920. Carolina: UNC Press Books.

Hall, S. (1992). Cultural Studies and Its Theoretical Legacies. In Cultural Studies. L. Grossberg, C. Nelson, and P. Treichler, ed., New York: Routledge, 277294. 
Harney, S, and Moten, F. (2013). The Undercommons: Fugitive Planning and Black Study. Minor Compositions (Autonomedia). Available at: http://www. minorcompositions.info/wp-content/uploads/2013/04/undercommonsweb.pdf

Hartman, S. V. (1997). Scenes of Subjection: Terror, Slavery, and Self-Making in Nineteenth-Century America. Oxford: Oxford University Press.

Katznelson, I. (2013). Fear Itself: The New Deal and The Origins of Our Time. New York: W.W. Norton \& Company.

Lemire, E. V. (2002). Miscegenation: Making Race in America. Philadelphia: University of Pennsylvania Press.

Mbembé, A. (2001). On the Postcolony. California: University of California Press.

Melamed, J. (2011). Represent and Destroy: Rationalizing Violence in The New Racial Capitalism. Minnesota: University of Minnesota Press.

Mitchell, K. (2011). Living With Lynching: African American Lynching Plays, Performance, and Citizenship, 1890-1930. Urbana-Champaign: University of Illinois Press.

Ngai, S. (2012). Our Aesthetic Categories: Zany, Cute, Interesting. Cambridge, MA: Harvard University Press.

Nyong'o, T. and K. W. Tompkins. (2018). Eleven Theses on Civility. Social Text Online. July 11. Available at: https://Socialtextjournal.Org/Eleven-ThesesOn-Civility/ [Accessed: 22 August 2018].

Nyong'o, T. (2009). The Amalgamation Waltz. Minneapolis: University of Minnesota Press.

Ranciere, J. (2006). The Politics of Aesthetics. New York: Continuum.

Reddy, C. (2011). Freedom with Violence: Race, Sexuality, and the US State. Durham: Duke University Press.

Reid-Pharr, R. (1996). Tearing the Goat's Flesh: Homosexuality, Abjection and The Production of a Late Twentieth-Century Black Masculinity. Studies in The Novel 28, (3), 372-394.

Reid-Pharr, R. (1999). Conjugal Union: The Body, the House and The Black American. Oxford: Oxford University Press.

Shapin, S. (1994). A Social History of Truth: Civility and Science in SeventeenthCentury England. Chicago: University of Chicago Press. 
Soyinka, W. (2002). Death and The King's Horseman. WW Norton \& Company. Spade D. (2015). Normal Life: Administrative Violence, Critical Trans Politics, and The Limits of Law. Durham: Duke University Press.

Tompkins, K.W. (2012). Racial Indigestion: Eating Bodies in the 19th Century. New York: NYU Press.

Tompkins, K. W. (2017). You Make Me Feel Right Quare: Promiscuous Reading, Minoritarian Critique, and White Sovereign Entrepreneurial Terror. Social Text, 35 (4): 53-86.

Wilderson III, F. B. (2010). Red, White \& Black: Cinema and The Structure of US Antagonisms. Durham: Duke University Press. 


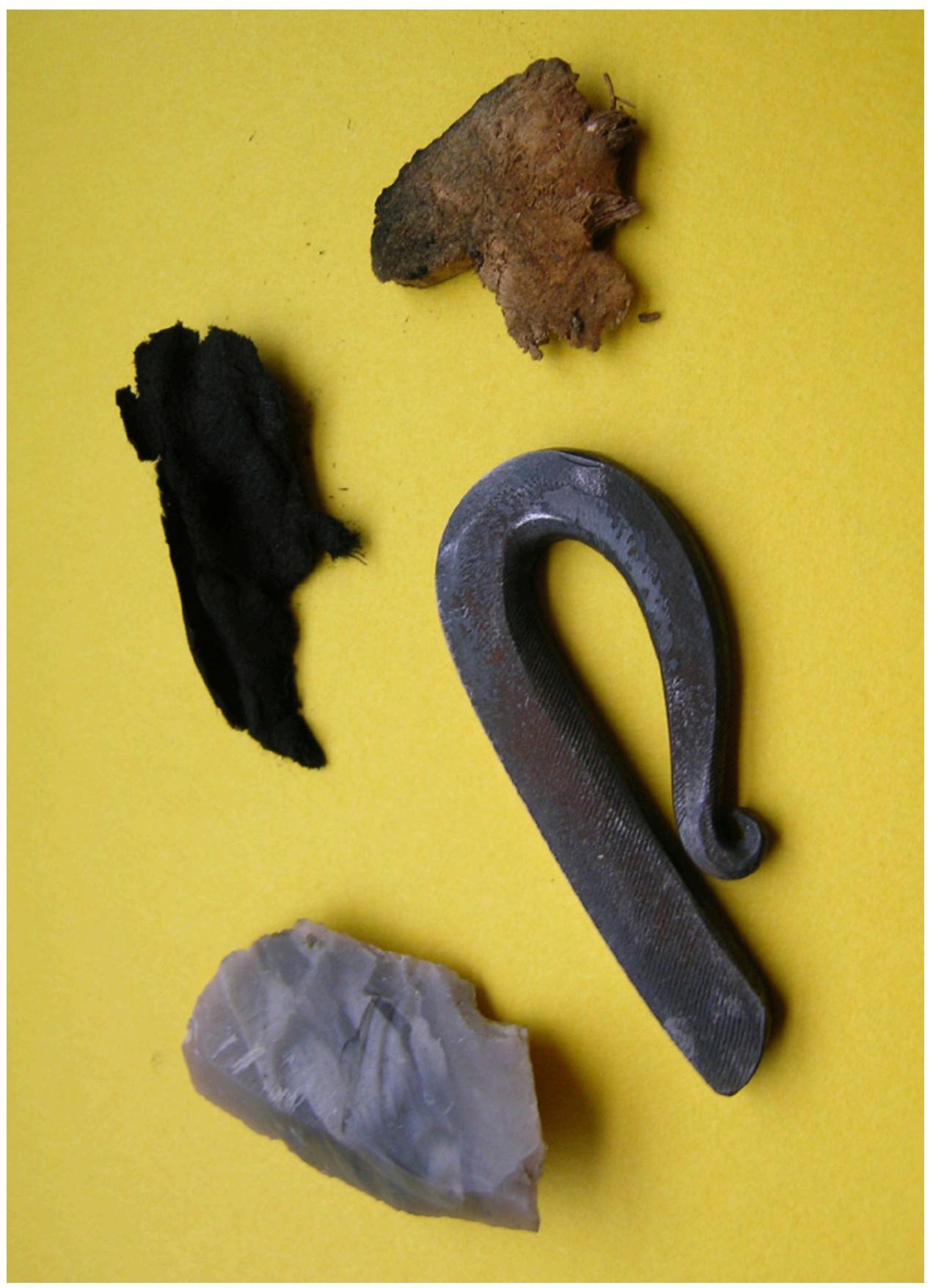

A tinder box: charred cloth, mushroom, flint, and tyrstan, Dirk van der Made, 2006 Creative Commons Attribution 3.0 (CC BY SA 3.0) 


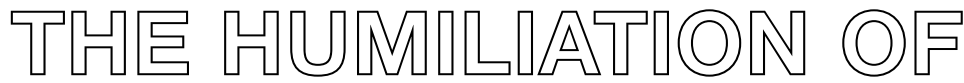 BSEX WIII OPIIMLSM". F[ELDNO『ES FROM TUNDER}

\section{Sarah Cefai}

UNIVERSITY OF THE ARTS, LONDON

In Sex, or the Unbearable, Lauren Berlant and Lee Edelman invoke the rubric of "sex without optimism" to explore options beyond the "normative function" of sex "as the mechanism of emotional cohesion that sustains heteronormativity" (2014, 13). They specifically link the "implication of sex in the normative logic of optimism" to "the presumption of sovereignty," which they claim is disturbed by "an encounter with the estrangement and intimacy of being in relation" (xiii-xiv, viii). The question of whether optimism disavows "what's unbearable in negativity" gets to the nub of the matter, pointing to the role of optimism in our capacity to bear or surmount "what overwhelms us in ourselves and in each other" (ix). This vital but often ordinary "experience of relation" links our capacity to be in the world to our vulnerability within it (viii-ix). The relation between nonsovereignty and negativity, self-certainty, affirmation or agency (our hope for a better life; our capacity to get through it) is constantly at play in our sexual ethics and aesthetics. Whatever sex might be, for each of us, and in whatever context, the authors suggest, sex foregrounds a dynamic relation between optimism and its other. Berlant and Edelman thus develop the rubric of "sex without optimism" to retrieve, examine and extend sexual and social possibility. Here, I use their rubric as a springboard from which to think about how the relations among optimism, nonsovereignty, and negativity might set up a kind of sister affective structurethat of humiliation. I cannot yet make claims beyond suggestions regarding the 
status of humiliation as itself an affective and discursive structure-autonomously or vis-à-vis optimism-although the work I undertake here is pursuant to this aim.

Sex without optimism also raises questions regarding the specific role of gender and sexual difference in how our cultural structures of humiliation are forged. Gender might be a blunt instrument with which to critically take on and address the fantasy of sovereignty, and no doubt there are reasons why Berlant and Edelman themselves do not pursue this path. Within normative optimism at least, the "putative sovereignty" that is defended from the risks of negativity brought on by "enjoyment" is, surely, epistemologically masculine (and white, etc.) (8). I would posit that the fantasy of sovereignty that governs how we encounter sex (our optimism about sex) is highly gendered, and that this gendering is important to the reification of patriarchal heterosexuality; (another time, we might also consider the implications of optimism too for heterosexuality's counter-discourses). For one, the paradoxical experience of being anchored and overwhelmed is quickly absorbed by the discursive notion of the tension between / among 'the sexes.' By which I mean to say, our ways of expressing vulnerability / affirmation, from the minor to the major, do nothing less than constitute the aesthetics of gender; (what is "gender" if not, at least in some respect, the ways we get attached-to one another and in the world, and each attachment vis-à-vis the other?). The gendered structure of optimism, as a condition of possibility for humiliation, comes to inform the gendering of structural / individual humiliation. So, rather than faithfully pursue Berlant and Edelman's rubric of "sex without optimism"-a very clever project, but beyond what I can advance here-I stay on sex with optimism, notably in its manifestations of "cruel optimism," to find ways of giving texture to the cultural context that humiliates (Berlant 2011).

My writing here is experimental and proceeds by way of example, experience, and a weak reference to the "politics of location" (Rich 1986, 210). The dating platform Tinder, in its generation of new aesthetic categories that apparently break with "narrative knowledge and knowledge as narrative," while purportedly speaking to / seeking out the pleasures and availabilities of sex, lends itself well to a study of the emergent formations of sex with, and without, optimism (Berlant and Edelman 2014, 3). Indeed, whatever our prejudices about the app (and Tinder is ripe for prejudice of all sorts, particularly in its barrage of aesthetic judgements), Tinder's scenes are at the forefront of transformations in sexual relations. I want to admit, however, that I did not intentionally seek out an object through which 
to examine how 'sex' intensifies "that which is structurally nonsovereign," or approach Tinder in the cold light of day as an object of research (Berlant and Edelman 2014, 5). Rather, my engagement with Tinder's emergent textuality is co-incidental to my practice of writing: "notes from the field" just happened. Nonetheless, in having taken up feminist theory as a "movement for change [that] lives in feelings, actions, and words" many years ago, my practice of writing was a priori open to Tinder's affective circuits (Rich 1986, 223). That is, my practice of writing, like my experience of Tinder, embodies "the constant pressure to adjust that is at the heart of being nonsovereign" (Berlant and Edelman 2014, 6). So, what I have written here occurs from within "structures of digital feeling" and exposes something of "the continuous lines that compose numerous intersecting durations of the experiential" (Seigworth 2015, n.p.). While it's awfully grand to invoke Michel Foucault in this way, not to mention perplexing (what would he make of Tinder?), I think that not only in writing but in sex too, "one writes to become other than what one is," and that this formulation of the nonsovereignty of sex and writing expresses an optimism for their forms (Foucault 1985, 104). However, Tinder takes the risks and fallout invited by this nonsovereignty to new proportions. If " $[\mathrm{w}]$ hatever circumscribes or mutilates our feelings makes it more difficult to act" (Rich 1986, 223), and if heteronormativity is just such a circumscriber in its "attempts to snuff out libidinal unruliness" (Berlant and Edelman 2014, 4), then my ruminations that follow here-on the theatre, circuits, status and stakes of "sex with optimism"-seek to provoke the "intersecting durations" of these proportions, among other things (Seigworth 2015, n.p.).

\section{\#1. Theatre}

We are in the love scene now.

Laura and Alec stand facing the audience; though really, they face one another as the love scene plays out in their faces.

Is there anything more intimate than the face of a lover? I don't mean the faces a lover makes (!), but the face of the lover's emotion. Fear shimmers in Laura's eyes-there is a dark side to her longing. She relinquishes herself as much as she finds her freedom. There is no going back, and she has the most to lose. It's the 1940s, she's "a woman in love," and an adulterous one at that (Beauvoir 1949). This particular love story is also likely to emanate from the closet of homosexual love experienced by its writer, Nöel Coward. 
I am, for a moment, confused and hesitant. I don't recognise this scene from the film, and consummation is a deciding factor in any love story. With this ecstatic union, what will happen next? Might the story be thrown off course? Or does Emma Rice-writer of the theatrical adaptation of the film Brief Encounter (Lean 1945), itself an adaptation of Coward's original screen play Still Life (1936)-believe that within the film this union really takes place, 'behind closed doors'? In the end the play stays true to the film, only bringing the love scene out of the closet of the 1940s to make more vivid on stage the emotion of falling in love. For, in 2018, despite all that we know now, all that has happened, we are taken by a love that is still, somehow, innocent of the very social conditions on which it comments. Especially so where these conditions shore up love's failed promise.

Facing the audience but really facing one another, Alec and Laura undress in synchronicity and slow motion. Like mime artists, they dance the intensity of succumbing. They absorb the melodic tenderness of Go Slow, Johnny (Coward 1961) into their movement-the expression of the song through the characters' undressing animates the scene. The crescendo of love's emotions gathers intensity from each of the scene's components, including us the audience. Drawn into the ensemble, we become ourselves crescendo elements, loved up. We're too heartbroken for the characters to feel we are voyeurs of a private emotion.

As her lover returns to his wife, Laura is taken into a terrible darkness. What life is left for her, within her marriage? From the breaking of her heart a power emerges-she rediscovers herself as the pianist. We know the force of feeling is inseparable from creativity itself; this is why feeling seeks expression, and why we can say, with Nick Cave, that "sorrow itself is a creative act" $(2013,7)$. Laura rediscovers her capacity to plumb the depths of her pain through art, which means to plumb the intensities of art and life itself. The creative force that courses through Rachmaninoff comes from the paradox between being anchored and overwhelmed. Concerto for Piano No. 2 in C Minor, Op. 18 (1901) becomes a "Love Song," expressing "an inexplicable longing, an unnamed and enigmatic yearning of the soul" (Cave 2013, 7).

Now we're in a love-grief scene and it howls with yearning.

The howl of heartbreak is one to be avoided. 
Heartbreak is an unravelling of the subject, except that the pain is an expression of love i.e. haunted by ideation (it's the attachment that howls). The scene in which the characters swing from the chandelier suggests that they were having great sex too. I just wonder whether the elevation of their romantic love, paradoxically represented as taboo and as over and above the taboo it represents, expresses or denies "what's unbearable in negativity" (Berlant and Edelman 2014, ix).

"I felt so utterly humiliated and defeated and dreadfully, dreadfully ashamed" Laura (Celia Johnson) confesses.

"Self-respect matters, and decency. I can't go on any longer" (Lean 1945).

Laura's particular heartbreak is the outcome too of her humiliation-she couldn't live up to a normative ideal that she understood was key to the feelings of others.

\section{\#2. Circuits}

I go to the theatre to collect one last scene. I want to exercise the nonsovereignty of the story. That right there is some serious optimism. What do I hope for? Nothing short of an open heart. I have learned that this is key to my ability to read and write. An open heart suggests an openness to others.

I was on countdown: 16 hours before leaving for Sydney. My very own grief city. A string of errands yes. But just one real thing to do before I leave. I know, as I make my way to the Empire Cinema, that love is a lot of theatrics. Despite the risk of these, I hope that love and theatre will come full circle on me. How else will I find your "capacity to repair" (Berlant 2008, 4)? I look for you in the theatre of love. One last look, before I leave. You can call me out on the stupidity (most everyone else I am told has this whole love/sex scene more sussed than me). I know this call can be out of concern: an open heart is hard won, and easily lost. But in this look, something is going on more than my feeling. This look gives out a cultural story-the nonsovereignty of a love/sex story, all the way from the crescendo of sensation in the love-grief scene, to the Tinder swipe; all the way from a Tinder match to seat D16.

In a description of the love scene the following juxtapositions come into play: gay vs. straight; sex vs. love; marriage vs. the love affair; film vs. theatre. Theatre's intimacy isn't visceral, as it is in, for example, 120 BPM (Campillo 2017): we're not in the room, affectively proximate to the (too) real, (too) close fucking, or 
dying body. Passionate love (the audience is moved to tears with the movement of it) occurs without visceral sex (it is the theatre after all). We see the face of the lover's emotion not the faces a lover makes. The challenge of intimacy beyond patriarchal sexuality admits to the prescience of these distinctions, and their role in the perseverance of questions of libido, commitment, affection, and attachment. The cultural politics of "[t]he love laws ... the laws that lay down who should be loved, and how. And how much," go on and on (Roy 1997, 33). The love laws travel in circuits. All we have to do now is work out what happens not only when sex is located in the bedroom of the middle-class couple, but in the quagmire of social media.

I swiped right on his face. (What kind of sentence is that?) He swiped right on me. This means we match. (I've substituted sentences for statements).

I quickly learn from other users that a match doesn't mean a thing because guys swipe right anyways. Though, in this instance, we arrange to meet, which I guess does mean something.

After an espresso martini (what are young people drinking these days?), he has a shot of tequila with me. Usually he wouldn't like it, but this time he did.

He walks home with me, but he doesn't kiss me.

On my sofa, he joins me for a cigarette. He rolls his own.

While we're talking, he puts his hand on my shoulder. It's so sweet and flattering. I enjoy it too much to wonder where he learned that.

We must have been talking Harvey Weinstein, though I can't think what for or why. But we must have been. Weinstein was in the air, about to enter conversation at any time.

"Kevin Spacey put his hand on my knee," he says.

To say that now, it's become so awkward! All of a sudden, we've said too much, without hardly saying anything at all. 
In the moment, I think it's a sort of accolade: what nice young man wouldn't be flattered? Or perhaps my suitor wishes to communicate his desirability to me (well, if Kevin Spacey wanted some... ). Not everyone can say that Kevin Spacey hit on them. I say now, with irony.

I find some entertainment in the fall of Spacey from the bright lights of Hollywood to my new friend's knee. We've all seen The House of Cards (2013- ). I'll admit to the schadenfreude on my part, especially seen as Spacey was knocked back where I wasn't. I gloat, I admit it. Spacey missed out: what a kisser! But, even that's weird to say now. His status having changed from closet case to sexual predator changes the terms of the joke.

Weirdly, but not so weirdly because it was in the air, that story broke in the following weeks. Anthony Rapp alleges ... (you know the rest), later claiming that his allegation took inspiration from the women who had come out about their experience of Weinstein (Gajanan 2018). I use the metaphor of the closet intentionally. Its purposes multiply these days.

I am disturbed by the story and weirdly, or not so, disappointed in him (Spacey, that is). My disappointment quickly turns into anger towards the discourse that emerges: it's a moral panic; it's the sex wars. A Guardian columnist writes, literally, "How dare you, Kevin Spacey?" and he goes on to say:

Remember Section 28, introduced by Thatcher's government in 1988, barring the so-called promotion of homosexuality in schools? How its defenders justified the homophobic legislation on the grounds that gay men were deviants and perverts who threatened the nation's children? ... I bet you that homophobic bigots will use Spacey's case to press the case that LGBTQ people threaten children. (Jones 2018, n.p.)

The bet was on, but we don't know who won. Why is sexual politics overburdened with recycled tropes? What do these tropes do, other than angle the burden of representation? Jones' critique of the misrepresentation of homosexuality exemplifies the limits of normative optimism. What about the workplace culture of patriarchal privilege in which men's fantasies of sovereignty facilitate their self-serving behaviour and a system that protects aggressors?

Meanwhile, Spacey is taken out of the circuits of cultural production faster than you can say s-e-x-u-a-l ... 
In The Guardian's Dating After \#MeToo 'series,' another journalist levels that "if you kiss a person who doesn't want to be kissed, that's sexual assault" (Edelstein 2018 , n.p.). I quickly check the UK law on sexual offences, which doesn't quite state that. The law uses the language of "sexual touching," which the journalist neglects to consider. Now, it's cultural law that matters-opinion and mob rule. "Should I ask my Date if I Can Kiss Her?" addresses men as the agents of sexual initiation with women. Sexual harassment is relocated within the domesticating 'lifestyle' discourse on casual sex and courtship, with little consideration of how relations of power, sex and intimacy are foregrounded by questions of power in the workplace (see Gallop and Berlant 2001).

Bumble's (2014) founder, Whitney Wolfe Herd, successfully sued Tinder for sexual harassment and discrimination (O’Connor 2017, n.p.). People describe Bumble as the "feminist Tinder," "focusing on the needs of one segment: women" (ibid.). We have feminism to thank for that? Following a match, the woman must initiate contact (apparently, Tinder's data say women don't). In any case, the platform doesn't interfere much in men's initiations-they simply initiate in response. Bumble's advertising is plastered on central London buses. It's a supercorporate-postfeminist-lifestyle-frenzy. So-and-so business woman joins the Bumble Family as a Bumble Ambassador. Users are invited to a Bizz Dinner on the theme of Advertising and Marketing. Programming Romance, a talk given in a Soho pub by the Branding Director, will focus on how Bumble is redefining digital dating. The Sofar Sounds events are transforming living rooms and retail shops into venues for secret, live shows, creating an immersive experience.

Maybe Feeld (2014) breaks the mould: a London based app for "open-minded couples and singles. Discover a space where you can explore your desires and find your people. Join solo or pair up with a partner, a lover or a curious friend." The website looks queer enough: "we believe nothing is more unpredictable or less binary than human desire." You got that right! Fantastically queer, until you consider that access to the platform depends upon you sharing your Facebook data-friends, photos, email-for the purposes of identity verification.

It's difficult to imagine that Grindr (2009) is less than 10 years old. 
The 'swipe' has a cultural logic that can't be easily subverted because it is rearticulating so well a bunch of stuff that was there anyway. The swipe spreads.

A city bar serves the cocktail: "Hot or Not". (The reference is lost on the bar tender, for whom "Hot" refers to the house-infused chilli tequila option.)

ITV's Love Island (2015-), successor to Big Brother (1999-) with more pool, bikini and bedroom, requires contestants to swipe 'In Real Life.' The objective of the game is to wind up matched in a couple. Contestants left out of a couple, i.e. not swiped right on, are more at risk of being dumped from the villa. To not be swiped right on is to lose the competition. Love Island is celebrated (by the TV industry) for bringing a generation of young viewers back to broadcast television.

A new app launches. Shapr (2018), it is a "networking app for professionals. This app lets you swipe right on your career. Instead of awkward dates, you get casual business meetings. Who doesn't love that?" Given what we already know about networking in the creative industries (McRobbie 2015), the concept of Tinder for work barely needs explanation. It barely needs explaining too, that men prefer causal business meetings to awkward dates. Why go on dates, with all the porn in the world at your fingertips (so to speak), and a long list of Tinder matches available for 'chat and more'?

I mark an undergraduate dissertation in which a student uses Zygmunt Bauman's Liquid Love to claim that Tinder is responsible for the dissolution of marriage. True, Bauman's claim that " 'relationship' is ... the sole game in town worth playing, despite its notorious risks" does warrant some merit in light of the popularity of dating apps (2003, viii). These apps gamify and sexualise dating, transforming the hook-up app into "an end in itself" (Chamorro-Premuzic 2014, n.p.). And by app, I mean us and our data. Moreover, the game takes the form of your gamble. Your gamble might risk your heart, or your desire, your night out, your time, your interest and attention, or your vulnerability to others-all that can be put at risk, but most especially the dignity that is essential to your status. It's remarkable that questions of gender and sexual difference are unaddressed in Bauman's claim that "if 'commitments are meaningless' while relations cease to be trustworthy and are unlikely to last, you are inclined to swap partnerships for networks" (2003, viii). Whose inclinations are these? Whose networks? 


\section{\#3. Status}

Such a relief, to burst from the theatre

Into our cool, imaginary streets

Where we know who's who and what's what, And command with Metrocards our destinations. ${ }^{1}$

It's a breath of fresh air, jumping out of the theatre. But theatre jumps too-it's aesthetics compete for our attention in our "act of passing by" (de Certeau 1984, 97). Phenomena from microcelebrity to audit culture, networking, CCTV and mobile phone cameras, data analytics, and entrepreneurialism, all place us on stage. Reality TV is never far away.

The stage sets the scene for comparison, gives us terms with which to measure others, check how we ourselves measure up, and demonstrate that we are measured in our responses. Tinder profiles are linked to Spotify and Instagram. More than reflections of taste, networked profiles embed us within the social by traversing different spheres of social life (augmenting what is possible) and acting as technologies of interpellation (calling us into new ways of relating). Profiles are the aesthetic, ideational forms by which our digital footprints are generated-the basis for the "generative" rules of the algorithm (Lash, cited in Beer 2009, 994).

These "virtuals that generate a whole variety of actuals ... compressed and hidden," (ibid.) are at play in the production of our status. The profile is an instrument of status, and reputation is the means by which status communicates. The past isn't the past-what matters to humiliation is that it's a reoccurring present in which our reputations travel: the past can always be used to humiliate us. Because our capacity for judgement is so highly mediated, we often don't know who's who and what's what; but, simultaneously, a premium is placed on self-knowledge and self-representation. As the regulatory circuits of cultural production and consumption shrink and tighten in "algorithmic cultures," the status of our profile, outward facing and data loaded, comes to stand in for our social and cultural citizenship (Hall 1997; Striphas 2015). 
Given that we internalise the historical stage-we imagine the exercise of power, entrapping ourselves within the logic by which it is exercised (Foucault 1977) our failure to meet the expectations of others creates an experience of humiliation that always relates our self-worth back to the theatrics of normative values (Skeggs 1997; Tyler 2013). Our proper names are attached to proper faces with searchable histories, but, they are only ever instantiating representations. Nevertheless, we 'follow' one another's names, lulled into thinking that we are following one another. The essence we encounter in the other, that disturbs or reifies our sovereignty, is mediated by status, constituting a further investment in normativity powered by the algorithm (Beer 2009; Striphas 2015). As we follow reputations we invest in a reputational economy that becomes increasingly hegemonic. This economy of reputation is the new cultural economy or political economy of culture. We try to command our own theatrics while our reputations dance on a screen before us. Whereas "[s] tories diversify; rumours totalize" (de Certeau 1984, 107).

"I don't think anyone wants to be one of a hundred colours in a box," Peggy (Elisabeth Moss) observes in 1960, as imagined in 2007 (Mad Men, Season 1, Episode $6)$. Her observation still resonates as a reflection on the nature of commodification. Advertising rests on schemas of individuation and as these schemas operate in ways that are increasingly individual, e.g. through tracking and targeting, they increasingly confine social value to the consumer while simultaneously extracting economic value from the depletion of the social. The association of individuality with consumer power is also increasingly linked to a new type of social status that incorporates gender as a social construct and embodied style through a personalised aesthetics of the self. Status is shaped through people's subjective identifications with the categorisations of identity that stratify the social, as well as by consumer power, yet appears to be greater than the sum of its parts. Our positioning within social media, within the whole scene of networked platform media, hinges upon a concept of status that is linked to the use of profiles to communicate reputational value-from the value of the workplace, to lovers, to presidents. It is, as Erving Goffman claimed some time ago, "the individual who is disqualified from full social experience" (1963, Preface). Perhaps. Though one's "social identity" (2) would now be better understood as one's reputationthe value that is produced in the affective and communicative exchanges that constitute one's status. 


\section{\#4. Stakes}

Desire itself brings us down at least a peg or two. No one falls for anyone, anymore. People are too guarded.

Even to have wanted, is to have fallen. Wanting is risking your status in a zero-sum game.

He is the perfect stranger. The "paradox" of the stranger is that their "attachment invokes disconnection” (Feldman 2012, 303).

A woman is never a stranger. As soon as she feels, she falls below the line. Despite her best intensions, she might throw out a look.

Meanwhile, there is no stranger as such. We all have proper names now-a reputation.

Meanwhile, we are all strangers now: the stranger "presents the synthesis" of attachment and detachment that typifies our reputation (Simmel 1971, 143).

Meanwhile, you never know until you've already fallen, when you're being catfished or when you've fallen in love.

I know there's no writing without risking yourself, but I don't know what I'm risking by writing. This risk transpires in the experience of shame, which has something to do with writing's transgressive difficulties and pleasures (Probyn 2005).

We might assume that sex invites the risk of humiliation because sex is shrouded in shame. Especially women's sex. Especially same-sex sexuality. Nowadays, sex is shrouded in social media.

I try to get my head around the paradox: "no one really cares what or how I write but me, but, I can't separate writing from my sense of self in relation to others"-the concept of the audience is present. That's the historical stage, the audience; that's the optimism. We throw out a look and hope for the best. Optimism without guarantees. 
It's no coincidence that my writing about Tinder is analogous to my writing about writing. Tinder's as much subject as object: Tinder writes itself. The imaging, the writing, the texting, the swiping, is Tinder's writing. The textuality of Tinder puts something at stake-something that combines with what would have been already at stake (In Real Life). However risky though, the stakes of Real Life are better because people retain access to the mere facts of one another's tangibility. In a range of ways their self-possession is less at risk of humiliation. We're tricking ourselves if we think that Tinder protects us from the shame of rejection.

Silvan Tomkins asked, "How can loss of face be more intolerable than loss of life?" (from Sedgwick and Frank 1995, 136). Could there be a less stable referent, or a more personal one, with which to trade? It becomes hard to throw out a look once we lose face. Losing face, we experience "the sick feeling of being exposed as thinking we are more than we really are" (Miller 1993, ix). I guess that's also the risk with writing. It's "the humiliation of having our poses of competence undercut by our own ineptitude" (ix).

You have to have an optimism that something is going to work out. This is already a kind of thinking we are more.

Optimism for something better renders us subject to the impact of a bad evaluation: "one must have expected good things to have come from the other person before the other's contempt produces shame" (Tomkins in Sedgwick and Frank 1995, 138). The way we care what others think is usually implied, for example, in an investment that is made possible by a transaction. Such as: I take the time to reply to his message. Taking the time to reply casts out optimism. They say they do, but people don't know what they're looking for. They use Tinder to look: what is the look of optimism one gives out as they select a picture for their profile? The intimacy of the face of the lover becomes the face of optimism.

Optimism, the stage: the idea upon which we base our performance; our perception of history and of mattering; our imagining of what other people can see or care about when we select photos for our Tinder profile.

Optimism, the "over-articulate tenderness," and "too much intensity" that scares off new lovers (Coward circa 1920s, quoted in Brief Encounter 2007).

Optimism, the phantasm of mutual pleasure and synchronicity; the fantasy of self-knowledge and control.

If our heart is at stake, everything is at stake. 
It doesn't matter how many times you write "No Strings Attached", and "Not Looking for a Relationship" in your bio, sex is still relational. Especially good sex, and especially bad. The experience is in excess-something's disturbed, yo! Even if you pay-although paying can make the terms of the transaction clearer. Whatever, there has to be an exchange, because the relationality of sex is us exchanging.

Being on a date with you, texting you, swiping you-it's not as simple as being looked at and judged; not being right or good enough. It's not just being rejected, though no one likes that (in any case, 'rejection' is making such a song and dance about it). It's not even the switch, from being something ("let's fuck") to nothing (I keep only your phone number and a vague memory). It's the way that all this gets mixed in with the shame of the mistake: you thought that you were good enough. It was such an implied, assumed thought that you didn't even think it. You simply thought, I wore my best for you. We tend to distract ourselves from the shame we experience in the knowledge of having an unmet expectation of positive appraisal.

"Humiliation is the price we pay for not knowing how others see us" (Miller 1993, x).

Not only is our status lowered, we discover that we are wrong about where we thought we were: we were wrong about ourselves. Our knowledge about ourselves was flawed, and our assumptions about where we fit in the pecking order were made in error. If stigma "constitutes a special discrepancy between virtual and actual social identity" then this discrepancy facilitates the humiliation we experience in being wrong about ourselves: we are embarrassed and ashamed not only because we realise that we are the subject of a "spoiled identity," but because we didn't know that we were (Goffman 1963, 3). This failure constitutes a specific type of injury in a world in which self-knowledge is premium. A world in which the networked profile is an instrument of status, and reputation is the means by which status communicates, is full of intervals in which you might be wrong about yourself. Platform media exacerbate and complicate the discrepancies between virtual and actual social life in ways we don't understand-in ways about to trip us up. You may even be "seen to be putting on airs by simply being out of place, by being on the other's turf" (Miller 1993, 11): yet we might not even have a place "[w]here we know who's who and what's what," and what better description of being online? 
In every swipe and chat, the exchange reproduces your status and you play with the possibility of being wrong about where you think you are in the world, which means being wrong about yourself. Teasing plays on the insecurity of self-knowledge; to humiliate someone is to deny their self-knowledge, to injure the pride they take in their humility. This play is gendered: if a woman is an academic and a man is a trader, or a strategist, or a website editor, she will get used to micro-humiliation-the more status he has, the more he has something to prove about his place in the world. So, she probably makes self-deprecating jokes. As London (Juno Temple) says, to "spare your fragile male ego" - "I thought we were both on the same page as to what we expected / wanted of the encounter," says a guy I met twice (Kaboom 2010). This is optimism in the form of an idea about mutuality. But this notion of equal status is refracted through gender: "[D]o you understand what self-deprecation means when it comes from someone who already exists in the margins? It's not humility, it's humiliation. I have built a career out of self-deprecating humour ... I put myself down in order to speak" (Gadsby 2018). Changing the joke of humiliation is a radical challenge to its terms.

"Jordan Peterson is right," the profile says. The profile responds to my question of whether the photo used is really of them: "Men can't say anything," the profile says. The profile had been catfishing-catfishing cum trolling. Perhaps I shouldn't reveal on my profile that I'm an academic: the revelation of status-related information is part of the structure of being targeted by a Jordan Peterson follower. The profile lets me know that I'm just a joke. When I throw out my desire for face-value, I appear vulnerable to tricks. The profile withholds its face on several levels and so is less likely to lose it. The profile is a mask, an avatar. I am stuck with the face-value of something faceless (it might even be a bot). The profile watches you lose yours. The profile lets you know it got off.

Being tricked is de facto humiliation: the person loses face because they didn't know they were being tricked. People are using Tinder to bring one another down a peg or two; that is a problem, but also this humiliation game is on a continuum with the self-deprecating humour that many of us with minoritized identities have been using as an everyday strategy of survival. Really, self-deprecation offers little recourse for resistance.

So, we might decide that love's gamble isn't worth it. It isn't worth the game. If we're gambling with our hearts, we're gambling with our status, and in our society that's near enough gambling with everything. 


\section{\#5. Coda}

He likes me too,

he tells me with his mineral breakfast.

He's got soft ears and rosy cheeks. Like

literally, a cherub fell into my bed.

An actor and a poststructuralist, virtually impossible to know

which one of us is faking it.

We are both in the business

of impression management.

Let us count the ways that we fit together.

Every which way we go, we fit.

Every actor needs a stage; every writer needs a muse.

"Every barista needs an espresso machine," he jokes.

He kills it.

He lounges in my bed as if it's his own-

even calls me over,

before he gets up to leave.

"I might disappear again," he says.

If he doesn't have time,

he doesn't have time.

I watch his thumb curl.

The thought of him with other women is way too raw.

I was having fun

up until a certain moment.

\section{Acknowledgements}

Thank you to Greg Seigworth and Anne Worthington, who each played a part in helping me find an audience (to "audience" my writing). I would also like to thank Emilie Severino for her generous insight - "partner in crime" for all things poetry, philosophy, and feminism. 


\section{Endnotes}

1. James Richardson, 'In Shakespeare', poem, The New Yorker, February 122007. Shared by Elizabeth Stephens on Facebook.

\section{References}

120 BPM. (2017). [film] France. Dir. Robin Campillo.

Beauvoir, S. (1949). The Second Sex. London: Vintage.

Beer, D. (2009). Power through the Algorithm? Participatory Web Cultures and the Technological Unconscious. New Media \& Society, 11 (6), 985-1002.

Berlant, L. (2008). Thinking about Feeling Historical. Emotion, Space and Society, 1 (1), 4-9.

Berlant, L. (2011). Cruel Optimism. Durham and London: Duke University Press.

Berlant, L. and L. Edelman (2014). Sex, or the Unbearable. Durham and London: Duke University Press.

Big Brother (1999-). [Reality T.V.] Channel 4: John de Mol / Endemol.

Brief Encounter. (1945). [film] UK: Dir. David Lean.

Brief Encounter. (2007). [play] UK: NC Aventales AG. Adapted by Emma Rice.

Cave, N. (2013). The Complete Lyrics: 1978-2013. London: Penguin.

de Certeau, M. (1984). Walking in the City. In: The Practice of Everyday Life. Translated by S. Rendall. Berkley, Los Angeles, London: University of California Press., 91-100.

Chamorro-Premuzic, T. (2014). The Tinder Effect: Psychology of Dating in the Technosexual Era. The Guardian, 17 January. [online]. Available at :https:// www.theguardian.com/media-network/media-network-blog/2014/jan/17/ tinder-dating-psychology-technosexual [Accessed 16 July 2018].

Coward, N. (1936). Still Life: A Play in Five Scenes. London: Samuel French.

Coward, N. (1961). Go slow, Johnny. In: Sail Away. New York: Chappell and Co.

Edelstein, J.H. (2018). Dating after \#MeToo: Should I ask my Date if I Can Kiss Her? The Guardian. 2 May. [online]. Available at: https://www.theguardian. com/lifeandstyle/2018/may/02/dating-after-metoo-should-i-ask-my-dateif-i-can-kiss-her [Accessed 2 May 2018].

Feeld, (2014). Available at https://feeld.co/ [Accessed 10 July 2018]. 
Feldman, Z. (2012). Simmel in Cyberspace. Information, Communication \& Society, 15 (2), 297-319.

Foucault, M. (1977). Discipline and Punish: The Birth of the Prison. London: Allen Lane.

Foucault, M. (1985). Death and the Labyrinth: The World of Raymond Roussel. Translated by C. Ruas. London and New York: Continuum.

Gajanan, M. (2018). “There is Strength in Numbers”: Anthony Rapp Shares Why he Opened Up about Kevin Spacey. Time Magazine. January 4. Available at: http://time.com/5088481/anthony-rapp-kevin-spacey-sexual-misconduct/ [Accessed 15 July 2018].

Gallop, J. and L. Berlant (2001). Loose Lips. In: L. Berlant and L. Duggan, eds. Our Monica Ourselves: The Clinton Affair and the National Interest. New York and London: New York University Press, 246-267.

Goffman, E. (1963) Stigma: Notes on the Management of Spoiled Identity. Englewood Cliffs, NJ: Prentice-Hall, Inc.

Hall, S. (1997). The Centrality of Culture: Notes on the Cultural Revolutions of Our Time. In: K. Thompson, ed. Media and Cultural Regulation. London, Thousand Oaks, CA, New Delhi: Sage., 208-238.

Hannah Gadsby: Nanette (2018). [comedy special] Netflix.

Jones, O. (2017). How dare you, Kevin Spacey? You've fuelled a vicious lie about gay men. The Guardian. 30 October. Available at: https://www.theguardian.com/commentisfree/2017/oct/30/kevin-spacey-vicious-lie-gay-men-accusation-attempted-sexual-assault [Accessed 30 October 2017].

Kaboom (2010). [film]. USA and France: Dir. G. Araki.

Love Island (2015-). [ Reality T.V. series] ITV,UK.

Mad Men (2007-2015). [T.V. series]. ABC (US), Channel 4 and BSkyB (UK). M. Weiner. Lionsgate Television. USA.

McRobbie, A. (2015). Be Creative: Making a Living in the New Culture Industries. Cambridge and Malden, MA: Polity Press.

Miller, W.I. (1993). Humiliation. Ithaca, NY: Cornell University Press.

O’Connor, C. (2017). Billion-Dollar Bumble: How Whitney Wolfe Herd Built America's Fastest-Growing Dating App. Forbes. 14 November. Available at: https://www.forbes.com/sites/clareoconnor/2017/11/14/billion-dollarbumble-how-whitney-wolfe-herd-built-americas-fastest-growing-datingapp/\#6dc3e302248b [Accessed 16 July 2018]. 
Probyn, E. (2005). Blush: Faces of Shame. Minneapolis and London: University of Minnesota Press.

Rachmaninoff, S. (1901). Piano Concerto No. 2 in C minor, Op. 18. [Score] London: Boosey \& Hawkes (1947).

Rich, A. (1986). Notes toward a Politics of Location (1984). In: Bred, Blood and Poetry: Selected Prose 1979-1985. New York and London: Norton, 210-231.

Roy, A. (1997). The God of Small Things. London: Random House.

Sedgwick, S. and A. Frank (1995). Shame and its Sisters: The Silvan Tomkins Reader. Durham and London: Duke University Press.

Seigworth, G. (2015). Structures of Digital Feeling. Keynote Address. University of Buffalo, March 15. Available at: https://www.academia.edu/26759922/ Structures_of_Digital_Feeling_-_Keynote_Address_-_University_of_Buffalo_March_2015 [Accessed 15 July 2018].

Shapr (2018). Available at http://www.shapr.co [Accessed 7 August 2018].

Simmel, G. (1971). The Metropolis and Mental Life. In: D. N. Levine ed., Individuality and Social Forms: Selected Writings. Chicago, IL: University of Chicago Press, 324-339.

Skeggs, B. (1997). Formations of Class \& Gender: Becoming Respectable. London, Thousand Oaks, CA, New Delhi, Singapore: Sage.

Striphas, T. (2015). Algorithmic Culture. European Journal of Cultural Studies, 18 (4-5), 395-412.

Tyler, I. (2013). Revolting Subjects: Social Abjection and Resistance in Neoliberal Britain. London and New York, NY: Zed Books Ltd. 


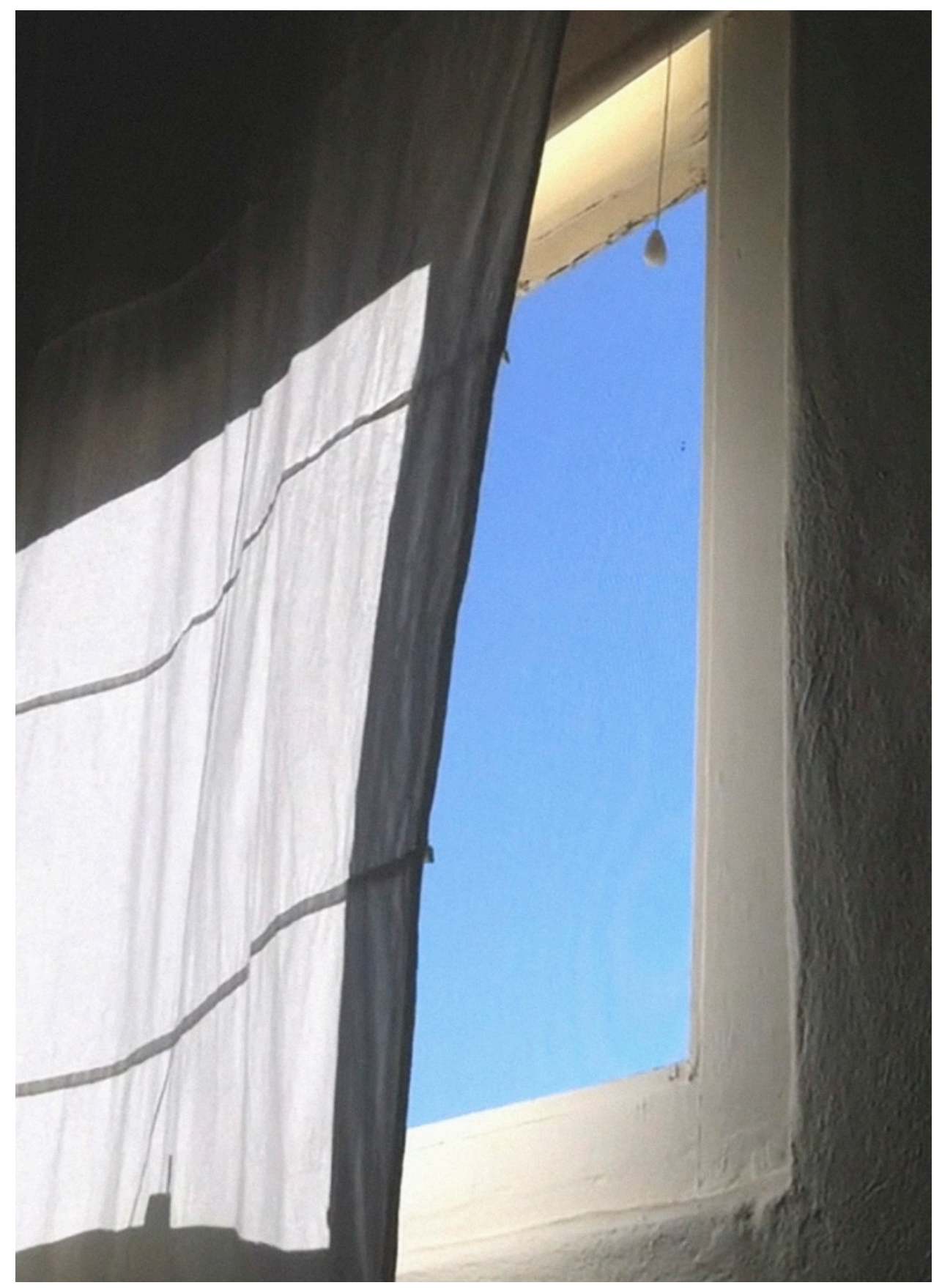

An Ode to John Smith (detail), iPhone 5 [2:34], Smiljana Glisovic, 2015 Creative Commons Attribution 3.0 (CC BY 3.0) 


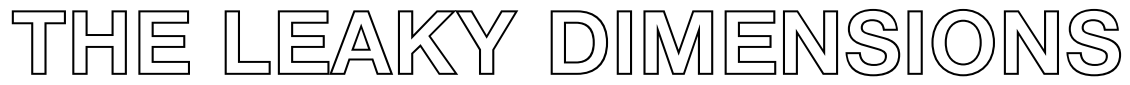 OF FIM AND W/AR, OR SOME GONNEGTVE 『SSUE}

\section{Smiljana Glisovic \\ RMIT UNIVERSITY}

A desire to understand a thing can precipitate a range of acts on the part of the researcher on their quest for knowledge. For an artist-researcher the materiality of their practice often plays a key role in their 'coming to know'. This writing interrogates how particular materialities played into my research process in coming to 'know war.' All of the gestures along the way were intentioned toward arriving at 'knowledge' through the body. The essay looks at the materialities of language, sculpture, performance, and moving image and their various potentials for creating knowledge events-encounters where we can come to know through experience. The central question in the research becomes: can a moving image work make war felt? This writing is an exposition of a short film I made in the process of this research and how temporality, duration and an ekphrastic practice can work to create such a knowledge event. This is a performative piece of writing that enacts the play of elements that drive creative-practice research. It shows up the complex tangle of the personal and bodily, the theoretical and writerly, which co-create our coming-to-know.

\section{KEYWORDS}

nonrepresentational theory, affect, moving image, creative-practice research, event 
The setting is Khao Lak, Thailand, 2015. It's hot. I'm reading the 2013 Winter issue of the Granta Magazine of New Writing themed "Betrayal” (2013). There are twelve works in the collection-fiction, non-fiction, a photo-essay, a poemand they all in their way, according to Granta press-releases, explore "the sting of betrayal by a loved one, our leaders, and from within our own hearts," they look at "betrayal's many forms," and the "many shapes of betrayal" (n.p). This collection had been on my bookshelf for some time but it is only in 2015 that I picked it up as a summer holiday read. A strange choice, perhaps, for a poolside trip to Thailand. But I like the short story form for a holiday read, easy to pick up and put down between dips in the pool. A really rewarding themed collection, though, is one where the related/unrelated short pieces resonate in a way that illuminates something bigger beyond the small bites on offer. For me it wasn't betrayal but war that held it all together.

Connective tissue, the fascia, holds things-apart, together. This is what we mean when we say things 'resonate': a vibration in and between things. We might think of the way sound does this as it travels through walls, connecting or remaking the boundaries between spaces and entities across those spaces. Resonance between parts could also be thought of, or experienced as, a certain kind of intimate relation between things that appear separate but are not. The force that things that are separate exert on each other, and the quality of that intimacy, is of interest here in this essay. In particular I am interested in resonances between the specific materialities of sculpture, performance and moving image, and philosophical frameworks that give us language around the question of knowledge and research. Further to this, this essay interrogates what an appropriate response to affectively intense material is-for the philosopher, the artist, the researcher, the audience, the reader.

The research investigation unpacked in this essay is about tactics for measuring the weight of war. I pointed to the moment by the poolside in Khao Lak as a kind of 'inciting incident' for this investigation. I set the scene in this way because I can pinpoint this moment as the moment when a troubling-that had already been lodged in me-started to arise and become inextricable from my reflection on the way my troubling took shape. My writing here is not a critique or literary analysis of the Granta collection, though it is tangled up in the story of it all. The content of the pieces in the collection, the thematic thread, was indeed about betrayal and not war. Reading the Granta collection that held within its pages 
contexts around the globe that had political conflict, sitting alongside the more focussed stories around the theme of betrayal, was certainly a gateway into my own investigation. My investigation was born of a special confluence of things: being in Khao Lak post the 2004 tsunami where its effects were still visible and the affects thick (devastation and relaxation); the dissonance between what I was reading and what I was doing (violence and relaxation); the state of being relaxed enough for knots of violence held deep down in my body to loosen a little and come up to the surface; the attention to the weight of the body in and out of the pool; in and out of the humid air; in and out of earshot of the hotel workers who were many, attending to only myself and 4 or 5 other guests. Syria, Lebanon, Burkina Faso, Wyoming were some of the places the stories were set. I was thinking of the Arab Spring, the Syrian crisis, the refugee crisis in Australia. This complex of things exerting their force on each other gave rise to an investigation into finding an appropriate response to my troubling about war.

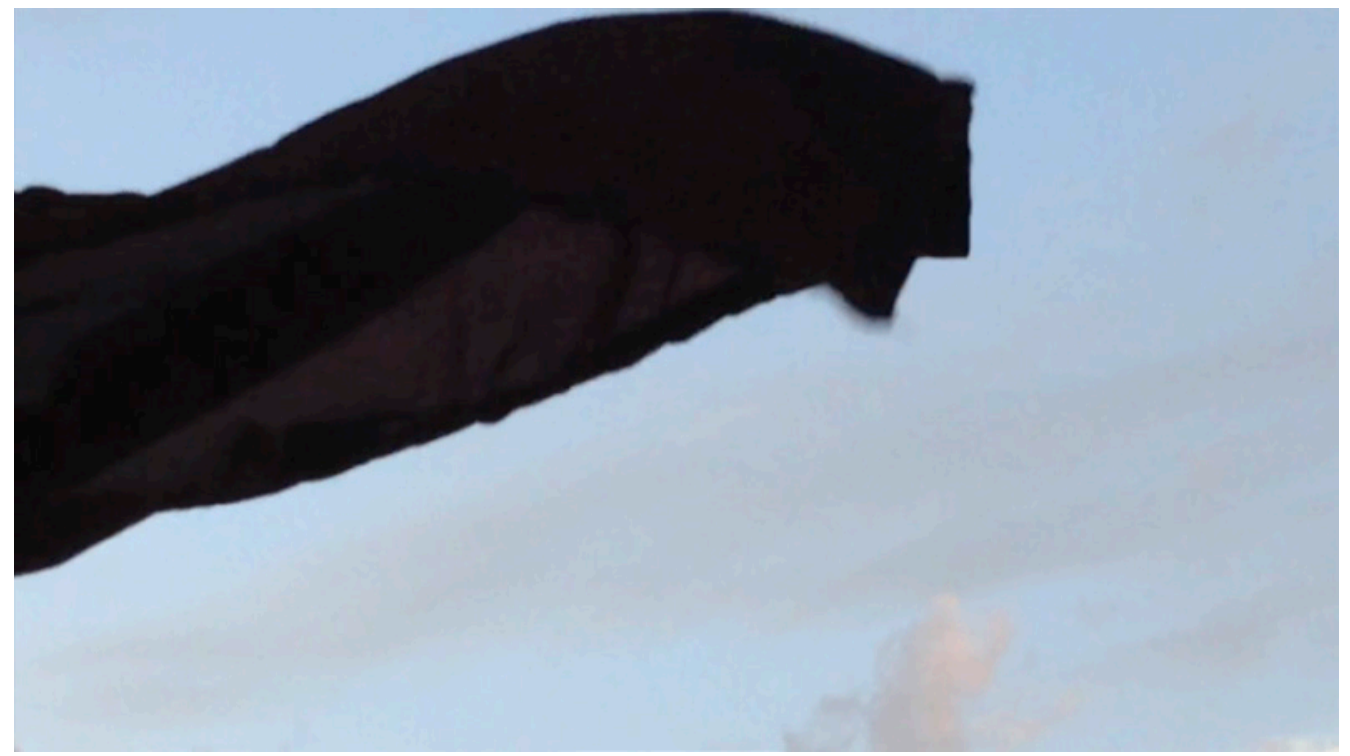

An Ode to John Smith, iPhone 5 [2:34], Smiljana Glisovic, 2015

This writing, which reads partly as an exposition of my search for a response to war, is an experiment into whether it can serve as the fascia of the story about how particular materialities in art might access a certain kind of knowledge. How exactly these materialities and concepts interrelate in the quest for a certain kind of knowledge, and how this kind of writing can give a sense of the quality of that interrelationship is also of interest here. I will trace various ways in which the body, in relation to knowledge, can figure in artistic research, both for the maker and for the audience. And how the materiality of the medium the artist-researcher 
is working with has particular significance in this dynamic between knowledge and body. I do reach for some theoretical concepts to help me understand and articulate the movements made along this investigation. I do this with the help of Deleuze and others on the topic of affect and the co-constitution of bodies, experiences, and worlds. I consider the problems with aesthetic representation and use non-representational theory to help me articulate knowledge as an 'event' rather than an 'artefact'. With this I privilege contingency, performativity, and the encounter. I will think through my acting training and how this has come to bear on the processes that have shaped this research. I look at sculpture in terms of how physical objects act on bodies in affective ways, and end with a discussion of how all this relates to the moving image and a short video work that I made: An Ode to John Smith (2015).

In Khao Lak, the troubling that bubbled up-as I read, and swam, and ate, and witnessed a minotaur being bludgeoned to death by the hotel staff-was that I needed to 'comprehend war', all of its effects and affects, in a total and graspable way. A discomfort in the shape of responsibility arose and I proceeded to use metrics as a way of alleviating it: I had to know all the facts, the where and who and why and how much (of it all) of all, wars. But simply 'knowing' the facts and figures would not do it, these facts and figures had to take on a weight, and it was this weight I wanted to manifest in the shape of a sculptural work. What would I measure? Dead bodies? The weight of them? Would I make a globe made of bullets? A globe that gets heavier as more bullets are added as wars around the globe flourish? I was thinking of a physical mass that would quantify war. My sculpture would be a rationalised object of war, without emotion or gore. I wanted to create a simple object, a single thing, unequivocal, something one could not debate. I didn't want to get caught up in the mess of it, in the things that leaked, but rather in numbers and hard facts that were physically relatable to the size of our own bodies. I am talking here about gravity-the natural pull of forces-the (indisputable) gravity of the situation. To turn the amorphous and invisible into something concrete is to bring it into the physical realm where it is governed by the same laws as our bodies. The 'meaning' and 'significance' of the work would lie in simple mathematics. The uncomfortable 'not knowing' would be alleviated through a knowledge with the body. What I wanted was epistemological control because anything otherwise was too frightening. I want to evoke Timothy Morton's "hyperobject" here because it is a conceptual offering that articulates how I was experiencing 'war' at his moment: too big for me to think: it is unthinkable, it is everywhere, it permeates all of our worldings (2013). The impulse toward mak- 
ing a simple object that did not permeate everything everywhere but had visible, sensible boundaries seemed a way I could contain this frightening 'everywhere'. By creating a physical object, rather than having to grasp a troubling idea-the thing I can't grasp, grasps me. The (imagined) sculpture would strike the body and make itself known. The thing I couldn't understand or relate to relates and makes itself understood by its size, weight, dimension. This was the first impulse, one that came from fear.

But I knew better than to think of an object as separate from me simply because it and I have skins that apparently keep things in and apart. An object and a body are openings toward a certain kind of material and affective relation. Seigworth and Gregg's definition of body in their rendering of affect is:

bodies defined not by an outer skin-envelope or other surface boundary but by their potential to reciprocate or co-participate in the passages of affect. [...] Affect marks a body's belonging to a world of encounters or a world's belonging to a body of encounters but also, in non-belonging $(2010,2)$.

Speaking of bodies does not mean human bodies. The thing that defines a body is simply this potential (not even ability) to "reciprocate and co-participate" in what the authors significantly call 'passages', as in movements, of affect. Plus: bodies also think. Deleuze defines the "thinking body" not as a body that thinks, but a body that plunges us towards the "unthought" $(1989,182)$. This kind of body must move toward a new way of being, it moves toward new knowledge that remains otherwise inaccessible. The body is our transport towards transformation. This kind of body is active, not controlled by the mind as a separate organ that resides in the head. Deleuze is theorising this in the context of his work on cinema. The lineage of the idea starts before this on his work on Proust with the notion that sensual "encounters...force us to think" $(1972,161)$. Here the argument is developed that our sensual encounters with artworks plunge us towards the unthought.

And let's not forget the researcher also has a body and not just a mind that thinks. My war sculpture proposition seems to hinge on the idea that I can create a condition for an encounter between the body of the sculpture and the body of the audience; that this encounter opens up passages of affect, of knowing. How does an artist-researcher go about creating this condition: a potentiality for the audience to be moved toward the unthought, which is to say toward a new way of becoming? Are there limits to the kinds of conditions I can create? Can a sculpture do this work? So far I have come up with no instruments of measure, only this kind of practice of exposition and plaiting of fascial tissue. What's more is that I do not have a sculptural practice. This is obvious, I'm sure, in the naive way I have been talking about what sculpture can 'do', how it 'speaks' or what it has the potential to instigate. 
My sculptural proposition was a very representative offering. By swapping representation for reverberation, we come to a non-representational way of proceeding. A non-representational researcher is not interested in observing the world and notating those observations in order to classify, order, and attach meaning to those observations. This kind of researcher's work uses “techniques that do not concern themselves so much with representing lifeworlds as with issuing forth novel reverberations" (Vannini 2015, 12). A reverberation is felt, sometimes maybe heard, a reverberation is hard to describe or represent. A reverberation moves through walls, like sound, it's no good to try and contain it; it may feel different depending on where and how you are standing, depending on who you are, depending on the receptivity of your flesh. Reverberations are a result of gestures and movements; there's only the moment or "event" of the act.

Erin Manning relates events to thinking: "to place thinking in the event is to once more challenge the idea that the precomposed subject is extra to the event, and that the thinking happens from outside-in" $(2015,61)$. The event is the thinking and the event is composed of an entire complex of reverberating entities. This is about presentness, privileging action, practice, performance. I am speaking here of the researcher's acts and of the audience as another actant in this field of relations. I am speaking about a co-evolution between all kinds of bodies involved in the act of research, and in the act of experiencing the thing offered up as 'the artwork' to an audience. This goes to the heart of the matter: the world is in flux, I cannot hold onto it, not even objects with their apparently well-defined boundaries will be held and measured and weighed. As a non-representational researcher I think and move like an essayist, in the first instance listening to what reverberates and how it intermingles in the continual flux of the world. This kind of research takes into its fold all of the inevitable contingencies. Research is contextual, situated, personal, biased; it has a human dimension. Accounting for these things can be interesting, revealing. Ignoring these things is probably bad research, less interesting, less true. To research is to participate in the unfolding of the world "from the very inside of our being" (Ingold 2015, viii).

Jill Bennett has done some wonderful work around the way "trauma might not readily conform to the logic of representation" and why art's capacity for affective experience is a powerful mode with which to explore these experiences (2005, 3). Bennett makes an important distinction that "affect doesn't come from an emotional response to a represented experience", which is perhaps what we might term sympathy or emotional identification, but rather a "direct engagement with 
sensation as it is registered in the work" $(2005,7)$. She, too, follows Deleuze's construction around the relationship between art's affective potential and concepts. She says "if this affective transaction does not in and of itself convey the 'meaning' of trauma, we must also pursue the question of how it might lead us toward a conceptual engagement" $(2005,7)$. This for me brings forth a provocative question: what does affective knowledge look like? Bennett's study looks at particular works of art and how they offer up an "empathic vision" of trauma in this non-representational aesthetic mode. Whilst this is also my project here

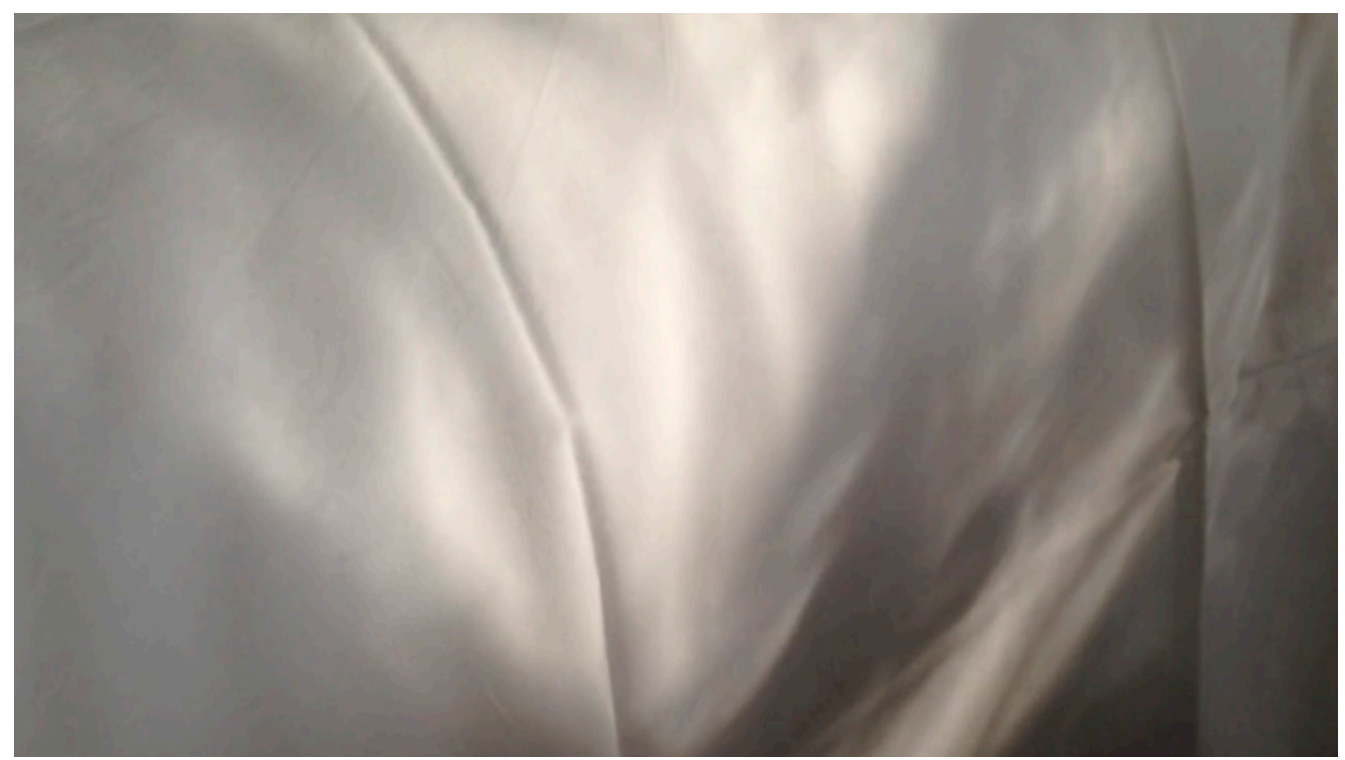

in relation to working with materials in the art context, in order to understand something of the subject of war; my focus is not structured along theoretical lines of 'empathy' as it is with Bennett, who constructs a beautifully crafted argument on empathy being affect plus thought. Whilst Bennett's study has the capacity to greatly influence the lines of inquiry here, my troubling was not about an instance of the trauma of war in relation to a particular lived experience. Rather than understanding someone else's pain and taking it on as my own (which is what much of the critical writing in this field focuses on and which Bennett unpacks), it is about the very inability to 'know' a thing such as war when it is outside one's own direct experience. My work is in understanding the quality of grappling with the impossible-to-know, rather than offering up an affective experience of the thing. Non-belonging and the hyper-object defined my troubling: the impossibility of having epistemological control over something devastating which is everywhere.

A sculpture of war has already been made: Balkan Baroque (1997), by Marina Abramovic. Actually, countless sculptures of war have been made (too many for there to be need of me giving any citations here). And actually, Balkan Baroque 
isn't really a sculpture, it is more a performance work, or perhaps we should call it a performed sculptural work? The work had some sculptural elements, such as the large pile of animal bones on which Abramovic sat. The number of bones and their weight are, I think, not especially relevant. It was more about her performative act of cleaning the bones, and the relationship between this and the other elements in the installation: a video depicting Abramovic playing a Doctor that lectures us on the nature of rats; Abramovic playing a Bulgarian seductress dancer; a video portrait of her mother, and a video portrait of her father. The real Abramovic sits in front of these videos on the pile of bones, and cleans them one by one with a brush. She is there in the dungeons of the gallery for 4 days, with the rising heat and stench of the blood and bone. In videos documenting the work you can see people holding hands over their faces to block the smell out. This work is about endurance, as much of Abramovic's work is. It is about the time she spends in the gallery, the effort of the body, it is about the impossibility of ever getting clean. Still, I would not call her act a futile one; it is an act she must continue to perform even if her task is impossible to achieve. The labor of the act is what is important, the difficulty, and through this pain we feel the pain of the Balkan war, and if we are to extend the affective dimension of the artwork into its theme, we might say that the pain of war is impossible to ever erase. In truth I can only imagine the affective dimension of Abromivic's work, which is more a cerebral act than an affective one, because I haven't experienced the work myself. But I am intrigued by the material leakage of this work-not only in the sense of the leaking stench of the bones as they decompose and surely Abramovic's perspiring body as she works-but the leakage of the various materialities of the live act, the video, the artefacts in the space. I can only imagine that to experience the work is to experience how these expressions are entangled with one another; but I can't quite imagine the affective intensity of these entanglements.

As an aside-Abramovic and I share the same motherland. I was much younger than she at the outbreak of war, and at the time she made this work. Actually, I was completely unaware of her or the work at the time. But I had the same impulse towards pain: I too was safe whilst many that I knew were not safe, and a certain kind of shame comes with that. I understand Abramovic's impulse toward creating pain for herself in order to alleviate some of the shame. This is an aside, but interestingly brings us back to this original feeling of needing to know what a thing feels like, as an act of responsibility. I wasn't thinking of making an artwork when I was thinking about my sculpture. I was only grappling with my 
own lack of understanding, and for me embodied cognition happens through the act of making, of handling materials, moving the body. But this isn't an aside at all. The entire project under construction and evaluation here is about fields not through-lines, about the quality of connection not a hierarchy between connected elements. Surely to proceed in this way does away with the concept of the aside.

And so I will tell you another part of this story that involves a 'healer' I see. The last session included her bringing up a long-forgotten memory from my own childhood. I had been in Australia only a year or two when the war back home broke out. My parents tried to shield me from it as much as they could, I suppose they thought it was not something a child could possibly process or understand. Nonetheless, what they never knew was that I went to bed every night composing speeches I would give to the entire nation which would move them in such a way that they would all stop fighting. I actually thought this was possible: for a ten year old to speak such words that would stop a war. It was a painful time, it was a pain that sat deep in my belly, which the healer is now trying to "throw up into the light"-whatever that means. The healer speaks in a language that I'm sure is inadequate to what she's actually seeing and experiencing during the session; but I mostly think I 'understand' what she's saying. Mostly I just feel things moving in my body. Mostly we don't speak. This story relates. It speaks of other practices that recognise that things can get stuck in our bodies. It also relates because it takes us back to how old my troubling with war really is. Back then I thought some poetry would help. I grew up and thought a sculpture would work to do the job. And now I'm writing words that keep working at the very same problem. Except that I am learning, with experiences such as the one with the healer, that access to these other non-verbal spaces, spaces that we so inadequately refer to as 'the light' for example, might be necessary.

My consciousness about this way of experiencing and thinking about the world, where the body was a way toward a certain kind of understanding and knowledge unavailable to other registers, was developed when I was training to be an actor. As an actor prepares they ask: where does it sit in my body? This question is particularly useful in moments that are difficult to understand, the moments that don't immediately yield an impulsive response to a situation, to how the character you are playing might react. Notice that I do not say feel, because in this school of thought feelings are irrelevant, it is how the body is moved that is of concern. Or rather: feelings take care of themselves and we do not need to manifest them or focus on them at all, they are only a consequence. By the time emotion arises as such the impulse, or the body's response to a stimulus, has already passed. Emotion is something we name after the body has already responded to a past moment. I take emotion here to mean a cognisant awareness, 
an ability to name and classify what has happened in/to the body as a response to something. Affects are the passages, the movements, in and between bodies that emotion doesn't quite capture (see Cataldi (1993) for a perspective on this via Merleau-Ponty's phenomenology). As an actor prepares they are most likely

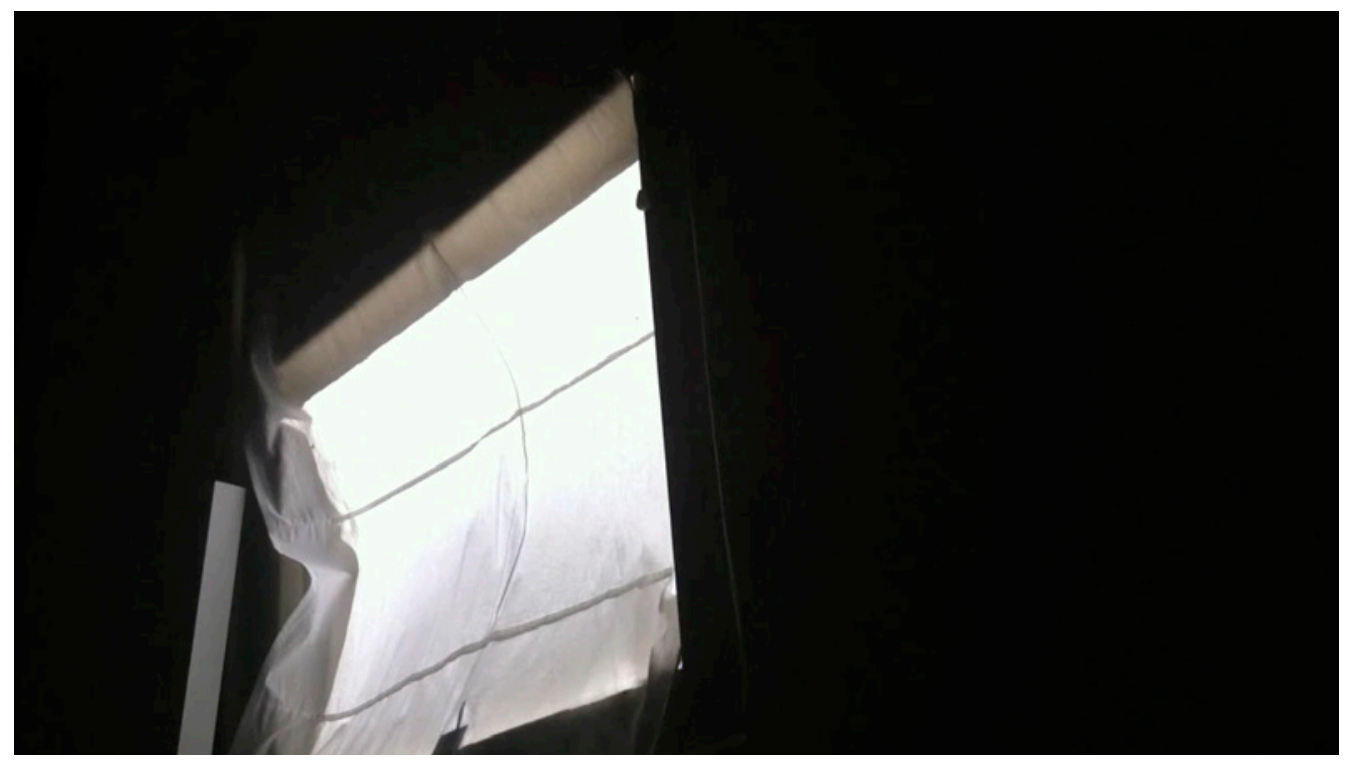

not thinking of the philosophical traditions that have engaged with these ideas; this was not the framework for the training. What I share here on acting was a knowledge I came to through experience. It is an experience I drew upon when thinking about my sculpture. From my current position reflecting back, I do turn to philosophical concepts on the subject in the hope it will help me draw together things that have so far sat apart. Manning, reading James, says:

to reorient the real to include that which can be experienced (rather than known as such) is to profoundly challenge the notion that knowledge is based on quantification, for what is real in James' account cannot, in all cases, be quantified. What is real is the field of relations through which an experience comes to act, comes to be felt as such. What is real is as much the in-act of experience unfolding as what has come to be $(2015,55)$.

Neither experience nor philosophy, neither the world, nor the researcher are already formed and simply on offer for observation, annotation, and deduction. The field of the stage helps me think this through in a material way. I think of the stage and everyone on/in it, all of its actants held together, part of the same membrane. As one actor moves (as a result of their body being struck by another body), everything changes, new relations are formed. Encounters change everything. 
We might think of the stage as an assemblage in the Guattari and Deleuzian sense (2004), where an assemblage is just this kind of encounter of relations between bodies. Assembl-ing would be a more accurate translation of "agencement" because it articulates the transitive nature of this thing that is a situation. There is a holding together but also a constant forming and reforming, never the same, never again quite in this way. An actor's main task is to attend to the singularity of each moment, or to 'stay present'. The present moment is found and lost simultaneously by virtue of impulses propelling you into the future-you are not feeling an emotion and then responding according to it. You do not play the emotion, that is a turgid approach, because you are then occupying the past and the future and not the present. An actor simply plays the present, in action, by allowing themselves to be moved by the other actors on stage. Pre-conceiving and determining cognitively how to respond to situations and events is apparently bad acting-and also bad research. The question: "where does it sit in my body?" is a passage of affect which 'moves' the actor across the stage, in relation to other bodies on stage. This is a kind of 'move' by a thinking body toward an 'appropriate response'. Paying attention to where something strikes the body and allowing impulses to arise in response to that sensation is a kind of thinking of the unthought. Of course all of this is held together by myriad things such as the situation that the play-script has already somewhat determined. This is to say that our 'impulses' are also structured, there are parameters within which we are working, there's always scaffolding that keeps a show from being utterly derailed.

My purpose here is to pay attention to the co-constitution and evolution of bodies, experiences, worlds, and to attune to the thought-in-the-making (see Manning \& Massumi 2014). It is also to explore what happens when there are interruptions to our experiences, in such instances such as war; how these traumas reach deep into our entanglements and worldings. And I'm wondering whether any of the concepts or philosophies I am occasionally drawing on can have a grounding effect/affect; I suppose in the way I had desired of the sculptural object? I've already made my confession that I do not have a sculptural practice and that all of this talk of sculpture only remained at the conceptual level.

I do have a moving image practice, and so I turned my attention to this. Of course, we have Resnais' Night and Fog (1956), and we have Farocki's Images of the World and the Inscription of War (1989). They both use the moving image as document, as evidence that is rooted in a particular time and place of traumas. They both interrogate the 'archive' and take us toward reading the images anew. But for my intentions I did not have images to go back to. My problem was not one of representation. I wasn't troubled by extant images of war. It wasn't the shock of a single image and its implications that I was interrogating, the emaciated or 
immolated body. I yearned for a sense of a kind of totality, an understanding, all at once, of all the places war touched. To proceed, I considered my move from sculpture to film. Though the sculpture as conceived was highly representational, its affect was conceived to arise from the physical size and weight of the object. And so in this same way I was interested in whether the moving image could achieve this sense of weight and size, this status as 'object', but not in a representative way? What is the weight of film: the celluloid, the light, the screen, the volume of air? Could weight on screen articulate gravity and dimension of the sort I had imagined for my sculpture-one that strikes the body? Was the only measurable thing in film its length, its temporal dimension? Or the inverse of that: could duration as a quantitative measure have qualitative affect? Film has a more determined temporality and duration than sculpture does. But temporality and duration are also important to sculpture. I won't perform an analysis of the material and ontological differences between sculpture and film, that is not my intention. The significance is the way in which my thought-experiment on sculpture led me to consider whether the moving image could do the work of making war felt. I could turn here to many films and a lot of excellent literature on the affective power of film, such as Marks (2000), Sobchack (1992), Rutherford (2011), Shaviro (2010), amongst others. But this literature doesn't quite address my particular concern around affect and weight. I wanted to understand pain in terms of weight. What can the moving image do in measuring the weight of pain? What is the difference between moving images and other art objects? How do I use the impulse toward sculpture and object creation in understanding moving images better?

To frame this discussion I would like to call on non-representational research again and proffer that film, too, can be a generating field of encounters rather than an object of the already thought. My moving image practice is one that I use to help me think. I turned to the moving image clips I archive in my mobile phone to help me think my way out of the sculpture and into another way of exploring my 'troubling.' I flicked through some small morsels of video I had captured here and there. I came upon a couple of clips that I had shot whilst in Khao Lak. One was a close up of the shadow of a tree cast on the hotel bed sheets. The other was a flag on the beach blowing in the wind. I found a couple of other ones that were of a similar material quality to the shadows on the bed sheet and the flag from Khao Lak. One was a curtain blowing in the wind, taken a couple of years earlier in my bedroom. I remember the moment: lying on the bed in a relationship-break-up stupor, noticing the quality of movement and 
becoming aware of the gentle warm breeze coming through the window. The light, the implication of breath, called forth the war sculpture. Not weight but weightlessness. Here, there is a significant confluence of things: hotel rooms, videos, wars. This brought to mind the filmmaker John Smith and his The Hotel Diaries (2001-2007) film series. Whilst on the film festival circuit Smith made small diary films with his camcorder in his hotel rooms. They appear accidental and mundane, there's nothing beautiful about his compositions. He stutters and lisps his way through seemingly unstructured and unthought-through musings on the state of the hotel, the grime on the taps, and on the faulty TV. But there are other topics of conversation, too. He tells us about what he has seen beyond the four walls where he is filming, things he cannot show us because he is in Gaza or Lebanon where he cannot take out his camcorder. He muses on current politics in his casual, laconic tone. He puts on an innocence that holds only so far. Sometimes he can't but throw in a sharp and exacting polemic. He is trying to identify with the various political situations he finds himself in, through his slightly stupid, uninformed, white male lens. Of course this is the part of the performance that helps us to identify with these war zones through him. But he doesn't really acknowledge the viewer, it seems he is only making these records and musings for himself. This is his holiday video which his unfortunate family members might be subjected to upon his return home-or that is the conceit.

I made my own Smith-inspired film, which resuscitated the sculpture. The images we see in the film are the curtain blowing in the wind, the light playing on the bed sheets, the light playing over a contact sheet from Mekas' film Paradise Not Yet Lost (1979), and the flag fluttering. The sound we hear is the blowing of wind, a siren in the background. I told the story of the sculpture in this video, with my own Smith-esque voice-over which was rather white text on a black screen. Smith's voice-overs have a sense of being a draft version, a work on its way to being something else, accidental sketches taken as prompts for thought. My film practice takes this same shape of the incidental, the improvisatory, the openings that precipitate further thought. I called this film 'An idea for a film', then 'An idea for a film of molten lead', then An Ode to John Smith. I had to make a work in order to gesture toward a work that I was never going to be able to make.

This kind of ekphrastic practice imagines the impossible work in such a way so the work is made in the imagination of the viewer. In this case the moving image work is posited as 'not the real thing'-just a stand-in for something else in the making-or that is the conceit. The intended sculptural work is about volume, something to put in people's paths, so that it isn't just another fleeting, forgettable piece of poetry. The film is apparently just an interruption while the other work is being properly conceived. The film consists of pictures of light and wind. The 
images themselves are not already reduced to meaning, but rather offer an experience of qualities such as lightness-perhaps evoking the question of gravitas, of dimension and significance, and how these are measured. There is an interplay of materialities here between the text on screen, the black space in the frame, the silence, the qualities in the moving images, the rhythms they play out. We might also call these aesthetic interruptions: the plunge into the black on screen, the move toward the text, the blunt address of those words. We might remember that affect is "both relatedness and interruptions in relatedness, becoming a palimpsest of force-encounters traversing the ebbs and swells of intensities that pass between 'bodies"' (Seigworth and Greg 2010, 2). Significantly there are no human figures in this video work. There is no one to identify with, a deliberate denial for the potential of emotional or sympathetic attachment. Rather the video creates a dwelling space for a thinking body to play out the tensions of my own grappling with the topic of war. The 'dwelling space' is created through time and relatedness between the frames of the film. The most basic measurable dimension of the film-as-object is its duration. Can duration measure the weight of pain? If we apply the logic of the sculpture here, we would be saying: can a time-based work be long enough, make its audience endure enough, to approach an understanding of something like war? And what kind of pictures would the audience need to endure?

But this is to treat film as an object. And this is the very thing that is put into question by the film. Length does not equal weight. So when I speak about time and length I mean: the length of a breath. An audience breathes together with the film. An audience is beholden to the duration of the work, this is an intimacy and a particular kind of fascia holding bodies together. What is between the frames is the other dimension of film's affective capacities that leak beyond the simple duration and time that we experience in a linear manner when we say: how long is the film? This capacity is a film's visual depth, the way events-thematic, textural, material-across the film resonate with one another. This chiming across the images has the potential to evoke a multiplicity which isn't determined by the linear, measurable length of the film, it is a leaking that can break the limits of the frame entirely. The film itself does not address this capacity of excess but rather its lack: I call the film a 'place card' as if it in itself is not enough, it doesn't do the job, it is not complete. This is a playful dimension of the work that puts in mind the particular access film has to formal registers different to the sculpture, or essay, or philosophical proposition. 
With video I worked toward the fleeting, banal, everyday image that was not of any thing but of quality (light, texture, movement: the most basic elements of the moving image). I also used words which did not anchor meaning in the images, but spoke of things I could not film. The weight of the sculpture is compared explicitly with the weight of the film. It is only a speculative proposition that hopes to precipitate a thinking about the relationship between objects, events, measures, and what the knowledge and art object or event are capable of instigating. To do this work the film puts scale and materiality at the centre of the investigation by positing questions around its own value, around what it can do as a place-card only, until it gets-it-right or manifests a sculpture of concrete, of molten lead. But then we watch the flag fluttering in the wind, awakening the rhythm of our own body, and here open the passages of affect: the event that precipitates movement, then thought. An Ode to John Smith became an accidental act in ekphrasis, whilst denying its own status as an artwork. The film is at-a-loss, rather than graspingit-all. The film leaks: it has a duration but no single temporal dimension; its spatial dimensions offer no anchors in a representational sense. Black space holds the text on the screen which plays out slowly, laconically arising and falling as a slow, not urgent, thought. This black space is another moment of vertigo, untethered in time and space, at-a-loss. The gravity of our subject cannot be given in terms of simple measure, there are leakages, and interruptions and also moments of lightness and lostness. The film is not an object. It is a body, like the actor, like the sculpture-full of potential and only a possibility. I am left with the echo of the following: to grapple; to handle; to act; to be present; to be at a loss.

In this grappling we're trying to come to an understanding. But non-understanding is also useful. Non-understanding, just like non-belonging, might give rise to alternatives. Jane Bennet proposes this for the potential of art $(2009,21)$. So does Morton: "art sometimes gives voice to what is unspeakable elsewhere" $(2010,12)$. The practice of art provides alternatives to thinking, alternate paths for research, alternative ways of knowing. In this instance the film enacts the limitations and possibilities for how art thinks the alternatives, where alternatives here mean not thing-containers of knowledge but conditions for "thinking otherwise". As McCormack says, the experimental quality of affective spacetimes is not so much that they provide "opportunities to prove or demonstrate a prefigured idea, but that they have the potential to generate a feeling of something happening that disturbs, agitates, or animates ideas already circulating in ways that might open up possibilities for thinking otherwise" (2013, 9-10). 
My ode is a provocation to experience 'otherwise', to ask: where does it sit in my body? This particular provocation happens by way of questioning the limits of the form. An Ode to John Smith is an unfinished thought and gesture; it is a space made of duration and light, for the contemplation of the heaviness of war. Attending to how these lines of thought and practice converge and refract as I have done in this essay can also find a place for the elsewhere or the otherwise. Both are experiments in the passages and interruptions in the search for understanding the ungraspable.

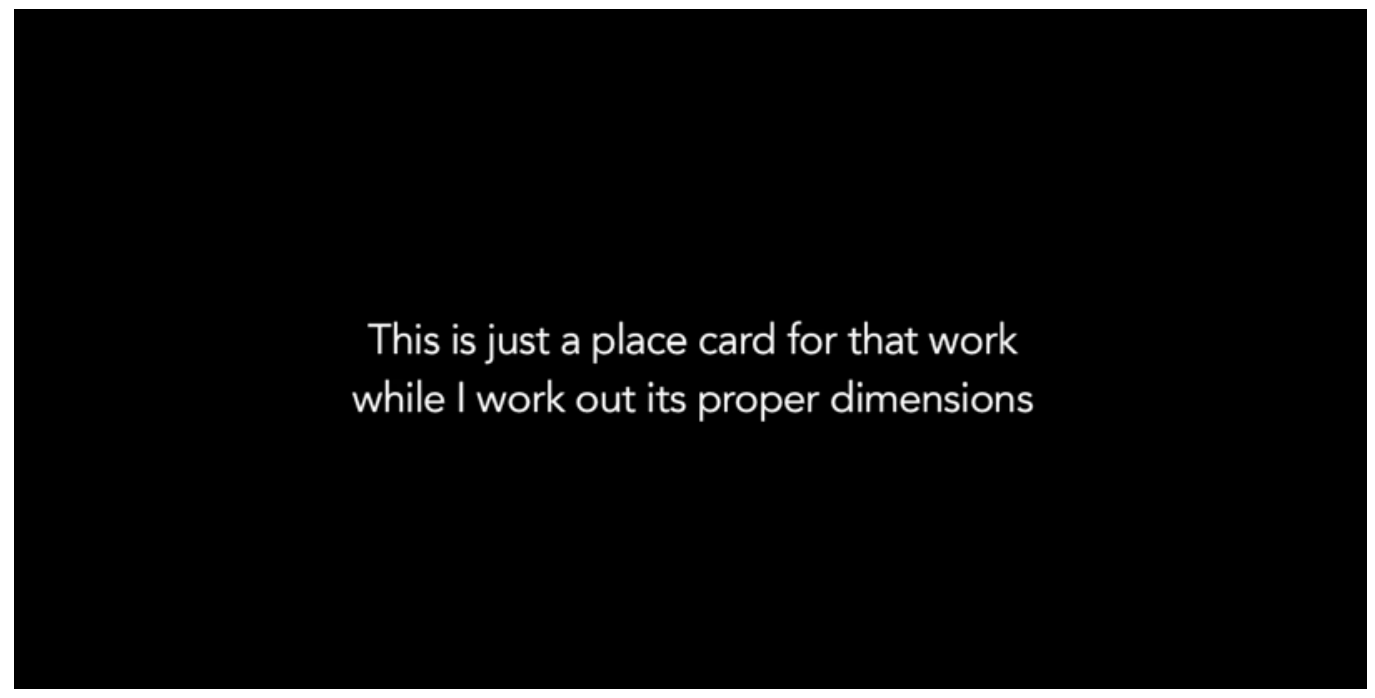

An Ode to John Smith, iPhone 5 [2:34], Smiljana Glisovic, 2015

\section{References}

Abramovic, M. (1997). Balkan Baroque [installation]. Venice Biennale: Venice.

Bennett, J. (2010). Vibrant Matter: A Political Ecology of Things. Durham: Duke University Press.

Bennett, J. (2005). Empathic Vision. Stanford: Stanford University Press.

Cataldi, S. L. (1993). Emotion, Depth, and Flesh: A Study of Sensitive Space. Albany:

State University of New York Press.

Deleuze, Gilles, \& Guattari, Félix. (1987). A Thousand Plateaus: Capitalism and Schizophrenia. Minneapolis: University of Minnesota Press.

Deleuze, G., Tomlinson, H., \& Galeta, R. (1989). The Time-Image (Cinema 2). Minneapolis: University of Minnesota. 
Deleuze, G. (1972). Proust and Signs. New York: George Braziller.

Images of the World and the Inscription of War (1988). [DVD]. Chicago, Ill.: Video Data Bank. Dir. Harun Farocki.

An Ode to John Smith. (2015). [videorecording]. Melbourne: Mobile Innovation Network Australiasia Film Festival. Directed by Smiljana Glisovic. Available at: https://vimeo.com/144438236 (password: video)

Ingold, T. (2015). Foreword. In P. Vannini, ed., Non-Representational Methodologies: Re-Envisioning Research. New York: Routledge, vii-x.

McCormack, D. (2013). Refrains for Moving Bodies. Durham:Duke University Press.

Manning, E. (2015). Against Method. In P. Vannini, ed., Non-Representational Methodologies: Re-Envisioning Research. New York: Routledge, 52-71.

Manning, E. \& Massumi, B. (2014). Thought in the Act: Passages in the Ecology of Experience. Minneapolis: University of Minnesota Press.

Marks, L. U. (2000). The Skin of the Film: Intercultural Cinema, Embodiment, and the Senses. Durham: Duke University Press.

Paradise Not Yet Lost (aka Oona's Third year). (1979). [videorecording]. New York: Arthouse, Inc. Dir. Jonas Mekas.

Morton, T. (2010). The Ecological Thought. Cambridge, Mass.: Harvard University Press.

Morton, T. (2013). Hyperobjects: Philosophy and Ecology After the End of the World. Minneapolis: University of Minnesota Press.

Night and Fog. 2003. [DVD]. USA: Criterion Collection. Dir. by Alain Resnais.

Rutherford, A. (2011). What Makes a Film Tick?: Cinematic Affect, Materiality and Mimetic Innervation. Bern; New York: Peter Lang.

Seigworth, G. J. \& Gregg, M. (2010). An Inventory of Shimmers. In M. Gregg \& G. Seigworth, eds., The Affect Theory Reader. Durham: Duke University Press, 1- 25.

Shaviro, S. (2010). Post Cinematic Affect. Winchester; Washington: Zero Books, 2010.

Hotel Diaries. 2007. [film] Chicago, Ill.: Video Data Bank. Dir. by John Smith.

Sobchack, V. (1992). The Address of the Eye: A Phenomenology of Film Experience. Princeton: Princeton University Press.

Vannini, P. ed. (2015). Non-Representational Methodologies: Re-Envisioning Research. New York: Routledge. 


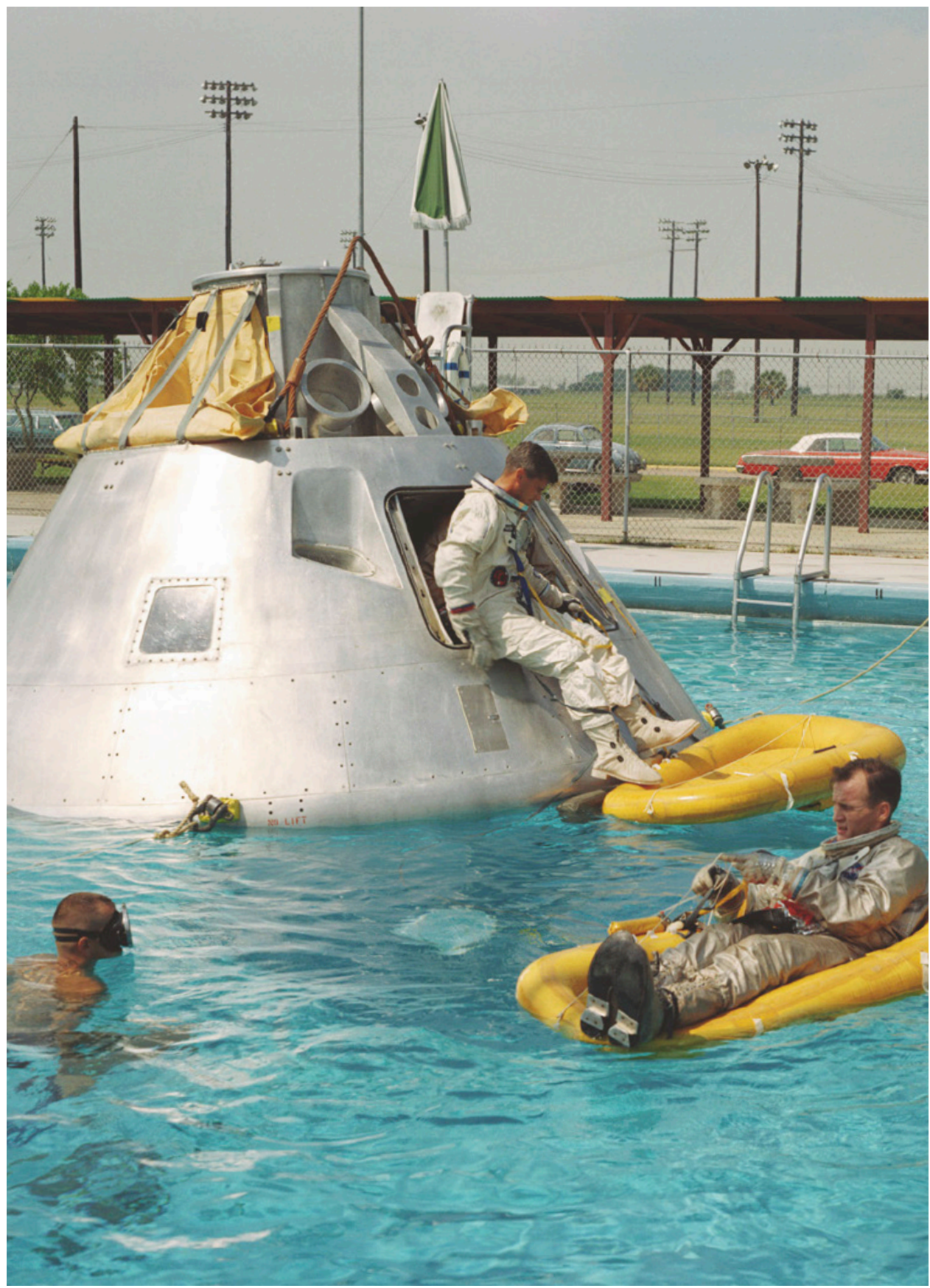

Apollo 1 Water Egress Procedures, NASA, 1966 


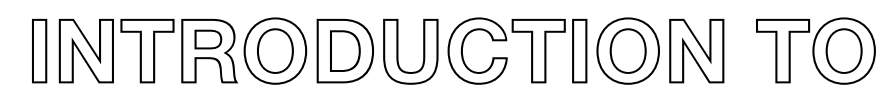

JERISM: EXGERTS

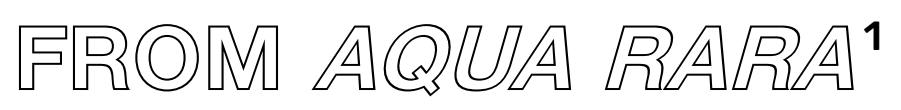

Jock Cousteaux

2014-2018

To learn to swim is to conjugate the distinctive points of our bodies with the singular points of the objective Idea in order to form a problematic field.

—Gilles Deleuze

Monstrous hybrids: I love that in swimming, the butterfly stroke features a dolphin kick.

- Ingrid Tatyanova

\section{\#aquariumchannel205}

All I can see are glassy fish swimming around in a tank for some programmable duration. Then a brief interlude of darkness: the screen fades to black for four, maybe five seconds, after which the program resumes and the loop begins anew. Programmatology.

4-5 seconds of black leader, with no text on this side of the glaze. One can only presume, then, that it was the fish being presented with a commercial?

Or had they discovered a new business model? 
The most compelling thing about this space is that I am unsure if it's an analog that looks digital, or a digital that looks analog. I think this in-between-ness contributes greatly to the earlier notion of a 'plastic green ecology' lurking behind the liquid crystal. And the sensual compressionism required to make this space primarily perceived as light and retinal stimulation is precisely what makes the vice-versa above so compelling.

Are these fish for real?

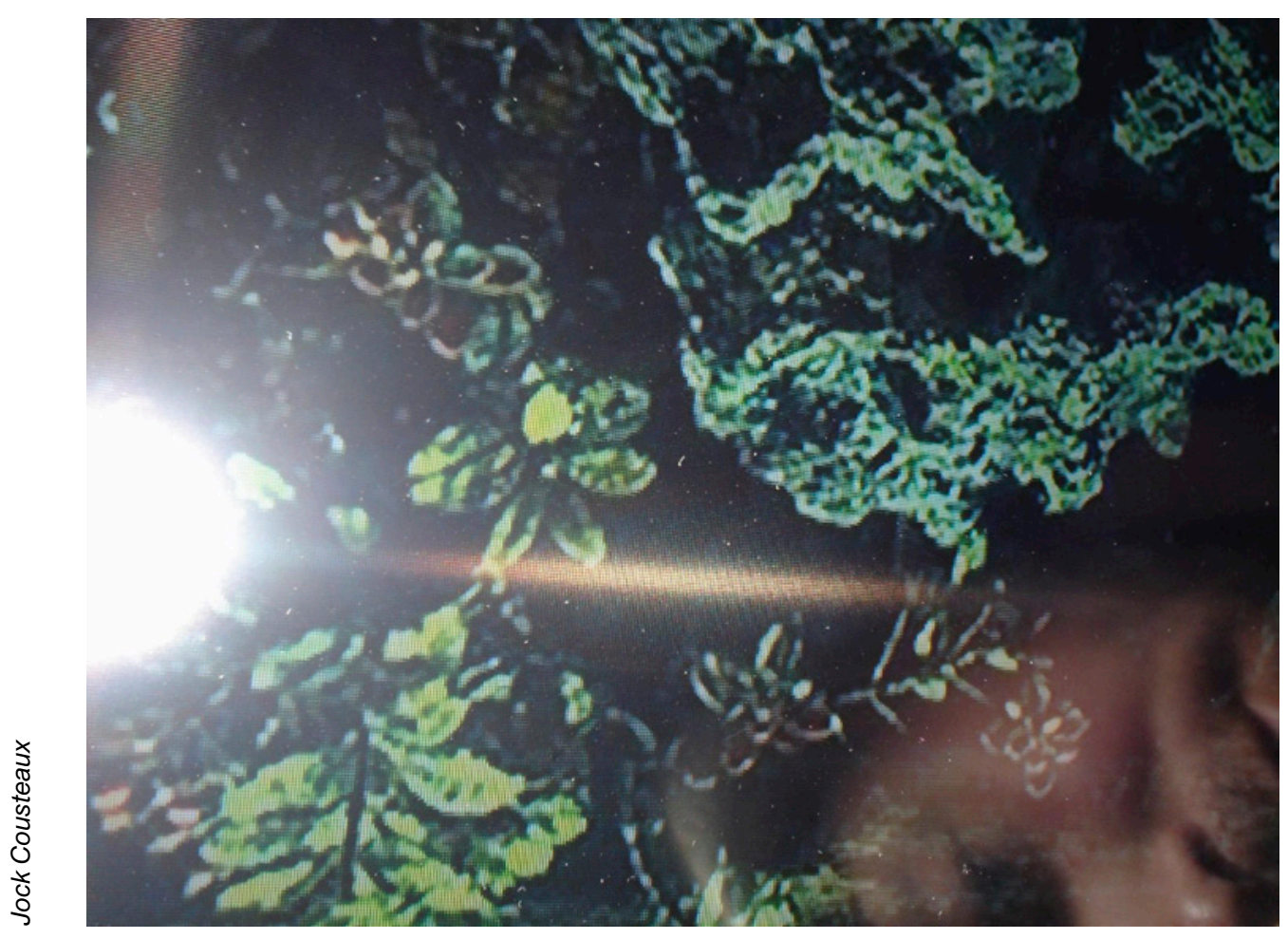

What is it to enter into a prolonged dialogue with an extended loop? With an aquatic animated gif on repeat, looping?

What is it to attempt the moiré as the image of thought? 
This particular community centre swimming pool I'm thinking of is a \# space, particularly during lane swimming sessions. In fact, during lane swimming sessions we might even describe the pool as a \#\# space, given the way that swimmers are partitioned by marker lines into channeled lanes of up-and-back rather than out and about swimming freely. Lane swimming is productive swimming, after all, and therefore it is spatially disciplined to optimize a certain efficiency.

Analyst: Have you ever had your schizoanalysis session in a saltwater swimming pool before?

Analysand: At first I thought the water was dirty. After I learned this wasn't the case I began to enjoy myself far more readily, just swimming around, and even began remembering recent visits to the ocean with my Muse. (But not those visits where the ocean itself was dirty.)

For almost the entire beginning of its existence in interstellar-space, the cradled baby has no understanding of the relationship between gravity and the anthropocentric vertical. Put differently, upon emerging from a sort of ocean-space the face begins first and foremost at a 90-degree angle to what will eventually become the Face.

The image rocks gently in the waves.

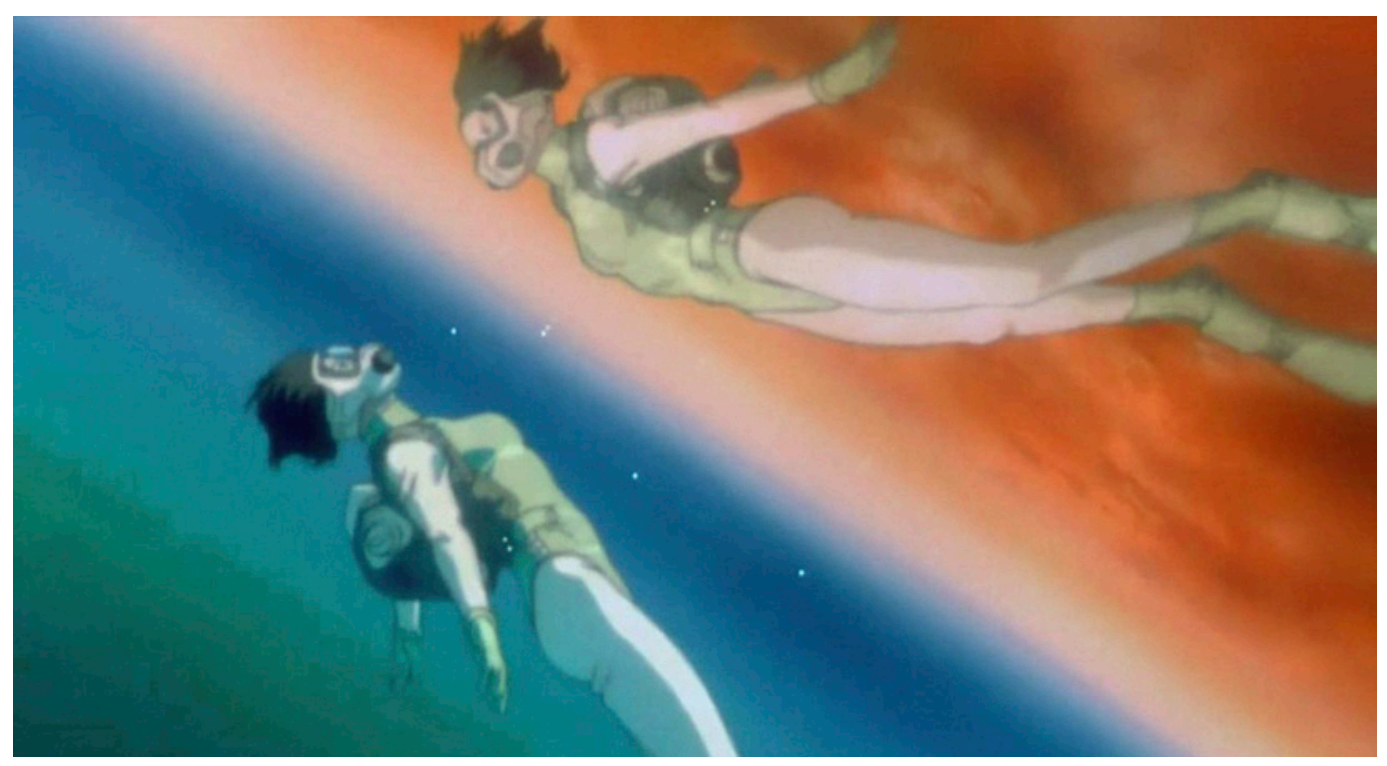


And perhaps if one were a cyborg-mermaid, or a ghost-in-the-she'll, there would exist a possibility of floating goggle-wise upwards to the air-of passing from ocean-space to interstellar-space in a movement through the fake surface tension of appearances. Of breaching the reflection.

There remains the possibility that just then one could momentarily experience the sensation of passing through both sides of a liquid screen.

The human fish-animal passes through a nebulous transitional phase of language in which it uses 'you' to refer to itself, 'you' to refer to the image in the mirror, and 'you' to refer to the parental observer. Soon it begins using 'I' as well, and sometimes will even use 'I' and 'you' in the same sentence or context to refer to itself in two different ways. Does it not feel like we could learn something about field perception-about renegotiating subject-object relationality in favour of the traject-if only we could relearn this listening and articulation of the child?

Such an understanding of the traject and reflexivity is perhaps a necessary basis for articulating an aquatic individuation adequate to the 'higher dimensionality' of the two-way mirror (with its multiplying technical descriptors, i.e. one-way mirror, two-way glass, one-way glass) - a context in which opacity and the incipience of diffraction demand the pronouns begin to multiply as well, adding to 'you' and 'I' the more abstract 'they' and 'maybe'.

"Boy's surface can be used in sphere eversion, as a half-way model. A half-way model is an immersion of the sphere, with the property that a rotation interchanges inside and outside, and so can be employed to evert (turn inside-out) a sphere."

Consider this sphere eversion a sort of 'Mercator projection' for the 'higher dimensionality' of Folded-Earth and Surfaceworld: Interstellar-Space (I/S); Ocean-Space (O/S); and Synthetic-Dataspace (S/DS). 


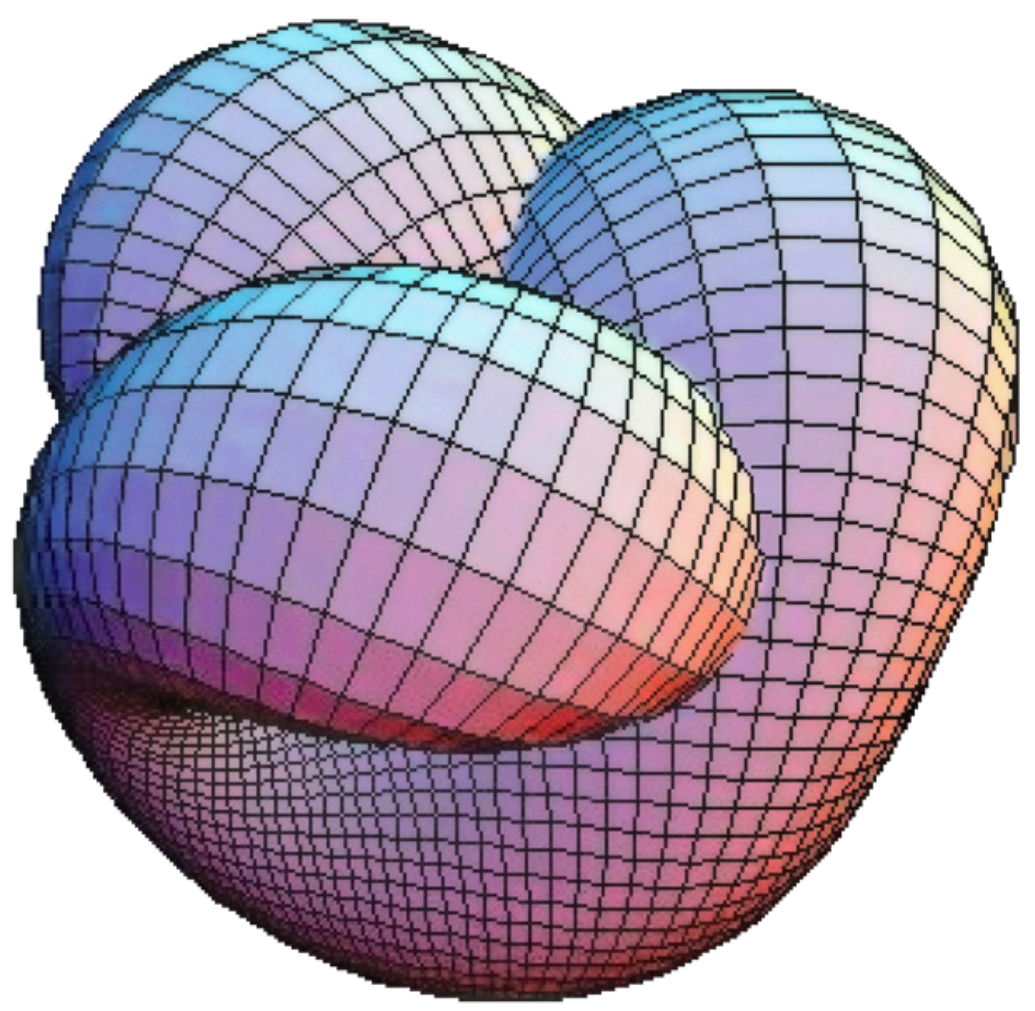

Boy's Surface (Top View), Maksim, 2006

The spine as calcifications or precipitates in an aqueous solution, produced from salts and other diffusions of the mineral layer floating suspensefully through water and deep time: vertebrae are oceanic before they are seismic. And yet somehow they are rooted as well, a hydroponic sort of arborescence perhaps, what the rings of a tree might resemble were they dragged through the water for a million years and then some.

Turned inward, into the vestibular system of the human fish-animal now, these same slightest precipitates may generate intense moments of vertigo for the binocular body: the semicircular canals cannot stand these sudden and infraperceptible changes to the channel. In this sense the spinal vertebrae could be said to hold a million potential vertigos within its living fossil record of mineral aggregation and assembly, intensively-deep time thus trembling, microaccelerational, derivative and portentous. 
A reminder, for human fish-animals at least, that buoyancy is not merely a static quality or standardized quantity (such as $9.81 \mathrm{~m} / \mathrm{s}^{2}$ ), but rather varies with the amount of air in one's lungs, gaseous. While floating, bobbing or treading in a body of water, the massive fluctuations in buoyancy that emerge by simply inhaling and exhaling air-we can perceive these. Breathing thus literally emerges as a matter of sinking or swimming, and to change one's breathing is thus also to change one's relationship to the oceanic.

The technological variant of floatation as a therapeutic modality-that is, the floatation pod or tank-offers itself to the holistic consumer under the rubric of 'sensory deprivation'. It is a peculiar form of sensory deprivation, however, in that current pod technics offer all sorts of options for ambient lighting and sound (including darkness and silence), reminding us that the deprivation at stake here does not necessarily concern the exteroceptive visual or auditory senses but rather the proprioceptive of 'internal' hapticity and the 'deprivation' of gravity. The precise density of salts in aqueous solution and the ambient air temperature forming a relatively warm and seamless transition between liquid and gas elements comprise the truly regulated aspects of this apparatus-the specific composition of sensory deprivation that meets temporal dose to distinguish its therapeutic benefits from its weaponization.

(p.215)

In witnessing the pure delirium or ecstasy of the reversed ampliphibriain maneuver experienced by the human fish-animal (taddler, toddler-as-tadpole)—namely, that joyful terror experienced while playing in the crashing waves for the first time, being knocked backwards or swept off of one's feet-one wonders about the tetrapods emerging from the ocean millions of years ago, being swept along a determinate forward vector for perhaps the first time, an acceleration-with-the-surf momentarily in excess of one's swimming gesture, terra firma still yet to be achieved-and what joyful terrors may have been experienced in the process, disequilibria that would ultimately be woven deep into the fleximotile spinal apparatus. 
To perform a sphere eversion of the human eyeball is to turn the humours inside-out, to 'flip' the orb and make of the eye a topological figure: a Boy's surface leaking the vitreous and aqueous into minor murmurings and becomings-oceanic. It is to introduce new tension on the looping 'Cartesian' conduits which form the ear's semicircular canal system and the basis of balance.

(p.229)

I'm reminded of an event that took place over twenty years ago, reminded of the weird temporal nexus between ocean and the unconscious, reminded that the body thinks thought often long before thought thinks itself, particularly when trauma of some sort is involved.

I was bodysurfing at Manly Beach in Australia, my first real intimate engagement with the ocean as an adult: as a neophyte I'm not certain if the waves were particularly large on the occasion, nor if the undertow was particularly strong (they both seemed that way to me); though weirdly, I recall the temperature at the beach had reached 40-degrees Celsius that day. I had been at it for a little while (maybe half an hour?), when all of a sudden a wave caused me to lose my balance and knocked me askew. I scrambled trying to get back upright and catch my breath, but just as my head surfaced the next wave was crashing down upon me even more forcefully, with me having barely whispered a sliver of air. The physics of turbulence beneath the surf were of such quality that my body tumbled and twisted along every possible axis of rotation, discombobulated. The terror of being underwater absent sufficient breath was magnified for a brief, yet interminable moment, by an additional panic: I did not know which way was up.

For the dried, desiccated human fish-animal reconstituting itself at the edge of the sea, we might describe this as an experience of the Real particular to ocean-space. And in 'retrocausal' terms befitting our unruly scientific program, we might describe this temporarily forgotten event as the incipience of a lived cartography of Surfaceworld. 


\section{Endnotes}

1. "Introduction to Jerkism" is intended here to evoke the line taken by the butterfly (as conceptual lepidoptpersonae). In some ways it is to suggest the earliest sketches of a speculative feedforward complement to theories of accelerationism, as jerk is the derivative of acceleration with respect to time' or 'the third time derivative of position, and has a well-established mathematical relationship to chaotic behaviour.

2. Maksim (2018). Boy’s Surface. [online]. Wikipedia. Available at: https:// en.wikipedia.org/wiki/Boy\%27s_surface). [5 April 2018] See also: Petit, J.-P. (1985). Topo the World. Savoir Sans Frontières. 


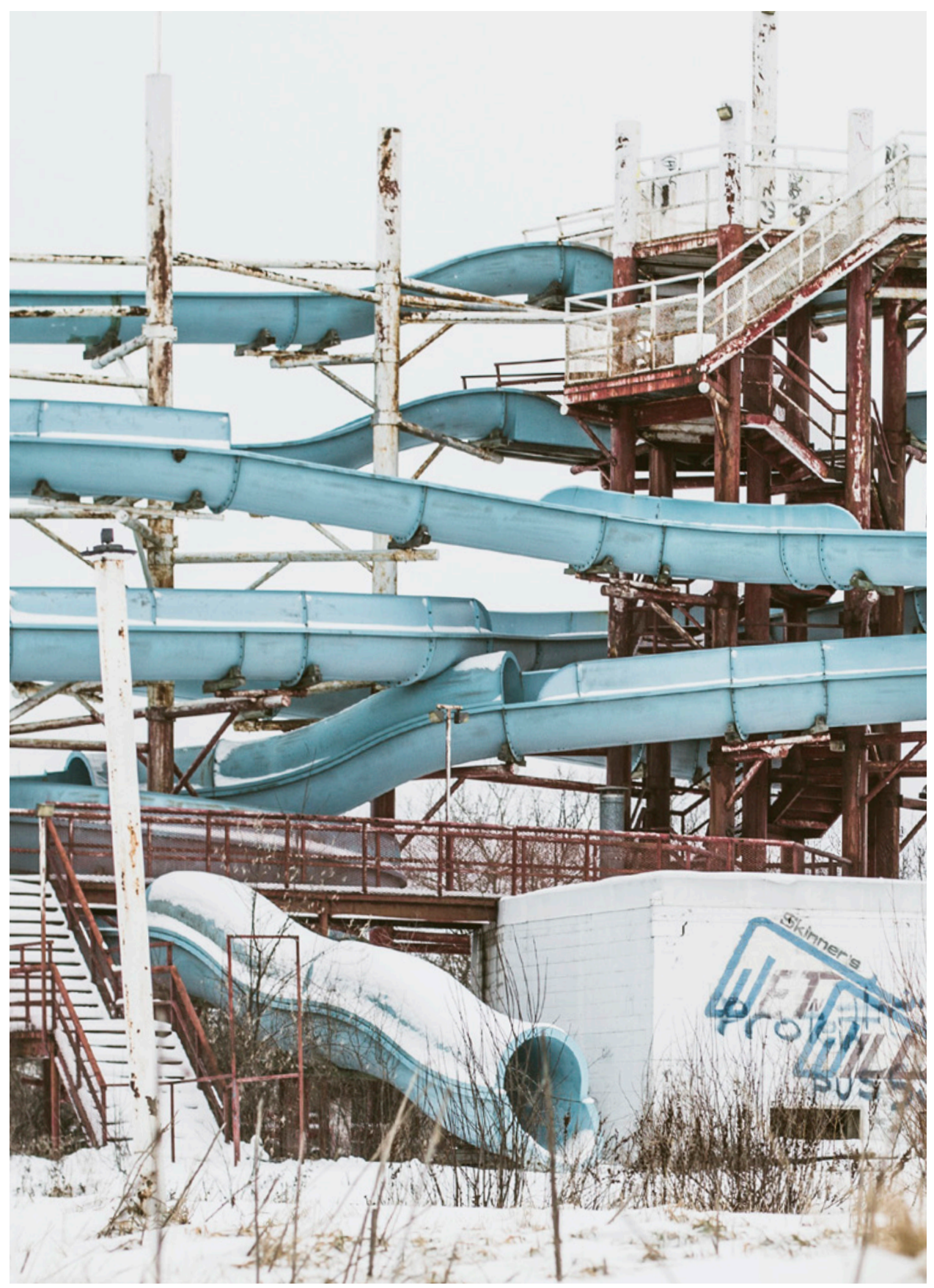

Untitled, Matthew Henry, 2015

Creative Commons Attribution 2.0 (CC BY 2.0) 


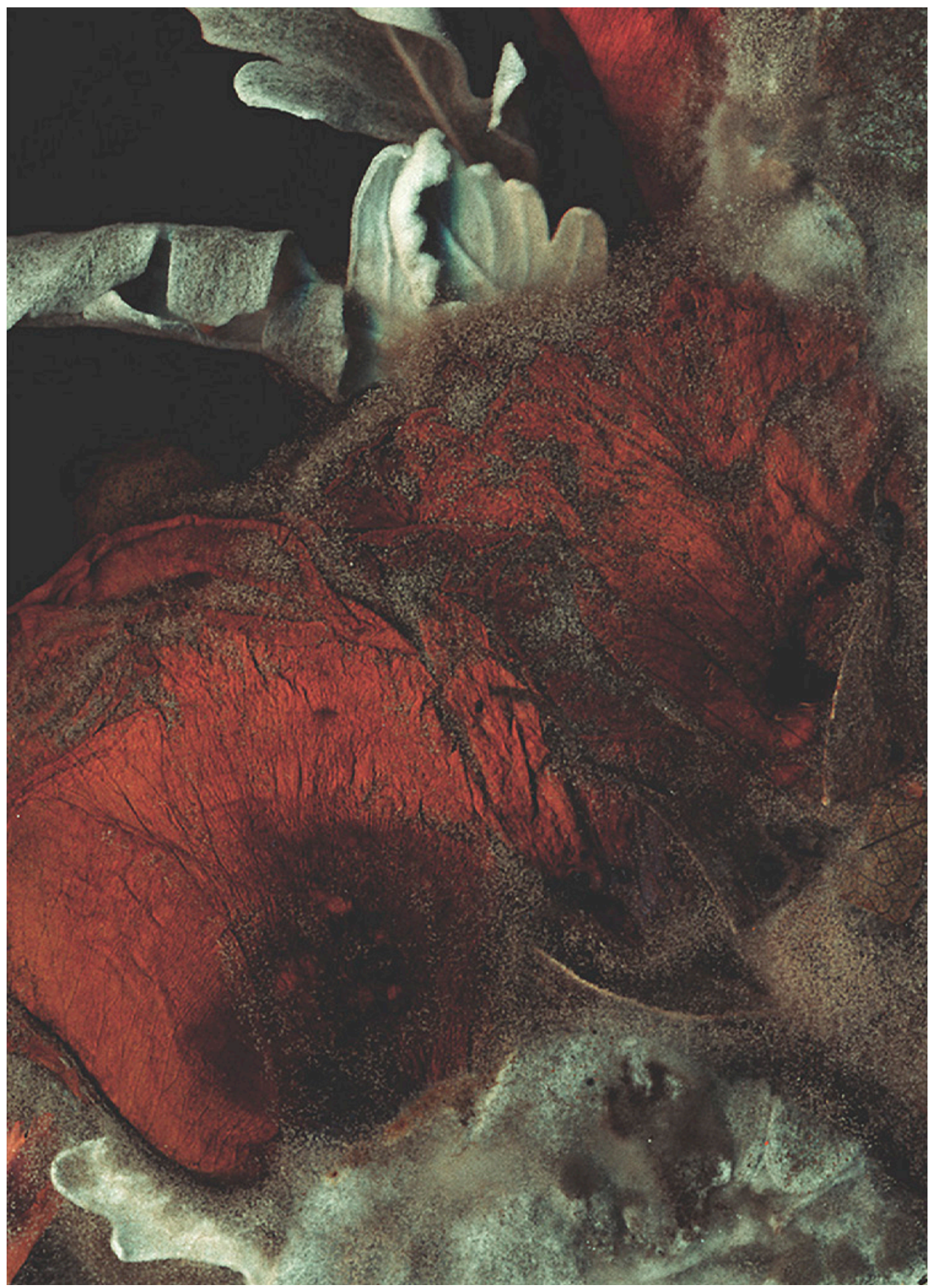

Decomposition Composition (detail), Mark Bulford, 2017.

Creative Commons Attribution 4.0 (CC BY 4.0) 

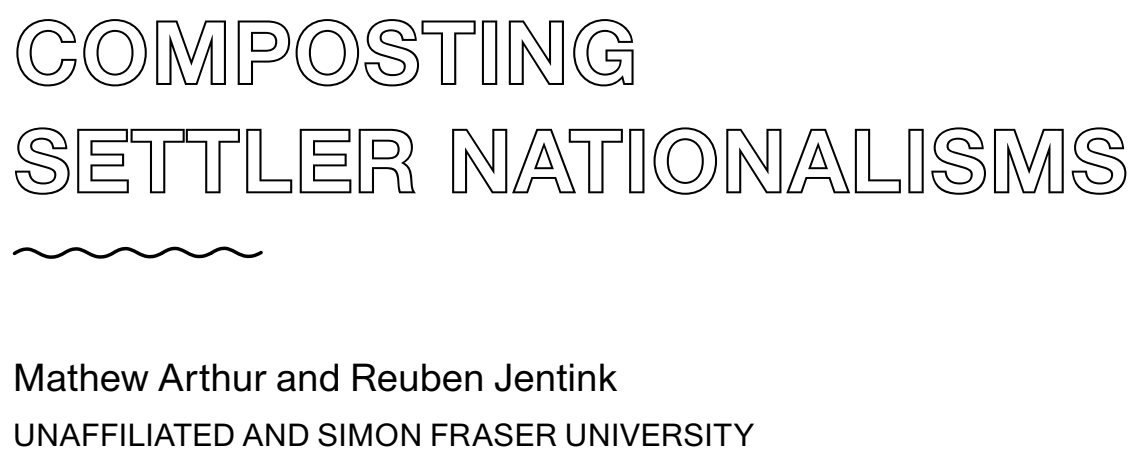

Our compost experiment plays out in two short provocations that work toward a list of provisional sensibilities to guide our knowing-together with nonhuman others as non-Indigenous theorists on Indigenous lands. In the first provocation, we briefly retell the history of colonial expansion as a matter of waste-making, and reframe Canadian-colonial occupation as a project of recycling-reproducing only beings and knowings that are deemed useful to nation-building. Eventually, and with the help of Indigenous science and feminist science studies, we cultivate a performative understanding of compost as a mode of multispecies storying that provokes accountability. In the second provocation, as we wonder how to tell stories that are culpable to and for their own telling, we hang on to the idea that nonhumans might have their own stories, or at least storied lifeways that generatively contribute to keeping on together in a place. We trace out crucial crossings between multispecies ethnography and Indigenous sovereignty by demonstrating how compost as a mode of attunement to nonhuman stories can be done in both theory- and art-making. Finally, we offer a tentative list of compost intimations that might guide our thinking, reading, and writing with human and nonhuman others as we continue to tend to our kinship obligations on Indigenous lands.

\section{KEYWORDS}

nationalisms, kinship, Indigenous sovereignties, multispecies ethnography, reading and writing practices 


\section{The mix of what we're in}

This text is leaky-and while it tries to make-stable the contours of a time in a place, it seeps past itself into something altogether unfinished. The composting-as-method we go on to propose is provisional and messy and others (like Donna Haraway) have set off its ferment (Franklin 2017). Why settler nationalisms? As we wrangled these words into place, we were slinging compost in a garden at a university campus on stolen Indigenous land, heading into our country's hundred-and-fiftieth year of having violently settled here. In the thick of ecological ruin and Indigenous protest, boulevards city-wide were lush with Canada 150 tulips planted to commemorate colonial rule. We found ourselves feeling around for a theoretical practice that might stay in the mess of things both ruinous and regenerative while responding to what is affecting and being affected in a place, at a time.

In what follows, we imagine compost as a way of thinking, reading, and writing with land as a storied place where humans and nonhumans are being made and unmade in the ongoing recomposition of a common world. Why compost? Because, in our take, compost is syncretic-it fuses and confuses human and nonhuman capacities across inter-imbricating scales, speeds, and states with a sense of messiness expedient to the disruption of the sanitizing, assimilationist force of settler nationalisms. Not only in sesquicentennial celebrations or national flowers, but in the very academic institutions of colonial sovereignty that are constantly at work recycling Western ontologies, epistemologies, axiologies, and methods at the expense of Indigenous land and life. Our understanding of land as the place of compost-thinking (rather than the academy) is informed by Indigenous political and intellectual sovereignties in which knowledge flows from land (Simpson 2014b; Watts 2013), and politics takes the form of a relational injunction to include all constituents of a territory in the task of getting on together.

Our experiment plays out in two short provocations-motley accumulations of stories and theoretical tetherings-that work toward a list of provisional compost sensibilities to guide our knowing-together with nonhuman others as non-Indigenous theorists on Indigenous lands. As we go along, we use 'story' and 'theory' interchangeably in order to give equal weight to Indigenous and non-Indigenous knowledge practices (see Atleo 2011, 141-54). And we should note, too, that our use of 'land' is not exclusive of other elements of place: seas, skies, and the rest. 
In the first provocation, we briefly retell the history of colonial expansion as a matter of waste-making, and reframe Canadian-colonial occupation as a project of recycling-reproducing only beings and knowings that are deemed 'useful' to nation-building. By way of this short restorying, we come to see that wasting, recycling, and composting are not just tropes or innocent imaginaries for industrialists, extractivists, environmentalists, or activists but are, instead, world-making material and discursive practices that shape lands and how we respond to the nonhuman constituents of a place.

We feel around for a theoretical situation for compost and, as we wonder what compost as a material practice and figure to think with can do, we land on 'affect' as a question of ever-shifting relational capacities, and theories of affect as a way of paying attention to things in ongoing transformation. But, because no two compost piles are the same and caring for compost requires attending to what is in the mix (in the case of this text, both Canada 150 tulips and tulip-kin), we come to realize that some modes of theory-making-even as they trouble Western notions of sovereignty-do not work in the compost-theoretical heap alongside Indigenous-empirical sovereignties. Eventually, and with the help of Indigenous science and feminist science studies, we cultivate a performative understanding of compost as a mode of storying, a world-making knowledge practice open to humans and nonhumans alike, that provokes accountability for the stories we tell.

In the second provocation, as we wonder how to tell stories that are accountable to and for their own telling, we hang on to the idea that nonhumans might have their own stories, or at least storied lifeways (and nonlifeways) that generatively contribute to keeping on together in a place. Thinking with anthropologist Anna Tsing and Vancouver-based artist annie ross, we trace out crucial crossings between multispecies ethnography (including storying practices that confound the concept of species) and Indigenous sovereignty by demonstrating how compost as a material and storying practice-and as a mode of attunement to nonhuman stories-can be done in both theory and art-making. Finally, we offer a tentative list of compost intimations that might guide our thinking, reading, and writing with human and nonhuman others as we continue to tend to our kinship obligations on Indigenous lands.

We start with a flower, genus Tulipa, a small anxiety in our relationship: one of us likes its unsubtle efflorescence, the other does not. First domesticated by the Ottomans, its bulbs landed in Antwerp in 1562 alongside tobacco and tea, tracing lines of trade and traversing unsteady borders to land on the grounds of Amsterdam's rich (newly flush from the exploits of the Dutch East Indies Company a transnational undertaking with the power to establish colonies and negotiate 
treaties). Then there was Tulipomania, the early seventeenth-century market craze of unchecked floral speculation, and tulip futures made possible by striated, fiery cultivars whose changes in pigmentation were transmitted flower-to-flower by aphids infected with the tulip mosaic virus.

Another time, another continent away, the national myth of Canada's 'cultural mosaic-a happy take on multicultural success-spreads like a virus, transmitted garden-to-garden by the Canada 150 Tulip in a botanical display of national unity. Developed in the Netherlands, trade-named by the Canadian government, and sold by a chain retailer of building supplies, the selectively bred Triumph cultivar (with a mottled red and white flower meant to evoke the Canadian flag) marked the sesquicentennial anniversary of Canada's Confederation-styled as 'Canada

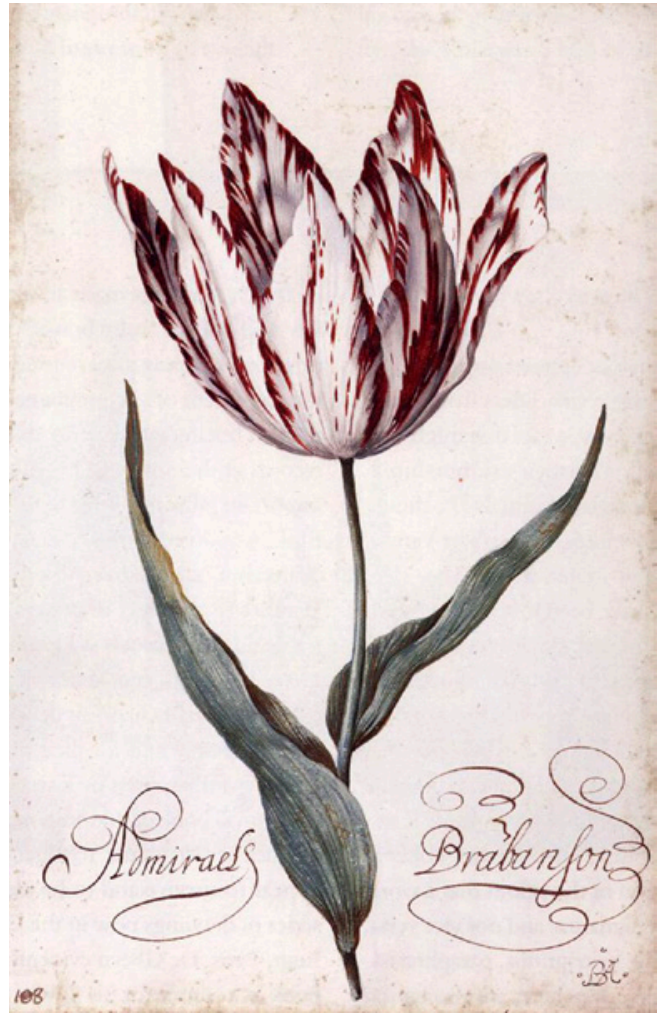

The Canada 150 (Carnaval de Rio) cultivar bears an uncanny resemblance to the virus-infected plants that fuelled Tulipomania.

Tulipa, Balthasar van der Ast, 1620. Gouache, $313 \times 202 \mathrm{~mm}$, Institut Néerlandais, Paris. 150.' In the lead-up to Canada 150 celebrations, a Liberal Member of Parliament described the official flower as symbolic of "rebirth and promises" (CTV 2016); hinting maybe that the sesquicentennial would coincide with Prime Minister Justin Trudeau's (now-broken) campaign promise of renewed state-Indigenous relations (see Palmater 2017), spurred on by the Truth and Reconciliation Commission of Canada's foregrounding of the cultural genocide of Canada's Indigenous peoples.

Prepending 'cultural' to 'genocide,' of course, allowed the Canadian federal government to sidestep international legal culpability, keeping genocide in the past tense (as a culture-decimating force 'back then') and reinforcing the normalization of colonial violence in the storying of present-day liberal democratic nationhood as a cultural mosaic in which Indigenous peoples might now participate with equal opportunity-nevermind that Canadian multiculturalism 
is an assimilationist framework institutionalized in Section 27 of the Charter of Rights and Freedoms that allows the state to determine what is acceptable in diversity at the expense of Indigenous life and land (MacDonald 2014; Palmater 2015; Simpson, James \& Mack 2011). We think a t-shirt designed by educator Eric Ritskes (2017) better announces Canada's legacy; it consists of an inverted

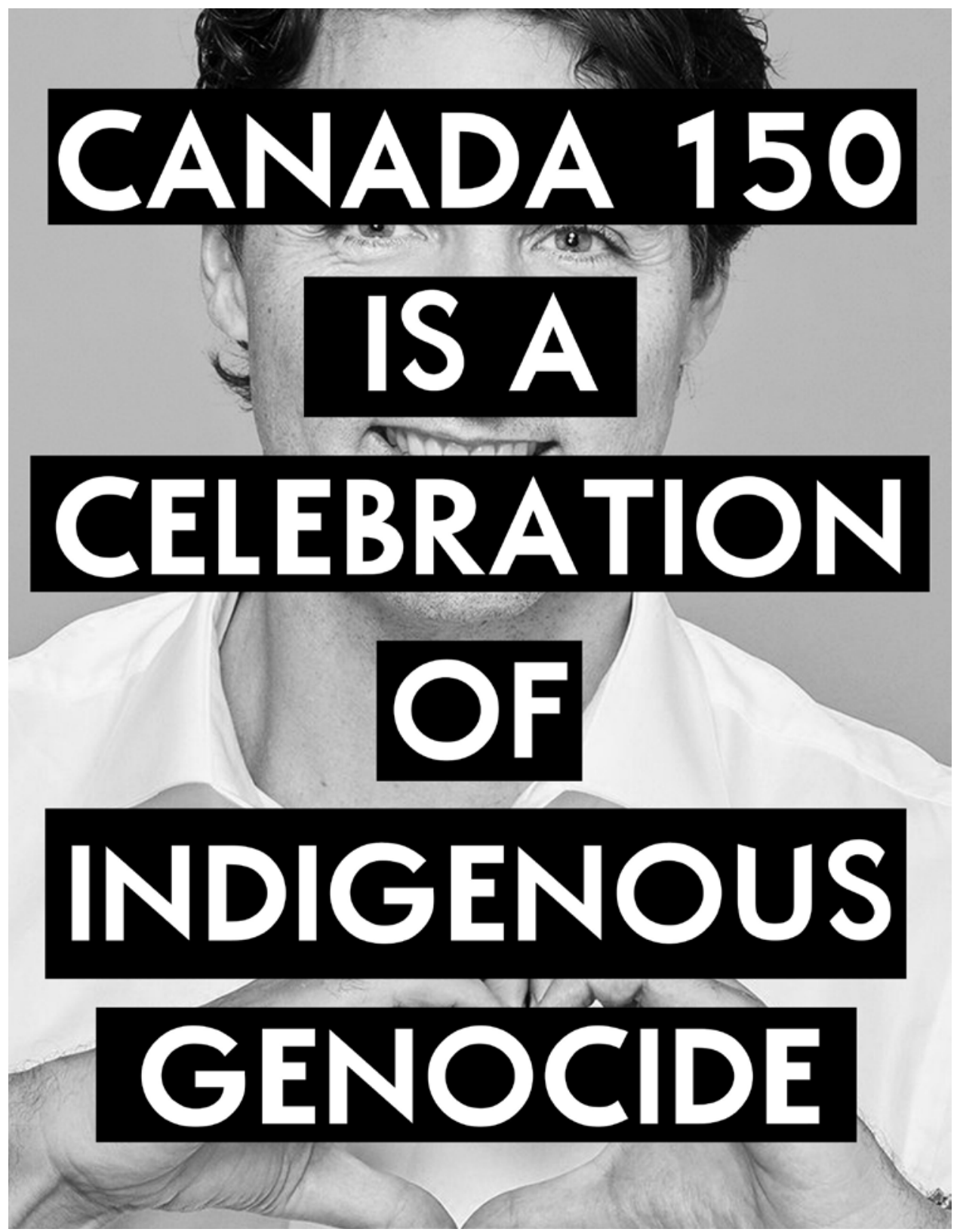


Canada 150 logo (a meshwork of diamonds forming a mosaic-like leaf) and the label: "Colonialism 150." From happy stories of national unity to more than a century of colonial violence, this is a lot for a flower to bear.

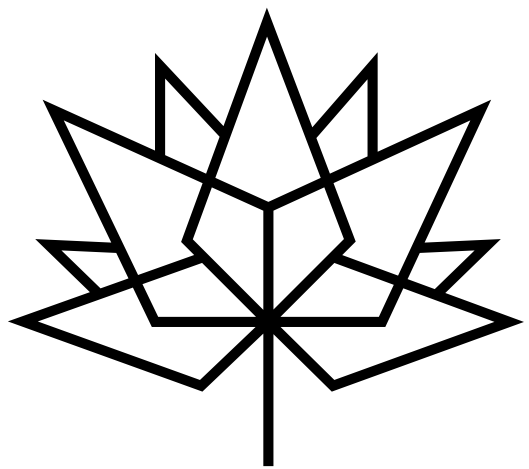

CANADA 150

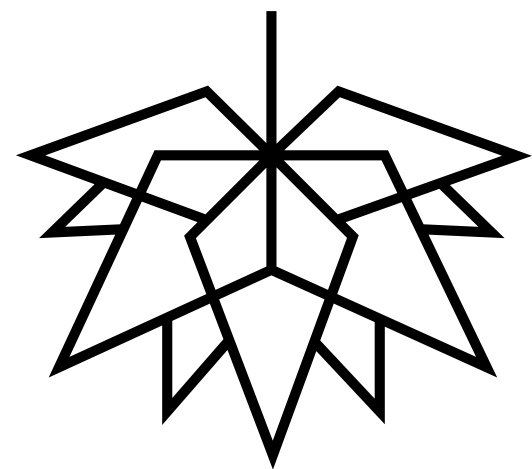

COLONIALISM 150

Caught up in this floral ethnography are the material marks of trade and territory; political and economic atmospheres; colonial aspirations and occupations; the temporalities of a plant's reproductive cycle or a nation's federation; a latticework of aphid vectors; and the shifting potentials of multispecied and nonliving entities: flora, insects, viruses, humans, and the conceptual categories they inhabit. Streaked red and white, a flower asks so much more, cropping up in questions about the governance of difference in state multiculturalisms, reifications of difference in scientific taxa and selective breedings (or transnational friendships), and the collapse of difference in the banal naming of botanical life under the rubric of nation-building. We are tangled in this story, too: one of us a third-generation Dutch-Canadian with an affinity for his motherland's flower, the other whose Franco-colonial ancestry spans more than 150 years on Indigenous territories. We stand together on the stolen land of the Musqueam, Squamish, and Tsleil-Waututh peoples-in what is now called Vancouver, British Columbia-sober with the weight of being here and accountable to the demands of Indigenous nationhood.

Writing from British Columbia's public research university on Musqueam territory, Cherokee theorist Daniel Heath Justice (2016, 352-353) describes Indigenous nationhood as sovereignty predicated on tribal webs of kinship responsibilities: entanglements in which humans, animal and plant-people, spirit-beings, and 
other geological, hydrological, and meteorological forces make nations together. By Western standards, Indigenous sovereignties are nonsovereign, but only in the mix-up of translating between two incommensurable forms of governance-one in which politics are shored up by natural and social sciences that apprehend tulips as 'natural' and distinguish humans from nature as 'cultural,' the other which is a science for living together where politics means accountability to a nonhuman world in which tulips are kin. Unlike the fixed stories of settler-Canadian nationhood that necessarily abstract violence to human and nonhuman bodies in projects of sovereignty requiring national unity, Indigenous sovereignties coalesce into forms of governance around relationships defined by situated ancestral laws communicated through ever-evolving stories and performed in ceremonies that provoke human participation in the ongoing renewal of land (see Corntassel \& Bryce 2012; Simpson 2016).

We stand, likewise, in a crowd of nonhuman others, wondering how to read and write stories about, what to do about, this pernicious Canada 150 flowerother than to compost it, to discompose its fast and easy reconciliations, to let it decompose, slowly, into the responsibilities and workings-together of soil. But also, to honour its spirited way of life: as it tends itself, tends for its invertebrate and microbial others; as it buds, withers, and feeds the dirt into which it can grow again, renewed. With the limp stems and putrescent blooms of Canadian-colonial nationhood heating up on our compost pile, we want to ask: how can we intervene in the naming, narrativizing, and performing of sameness and difference as a measure of Canada's colonial success? Which kinships, which sovereignties matter? Which beings and belongings-together can be read or written into nationhood? Here, and following Bruno Latour (2002), we invoke sameness and difference in both ontological and epistemological registers in order to read Canadian multiculturalism as mononaturalism: the idea that we inhabit a singular reality configured by verifiable natural laws that structure sameness and difference in biophysical terms (always already primed by metaphysical givens tied to Western intellectual histories), while whatever aberrations or disagreements remain in the wake of mainstream technoscientific articulation are relegated to the cultural field as it avowedly contours and conditions ontologies and epistemologies incommensurable with those that obtain 'facts.'

Meanwhile, Canada's federal, provincial, and civic governments have made reconciliation the ambition of state-Indigenous relations under the ambit of multiculturalism, while the governance of difference-the authority to say what counts as an entity, which entities count, and which knowledges authorize their accounting-continues to hang on the "evidence-based" approach of Canadian liberal democracy and its "great advantage of neutrality" (Policy Horizons Canada 
2013); even as 'evidence' is invoked to explain away the destruction of Indigenous lands in extractive projects. But there is no neutrality in backgrounding 'nature' as mere material support for human life or fashioning flora into nation-building props. There is no neutrality in the half-millennium of human control over tulip reproductive cycles and genetic compositions, over how or where a form of existence can continue on. Human-tulip relations have forged economies, carved out transcontinental mobilities, and propped up the makings of nations in ways that require Indigenous stories about plant-peoples as political subjects and familial relations to be fiction.

Anxious with the question of which political and intellectual sovereignties matter, we are looking for evidence of a different order, through the invested and decidedly not-neutral living-out together of a common world animated by Indigenous empiricisms, in which knowing is an ongoing relational response to the conditions of keeping on in a place based on participation in the continuity of all lifeforms or forms of existence (including nonlife) and cultivating attentiveness to the teachings nonhumans have to offer. In Indigenous empiricisms, human-nonhuman diplomacies are encoded in stories, and stories are told, retold, and tested against human and nonhuman thriving (see Atleo 2011; Simpson 2015). If it is in the everyday sharing of stories that nations are made, as Sara Ahmed (2000, 98) contends, then the stories we tell about tulips matter: they shape materialities, pattern shared meanings, insinuate value, and guide our response to the humans and nonhumans around us. As a storying practice, the Canada 150 Tulip not only maintains settler nationalisms, but stipulates a mode of encounter for meeting nonhumans which carries the weight of an entire system of being, knowing, and doing that reinforces settler nation-building projects.

In the mix of competing sovereignties (one scaffolded on abstract rights as species-based entitlements and proprieties bound up in evidence-based claims in which the terms of being and knowing are always already set, the other rooted in kinship responsibilities to a constellation of entangled nonhuman others), we also want to ask: how can we think, read, and write with nonhumans, including those caught up in the erasures and extinctions of colonial nation-building? What would it mean to compost settler nationalisms? 


\section{Turning to compost}

We arrive at compost in the thick of three everyday tropes implicit in both agricultural and industrial histories of nation-building and liberal ecological sensibilities: waste, recyclable or recycled materials, and compost. As material and conceptual or discursive repertoires, these tropes are not just nouns describing befores and afters, finitudes and excesses, or goods and bads-rather, they are wastings, recyclings, and compostings done by humans, fungi, industrial robots, crabgrasses, and seagulls. Our understanding of making, using, disposing, remaking, and regenerating as world-making practices in which method and matter are always co-shaping is informed by John Law and feminist science studies at large (2015) in the idea that practices (as done by humans and nonhumans) are productive-do something in and to the world-and that what is practiced or repeated is done at the expense of what is not. And, it is human practices that spark our concern: material and conceptual exclusions of nonhumans and those held to be less-than-human enacted in colonial renditions of waste, recycling, and compost.

Histories of colonial expansion, for example, might be read through the effects of waste-making practices: having laid waste to their own lands in overexploitation, Europeans set sail in search of new resources and routes by which to exchange them (Beinart \& Hughes 2007, 2-10). In the 'new' world, unwilling to participate in the performance of waste as 'surplus,' Indigenous peoples were deemed incapable of industrializing their lands into usefulness and, in the instantiation of land-tenure frameworks based on intensive cultivation as a measure of ownership, were dispossessed not only of their lands but of the possibility of enacting sovereignty predicated on regenerative land use practices. As James Tully (1993, 147, 156-63) notes, the material practice of wasting and its correlate conceptual shapings (as both under- and overuse) were integral to the colonial project, in both the coupling of ownership and overproduction, and the rendering of Indigenous territory as squandered wasteland in order to justify expropriation in the service of making lands useful to the demands of nation-building.

Even now, lands figured as resource, and the subject of national anxiety and frenzied media attention (including the Athabascan tar sands or the cedar forests and shale gas deposits of the Pacific Northwest), are said to be wasted opportunities when left untouched (Lorenc 2016). Then, there is the waste that extractive endeavours afford: a breached tailings pond at Imperial Metals' Mount Polley copper and gold mine that spilled millions of cubic metres of arsenic-poisoned slurry into the watershed of Secwepemc territories in central British Columbia. Or, further north, the stalled Site C hydroelectric dam-dreamt up to capture an 
oversupply of power while drowning thousands of hectares of land in the heart of Treaty 8 Nations' ancestral lands. For the extractivist, land left untouched sits wasting away. But after intensive cultivation, land is laid to waste along with a host of entirely other beings, knowings, and doings tied to Indigenous lifeways.

In On Garbage, John Scanlan (2005, 71-81) moves that Western philosophy and science attained mastery over nature (which, on Indigenous territory, we are inclined to render as 'land') in ongoing performances of sanitization: acts of extraction or separation in which beings and knowings deemed useful mark the disposal of everything and everybody else. Seen this way, Western wasting enacts Western-colonial sovereignty-the authority to say which ontologies and epistemologies count, to say what is useful or valuable and therefore qualified for incorporation into the political body. Just as our national identity leans on multiculturalism as a means to camouflage the ongoingness of the colonial project, the idea that being Canadian means being sustainable (see Boyd 2004, vii) implies that we have made a clean break from waste.

But recycling-the mainstay of liberal ecological sensibilities-works like waste, reproducing only what is considered valuable: useful materials, useful concepts. As Daniel Lang (2007) writes, "recycling means never having to say you're sorry"-it serves as a material and discursive alibi for the absence of real change (n.p.). When its cover is blown, however, recycling proves as materially costly as waste: from the effects of energy-intensive re-manufacturing processes to the by-production of hazardous contaminants (MacBride 2011; Rogers 2006, 176-79). Moreover, there are material limits to what recycling can $d o-$ as Michael Huesemann writes, "how will it ever be possible to recycle the numerous chlorinated organic hydrocarbons that have bioaccumulated in animal and human tissues across the globe?" (2003, 260). Unlike recycling, and despite the measured inputs and rigid stages of industrial composting, almost all compost processes are able to break down hydrocarbons-compost is materially regenerative (US EPA 1998). And, while much has been said about recycling as a figure for the reproduction of conceptual architectures of power (Kendall \& Koster 2007), we want to know: what can compost-as it figures material regeneration-do for theory-making?

Our experiment with compost hangs in the balance between decomposition as the undoing of Western intellectual and political sovereignties that rely on enclosures like 'subject' or 'species' (and authorizations like 'science' or valuations like 
'useful'), and recomposition: making and remaking a different world alongside nonhuman co-constituents of land. Thinking with decomposition is certainly generative in blurring inherited conceptual categories and reframing bodies as nonsovereign, leaky or permeable, and belonging to a world (see Barnett 2016). But while decomposition is ubiquitous, an Earth-process that gets by just as well without human aid, compost pulls humans into the mix amidst water, oxygen, carbon, nitrogen, earthworms, bacteria, fungi, molds, protozoa, and other organic and inorganic matters (Park \& Allaby 2017; Trautmann \& Olynciw 1996). Perhaps this is what Donna Haraway calls "staying with the trouble": multispecies players-including humans, their legacies of ruin, and their agencies of care-living and dying together in "flawed translations across difference," attuned to the possibility of somehow getting on together $(2016,10)$.

And so, compost is about going to the trouble of trying, and trying again, in the midst of always different difference. As Haraway says of compost, "you can put the wrong things into it," it can be a place of "culpable failure" (Franklin 2017, 51). Nuancing the difference between recycling and compost, or between compost as decompositional and recompositional as a matter of staying with the trouble, offers up cautious hope for regeneration amenable to Indigenous sovereignty as human and nonhuman cooperation in the ongoing renewal of land; where culpable failure is a matter of learning from doing, while paying attention to everyone (including nonhumans) and keeping on together in a place.

Our work, as such, ferments in the mix of a number of 'turns' concerned with the inclusion of nonhumans in makings of theory and in social, cultural, and political life at large, including critical animal studies, posthumanisms, ontological turns in science studies and anthropology, new vitalisms and materialisms, and theories of affect as a circulating, world-making force. But while turning is a responsibility of composting, turns in knowledge are so often enacted as overturning: modes of citational abjection, of throwing entire bodies of knowledge to waste, or of discrediting moves (often in service of newness) that never quite arrive at turning as attending to something that has been there all along-like Indigenous knowledges. Turns can be the estate of recycling, too: refashioning something old to turn it into something new without ever disrupting authorial, disciplinary, and institutional forms or warrants-never questioning inheritances, their obligations, and their citational architectures.

Speaking of inheritances, we take seriously the risks of 'non' as a prefix for human in light of histories of scientific racism, affirming alongside Dakota theorist Kim TallBear (2012) that systems of knowledge (namely Western philosophy and social and natural sciences) invoked to animate nonhumans have historically de-ani- 
mated Indigenous peoples, even as Indigenous peoples have never forgotten that nonhumans are agential and enmeshed in social relations as cultural and political subjects. With Zakiyyah Jackson (2015), we acknowledge, too, the many ways that race comprises the terms through which 'nonhuman' comes into coherence.

We are hanging on, nonetheless, to the risks of thinking alongside 'nonhuman' even as compost matures within wider agricultural histories fraught with violence to bodies and lands. In our take, attending to the place-bound particularities of compost includes caring for how bodies arrive at the site of compost already subject to reciprocally constructing terms like gender, race, sexuality, class, and ability, and the segregations of conceptual categories like subject/object, life/nonlife, or species. There is no universal composting subject. We recognize, too, the trouble of multiple and divergent agricultural worlds so often rendered singular as civilizational 'fact', as compost becomes embedded in practices of everyday life as an often-greenwashed panacea to ecological ruin at the expense of Indigenous and other non-Western agricultures-and their attendant ontologies and epistemologies-that assert the cultural nature of land.

So, we are in search of a theoretical framework and citational lineage from and in which to do compost as a theory-making method-a framework capacious enough to encounter the nonhumans of compost as social subjects, generators of knowledge, and co-collaborators in the fluctuations of culture and politics. Any theoretical or disciplinary tethering for composting settler nationalisms must stay with the trouble of violent colonial pasts and presents, including ongoing material and theoretical performances of wasting and recycling as modes of Indigenous dispossession (both materially and in knowledge projects, especially those of the academy that work to reanimate the nonhuman), and as a means of apprehending nonhumans as inert or insensate and devoid of agency as mere objects, natural 'resources,' or nation-building props. The theoretical situation of compost, moreover, should be empirical: attentive, as in the act of composting, to material workings through doing, sensing, and learning-and alert also to the ways in which the 'parts' and functions of a process or thing (like composting and its constituent matters) are encountered, named, and evaluated through the ontologies, epistemologies, axiologies, methods, and citational arcs of Western philosophy and science, and thus regulated by the enclosures and exclusions of Western political and intellectual sovereignties authorized by what counts as normative in being, knowing, and doing. 
The workings of compost are not static, they are always in the making and hard to pin down. Accordingly, the specifications of our theory-choosings and -makings must somehow remain tensile and on the move. We agree with Sebastian Abrahamsson and Filippo Bertoni who write that, in composting, there are no "normative guidelines for togetherness"-composting is not a question of kinds of relation but rather of asking what compost-relations "can do" (2014, 126-127). As a question of slippery methods and leaky subjects, with ever-shifting capacities who are always in the making, it would seem reasonable that our experiment inhabit a zone of theory-making staked out in the processual Spinozan-Deleuzian definition of 'affect' as the power "to affect and be affected" that unfolds in and between bodies and worlds being made and is, as such, "proto-political" in its implicit relationality (Massumi 2015, ix). For Brian Massumi, affect offers a problem rather than a solution, a different kind of staying with the trouble: to attend to the always-transitioning capacities of bodies in relation is to witness a "matrix of variation" that forces theory-making to indefinitely regenerate the terms involved in ways that crosscut inherited conceptual categories and disciplinary territories (50).

Crucially, as a mode of theory-making that attends to what a body can do (where 'can' signals relations in encounter that always exceed a body), affect puts pressure on the privileging of language and cognition as markers of human exceptionalism. Language, in Massumi's take, belongs to a continuum of bodily potentials that include the nonlinguistic, such that the linguistic is merely a threshold past which the feeling of a change in bodily capacity being expressed changes qualitatively in nature. And, because cognition accompanies a body as it is always being made, always affecting and being affected, thinking is not interior to a subject, rather it is "in the world" $(2015,211-12)$.

Affect, it seems, does most of what we think a compost theory should do-and we are alive to the possibilities of locating thinking in the world and the promise of what an ongoing, relationally situated regeneration of conceptual terms might do for theory-making. But as non-Indigenous scholars living and working on lands inscribed with settler schemes of beings, knowings, and valuings, we wish to remain productively skeptical of the ways in which theories of affect methodologically bracket out what comes after or above the threshold of being registered or qualified (including epistemological concerns), and their privileging of what Lawrence Grossberg describes as "singular event or plane" rendered as "the universal ontological substance of the real" $(2010,192)$. We wonder, too, if theories of affect-in the tradition of Spinoza, Deleuze, and Massumi-again enact the mononaturalism (in privileging affect as an ontological heuristic) and mul- 


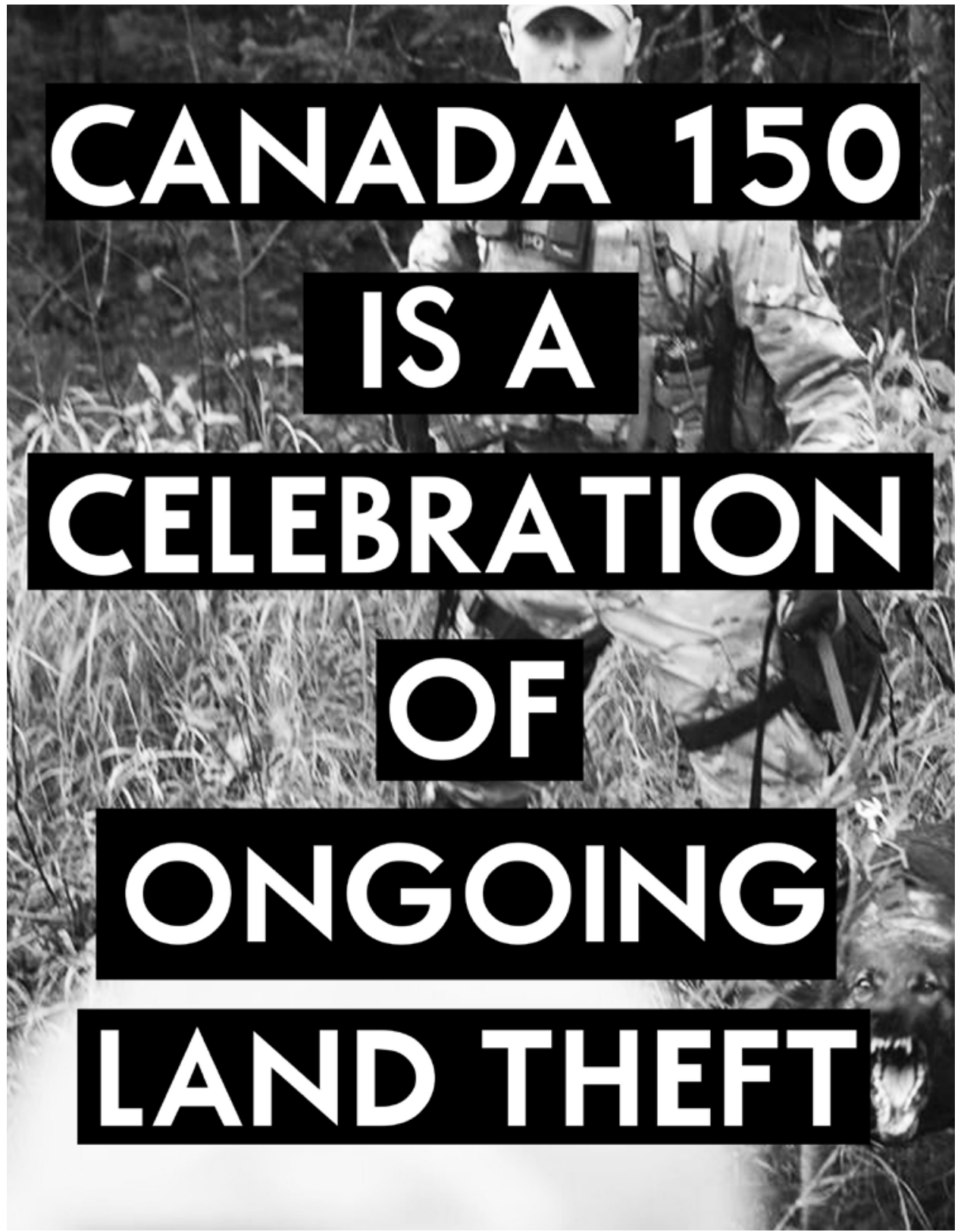

Anti-Canada 150 Poster Pack, Anonymous, 2017 
ticulturalism (in affect's situational or subjective registration) of Western liberal democracy in ways that decentre Indigenous stories and empiricisms, kinships and sovereignties. ${ }^{1}$

As Anishinaabe and Mohawk theorist Vanessa Watts (2013) cautions, while critical focus on ontology might allow for a river's agency (or, in the case of this text, a tulip's agency), it cannot account for a river's-or tulip's-own knowing; to bracket out epistemology leaves ontology empty and ready for inscription in ways that fictionalize Indigenous creation stories and invalidate human to nonhuman communication and treaty-making practices. Of course, in thinking affect as infra-cognitive, and the registration of affect as continuous with (albeit qualitatively different from) the nonlinguistic, it is conceivable that in its own way a tulip might register changes in its capacity in terms of meaning.

We affirm the entanglement of ontologies and epistemologies in reality-patterning stories (including settler national narratives and Western theoretical canons), and their power to make present or absent the entities that are available to live with, think with, and care with-the power to make kinships and sovereignties-in order to rephrase the question of what compost can do (as both a material practice and figure to think with) as a question of whose stories, whose theory-makings matter in the place where we are. Inasmuch as theories of affect promise to open our compost-thinking to nonhumans and nonlife, we also recognize that affect cannot do everything. In its Massumian vein, affect as theory is decompositional: writing the body as porous, unsettling disciplinary and generic territories, and foregrounding the inadequacies of capture and translation as discursive operations that aim to say something about a world always in the making. And, the theorization of affect is anticipatory in its attention to how things come to be in temporary composition, tracing emergent modes of power and the precarious atmospheres of political unrest (Massumi 2017). But as storying practices that shape and are shaped by the world's unfurling, as a matter of ongoing recomposition, can theories of affect continue to remain agnostic about what worlds are being remade in their own worldly implications?

In theory-making, attending to the relational textures of being a person folded into a place is a matter of accountability in citational habits, in deciding theoretical foci, in choosing methods and moods, in centring some political projects and not others, in choosing to collaborate and shake up the individualist politics of attribution, and in becoming sensitized to who or what is being called upon to authorize, translate, or nuance what or whom. Does the privileging of potential (even 'bad' potential) in theory-making obscure culpable failure? Can theories of affect make room for Indigenous sovereignties? Sometimes this will mean not do- 
ing affect theory at all. Accordingly, we want to ground our compost theorization in Indigenous sciences (a term deficient in describing the intra-impingements of spirituality, philosophy, natural science, and politics in Indigenous empiricisms)not to claim innocence in our place on Indigenous territories, but to rise up to the relational responsibilities of being here, and as a matter of demonstrating what we think a compost theory should do as a world-making knowledge practice that attends to what is in the mix in a place. In doing so, we knowingly risk collapsing multiple and situated indigeneities or belongings-to-place-but some loose commonalities can be ventured.

Niitsitapi (Blackfoot) theorist and education activist Leroy Little Bear describes three interrelated tenets of Indigenous sciences. First, and related to the verbheavy nature of many Indigenous languages, Indigenous sciences share an acknowledgement that everything in the world is in "constant flux," dissolving, transforming, and reforming. Second, the nature of constant flux is taken to be both a question of being and knowing: everything in existence comes into being as fleeting accruals of energy waves or oscillations accompanied by a transfer of energy, and knowledge is located in (and transmitted by) transfers of energy such that units of analysis like 'particle' or 'wave' in classical and quantum physics, 'affect' as a name for body- and world-making forces, or Indigenous words that end up translated as 'spirit' are all capable-as part of a web of knowing-of describing the same thing. Importantly, and pointing to the third tenet, allowing for multiple or divergent modes and expressions of knowing does not slip into relativism because 'truth' is related to, or tested against, the continuity of all forms of existence that make up a place as kin. Third and finally then, because everything being unmade and remade is animate, everything has spirit (or is comprised of waves, or has the capacity to affect and be affected) and, as Little Bear reckons, "if they all have spirit, that's what we refer to as all my relations" (2011, np). Significantly, what distinguishes Indigenous sciences from affect studies and other 'new' materialisms or posthumanisms, as Chinese-Métis theorist Sebastian De Line (2016) notes, is an explicit framing of relations between bodies as positioned "deep within networks of belonging" that are "personal, intimate, and shared" rather than impersonal and abstract (6).

Because we want to ground our thinking in what is here, on the pile-in the mix, to be accountable for Canada 150 Tulips and to tulips as kin, we must also stay with the trouble of our own non-Indigenous systems of knowledge-even as Indigenous sciences help us to see our relations with the nonhumans of compost 
as personal and intimate. We are cautious, too, of the trend to invoke Indigenous knowledges as analytical accessories that do the work of undoing Western conceptual categories (see Todd 2016; Wilkinson 2017). Regeneration is not recycling-and it requires attunement to that which is here now, and to what 'that which is here' needs in order to transform or keep on. We want to stress, too, that even as we identify the abstractions of certain modes of theory-making as incompatible with our own understandings of the obligations of non-Indigenous theorists on Indigenous lands, a compost-inspired theory can never be prescriptive: just as the constituent scraps of compost invariably vary, there can be no rules or citational quotas for a compost theory and, just as no two compost heaps are the same, there can be no cut-and-dry political imperative for compost-thinking.

Rather, goods and bads in composting are merely about paying attentionthrough trial and error-to what works in the mix; in this sense, any theoretical framework that makes room for nonhumans might reasonably engage or at least acknowledge Indigenous systems of knowledge, forms of governance, and practices of everyday living that have sustained and continue to sustain nonhuman lives (and nonlives) for millennia. Karen Barad's agential realism, for example, affirms that theory-making is world-making, that philosophy and natural and social sciences are ontological, epistemological, and ethical engagements, that nonhumans can and do know, and that matter-what the world is made of-is intimate: "feels, converses, suffers, desires, yearns and remembers" (Dolphijn \& van der Tuin 2012, 59). We should note, too, that agential realism is not exclusive of affect (Sheldon 2016) and, like affect, its citational and theoretical patternings are predominantly Western. Reworking physicist Niels Bohr's insights about the interplay of experimental and theoretical apparatuses and his assertion that interactions between agencies and objects of observation are integral to quantum phenomena, Barad (2007) proposes that the ongoing self-differentiating materialization or material configuring of the world is rendered intelligible only by cuts in its fabric-such that, in temporary stabilizations, materialities, meanings, and responsibilities emerge simultaneously as things come into coherence as things.

Reality, in Barad's construal, is not anterior or independent but, rather, comprises a "topologically dynamic complex of performances" $(2007,380)$; as the temporary resolution of ontological indeterminacies through cuts as specific, enacted relational patternings or 'intra-actions,' knowing is simultaneously available to and constitutive of human and nonhuman 'individuals' (including nonhuman life and nonlife), and-in the making of differences, in matter's differential responsiveness-being, knowing, and responding to inclusions and exclusions are inseparable acts. Barad's project is complex, and we offer it here only in the form of a short provocation to demonstrate a way of thinking, reading, and writing 
with nonhumans that calls, explicitly, for relational responsibility in knowledge practices. We find the idea of agential 'cuts' fitting for thinking through both the ways in which Western ontologies, epistemologies, and systems of value have, in their reenactments, inscribed Indigenous lands with literal, material scars and the more subtle erasures of Indigenous land and life that happen even in Western sovereignty-disrupting theory-makings.

To attend to cuts is to challenge the underpinnings of intellectual and political sovereignty in Western philosophy and natural and social sciences while still attending to how 'individual' things come into coherence. In making-stable what is always on the move, cuts do not throw out the possibility of having stories-in-common for getting on together, they simply ask that we-those who share the same stories-are paying attention to how our stories come to be.

\section{Doing compost}

Doing compost starts in the garden with cuts. It is in weeding, transplanting, or deadheading that grounds are readied for Canada 150 Tulips and teeming heaps of those more subversive trimmings (who did not make the cut) assemble. For a garden to be tamed into form, as Thylias Moss (2011) writes, some plants must go to a "killing field or field of minor-league obscurity, an agricultural pesticide-ridden or penal death row" (285). The rose garden at the far end of the University of British Columbia-our campus, for example, is shaped by stern curvilinear hedges with repressed bursts of colour, a clipped formality achieved only by what has been made absent. Here, the story of what makes a formal English-style rosarium is inseparable from its material effects, sharpening the dull blades of shears, overheating leaf-blower engines, and hewing hedges into intricate geometries. The material presence of the rose garden, too, is an ontological, epistemological, and axiological engagement bound up in histories of imperial and colonial nation-building practices: that the grounds are on unceded Musqueam land requires the displacement or cutting-out of an entirely other way of being, knowing, and doing, in which the nonhuman inhabitants of a rose garden can know and be known as kin, as social, cultural, and political subjects.

Pragmatically, landscaping is agential realism in action, oversimplified of course and explained in terms more leisurely than quantum phenomena. In trimming, a campus rosarium or national garden is brought into form or coherence by cutting 
other things out-Indigenous bodies and bodies of knowledge, the possibility of sentient and knowing nonhumans, and nonhumans as kin. What is made present is made durable or valuable and comes into focus as something to respond to, even celebrate, at the expense of what is thrown out. In the garden, though, unwanted things have a way of growing back-of resisting cuts or making their own way-whereas roses and their imperial-colonial nostalgia or Canada 150 Tulips and their promise of multicultural success must be maintained. For Sara Ahmed (2010, 21-33, 133-59), nationalisms are maintained in both stories and "happy objects," objects which have been storied in repeat encounters and whose capacities to affect (to make us happy, for example) have been already determined in histories of cuts, in turning to or including some things and turning away from or excluding others.

The maintenance of 'Canada' as a happy story of multiculturalism relies on nonhumans being in compliance, being storied and turned toward in certain ways: as easy resources that generate already-determined social goods rather than troublesome kin, as flourishing or at least being 'under control' rather than being in distress or in anthropogenic disaster. It is tourism board-funded clips of pristine wilderness and not aerial photos of clearcut northern British Columbian forests that are markers of national happiness. For Ahmed, accounting for how goods and bads are established in objects that orient or gather bodies around them puts pressure on the relationship between happiness and nationhood in ways that "recognize the impossibility of putting certain histories behind us" (159).

Theories of affect, feminist science studies, and Indigenous sciences can all help in the task of remaining accountable for cuts-for what stories are made or repressed-and for the ways in which these stories cut across the registers of being, knowing, and responding-to as they accrue in (and are provoked by) 'objects' or nonhumans and our patterns of encounter with them. As compost gathers together the undulations and muddy crossings of mutually affecting or intra-acting phenomena in constant flux, it implicates human modes of story-making like biological or biochemical theories about what the living matter of compost is and how it works, ethological accounts of how nonhuman life behaves in compost, and histories or ethnographies of how humans compost. Because we are invested in staying with the trouble of unhappy histories while having stories-in-common for getting on together, we are most interested in stories of humans and nonhumans composting together-in multispecies ethnographies that theoretically integrate human and nonhuman entanglements in the sometimes-speculative endeavour of flawed translation across difference. 
As we see it, multispecies ethnographies are compatible with Indigenous empiricisms (and sovereignties that take into account the endurance of nonhuman others), as texts that come to be in the ongoingness of keeping on together with nonhumans. Multispecies stories, moreover, often take into account nonhuman modes of "storied experience," what Thom van Dooren (2016, 67-69) describes as the nonhuman capacity to engage worldly happenings as meaningful. We are cautious, though, in seeking out sites of compost hope, turning again to dispossessed humans, nonhumans, and their knowledges as resources for ecological resilience (Simpson 2014a). We insist, as such, the work of turning and turning the pile is not a turning-to (as if there were someone or something to look to for answers, some 'pure' state of encounter, or a final answer about the workings of agency or knowledge), but rather a turning-with: an always present living-out together in "this here and this now," always situated (see Butler 2017). Being together in compost is not always pleasant-with jarring smells and off-putting ooze-and stories of human and nonhuman entanglement are not always happy stories even as they work at regeneration.

Take, for example, the Red River, whose unhurried course has been reinscribed by the North Dakota and Minnesota border, but whose waters crosscut national lines to empty into Lake Winnipeg in Canada. In April of 1997, the river flooded and, along its course, levees and emergency dams failed-an unhappy story by most accounts. But Kim TallBear (TallBear \& LaBare 2015) describes her encounter with the aftermath otherwise: abandoned farmlands have returned to wetlands and are home again to seabirds. She does not describe what the river has ruined, but rather "the devastation to the Earth wrought by white people's agriculture," now undone by the river's force (n.p.). Quoting Eben Kirksey (2015) TallBear calls these lands "sites of biocultural hope" (n.p.). As both the story of a river's own agency (the cuts it makes as it is both in-the-making and making the world), and a story that marks human lives with twisted fences and submerged dirt roads, the Red River flood might be read as a kind of compost process in which humans and nonhumans negotiate regenerative ways of getting on together amidst waste or ruin. The new wetlands that emerge from ruin are not pure: rotting farmhouses, overturned cars, grasses, and seabirds are all caught up in the water's rise and fall in varying states of decay and growth-like compost.

Attending to the ongoingness of place and cultivating attunement to human and nonhuman needs in regeneration, through the figure of compost, allows us to recognize the trouble of violent colonial pasts, contest what counts as waste 
or what is recycled as useful, and to remain attentive to the material workings of regeneration. In this way, doing compost as theory is staying with the waste. For multispecies ethnographer Anna Tsing (2015), we inhabit a world marked by economic and ecological ruin: for us, the perhaps soon-to-be-flooded reservoir of the proposed Site C dam and poisoned watersheds surrounding the breached Mount Polley mine tailings pond. As Tsing argues, neither averting ourselves from wasted places in favour of happy stories of technoscientific fixes nor turning to sites of ruin as hopeless dystopias will help us to think about "collaborative survival" (19). Instead, she asks that we follow nonhumans around as they lead us back to places laid waste by civilizational force and still bearing colonial and capitalist pressures-but places alive in regeneration even in ruin. And, following nonhumans around (like Canada 150 Tulips and tulip-kin) while making accountable accounts is how we want to do our compost-thinking.

Tsing, we think, is a practiced composter, attuned to what is making- and unmaking-together in a place. Her text is a lively tracing of mushroom commodity chains, including the networked lives of matsutakes and their Japanese-, Lao-, and Cambodian-American pickers, sellers, and buyers who are connected and disconnected in waves of transoceanic migrations, present realities of colonial expansion, asymmetrical demands of capitalism and citizenship, competing interests of industrial forestry and forest conservationists, and the transformations of global warming. In what she deems an "anti-ending," Tsing concludes her ethnography of the matsutake by describing her first encounter with the mushroom. Down on all fours, below gangling tanoak and between the rotting stumps of once-towering Douglas fir, Tsing describes how she learned to feel the forest floor with her hands. "We were looking for mushrooms by feel alone," she recounts. But mushroom hunting, as we learn, is more artful than pawing about wildly; one needs to know particular plants and fungi and where mushrooms are likely to pop up. This method, writes Tsing, is a "combination of intimate knowledge and feeling through the duff" that focuses attention to the here and now, in "the middle of things" (277-278). At the end of Tsing's text, we find ourselves never quite arriving, always back in the middle of human-mushroom relations.

Like Tsing, feeling through the leaf litter for matsutakes, we continue to get a feeling for compost by fumbling around with our hands-homing, honing in, and grounding ourselves here and now. Even as compost theory happens in the abstract, we learn and continue to learn from the material practice of composting. For us, this learning began in and around the compost bins at the $\mathrm{x}^{\mathrm{w}}$ 'içว digenous Health Research and Education garden at the UBC farm, where we volunteered last summer. We dug into the compost and sensed its heat and dampness; we scrunched our noses at the sudden smells, discovering that compost learning is 
not only visual or tactile and is not always pleasant-that compost can be trouble. We learned that we could get a sense for the state of decay, of where a pile was 'at' in its process of decomposition and recomposition, by paying attention to who or what was still around. Sometimes we failed. We got to know which plant-kin are easily decomposed and those that crop up again and again in weedy tufts around the pile. We learned something of both Western and Indigenous sciences. By getting to know the heap in its ongoing composition (or compost-ition), we came to know something of compost and composting. In learning to attend to ongoing recomposition as a way of knowing the world, we found ourselves back in the middle of things-and wondering if we might extend our understanding of compost beyond the garden and beyond compostable carbon-based life.

With Tsing (162), we recognize that 'species' are "not always the right units" for telling stories and that the term 'multispecies'-as TallBear $(2015,234)$ notes-is incapable of making room for Indigenous understandings of nonliving or immaterial nonhumans as sentient and knowing subjects. In learning from the messiness and unpredictability of compost (which can often include nonliving things), we have realized that conceptual categories like 'species' are storying cuts which, while sometimes useful, make absent the teachings that inorganic nonhumans have to offer and the ways in which nonlife affects and is affected by human life. What might an inorganic composting practice look like? In the series "Happy Birthday Super Cheaper," Vancouver-based sculptor annie ross weaves ceremonial garments for throwaway items: a plastic T-Rex, a detergent bottle, or a brass deer figurine. These items, ross (2009) writes, would otherwise end up in a landfill, "where it all ends up, unless someone pulls you out, or you pull yourself out, and put it all back together" (n.p.).

Pulled from the waste, ross' series can easily be read as recycling, having something in common with DIY or maker projects that repurpose trash. But ross' objects are not upcycled into reusability, she makes no such demands of the junk she assembles, and plastic dinosaurs remain plastic dinosaurs. What is regenerated in ross' art-making compost practice is not the object, but how the object is storied, a mode of encounter. Resonant with ross' own words, 'compost' finds its roots in the Latin composita, something 'put together'-and we wonder if the labour of putting it all back together attends to stories doubly: restorying throwaway objects (and how we might encounter them) while staying with the trouble of the stories that shaped how these items came to be as artifacts of overuse and 
ruin. What if composting inorganics is as simple as paying attention differently? In clothing cast-off items, ross asks that these objects become recognizable as subjects, relatable-to as kin, apprehendable as having the capacity to affect, and deserving of response which might otherwise have been extended toward humans or, at best, animals. If it is possible, then, to 'compost' plastic or brass, it is a matter of apprehending compost as a mode of encounter or, as Warren Cariou (2017) says, recognizing the "sensory skills and the teachings" these material forms have to offer as they are (n.p.).

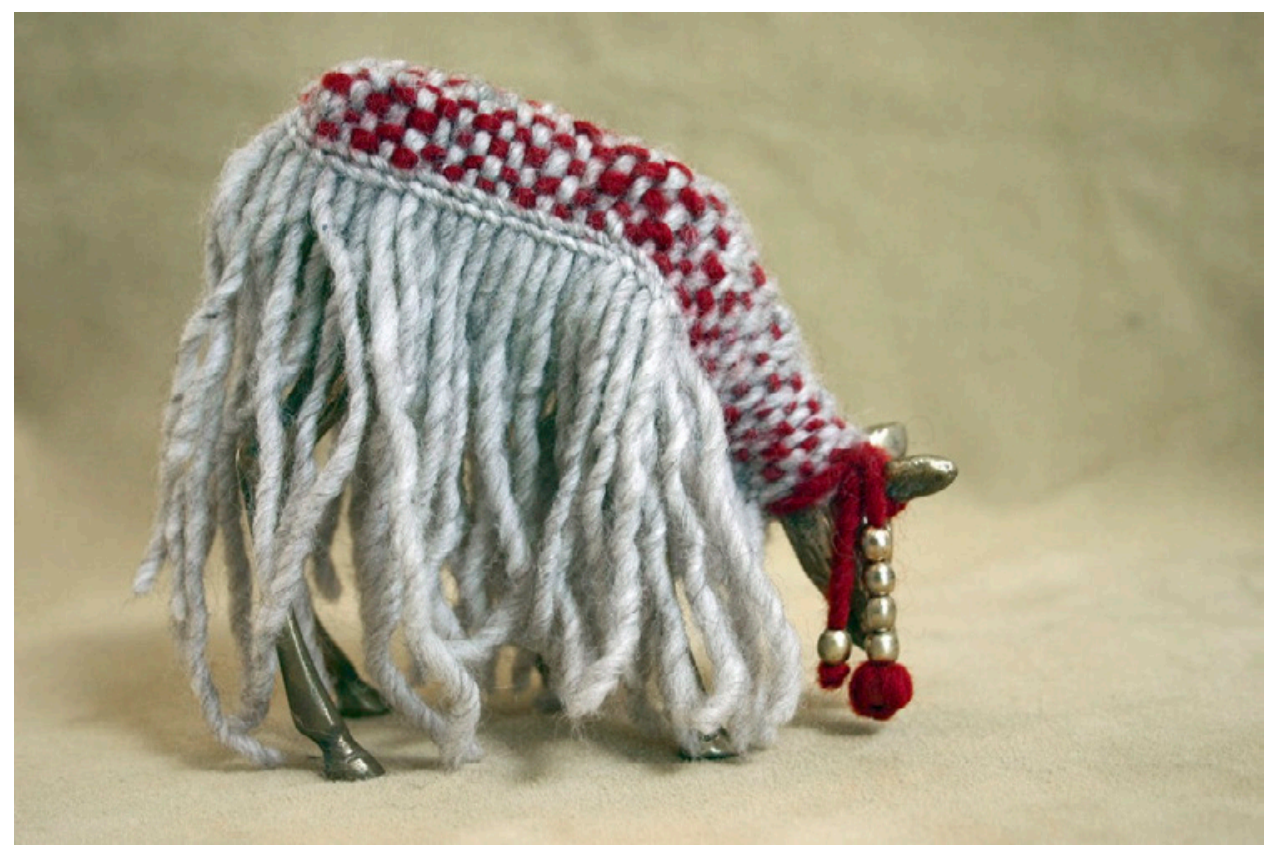

annie ross, Petroglyph Deer Goat, from the series Happy Birthday Super Cheaper, 2005-2007

Opening ourselves to material encounters reveals our vulnerability to nonhuman others and, to illustrate, Anna Tsing proposes that a walking stick is an "encounter in motion," a person-and-stick (29). Concatenations of human and nonhuman abound, most obviously in going through the motions of sustaining livelihoods as with the matsutake and its pickers, or entire lifeways as with salmon and their coastal Indigenous kin-but also between humans and the many nonliving material supports of human life. Relying on the help of nonhuman and nonliving others is a fact of the everyday, not the stuff of heroic or happy stories but of messy encounters and sometimes-failed collaborations. Thinking through collaboration, Tsing asks: "how do gatherings sometimes become 'happenings?" (29). More than just a collection of things, a happening establishes expectations, responsibilities, and agreements between those, human and nonhuman, who have (or find themselves to have been) gathered. 
As a place of contingent capacities, a compost pile is one such happening-whether the pile is a heap of organic and inorganic scraps, a bibliography, a body of theory, an institution, or a nation-where the responsibilities of turners, decomposers, makers, and bystanders must be continuously negotiated. Perhaps this 'happening' is akin to what Ahmed (2010) calls a "politics of the hap," where the 'hap' of 'happiness,' traced to Middle English, suggests chance or possibility. As Ahmed sets out, such a politics attends to how what is came to be, and to what has been made impossible-but works "toward a world in which things can happen in alternative ways" (223). To think, write, and do compost might mean recognizing the already wasted and its per-haps, its could-be-otherwise-never atrophying in the happy promise of ecological or theoretical utopias, but being creative about, with, and in wasted landscapes and sites of knowledge and the responsibilities they provoke.

Both Tsing and ross teach us that encounters with matsutake mushrooms and plastic dinosaurs (or Canada 150 Tulips) are not mere gatherings, but happenings in which beings, knowings, and doings are unmade and remade-that following mushrooms around or weaving finery for trash to wear can be an act of composting settler nationalisms in the enactment of worlds, in theory and in practice, incommensurable with Western political and intellectual sovereignties. Tsing and ross, alike, draw our attention to wasted sites and objects that offer biocultural hope in regeneration, acknowledging that the realms of culture and politics are continuous with the nonhuman world including nonliving things. To encounter a motley mix of often cast-off things as compost, as a non-neutral happening that establishes expectations and responsibilities, is to live out the difference between Western and Indigenous sovereignties.

In focusing back on sites of ruin or throwaway objects, Tsing and ross demonstrate culpable failure: that we must stay with the trouble we have made even as we try again and again. And, in Tsing's account of Mien and Hmong refugees, Native Americans, and matsutake mushrooms getting on together (for better and worse), we learn that as non-Indigenous theorists and activists on Indigenous lands, being 'for' Indigenous sovereignty does not entail a waste-making reversal or making-pure-but rather that being here together requires careful attention to what is in the mix and how it might work together (or not). Finally, through Tsing, ross, and compost itself, we learn ways of knowing what is good-beyond inherited categories-by living in relationships with humans and nonhumans over time-what we have been calling Indigenous empiricism. 
In the figure of compost as a happening, a place of mistakes and responsibilities between kin, we see intimations of an ontology of entangled human and nonhuman composters-together who arise in webs of belonging, being made and unmade together in regenerative processes. Whether the workings of compost are personal or impersonal-whether they emerge in or from Little Bear's constant flux, Barad's intra-action, or Massumi's affect-the ontology of compost is webbed to how we come to know a heap's composition. Thinking with compost as a material practice and a figure for theory-making unearths a way of knowing that attends to what is always in-the-making and to how that which is being made is encountered, named, evaluated, and otherwise 'cut' in Western and non-Western systems of knowledge; in the theory-makings of philosophy, science, or cultural and political theory; in the storied experiences of nonhumans; and in the fleeting atmospheres, intuitions, or impressions that make knowledge known-just as composters-together constitute these multimodal and multisensory knowings. To compost in this way is also to think, read, and write as methods of attending to emergent materialities and meanings such that we might have stories-in-common for being here together, even as we stay with the trouble of fraught pasts, precarious and sometimes-ruined presents, or uncertain futures.

In composting, we experiment with what goes into the pile, finding that different combinations or techniques work differently-different materials, methods, texts, or moods do difference differently. To attend to what is in the mix in a place might mean finding erasures or connections between Indigenous and non-Indigenous stories, between citational lineages, styles, or disciplines and mediums (like Tsing's mushroom anthropology or ross' art-making). Because what matters in the constituent materials and practices of compost is syncretism, composting requires an ethics: a way to know what is good or what works in the midst of constant change. And, in compost-thinking, we are indebted to Indigenous empiricismsknowledge practices that, in attending again and again to relations, find value in everyone (human and nonhuman, living and nonliving) enduring in a place.

While never easy, compost is slow-it gives us time to react, to sense, to consider, and reconsider. Being together in compost's slow regeneration suggests a politics of cultivation, a way of storying how we might keep on together as mutually-affecting individuals and collectives in messy and sometimes fraught collaborations, that is attuned to how stories themselves can shape a mode of encounter. In attending to what everyone in the mix needs, in the midst of ongoingness, the politics of doing compost-materially and as theory-making-will always exceed the enclosures of Western sovereignties and settler nationalisms, turning-with what kinships and sovereignties are already here and to what we humans and nonhumans might compost together. 


\section{Endnotes}

1. Significantly, we do not want to discount productive intersections of affect and Indigeneity such as: Meera Atkinson and Michael Richardson (2013) writing on trauma and embodiment in multimodal Indigenous storytelling; Driftpile Cree theorist Billy Belcourt (2016) mapping the affectivities of queer experience and life on the reserve; Jennifer Biddle (2013) witnessing the traumatic affect of Indigenous Australian cinema; Tanana Athabascan scholar Dian Million (2009) emphasizing the importance of the felt histories of Indigenous women; or Maori and non-Maori scholars collaborating on the interchange between Indigenous relational framings and national affective-discursive repertoires (Wetherell et al. 2015).

\section{References}

Abrahamsson, S. and Bertoni, F. (2014). Compost Politics: Experimenting with Togetherness in Vermicomposting. Environmental Humanities 4, pp.125-148. Ahmed, S. (2010). The Promise of Happiness. Durham: Duke University Press.

Atkinson, M. (2017). The Poetics of Transgenerational Trauma. London: Bloomsbury. Atkinson, M. and Richardson, M. (2013). Traumatic Affect. Newcastle upon Tyne: Cambridge Scholars Pub.

Atleo, E. R. (2011). Principles of Tsawalk: An Indigenous Approach to Global Crisis. Vancouver: University of British Columbia Press.

Barad, K. (2007). Meeting the Universe Halfway: Quantum Physics and the Entanglement of Matter and Meaning. Durham: Duke University Press.

Barnett, J. T. (2016). Politics of Edibility: Reconceptualizing Ecological Relationality. Environmental Communication, pp. 1-14.

Beinart, W. and Hughes, L. (2007). Environment and Empire. Oxford: Oxford University Press.

Belcourt, B.-R. (2016). “A Poltergeist Manifesto.” Feral Feminisms 6. Available at: http://feralfeminisms.com/a-poltergeist-manifesto [Accessed 20 May 2017].

Biddle J. (2013). "Radical Realism and Other Possibilities in Contemporary Intercultural Indigenous Australian Cinema.” In: Traumatic Affect. Edited by M. Atkinson and M. Richardson. Newcastle upon Tyne: Cambridge Scholars Pub., pp. 230-239. 
Boyd, D. R. (2004). Sustainability Within a Generation: A New Vision for Canada. Vancouver: David Suzuki Foundation.

Butler, M. (2017). Whadda YOU mean?: Semiotics Workshop. [lecture] Humanities 101. Vancouver: University of British Columbia.

Cariou, W. (2017). Landsensing: Body, Territory, Relation. Mikinaakominis/TransCanadas: Literature, Justice, Relation. Toronto: University of Toronto.

Corntassel, J. and Bryce, C. (2012). Practicing Sustainable Self-Determination. Brown Journal of World Affairs, 18 (2), pp. 151-166.

CTV Ottawa. (2016). Maple leaf tulip unveiled to honour Canada's 150. CTV News Ottawa, [online]. Available at: http://ottawa.ctvnews.ca/maple-leaf-tulip-unveiled-to-honour-canada-s-150-1.2894256 [Accessed 29 September 2017].

De Line, S. (2016). All My / Our Relations: Can Posthumanism Be Decolonized? [online] open! Platform for Art, Culture \& the Public Domain. Available at: https://www.onlineopen.org/all-my-our-relations [Accessed 20 May 2017].

Dolphijn, R. and van der Tuin, I. (2012). Interview with Karen Barad. In New Materialism: Interviews \& Cartographies. Ann Arbor: Open Humanities Press, pp. $48-70$.

Franklin, S. (2017) Staying with the Manifesto: An Interview with Donna Haraway. Theory, Culture \& Society, 34 (4), pp. 49-63.

Grossberg, L. (2010). Cultural Studies in the Future Tense. Durham: Duke University Press.

Haraway, D. (2016). Staying with the Trouble: Making Kin in the Chthulucene. Durham: Duke University Press.

Huesemann, M. (2003). Recognizing the Limits of Environmental Science and Technology. Environmental Science \& Technology, 37 (13), pp. 259A-261A.

Jackson, Z. (2015). Outer Worlds: The Persistence of Race in Movement "Beyond the Human." GLQ: A Journal of Lesbian and Gay Studies, 21 (2), pp. 215-218.

Justice, D. H. (2016). “Go Away, Water!” Kinship Criticism and the Decolonization Imperative. In L. Morra and D. Reder, eds., Learn, Teach, Challenge: Approaching Indigenous Literatures. Waterloo: Wilfrid Laurier University Press, pp. 349-371.

Kendall, T. and Koster, K. (2007). Critical Approaches to Cultural Recycling. Other Voices, [online] 3 (1). Available at: http://www.othervoices.org/3.1/guesteditors/index.php [Accessed 10 September 2017].

Kirksey, E. (2015). Emergent Ecologies. Durham: Duke University Press. 
Lang, D. (2007). 'Give Us the Dumpsters -Or - Give Us Life': Res Derilictae and the Trash of Free Trade. Other Voices, [online] 3 (1). Available at: http://www. othervoices.org/3.1/dlang/index.php [Accessed 10 September 2017].

Latour, B. (2002). War of the Worlds: What About Peace? Translated by C. Bigg. Edited by. J. Tresch. Chicago: Prickly Paradigm Press.

Law, J. (2015). What's Wrong with a One-World World? Distinktion: Scandinavian Journal of Social Theory, 16 (1), pp. 126-139.

Le Guin, U. (1989). The Carrier Bag Theory of Fiction. In: Dancing at the Edge of the World: Thoughts on Words, Women, Places. New York: Grove Press, pp. 165-170.

Little Bear, L. (2011). Native Science and Western Science: Possibilities for a Powerful Collaboration.

Available at: https://www.youtube.com/watch?v=ycQtQZ9y3lc [Accessed 10 September 2017].

Lorenc, C. (2016). Viewpoint: Landlocked oil is wasted opportunity. Saskatoon StarPhoenix, [online]. Available at: http://thestarphoenix.com/opinion/columnists/1011-edit-lorenc-view [Accessed 10 September 2017].

MacBride, S. (2013). Recycling Reconsidered: The Present Failure and Future Promise of Environmental Action in the United States. Cambridge, Mass.: MIT Press.

MacDonald, D. B. (2014). Aboriginal Peoples and Multicultural Reform in Canada: Prospects for a New Binational Society. Canadian Journal of Sociology/Cahiers canadiens de sociologie, 39 (1), pp. 65-86.

Massumi, B. (1995). The Autonomy of Affect. Cultural Critique, 31, pp. 83-109.

Massumi, B. (2014). What Animals Teach Us about Politics. Durham: Duke University Press.

Massumi, B. (2015). Politics of Affect. Cambridge, UK: Polity Press.

Million D. (2009). "Felt Theory: An Indigenous Feminist Approach to Affect and History." Wicazo Sa Review 24(2), pp. 53-76.

Moss, T. (2011). Tarsenna's Defiance Garden in which I Love to Spit. In: A. Hawthorne Deming and L. E. Savoy, eds., The Colors of Nature: Culture, Identity, and the Natural World. Minneapolis: Milkweed Editions, pp. 284-293. 
Palmater, P. (2017). Justin Trudeau has forgotten his promises to Indigenous Canadians: What happened to allowing First Nations to say 'no' to pipelines? CBC News, [online]. Available at: http://www.cbc.ca/news/opinion/promise-to-indigenous-1.3972965 [Accessed 29 September 2017].

Palmater, P. (2015). Genocide or Mass Murder - Canadian and Church Officials Must be Held to Account. [online] IndigenousNationhood. Available at: http://indigenousnationhood.blogspot.ca/2015/06/genocide-or-mass-murder-canadian-and.html [Accessed 29 September 2017].

Park, C. and M. Allaby. (2017). Compost. In A Dictionary of Environment and Conservation. London: Oxford University Press, p. 90.

Policy Horizons Canada. (2013). The Case for Evidence-Based Policy. Ottawa: Policy Research Initiative, p. 6.

Ritskes, E. (2017). Colonialism 150. [online] Available at: https://teespring.com/ shop/colonialism-150 [Accessed 20 May 2017].

Rogers, H. (2006). Gone Tomorrow: The Hidden Life of Garbage. New York: The New Press.

ross, a. (2009). Happy Birthday Super Cheaper. Blurb.

Scanlan, J. (2005). On Garbage. London: Reaktion.

Sheldon, R. (2016). Matter and Meaning. Rhizomes: Cultural Studies in Emerging Knowledge, 30, n.p.

Simpson, J., James, C., and Mack, J. (2011). Multiculturalism, Colonialism, and Racialization: Conceptual Starting Points. Review of Education, Pedagogy, and Cultural Studies, 33 (4), pp. 285-305.

Simpson, L. (2014a). Indigenous Resistance Lifts the Veil of Colonial Amnesia. Geeze, Winter 2014, pp. 13-15.

Simpson, L. (2014b). Land as Pedagogy: Nishnaabeg Intelligence and Rebellious Transformation. Decolonization: Indigeneity, Education \& Society, 3 (3), pp. 1-25.

Simpson, L. (2015). Dancing on Our Turtle's Back: Stories Of Nishnaabeg Re-creation, Resurgence And A New Emergence. Winnipeg: Arbeiter Ring Publishing.

Simpson, L. (2016). Land and Reconciliation: Having the Right Conversations. Electric City Magazine [online]. Available at: http://www.electriccitymagazine.ca/land-reconciliation [Accessed 10 September 2017]. 
TallBear, K. (2012). An Indigenous Ontological Reading of Cryopreservation Practices and Ethics (and Why I'd Rather Think about Pipestone). American Anthropological Association, 111th Annual Meeting. San Francisco.

TallBear, K. (2015). An Indigenous Reflection on Working Beyond the Human/ Not Human. GLQ: A Journal of Lesbian and Gay Studies, 21 (2-3) pp. 230235.

TallBear, K. and LaBare, J. (2015). Matters of Life and Death. Available at: https:// youtube.com/watch? $\mathrm{v}=\mathrm{tjiVcwpBhSc} \& \mathrm{t}=885 \mathrm{~s}$ [Accessed 20 May 2017].

Todd, Z. (2016). An Indigenous Feminist's Take on The Ontological Turn: 'Ontology' Is Just Another Word for Colonialism. Journal of Historical Sociology, 29 (1), pp. 4-22.

Trautmann, N. and Olynciw, E. (1996). Compost Microorganisms. [online] Cornell Composting: Science \& Engineering, Cornell Waste Management Institute. Available at: http://compost.css.cornell.edu/microorg.html [Accessed 20 May 2017].

Tsing, A. (2015). The Mushroom at the End of the World: On the Possibility of Life in Capitalist Ruins. Princeton: Princeton University Press.

Tully, J. (1993). Rediscovering America: The Two Treatises and Aboriginal Rights. In: An Approach to Political Philosophy: Locke in Contexts. Cambridge: Cambridge University, pp. 156-163.

United States Environmental Protection Agency (US EPA), Office of Solid Waste and Emergency Response. (1998). An analysis of composting as an environmental remediation technology. Washington, DC.

van Dooren, T. (2016). Flight Ways: Life and Loss at the Edge of Extinction. New York: Columbia University Press.

Watts, V. (2013). Indigenous Place-Thought and Agency Amongst Humans and Non-Humans (First Woman and Sky Woman Go on a European World Tour!) Decolonization: Indigeneity, Education \& Society, 2 (1), pp. 20-34.

Wetherell, M., McCreanor, T., McConville, A., Moewaka Barnes, H., and le Grice, J. (2015). "Settling Space and Covering the Nation: Some Conceptual Considerations in Analysing Affect and Discourse." Emotion, Space and Society, 16(2), pp. 56-64.

Wilkinson, D. (2017). Is There Such a Thing as Animism? Journal of the American Academy of Religion, 85 (2), pp. 289-311. 

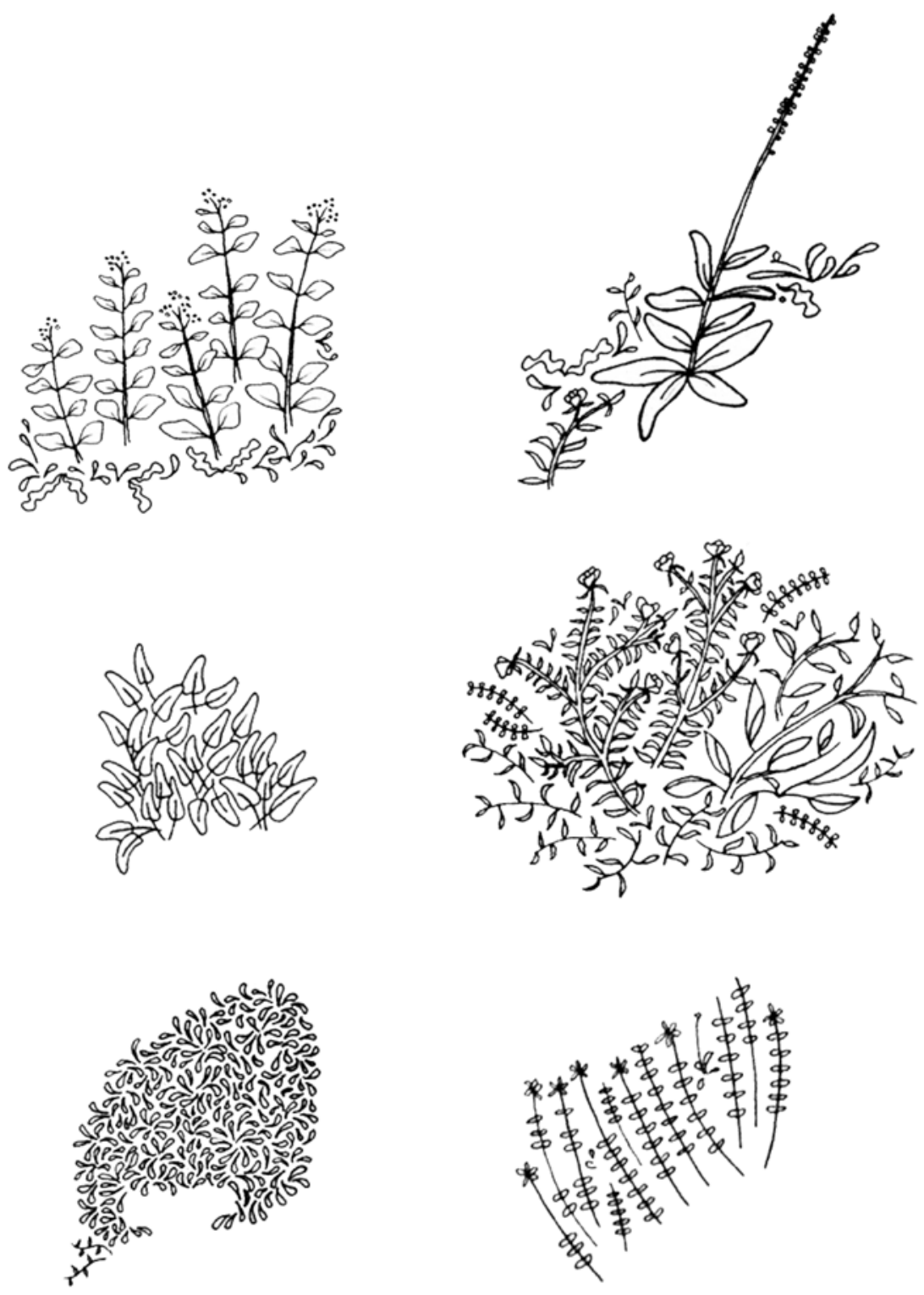


\section{SONNETS}

Maya Pindyck

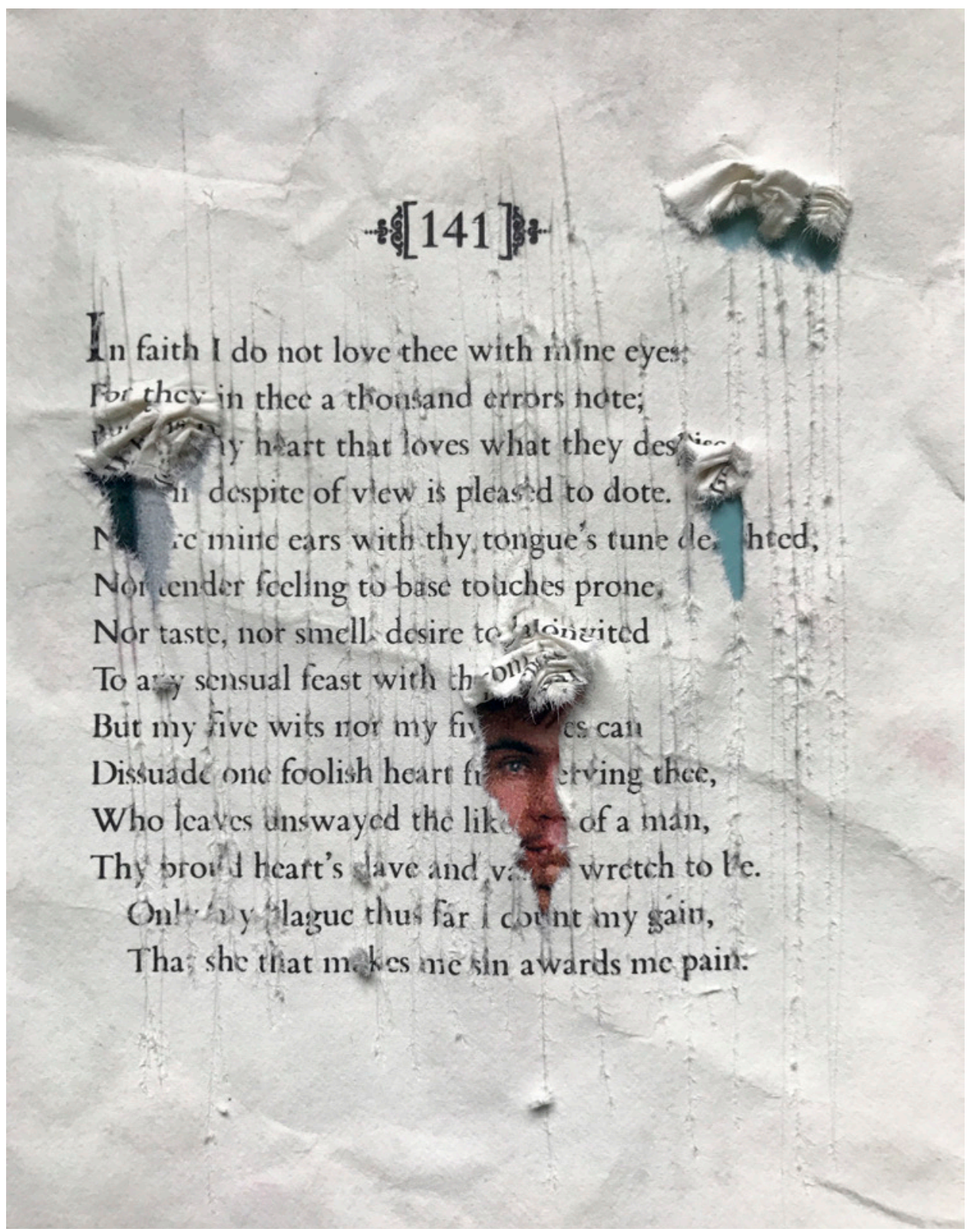




\section{$+[113]+$}

Since I left you, mine eye is in my mind,

And that which governs me to go about

Doth part his function and is partly blind,

Seems seeing, but effectually is out;

For it no form delivers to the heart

Of bird, of flow'r, or shape, which it doth latch.

Of his quick objects hath the mind no part,

Nor his own vision holds what it doth catch;

For if it see the rud'st or gentlest sight,

The ma weet favor or deformèd'st creature,

Th (hountam, or the sea, the day, or night,

The crow, or dove, it shapes them to your feature.

Incapable of more, replete with you,

My most true mind thus maketh mine eye untrue.

This project draws inspiration from Richard Serra's "Verb List" (1967) to intervene onto Shakespeare's sonnets. I enact one or more action(s) on each sonnet: crumpling, cutting, erasing, burning, staining, concealing, scratching, freezing, folding, etc. Responding to a persistent White culture of literary elitism, this project explores what haptic interventions can do to a canonized cultural object. I want to see what working different bodily touches onto (an arguably touching) sonnet might generate. I see these visceral interventions layering another kind of poetry onto Shakespeare's poetry-one that prompts a relationship between text and action while questioning Shakespeare's cultural currency. 


\section{Sonnets (cont.)}

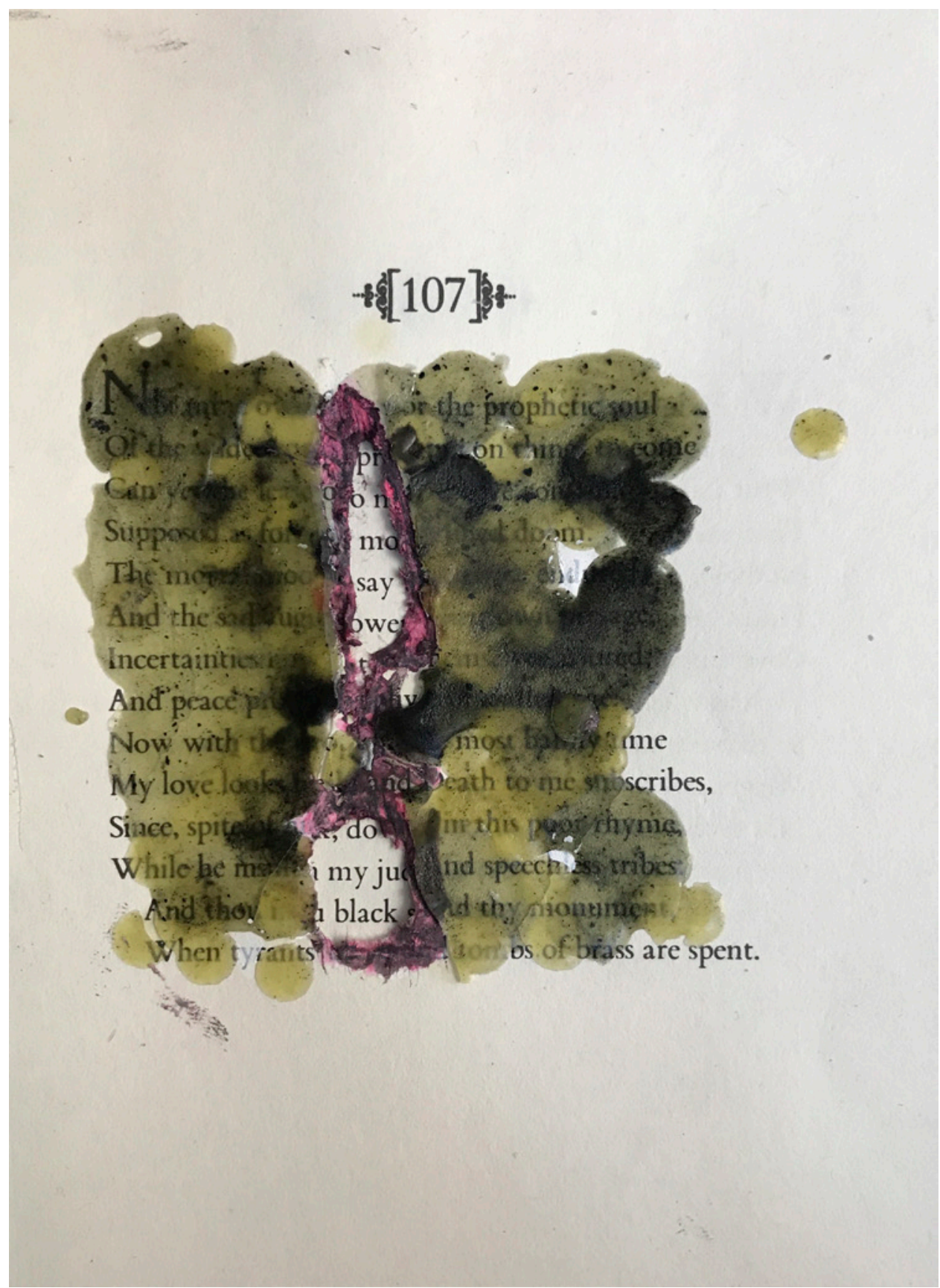




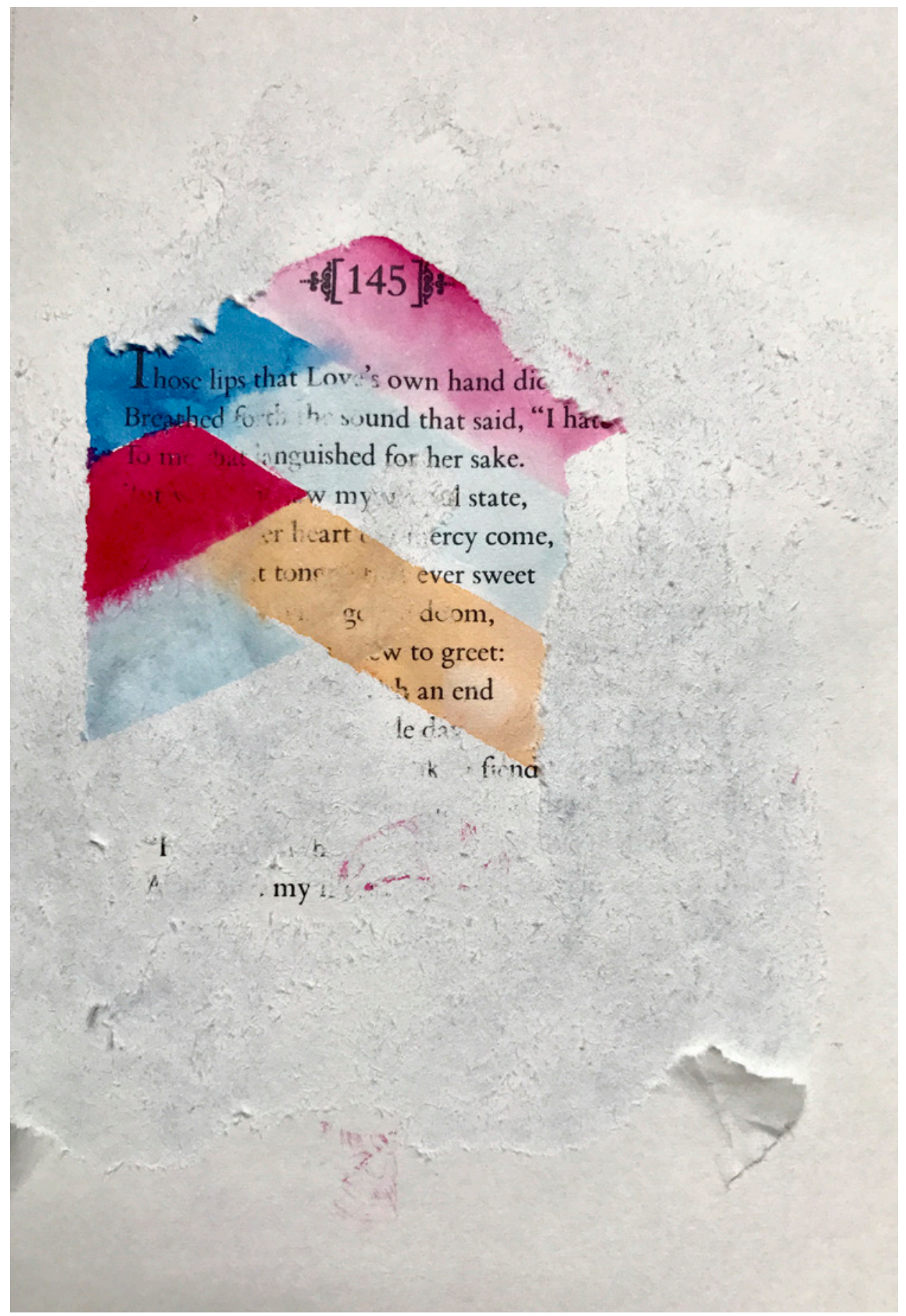




\section{Contributors}

\begin{abstract}
$\sim \sim \sim$
MATHEW ARTHUR is an information designer and community education activist in Vancouver, Canada. He is co-editor-in-chief of Capacious: Journal for Emerging Affect Inquiry.
\end{abstract}

SARAH CEFAI is a Lecturer in Communications and Media at the London College of Communication, University of the Arts, London. Her current work investigates the discursive and affective structures of humiliation through the example of various media cultural practices and formations. Her research is published in Cultural Studies, the European Journal of Cultural Studies, and more.

SMILJANA GLISOVIC is an early-career maker-researcher interested in documentary and poetic forms in audiovisual art practice. She has worked as an artist, actor, writer, and filmmaker across various mediums and forms. She teaches Creative Writing and Cinema at RMIT University.

M. GAIL HAMNER is Professor of Religion at Syracuse University. She has published American Pragmatism: A Religious Genealogy (Oxford, 2002) and Religion and Film: The Politics of Nostalgia (Palgrave, 2012), in addition to a number of essays and book chapters on film, affect, and philosophy. An affiliated faculty in SU's Women's and Gender Studies program and Film and Screen Studies program, Hamner teaches at the intersections of affect studies, Continental philosophy, gender/sexuality studies, and media/film theory. She enjoys reading Merleau-Ponty and obscure philosophers like Souriau and Simondon, and is currently working on a book that theorizes film as a fold of the global public sphere and uses this theory to analyze the religious affects of fim's "abnormal" bodies.

REUBEN JENTINK is a graduate student in the Curriculum \& Instruction: Equity Studies in Education program at Simon Fraser University. He is a community education activist, working with Humanities 101, a tuition-, prerequisite-, and credit-free program run with residents of Vancouver's Downtown Eastide/South.
D. SOYINI MADISON focuses on the intersections of labor activism, political economy of human rights, and indigenous performance tactics. Her book, Acts of Activism: Human Rights and Radical Performance (Cambridge University Press), is based on how local activists in Ghana employ modes of performance in their day-to-day struggles for women's rights, water democracy, and economic justice. Madison is the author of five books and hundreds of articles and is presently working on the third edition of her book, Critical Ethnography: Methods, Ethics, and Performance (Sage Publications). Her most recent book, Performance, Ethnography, and Communication: Improvisation, and Enactments of Experience, will be published in Spring 2018.

LEA MULDTOFTE is a PhD fellow at the School of Communication and Culture, Aarhus University in Denmark. Her work concerns the conditions for subjectivation processes in contemporary sociotechnical milieus, and how this is thematised in contemporary aesthetic articulations. Recently her interest has also included body politics and ortho-practices with special regards to the micro-politics of the anorexic body.

ANDREW MURPHIE works on philosophy and a politics of differential organisation within a "third revolution" in media and communications (Al and automation, VR, data and signaletics, the world as medium). He also works on climate change as part of catastrophic multiplicity. $\mathrm{He}$ is an Associate Professor in Media and Communications at UNSW Sydney.

TAVIA NYONG'O is Professor of African-American Studies, American Studies, and Theatre Studies at Yale University. His research interests include the cultural study of performance; black diasporic studies; Marxism and post-Marxism; queer and feminist aesthetics; and popular music studies. His books include: The Amalgamation Waltz: Race, Performance, and the Ruses of Memory (U Minnesota, 2009), which won the Errol Hill Award for best book in African American theatre and performance studies, and Afro-Fabulations: The Queer Drama of Black Life (NYU Press, 2018). 
MAYA PINDYCK is an interdisciplinary poet/artist and scholar. Her most recent poetry collection, Emoticoncert, was published by Four Way Books in 2016. She earned her PhD in English Education from Columbia University's Teachers College and her MFA in poetry from Sarah Lawrence College. Maya is an Assistant Professor of Liberal Arts and Director of the Writing Program at Moore College of Art \& Design in Philadelphia.

MARNIE RITCHIE is a PhD Candidate in the Department of Communication Studies at the University of Texas at Austin, and an incoming Visiting Assistant Professor in the Department of Communication at Pacific Lutheran University. Her dissertation explores the visceral dimensions of national security, surveillance, and intelligence in the War on Terror through renewed rhetorical reading practices. She has an unrelenting passion for Nietzsche.

DAVID BEN SHANNON is a PhD student in the Biosocial Research Lab at Manchester Metropolitan University's Education and Social Research Institute. He is an electro-acoustic, film and theatre composer, and a former Primary and Special Education teacher and Assistant Head Teacher. David's research interests include affect, sonic research-creation, dis/ability, and neuroqueerness and early childhood. David is one half of the electronic music duo Oblique Curiosities.

SEAN SMITH (heteronym of Jock Cousteaux) is an artist, writer and athlete living in Toronto, Canada. He holds a PhD in Media Philosophy from the European Graduate School and has exhibited and performed internationally as part of the Department of Biological Flow, an experimental collaboration in arts-based research inquiry with Barbara Fornssler. He was the inaugural Artist/ Scholar-in-Residence at the University of Western Ontario in 2011-12, a participant of the Wood Land School" The Exiles residency in 2013, and one of the curators of Channel Surf, a $200 \mathrm{~km}$ canoe journey and open platform for the arts that was one of 5 projects worldwide accepted to Project Anywhere in 2015. His current performance-theory project, Aqua Rara: Field Notes and Companion Guide, weaves and swims a practice of embod- ied art-philosophistry that begins by watching the Aquarium Channel on loop before drifting... elsewhere. It is forthcoming from Delere Press in 2019.

BEN SPATZ is Senior Lecturer in Drama, Theatre and Performance at the University of Huddersfield England; Arts \& Humanities Research Council Leadership Fellow (2016-2018); author of What a Body Can Do: Technique as Knowledge, Practice as Research (Routledge 2015) and numerous articles; convener of the Embodied Research Working Group within the International Federation for Theatre Research; and editor of the new videographic Journal of Embodied Research published by Open Library of Humanities. Their recent talks and workshops include "What is a song?" (The British Library), "Beyond Performer Training" (University of Kent), "An Epistemic Context for Martial Arts" (University of Cardiff), "Decolonizing Song-Action" (Maynooth University), "Re-Reading Grotowski in the Anthropocene" (University of the Arts Helsinki), and "Future Documents: Video Epistemology and Embodied Research" (University of Manchester; University of Aberdeen).

KYLA WAZANA TOMPKINS is Associate Professor of Gender and Women's Studies and English at Pomona College. Her work has appeared or is forthcoming in Social Text, Callaloo, American Quarterly and elsewhere. Her first book Racial Indigestion: Eating Bodies in the Nineteenth Century won the Lora Romero Award for Best First Book from the American Studies Association and best first book from the Association for the Study of Food and Society.

SARAH E. TRUMAN is a SSHRC Postdoctoral Fellow at Manchester Metropolitan University's Education and Social Research Institute. Her SSHRC funded research focuses on QT/BIPOC speculative fiction and youth cultural productions of speculative fiction. She is the author of Searching for Guan Yin (White Pine 2011); co-editor of Pedagogical Matters: New Materialism and Curriculum Studies (Peter Lang 2016); and co-author of Walking Methodologies in a More-than-Human World: Walkinglab (Routledge 2018). Sarah co-directs Walking Lab and is one half of the electronic music duo Oblique Curiosities. 


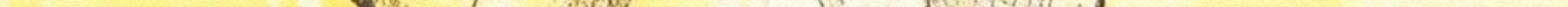

